\title{
Geophysical Investigations of the South-Western Wairarapa Region of New Zealand
}

\author{
Jennifer Louise Rollo
}

\author{
A dissertation presented to \\ Victoria University of Wellington \\ in fulfilment of the thesis requirements \\ for the degree of
}

Master of Science

in

Geophysics

Institute of Geophysics,

Research School of Earth Sciences,

Victoria University of Wellington,

Wellington, New Zealand

1992. 
For my parents

Jessie and Peter

- ii - 
Amid all the revolutions of the globe the economy of Nature has been uniform, and her laws are the only things that have resisted the general movement. The rivers and the rocks, the seas and the continents, have been changed in all their parts; but the laws which direct these changes and the rules to which they are subject, have remained invariably the same.

Playfair, Illustrations of the Huttonian Theory $\S 374,1920$. 


\section{Abstract}

A model of the sub-surface structure of the south-western part of the Wairarapa sedimentary basin in central New Zealand was constructed from geophysical data obtained by the author during the period 1990-1991.

A total of 122 new gravity observations, eight magnetotelluric (MT) stations and approximately two kilometres of seismic refraction lines were established in the study area. All methods complemented each other in the determination of the final result. The gravity data provided the depth for the basement layer of the basin, and determined the position of a fossil fault in the region of the Wharepapa River channel. The MT and seismic data confirmed the fossil nature of the fault. The results for the boundaries determined by the MT surveys were also shown to agree with the upper layers of the gravity model.

The final model presented is of a sedimentary basin with thickness of approximately $2 \mathrm{~km}$, with a fossil fault dividing the basin near the vicinity of the Wharepapa River. To the west of the study area is a highly anomalous region which could not be fully modelled in this study because of lack of data in this particular area. 


\section{Contents}

Dedication .......................................................................................................... ii

Quote ........................................................................................................... iii

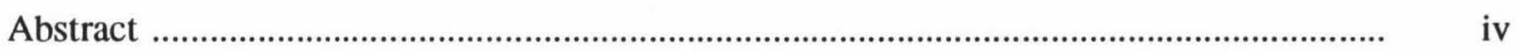

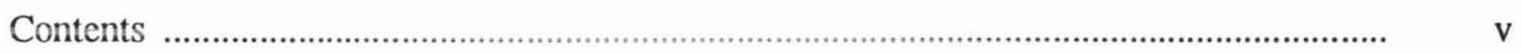

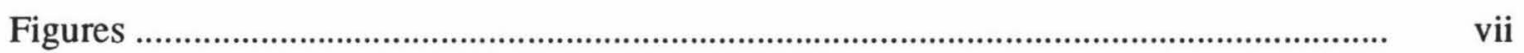

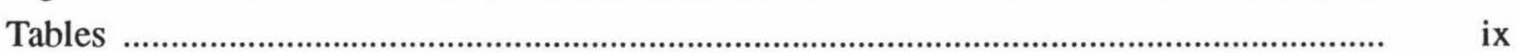

Chapter 1 Introduction ...........................................................................................

1.1 Preliminaries ................................................................................................

1.2 Faults in Central New Zealand ........................................................................ 5

1.3 The Wairarapa Fault ........................................................................................... 5

1.4 An Historical Account of the 1855 Earthquake ..................................................... 9

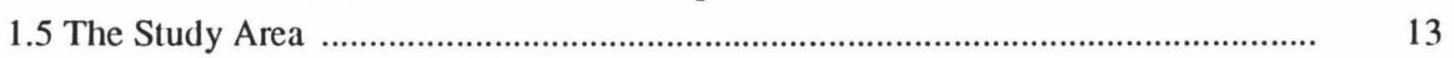

1.6 Geology of the Study Area .................................................................................... 13

1.7 Previous Work Carried out in the Area ............................................................... 19

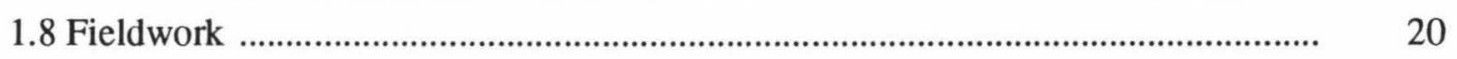

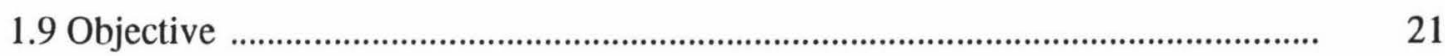

1.10 Summary of the Following Chapters …............................................................. 21

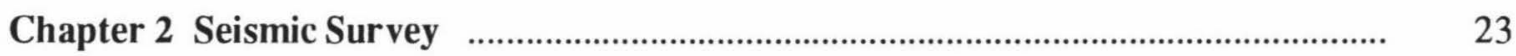

2.1 Refraction and Reflection Work ............................................................................ 25

2.2 Basic Refraction Theory .................................................................................... 25

2.3 Refraction Surveying ...................................................................................... 27

2.4 Fieldwork .................................................................................................... 28

2.5 Instrumentation ........................................................................................... $\quad 30$

2.6 Methods and Theory of Data Analysis …........................................................... 31

2.7 Uncertainties ................................................................................................ 41

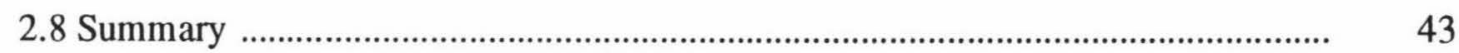

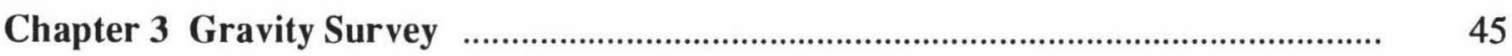

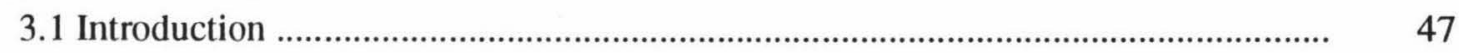

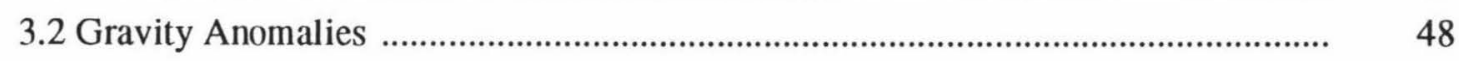




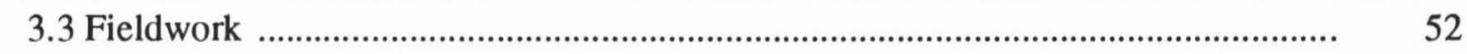

3.4 Instrumentation ..................................................................................... 53

3.5 Gravity Data Reduction ..................................................................................... 54

3.6 Removal of the Regional Gradient ................................................................. 62

3.7 Uncertainties ................................................................................................ 64

3.8 Contouring …............................................................................................ $\quad 70$

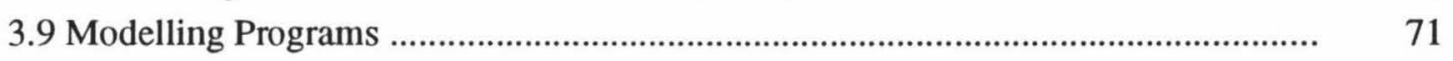

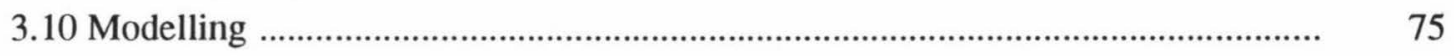

Chapter 4 Magnetotelluric Survey …………............................................................. 91

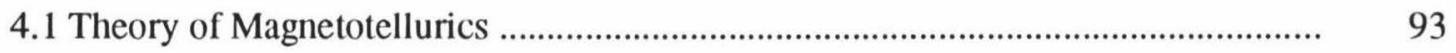

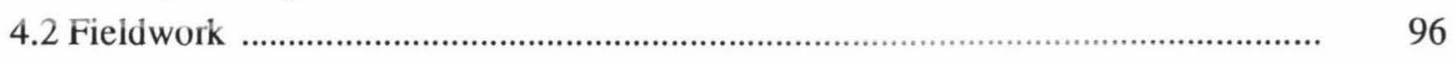

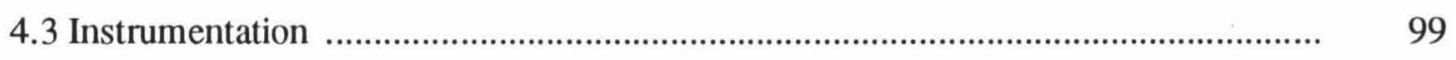

4.4 Data Analysis ............................................................................................ 102

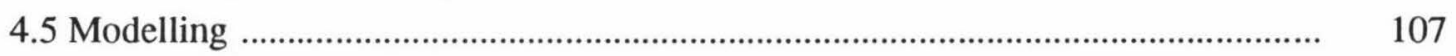

4.6 Uncertainties ............................................................................................. 121

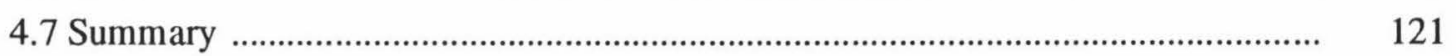

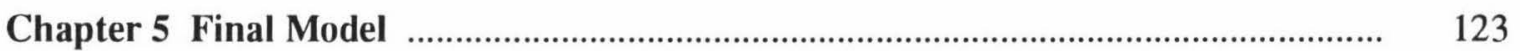

5.1 Discussion of Previous Results ......................................................................... 125

5.2 The Final Model .......................................................................................... 125

Chapter 6 Conclusions …................................................................................................. 129

6.1 Overview and Final Conclusions ..................................................................... 131

6.2 Suggestions for Further Geophysical Investigation ............................................. 132

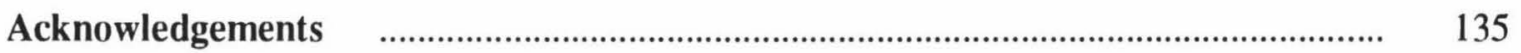

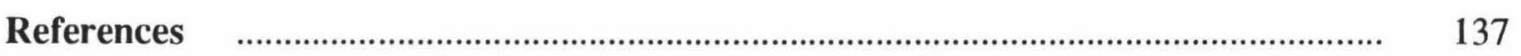

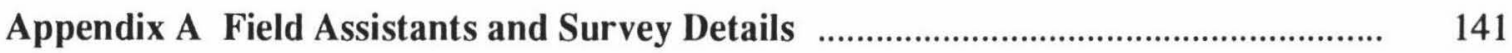

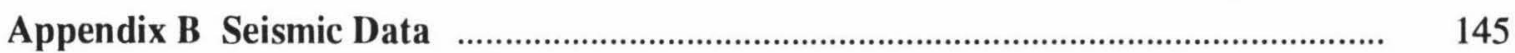

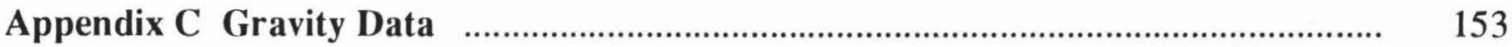

Appendix D AMT Data Generated by AMTAV ....................................................... 159

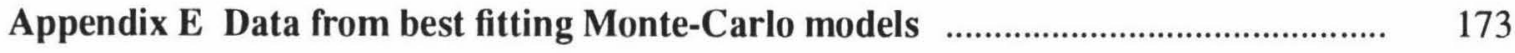




\section{Figures}

Figure 1.1 Mobile belt coinciding with the tectonic plates ................................................ 3

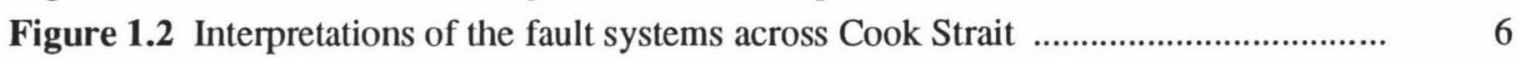

Figure 1.3 Major faults in central New Zealand ............................................................. 7

Figure 1.4 Interpretation of the Wairarapa Fault south of Lake Wairarapa. .................... 8

Figure 1.5 Effect of the 1855 earthquake on the Wairarapa Basin ..................................... 10

Figure 1.6 Interpretation of the 'fault' trace at Thrust Creek ............................................ 12

Figure 1.7 Faults in the study area, after Ghani (1974) ....................................................... 14

Figure 1.8 Aerial photograph of the study area .............................................................. 15

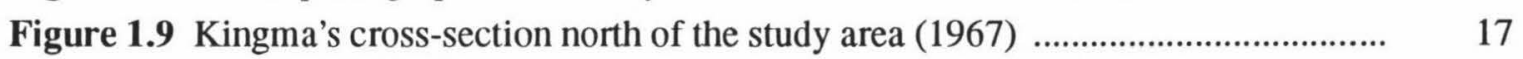

Figure 1.10 Localities of Maddocks' profiles in the study area ........................................... 20

Figure 2.1 Velocities and travel paths of seismic waves .................................................... 26

Figure 2.2 Physical geometry of a refracted wave ........................................................... 27

Figure 2.3 Layout of a spread for seismic refraction surveying ....................................... 28

Figure 2.4 Locations of seismic spreads, WKH-S1, WPP-S2 and PN-S3 ......................... 29

Figure 2.5 Example of a seismogram from the west end shot at WPP-S1 ......................... 32

Figure 2.6 Forward and reverse shots shown on an x-t graph ......................................... 34

Figure 2.7 Model for WPP-S1 ...................................................................................

Figure 2.8 Ray tracing through the WPP-S1 velocity model .............................................. 37

Figure 2.9 WKH-S2 refraction spread ...........................................................................

Figure 2.10 Velocity model for WKH-S2 spread ........................................................... 38

Figure 2.11 Ray tracing through the WKH-S2 velocity model ........................................... 40

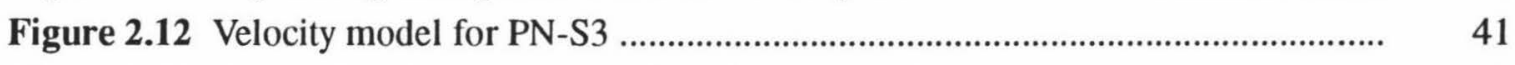

Figure 2.13 Ray tracing through the PN-S3 velocity model ............................................... 42

Figure 3.1 Gravity anomaly caused by a sub-surface sphere ........................................... 49

Figure 3.2 Attraction of a faulted slab having infinite throw ............................................ 49

Figure 3.3 Localities of gravity stations in the study area ................................................ 53

Figure 3.4 Topographic section illustrating Bouguer corrections ..................................... 59

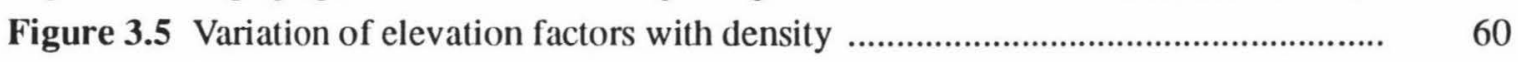

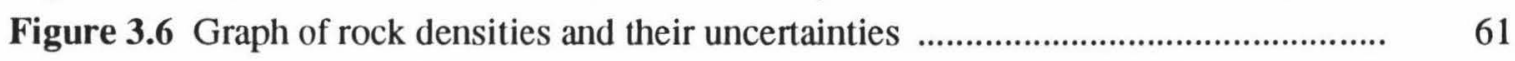

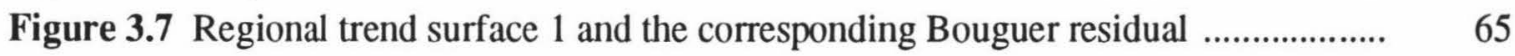

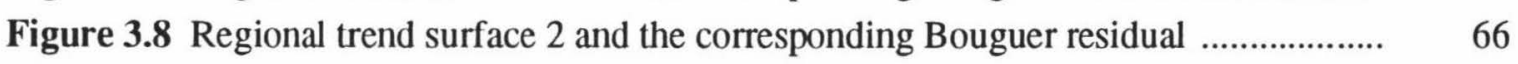

Figure 3.9 Regional trend surface 3 and the corresponding Bouguer residual ...................... 67 
Figure 3.10 Contour map of the Bouguer residual anomalies in the study area

Figure 3.11 Example of a starting model used in SAKI .................................................. 73

Figure 3.12 3-D Model from Talwani and Ewing ……................................................... 75

Figure 3.13 Position of Profile lines A to D ..................................................................... 77

Figure 3.14 Models A and B corresponding to Profiles A and B ....................................... 78

Figure 3.15 Models $C$ and D corresponding to Profiles $C$ and D .................................... 79

Figure 3.16 Position of Traverse lines E, F, G, H, I and J ...............................................

Figure 3.17 Models $\mathrm{E}$ and $\mathrm{F}$ for Cross-sections $\mathrm{E}$ and $\mathrm{F}$............................................... 82

Figure 3.18 Models $\mathrm{G}$ and $\mathrm{H}$ for Cross-sections $\mathrm{G}$ and $\mathrm{H}$............................................... 83

Figure 3.19 Locality of gravity Cross-sections T, U, V, W, X, Y and Z ........................... 84

Figure 3.20 Model W .......................................................................................... 85

Figure 3.21 Model X .......................................................................................... 86

Figure 3.22 Model Y ............................................................................................ 86

Figure 3.23 3-D gravity model of the study area ............................................................. 88

Figure 3.24 Calculated fit of the 3-D model ..................................................................... 89

Figure 3.25 Contour of residuals from 3-D model ........................................................ 90

Figure 4.1 Locality of MT sites in study area …............................................................... 98

Figure 4.2 Block diagram of the MT field set-up used in this study ................................. 100

Figure 4.3 Plots of period vs apparent resistivity and phase at WKH2 ............................ 108

Figure 4.4 Plots of period vs apparent resistivity and phase at WPP2 ................................ 109

Figure 4.5 Plots of period vs apparent resistivity and phase at WPP3 ............................... 110

Figure 4.6 Plots of period vs apparent resistivity and phase at PN2 ................................. 111

Figure 4.7 Best 20 Monte-Carlo models for WKH2 ..................................................... 114

Figure 4.8 Best 20 Monte-Carlo models for WPP2 ......................................................... 114

Figure 4.9 Best 20 Monte-Carlo models for WPP3 …......................................................... 115

Figure 4.10 Best 20 Monte-Carlo models for PN2 ….................................................... 115

Figure 4.11 Final models for sites WKH2, WPP2, WPP3 and PN2 …............................. 116

Figure 4.12 Plot of invariant phase vs period and best fit model, WKH2 ….................... 117

Figure 4.13 Plot of invariant app. resistivity and best fit model, WKH2 .......................... 117

Figure 4.14 Plot of invariant phase vs period and best fit model, WPP2 …....................... 118

Figure 4.15 Plot of invariant app. resistivity and best fit model, WPP2 ............................ 118

Figure 4.16 Plot of invariant phase vs period and best fit model, WPP3 ........................... 119

Figure 4.17 Plot of invariant app. resistivity and best fit model, WPP3 ............................ 119

Figure 4.18 Plot of invariant phase vs period and best fit model, PN2 ............................. 120

Figure 4.19 Plot of invariant app. resistivity and best fit model, PN2 ….......................... 120

Figure 4.20 Pseudo-section of sites WKH2, WPP2 and WPP3 …..................................... 122

Figure 5.1 Relative positions of the MT sites on the gravity model ................................. 126

Figure 5.2 Final model of the sub-surface structure in the study area ............................... 128 


\section{Tables}

Table 1.1 A selection of historical New Zealand earthquakes, from Eiby, (1989). ............ 4

Table 1.2 Table of depths and ages of rock in Figure 1.9. ................................................... 17

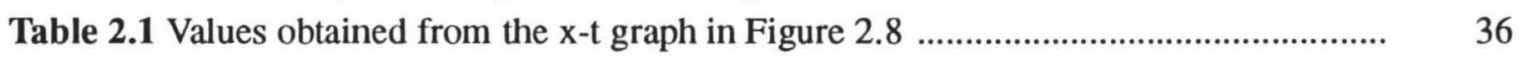

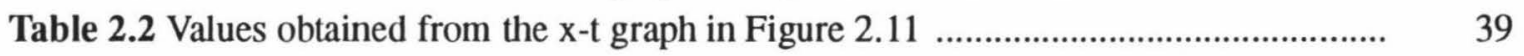

Table 2.3 Values obtained from the $x$-t graph in Figure 2.13 ............................................ 40

Table 2.4 Two different interpretations of the $\mathrm{x}$-t graph for PN-S3 ..................................... 43

Table 3.1 Density Contrasts Adopted by Woodward et al. (1978) ....................................... 60

Table 3.2 Density contrasts adopted in final model .......................................................... $\quad 62$

Table 3.3 Possible sources of error in gravity measurements, from Rymer (1989) ............. 68

Table 4.1 Grid co-ordinates for the MT sites .................................................................. 97

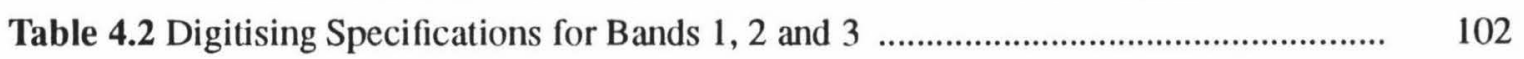




\section{Chapter 1}

\section{Introduction}

This chapter introduces the geological complexity of the study area. The Wairarapa Fault is isolated and discussed, and an historical account of the largest movement along the fault in 1855 is included. Previous geological and geophysical work carried out in the area is mentioned and finally the purpose of the study is outlined. 
If a man will begin with certainties, he shall end in doubts; but if he will be content to begin with doubts, he shall end in certainties. - Francis Bacon, "The Advancement of Learning."

\subsection{Preliminaries}

The mobile belt is a region of seismic and volcanic activity in the Pacific Ocean. This belt is defined by the boundary of the Pacific plate with the Eurasian, Australian and North American plates, as shown in Figure 1.1. This diagram shows the mobile belt as the shaded region, with the supposed direction of plate movement indicated by arrows. Although this area of tectonic activity is the most geologically active region on the Earth's surface, earthquakes and volcanoes also occur elsewhere in very definite zones, coinciding with the other active plate margins.

New Zealand, in the far southwest region of the Pacific Ocean is positioned on the boundary between the Pacific and Australian plates. Tectonic activity associated with the meeting of these two plates is the cause of New Zealand's volcanic and seismic activity. The Alpine Fault in the South Island defines the plate margin, but the plate movement in the North Island is more subductive than strike-slip, resulting in a broad volcanic and seismic zone.

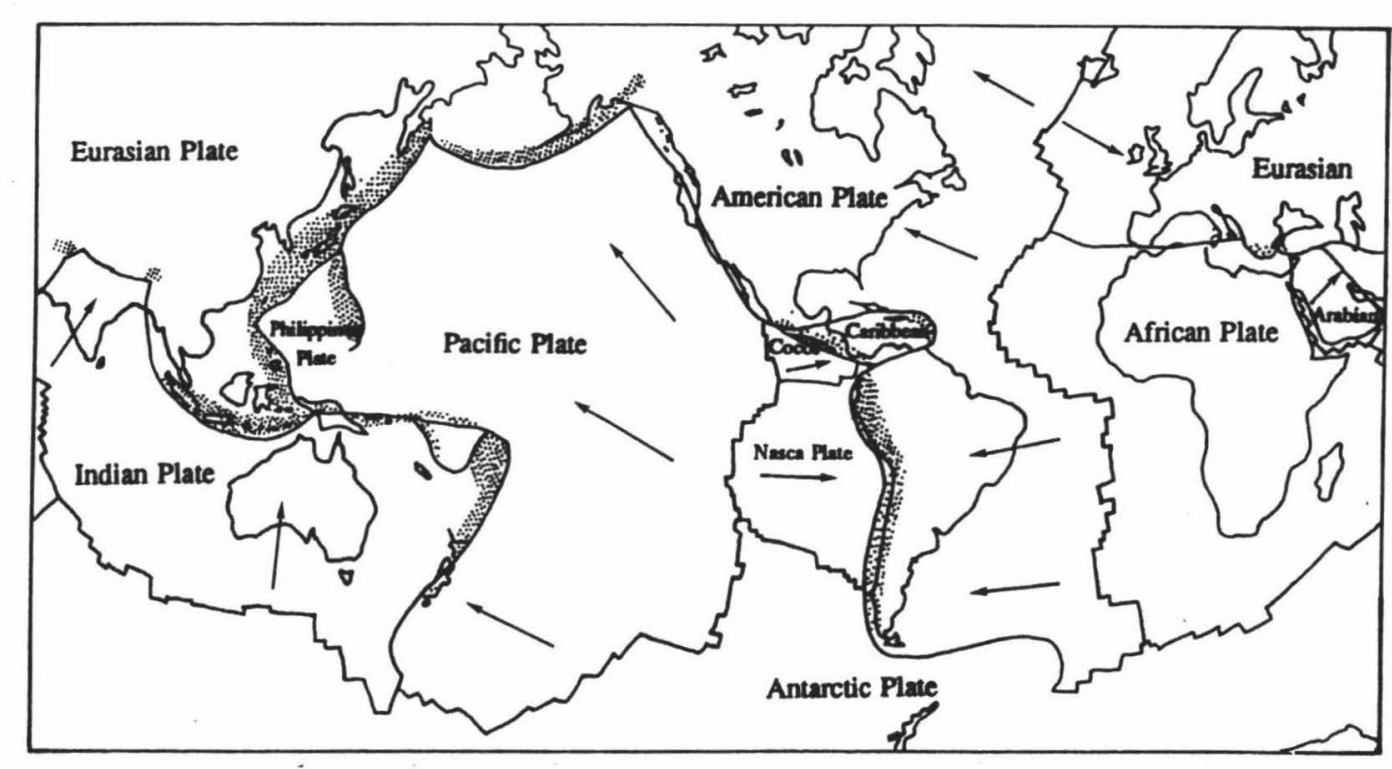

Figure 1.1 Mobile belt coinciding with the tectonic plates, from Eiby (1989) 
New Zealand, as in other countries of similar tectonic situation, is constantly under threat of severe earthquakes. The country is shaken by microearthquakes ( $<$ magnitude 3 ) every day. Although world-wide research continues into earthquake prediction, the magnitude, time and location of earthquakes cannot be foreseen. However by studying past earthquakes and faults, we might have better tools to help with prediction in the future. With the relatively recent colonisation of New Zealand, the record of earthquakes is not very large. Table 1.1 shows selected major earthquakes from the first recorded up until 1984.

Table 1.1 A selection of historical New Zealand earthquakes, from Eiby, (1989).

\begin{tabular}{|c|c|c|c|}
\hline Date & Location & Magnitude & Comments \\
\hline $1440 \pm$ & Wellington & Poss. 8 & $\begin{array}{l}\text { Known in Maori tradition as } \\
\text { the land swallower }\end{array}$ \\
\hline 1773, May 11 & Queen Charlotte Sound & & $\begin{array}{l}\text { First earthquake reported by } \\
\text { a European observer }\end{array}$ \\
\hline 1843 , July 8 & Wanganui & $\leq 7.5$ & \\
\hline 1848 , October 16 & NE Marlborough & 7.1 & \\
\hline 1853, January 1 & New Plymouth & 6.5 & \\
\hline 1855 , January 23 & SW Wairarapa & Poss. 8.1 & $\begin{array}{l}\text { Extensive faulting and } \\
\text { coastal uplift }\end{array}$ \\
\hline 1888, September 1 & North Canterbury & Approx. 7 & $\begin{array}{l}\text { Faulting at Glynn Wye pro- } \\
\text { vided one of the earliest ob- } \\
\text { servations of transcurrent } \\
\text { faulting }\end{array}$ \\
\hline 1917, August 6 & North Wairarapa & $<6$ & Felt Auckland to Cheviot \\
\hline 1931, February 3 & Hawkes Bay & 7.9 & \\
\hline 1942, June 24 & Southern Wairarapa & 7 & \\
\hline 1942, August 1 & Southem Wairarapa & 7.1 & \\
\hline 1966, April 23 & Cook Strait & 6.1 & \\
\hline 1968, May 24 & Inangahua & 7 & Fault breakage \\
\hline 1977, January 18 & Cook Strait & 6 & \\
\hline 1984, December 31 & Bay of Plenty & 6.3 & \\
\hline
\end{tabular}

A seismic network was not set up in New Zealand until the middle of this century. The faults throughout New Zealand are expressions of movement associated with seismic activity. A good example of this is shown in the northern Wairarapa at the Waiohine River in a series of steplike terraces. Movements range from $118.5 \mathrm{~m}$ horizontally and $18.5 \mathrm{~m}$ vertically on the highest terrace, to $12.2 \mathrm{~m}$ horizontally and $1.5 \mathrm{~m}$ vertically on the lowest terrace, with this last movement occurring in the 1855 earthquake (Stevens, 1974). These movements are permanently recorded in 
this series of terraces. The study of faults therefore is of interest, and in a country such as New Zealand, there is great potential for such work.

\subsection{Faults in Central New Zealand}

New Zealand is transected by a network of faults because of its tectonic situation, as discussed in Section 1.1. The subduction of the Pacific plate beneath the southern North Island occurs east of Cook Strait, however, south of the Strait the plate is difficult to detect structurally (Carter et al., 1988).

The tectonic activity in central New Zealand has generated much interest with regards to the fault systems between the North and South Island. Many authors have attempted to join the major faults in the North Island with those in the South (McKay, 1892; Lensen, 1958; Kingma, 1974; Stevens, 1974)(see Figure 1.2). Both Ghani (1974) and Katz and Wood (1980), suggested that although some of the North and South Island faults may indeed be continuations of each other, through the Cook Strait they are very fragmented. Carter et al. (1988) used seismic reflection data to reveal that the major dextral transcurrent faults of New Zealand do not link directly across Cook Strait, with the Wairau Fault being the possible exception to this. They propose that the faults end in the central Cook Strait region along an "apparent dextral offset". The reason for this being the clockwise rotation and movement of the fault belt caused by movement between the Indo-Australian and Pacific plates in the Cenozoic era.

Central New Zealand is somewhat of an enigma in terms of the geological complexity. There are continual new interpretations for the fault systems in this region of New Zealand, as detailed above. Figure 1.3 shows a map of the major strike-slip faults in the Wellington region (Wairarapa, Wellington, Ohariu, Shepherd's Gully and Pukerua Faults), with an inset showing the Indo-Australian plate boundary and accompanying Axial Tectonic Belt. The investigation of the Wairarapa Fault was the purpose of this study and this fault will be described in detail below, in Section 1.3.

\subsection{The Wairarapa Fault}

The Wairarapa Fault is well defined for 75 kilometres between the western corner of Lake Wairarapa to Mauriceville. The earthquake recurrence interval is estimated as 1000 years, with the most recent large earthquake occurring in 1855. The horizontal slip-rate of the fault is estimated at between 10 and 12 millimetres per year, and the horizontal single-event displacement 

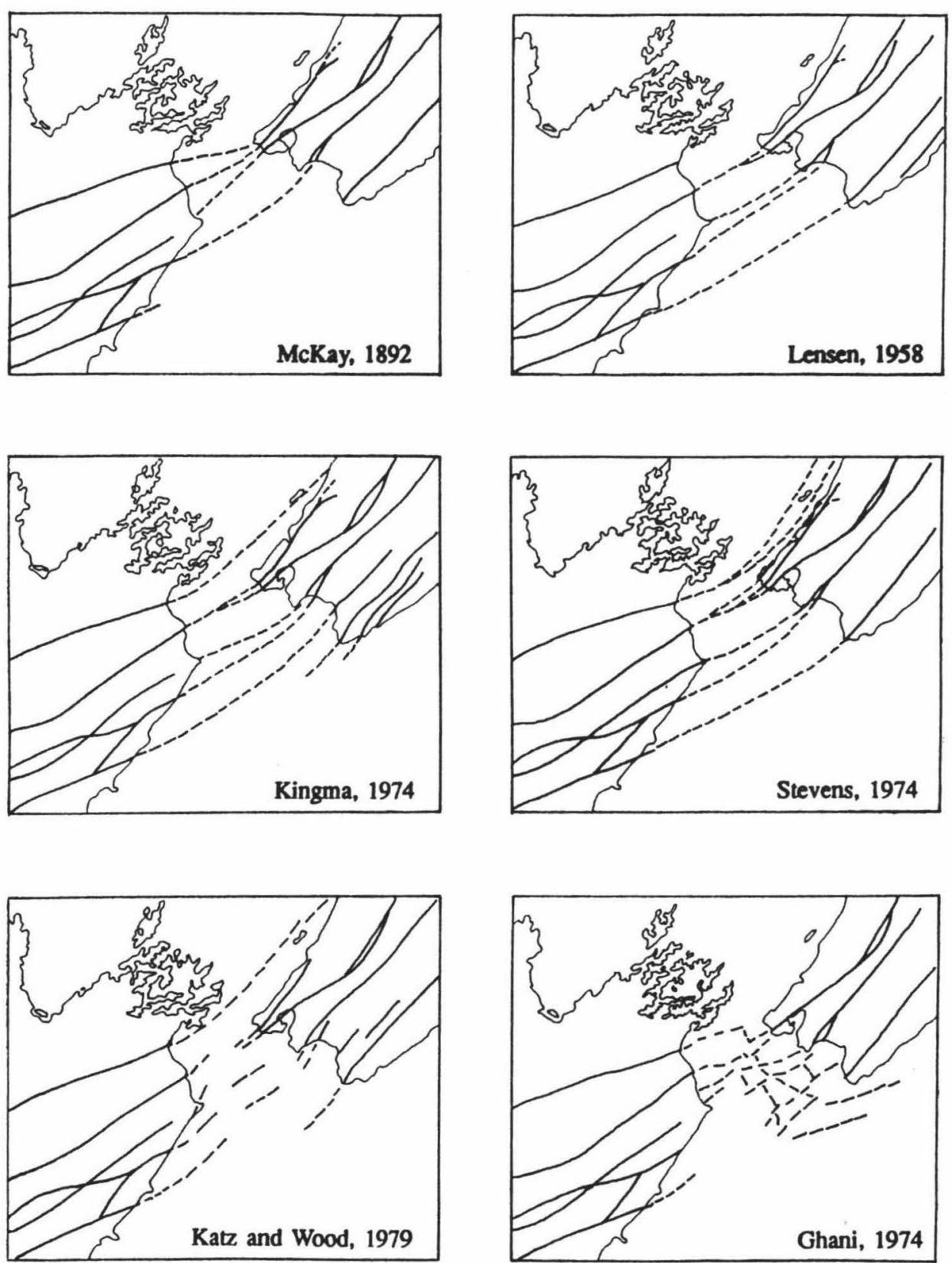

Figure 1.2 Interpretations of the fault systems across Cook Strait 


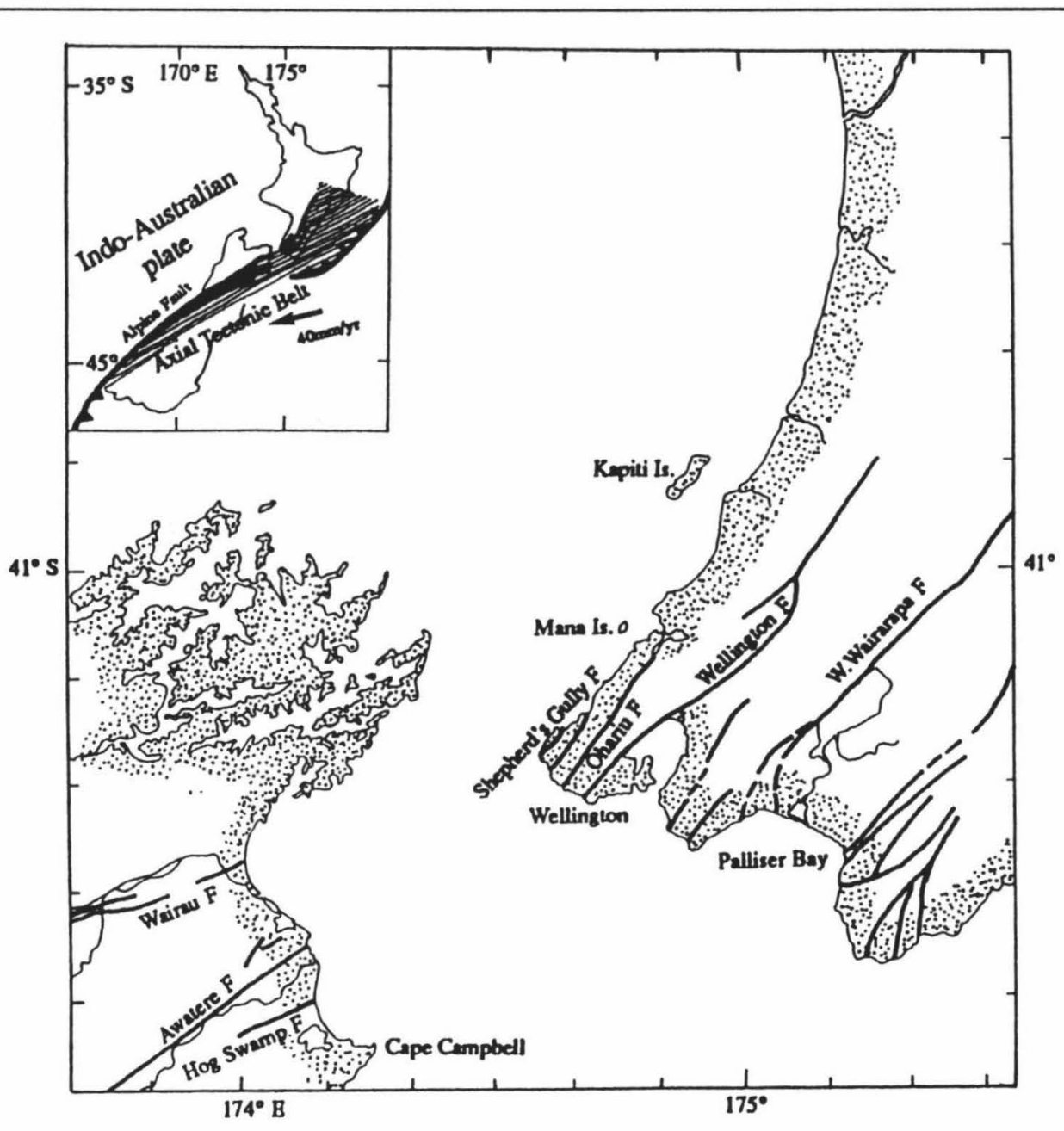

Figure 1.3 Major faults in central New Zealand, from Carter et al. (1988)

is 12 metres. On scales of less than or equal to 1:250 000, the fault appears as a continuous line, but it is in fact a series of straight segments separated by 100 to 500 metre left-slopping offsets (Grapes and Wellman, 1988). South of Lake Wairarapa, the line of the fault is not a single trace. The former fault has been suggested to bifurcate into branches running down the Wharepapa River and the Muka Muka Stream. Homer and Moore (1989) show a further branch at the mouth of the Te Mahonge Stream ( named on the map by Smith (1849), but not named on more recent topographical maps.) This area shall be referred to as Thrust Creek as in Homer and Moore (1989). The reasoning behind this interpretation shall be discussed in Section 1.6. Figure 1.4 (a) shows the localities of these 'branches', and (b) the latest interpretation of the Wairarapa Fault 
from Grapes (1991).

There is some debate as to the existence and location of the Wairarapa Fault 'branches'. The south-west and north-east portions of the fault are unclear and Dr R. Grapes (pers.comm.) explains that the fault is no longer continuous from the south-west corner of Lake Wairarapa,

(a)

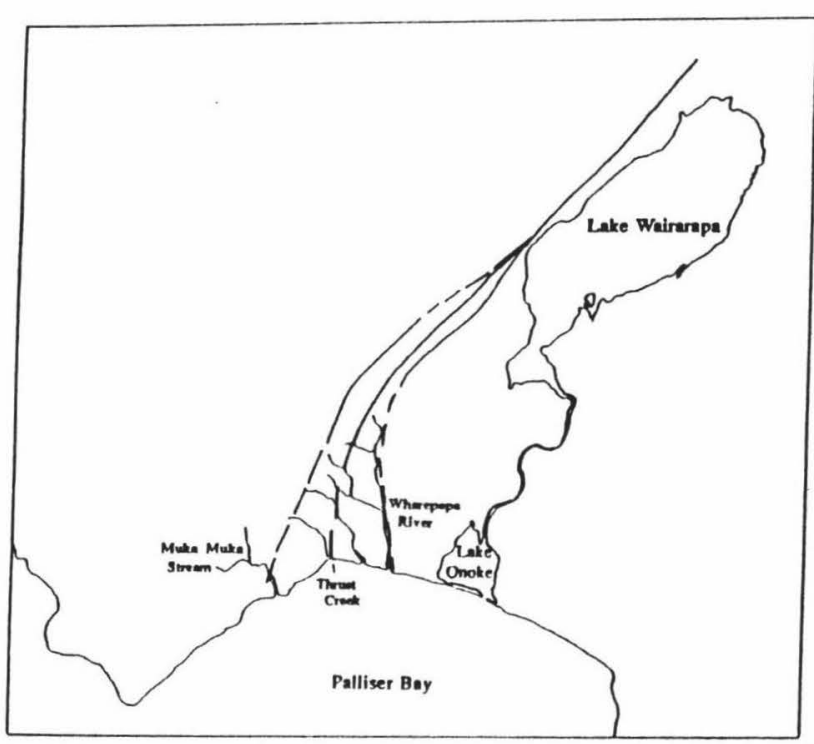

(b)

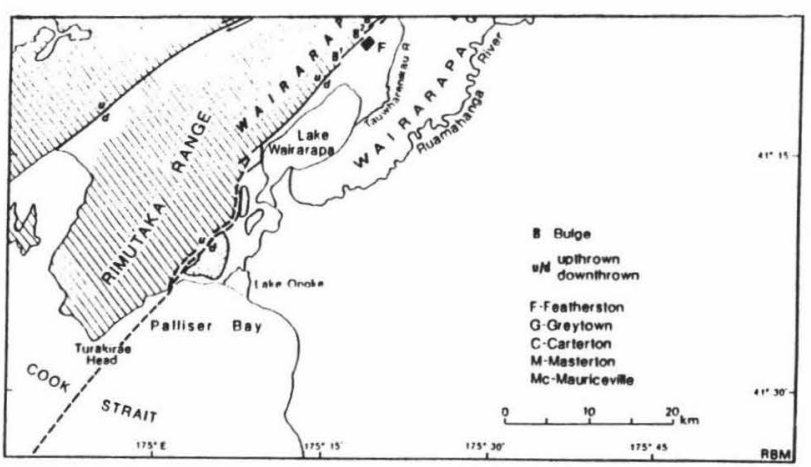

Cross hatched area = Lale Triassic - Jurassic greywacke

The narea = Late Miocene - Pleistncene cor he

respective ranges (after (iHANI 1978)

Figure 1.4 Two interpretations of the Wairarapa Fault south of Lake Wairarapa 
running down to the coast at Palliser Bay. There is presumed to be an old fault trace buried within the region of the Wharepapa River, but there is no surface evidence for a present-day trace running down the river. During the 1855 earthquake no movement was recorded along the Wharepapa River, so if a trace does exist, it is ancient and possibly not an active part of the Wairarapa Fault today. The main evidence which has led many people to believe the fault runs down the river is it's perpendicular and straight course of flow into the sea. Rivers often follow their course along fault lines.

The three forementioned 'branches' of the Wairarapa Fault are not considered to exist in a modern context, or more specifically do not exist as clearly defined faults, but rather as fault zones. Greywacke to the west of the Wharekauhau area has been highly contorted and extruded in the Thrust Creek region, and lies as basement beneath the Wairarapa sedimentary basin. It outcrops in areas such as along the Wharekauhau Stream, but does not appear commonly in the region, and when it does it is in a very crushed and eroded state. The Wairarapa Fault, south-west of Lake Wairarapa becomes complex. Ongley (1943) shows evidence of movement during the 1855 earthquake, with slumping of land and fault scarps further up the valley. There is no clear pattern of continuity of the fault and this gives us good reason to believe that in the study region we are dealing with a fault crush zone, rather than the continuous fault shown on Kingma's 1967 geological map.

Movement on the Wairarapa Fault has caused some of New Zealand's larger earthquakes. New Zealand's largest recorded earthquake was the one occurring in the Wairarapa in 1855. Since then there have been several large earthquakes in the Wairarapa. One in north Wairarapa (1917), and two within 1942 in southern Wairarapa, as shown in Table 1.1. With the relative proximity to Wellington, (with only the Rimutaka Ranges separating the two large sedimentary basins of Wellington and the Wairarapa), any sizeable earthquake in the Wairarapa region has a significant effect in Wellington. With its relatively frequent activity and subsequent effect on central New Zealand, and Wellington in particular, the Wairarapa Fault is continually under study.

\subsection{An Historical Account of the 1855 Earthquake}

New Zealand was not well colonised by Europeans in the mid nineteenth century. It is therefore not surprising that most information on the Wairarapa earthquake of 1855 , comes from only a handful of eyewitness accounts. A report was made detailing the earthquake to the 
Geological Society of France by Sir Charles Lyell. His information came from conversations with E. Roberts, W. Mantell and F. Weld, three men present at the time the quake struck on January 23rd 1855 (Ongley, 1943).

The earthquake has been estimated to have reached magnitude eight on the Richter Scale, making it the largest earthquake in historical New Zealand. The earthquake is thought to have originated on the south-westem part of the Wairarapa Fault on the eastern of the Rimutaka Ranges, 25 kilometres east of Wellington city (Eiby, 1989). The coastline rose $1.5 \mathrm{~m}$ from the sea at Wellington during the earthquake and the Wairarapa Fault moved upwards $2.7 \mathrm{~m}$ and horizontally by 12 metres as shown in Figure 1.5. A total area of some $900000 \mathrm{~km}^{2}$ spreading from the Wairarapa coast north to Woodville, and to Cape Terawhiti in the west was affected by the earthquake (Lyell, 1856). The effect was not of straight uplift, but rather of tilting. Scarps are still visible along the trace of the fault running down the eastern side of the Rimutaka Ranges, although much has been overgrown or eroded. Grapes and Wellman (1988) describe the evidence from the 1855 earthquake.

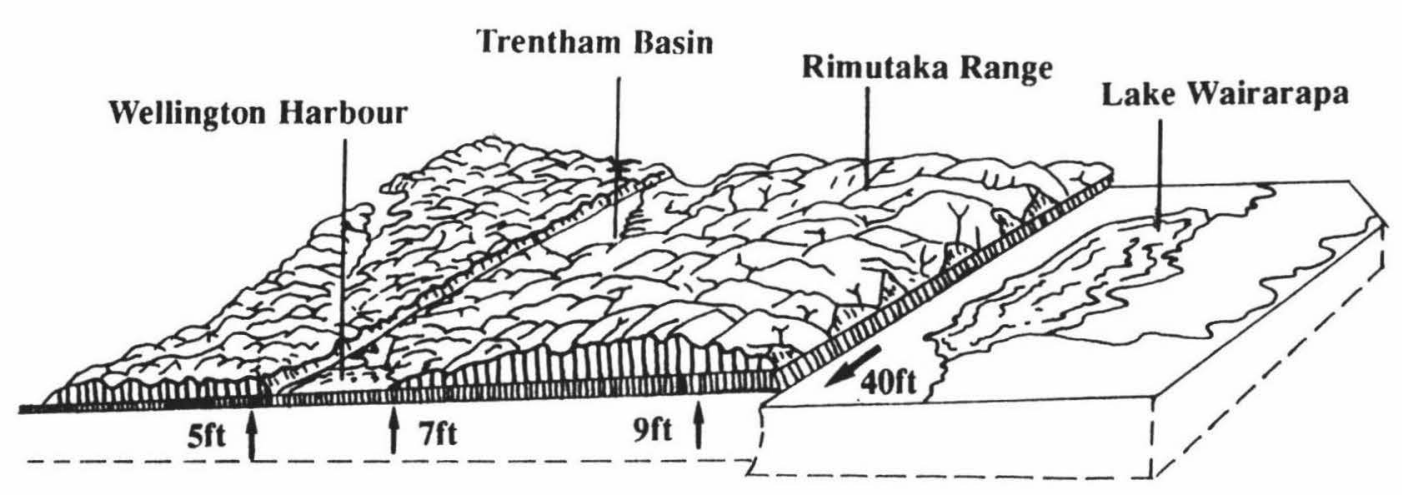

Figure 1.5 Effect of the 1855 earthquake on the Wairarapa Basin, from Stevens (1974) 
By 1943 only four further sources of information about the 1855 quake had been published (a report by Roberts in Taylor, 1855; Vennell, 1891; Iorns, 1932; Crawford, 1870). With the lack of published accounts of the earthquake, a selection of Roberts' comments have been quoted below:

The shock was of the greatest violence in the narrowest part of Cook's Straits, a few miles to the S.E of Port Nicholson; but it was felt over the whole of the islands and by ships at sea 150 miles away from the coast; the whole extent of the area over which the convulsion was felt must have been 360,000 square miles.

Its effects were most violent in the immediate vicinity of Wellington, where a tract of land of 4,600 square miles in extent was elevated to a height varying from one to nine feet, the greatest elevation being a range of hills called the Rimutaka (a spur from the Tararua Mountains), which terminates abruptly at the sea coast at Cook's Straits.

This range, which appears to have been in the direct line of the subterranean action, was elevated nine feet, while the whole country as far as Wai-nui, about two miles northward of the foot of the road leading down the Par-pari, was elevated with it, though the elevation at the last named point was on the sea coast very slightly. On the eastern side of the range is the valley of the Wairarapa, the centre of which is occupied by a lake. This valley and plain remain on the same level as before, the range of hills having gone up along a perpendicular precipice of nine feet in height, which has been traced to a distance of ninety miles inland.

The Rimutaka Range was very much shaken in its elevation, and a great many slips occurred, laying bare the western side as well as on the eastern.

Roberts' report gave an account good enough for subsequent investigation of the area for research into the effects of the 1855 earthquake. The report was thought by Ongley to have containdseveral inaccuracies. One, which Ongley refers to in his 1943 paper, is Roberts' description of a fault running down the Muka Muka Stream, and also another down the Te Mahonge Stream. The confusion however lies in the fact that Roberts refers to the whole of the western side of Palliser Bay coast as Muka Muka. Ongley claims instead that the fault is "three- 
quarters of a mile east across the bay [Palliser Bay], where the west side is dark indurated crushed greywacke and argillite." It appears even so, that the area both men are referring to was at Thrust Creek.

In Kingma's geological map of 1967, a branch of the Wairarapa Fault is still shown running down the Muka Muka Stream. The existence of the Muka Muka fault branch, like that following the Wharepapa River to the coast, is unknown. The fault described by Ongley as being "threequarters of a mile across the bay", and also by Lyell (see Figure 1.6), is now believed to be the crushed zone of greywacke at Thrust Creek, which has been overturned and could appear as a fault trace. Lyell's interpretation has been redrawn by Grapes (1988), also shown in Figure 1.6.

Ongley (1943), describes the 1855 scarplet as following north from the first visible sign one mile from the coast. There are various areas as shown in Figures 1 and 2 of Ongley's 1943 report, where there were obvious fresh signs of movement after the 1855 earthquake. Movement in the study area in 1855 is not obvious, so any fault trace in the region must be buried and is probably inactive.

(a)

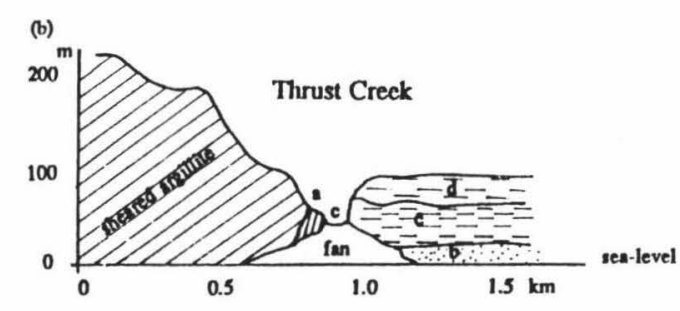
A argillite
B Tertiary
c,d line of vertical fault

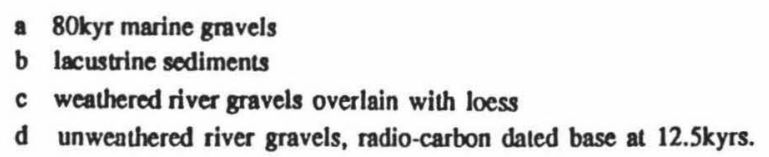

Figure 1.6 Interpretation of the 'fault' trace at Thrust Creek, by (a) Lyell and (b) Grapes (1988) 


\subsection{The Study Area}

The area under study lies between $41^{\circ} 19^{\prime}$ and $41^{\circ} 23^{\prime}$ North and $175^{\circ} 02^{\prime}$ and $175^{\circ} 08^{\prime}$ East, which represents 5978000 to 5985000 and 2681000 to 2689000 on the NZMS260 sheets. An aerial photograph of the study region is shown in Figure 1.8. Superimposed on the plastic overlay are symbols showing the locality of the gravity stations • , MT sites 0 and seismic spreads -----.

\subsection{Geology of the Study Area}

The Wairarapa region lies in the southern part of the North Island of New Zealand. This area of the North Island is the convergent part of the plate boundary between the obliquely convergent Australian and Pacific plates (Cape, 1990). For this reason the Wairarapa region especially, is geologically very active.

Alluvial material was deposited into the Wairarapa Valley during the ice ages, mainly supplied from rivers draining the Tararua Range. With stabilised climatic conditions, the river gravel supplies lessened and the river beds lowered by cutting into and removing deposited gravels. The present shoreline is one of submergence. From the uplifted marine terraces bordering Palliser Bay to the west of Lake Onoke (which provided most of the survey sites), it is indicated that the sea level was of an even greater height than the actual terraces (Bloom, 1951). As the sea levels changed the marine terraces receded and advanced up and down the valley, as far north as the Lake Pounui region. Ghani (1974) worked in the area finding the different heights and positions of the marine benches. Bloom (1951) made detailed stratigraphic sections in the area. He describes the lithology of the Wharepapa Formation (named from its typical development along the Wharepapa River), as "rudely sorted, coarse gravel with silt band up to several feet thick", and gauged at between 15 and 60 metres in thickness.

The region under study is fractured by numerous faults and splinter faults as shown in Figure 1.7, with the orientation and location of the fault zone in a dotted rectangle. The Echo Gully, Dog Hill and Battery Hill Faults are part of the belt of strike-slip faults located west of the western edge of the Wairarapa Valley, caused by the deformation of the plate boundary zone. At this zone Mesozoic strata and Cenozoic deposits, with minor volcanic components, rest on the subducted Pacific Plate, the top of which is less than $30 \mathrm{~km}$ deep below the Wairarapa Valley (Cape, 1990). The Dry River Fault separating Cretaceous from Jurassic rock in the Aorangi 


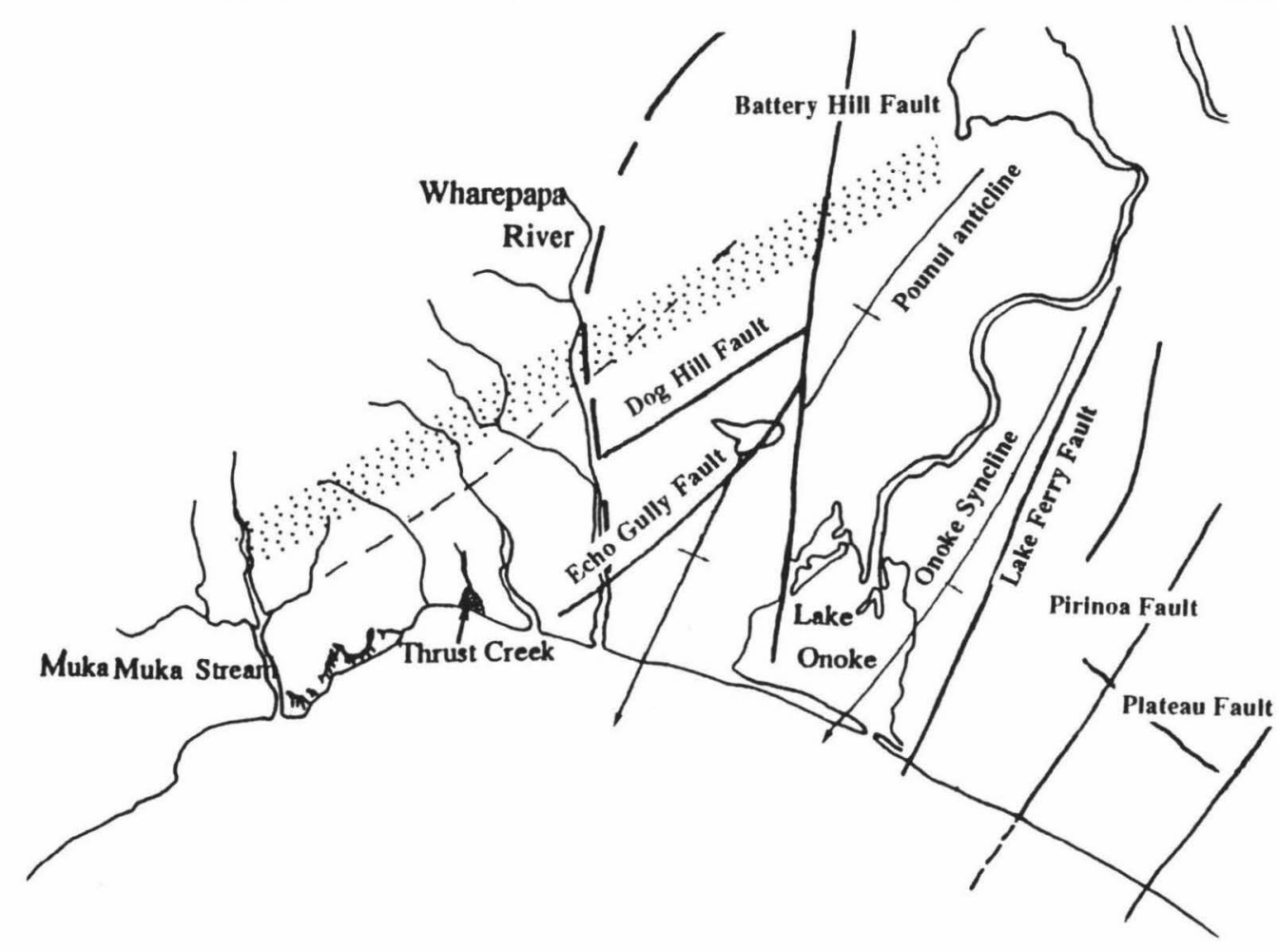

Figure 1.7 Faults in the study area, after Ghani (1974)

Mountains, has been projected northeast which explains the boundary between Cretaceous and Pliocene rocks (Woodward, 1978).

The Basement rocks are highly faulted and folded Mesozoic greywackes and argillites which outcrop to form the Rimutaka-Tararua Range and the Aorangi Mountains. Between these, the basement is down-faulted and covered by thick Cenozoic sedimentary rocks and unconsolidated sediments. Gravity anomalies in this area are caused by differences between the Cenozoic material, and the underlying surrounding Mesozoic basement rock (Woodward, 1978). The Rimutaka Range is one of the most rapidly rising blocks of land in New Zealand today. Each time there is movement along the Wairarapa Fault, the ranges are further pushed up.

The cross section B-B' in Kingma's geological map just north of the study area is shown in Figure 1.9 and is an indication of the surface geology in the area. Kingma's representation of the geology in the region west of the Wharepapa River to the Wharekauhau Stream as greywacke is incorrect. In this region we are still dealing with 


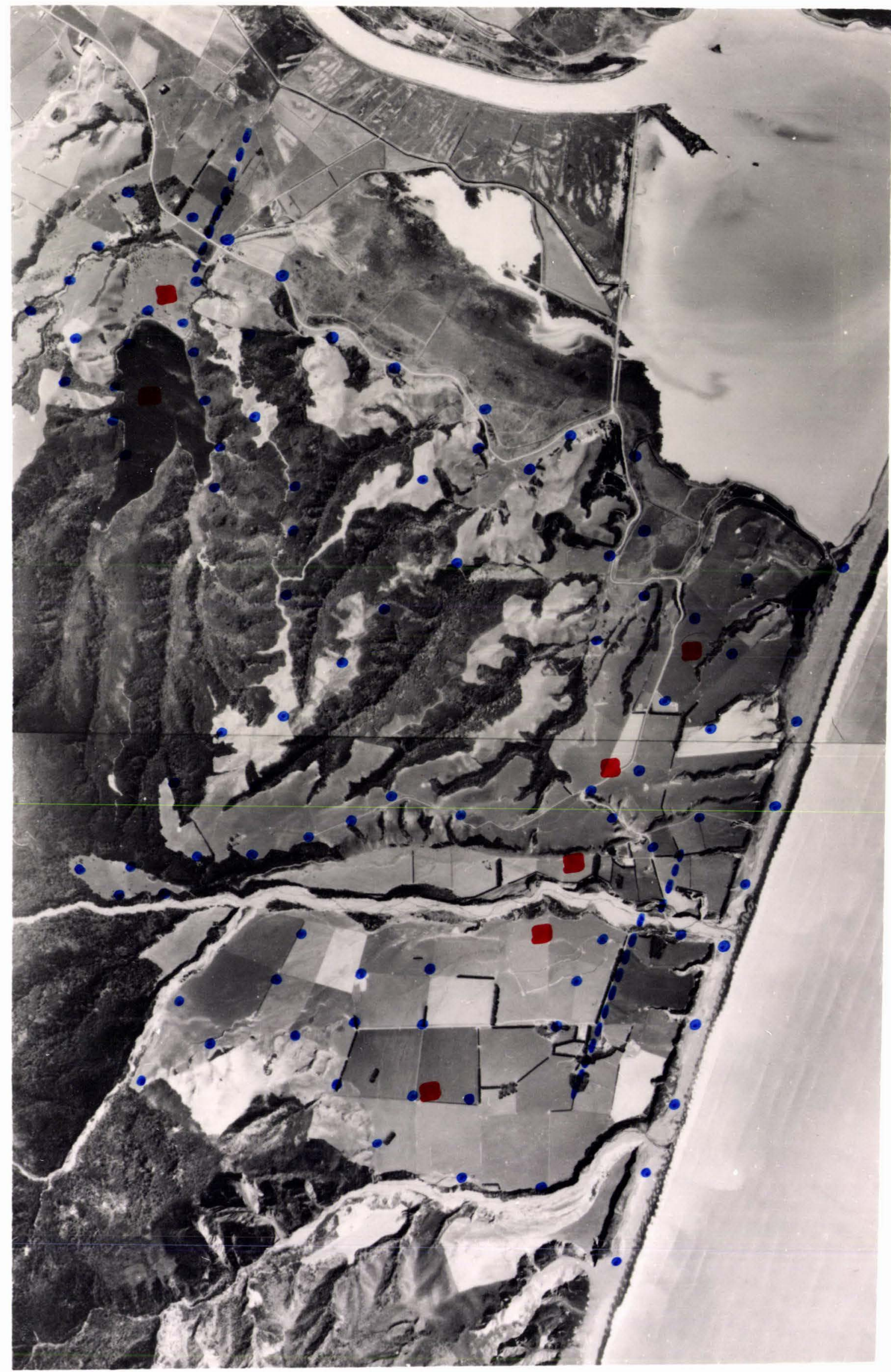

Figure 1.8: Aerial photograph of the study area 
material of alluvial origin, and not greywacke as he describes. Greywacke first becomes visible in the Wharekauhau Stream, where there are several outcrops along the length of the stream.

From Kingma's cross-section, we can see the approximate age and depth of material in the study area. Table 1.2 shows an estimation of the depths and densities of the ages of the subsurface material in Kingma's interpretation.

Table 1.2 Table of depths and ages of rock in Figure 1.9.

\begin{tabular}{||c|c|c|c||}
\hline \hline Symbol & Age & Approx. Depth(km) & Approx. Density $\left(\mathrm{Mg} / \mathrm{m}^{3}\right.$ \\
\hline Wc & Mid-Pleistocene & 0.75 & 2.0 \\
Wo-W & Pliocene & 1.5 & 2.20 \\
Tt-k & Upper Miocene & 2.3 & 2.35 \\
L-P?+S & Lower Miocene & 4.3 & 2.45 \\
K-O+U? & Upper Jurassic & 20.0 & 2.67 \\
\hline
\end{tabular}

All depths are extrapolated and densities are within the range of approximately $0.1 \mathrm{Mg} / \mathrm{m}^{3}$. Bloom (1951) admits that little is known of the sub-surface structure of the Wairarapa depression. Since 1951 little advance has been made into seeking more knowledge of the structure in the study area.

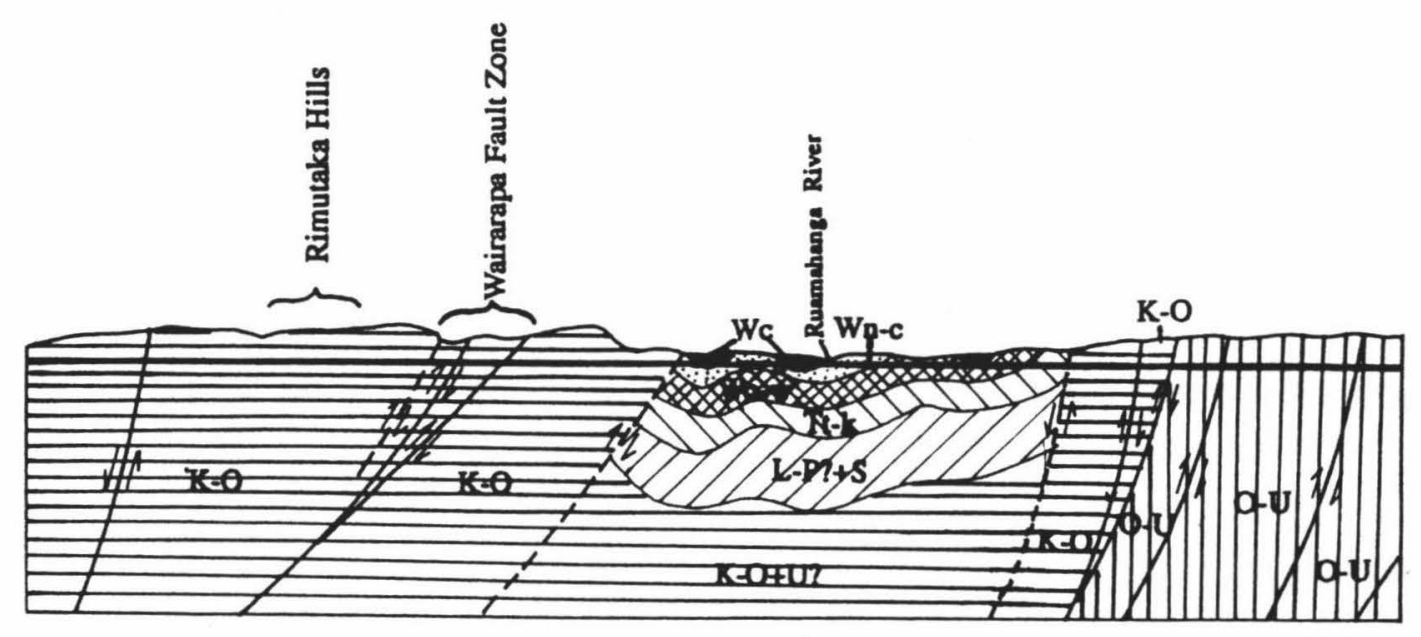

Figure 1.9 Kingma's cross-section north of the study area 
The geology of the entire south-eastern flank of the Rimutaka Ranges is moulded by the presence of the Wairarapa Fault. The Wairarapa sedimentary basin has consequently been warped and tilted by movement along the fault. This movement has not been evenly distributed and there is evidence of transcurrent, strike-slip displacement. More recent movement along the fault seems to be shown in some areas as a reversal of earlier trends and much faulting has occurred in the sediments, some distance away from the main fault trace (Bloom, 1951).

No detailed description of the geology of the area existed prior to the $1950 \mathrm{~s}$. Reconnaissance surveys were carried out by McKay (1888), but he gave no mention to any fault scarp. The raised sea benches and marine terraces were noted by King (1930), and Ongley (1943) traced the fault for the entire length of the Wairarapa Valley.

King (1940) describes the Wairarapa basin as "...a broad syncline, asymmetrical, one limb of which is partly transected by a fault, and which pitches gently to the north." The region is by no means simple structurally. Much deformation has occurred in the region with forces acting to produce faulting with no clear pattern. The Wairarapa Fault in this region is reduced to a shear zone with much residual splintering in definite zones and crushing of the local greywackes.

In Section 1.3 the discontinuity of the Wairarapa Fault in the study area was explained. The misinterpretation of a third 'branch' by Homer and Moore (1989), is what is now believed to be the region described by Roberts to Lyell in 1856. It is however not a third branch of the fault. Instead we are looking at a contact between greywacke to the left and Pleistocene gravels to the right of the stream mouth. A fault can loosely be described as the contact between two different materials, such as sediment and greywacke for example. In the Thrust Creek region it appears that there is an active fissure beneath the gravels which have come up some $20 \mathrm{~m}$ since 1855 (Grapes, pres. comm.). The reasoning for this lies in the fact that the greywacke is still being actively deformed. Grapes (pers. comm.) believes that the extruding greywacke outcrops being deformed constantly by gravitational forces, may be parallel to the original bedding. The material in the region has been highly contorted and is now overturned with lacustrine, overlying beach and fluvial gravels, and appears as a fault.

The pattern in this area of complete pulverisation of material is indicative of the forces acting further north up the valley. The region has become a complex, crush zone and one which is constantly being deformed. Although the Thrust Creek area did move during the 1855 earthquake, it is a constantly active fissure today. 


\subsection{Previous Work Carried out in the Area}

The area around Lake Pounui was the first under survey by the author. As more work was carried out in the area, the geological complexity of the region became more apparent. Eventually what began as a study of the history of Lake Pounui became a more widespread study of the area to determine the depth to the basement rock and the behaviour of the Wairarapa Fault in this region. In Sections 1.3 and 1.6 it was shown how the interpretation of the fault systems in this region is very subjective. Although the geology of the area has been mapped and worked on by many authors (Grapes and and Wellman (1988), Ghani (1974) and Kingma (1967) to name a few), the surface geology has been extrapolated to considerable depths which does not make for reliable or accurate interpretation. Several geophysical studies have been carried out across the Wairarapa Fault from its beginning at Mauriceville to its exit on land in the North Island at Palliser Bay (Heine (1964), Gibbs (1974), Maddocks (1970), Gresham (1967), Woodward (1978), Cape et al. (1990)). These surveys apart from Maddocks' are well north of the study area. So although the Wairarapa region has been the subject of much geological and geophysical investigation, very little work has been done in the specific study area.

Only seven further gravity stations were in the DSIR's data base for this area, so Maddock's work is the most survey carried out in the area, up until this time. Maddock's survey consisted of two profiles running at approximate right angles to the fault as mapped by Kingma (1967). Figure 1.10 is a map of Maddock's profiles showing station locations, with the present study area enclosed in a dotted rectangle. Maddocks only used the gravity surveying technique. His interpretation is of a reverse fault dipping between $40^{\circ}$ and $60^{\circ}$ east, with a throw of about 500 metres. Basement, he concluded, dipped east towards the fault, and there was a possibility of a smaller fault approximately half way along the profile (corresponding with the Wharepapa River). The locality of the former fault described by Maddocks, corresponds to the trace at Thrust Creek and progressing further up the valley into the crush zone.

There is great potential for further geophysical work to be carried out in the study area. Modelling programs have developed since 1971, the time of Maddocks' work, so with the additional surveys employed for a compliment to the gravity data, a clearer picture of the situation in the south-west Wairarapa is possible. 


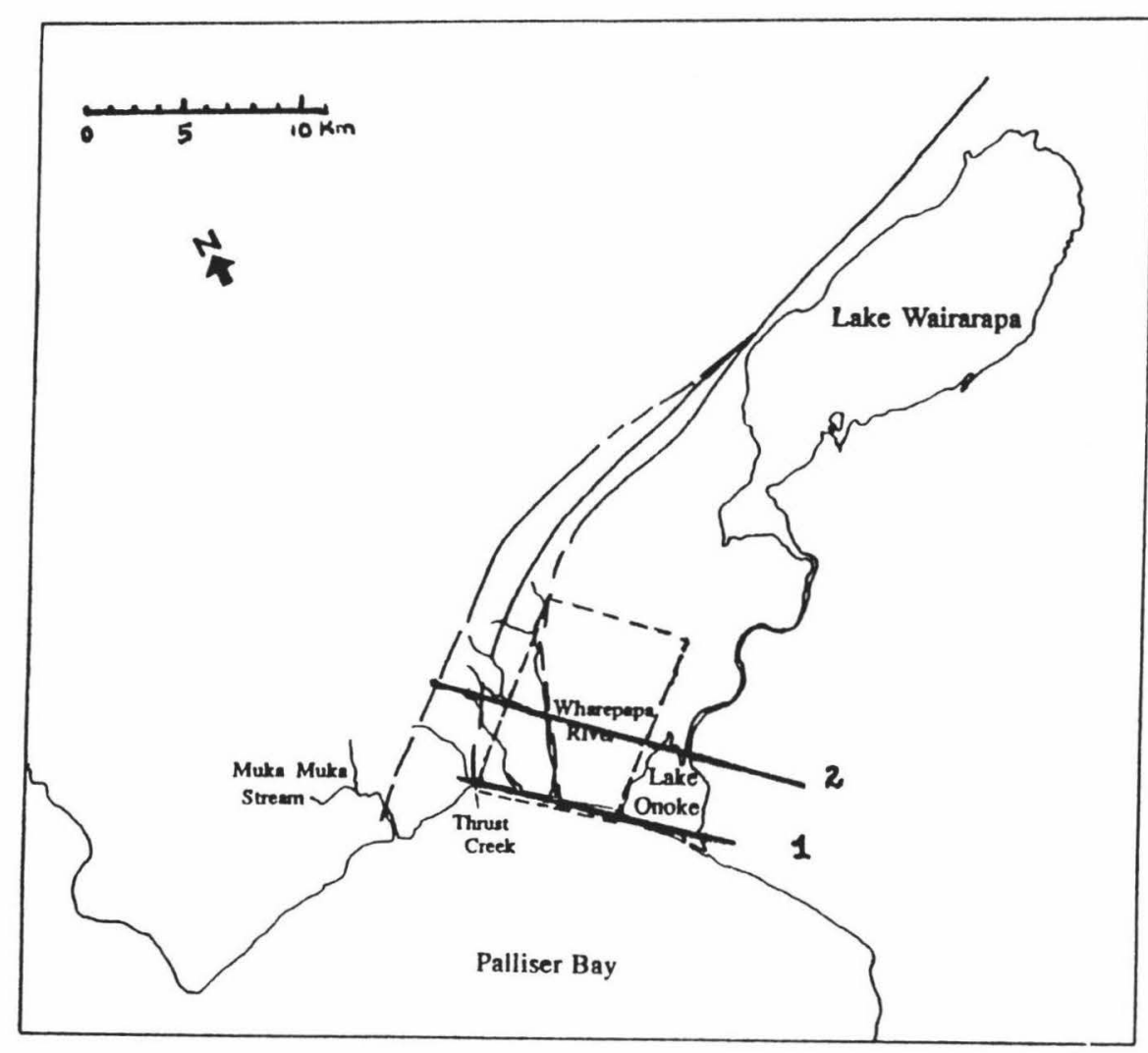

Figure 1.10 Localities of Maddocks' profiles in the study area

\subsection{Fieldwork}

The fieldwork for this study was undertaken over a period of two years, 1990-1991, mainly during the first few months of each year. Thirty five gravity stations and two MT sites were set up in 1990. While three seismic spreads, ninety gravity stations and six MT sites were set up in 1991. Each survey involved at least two team members including the author. The list of people involved in the fieldwork is contained in Appendix A.

There were no major problems involved with the fieldwork, except at times accessibility was awkward for the gravity surveying. This meant that some locations which were desirable to be included in the survey were not able to be used.

Detailed accounts of the fieldwork for each survey method can be found in the appropriate chapters. 


\subsection{Objective}

The previous sections in this chapter show the geological complexity of the south-west Wairarapa region. With this in mind, the goal set in preparing this study was to use several geophysical techniques to survey the region. The main objective was to prove the existence, or otherwise, of the branch of the Wairarapa Fault running down the Wharepapa River as mapped by Kingma (1967). This analysis should also determine the depth to basement to a much greater accuracy than is presently known. Many believe that no fault trace exists along the Wharepapa River, but that the surrounding area to the west of the stream is a fault crush zone. Results from the various techniques shall help determine which description is more applicable.

\subsection{Summary of the Following Chapters}

The following chapters contain the interpreted data and analysis from the three separate survey methods employed for this study. The main point of each chapter is to present information determined from the surveys. So although each begins with an outline of the theory behind each particular method, it is only dealt with briefly and the reader is guided by references for further information.

Chapter 2 contains information on the seismic refraction survey which provides data used in the following chapter on the gravity survey. Chapter 2 is not dealt with in such detail as the two which follow it, as the seismic surveys were not intended to be a reconnaissance of the area like the gravity and MT methods, but as a support to the main surveys. Chapter 4 deals with the MT survey which is followed by a chapter in which the interpretations from those preceding, are amalgamated for a final model of the sub-surface structure of the study area. This leads logically onto the final concluding chapter. 
$-22-$ 


\title{
Chapter 2
}

\section{Seismic Survey}

\author{
A total of three refraction spreads were \\ laid throughout the study area. The seismic data was obtained to help \\ constrain the density values for the gravity models, by giving \\ the velocities of the sub-surface strata. If the seismic data \\ could determine depths to the basement level, further \\ information could be added to confirm the depth of the results \\ from the gravity data.
}


Chapter 2-Seismic Survey

$-24-$ 
Some force whole regions, in despite $O^{\prime}$ geography, to change their site: Samuel Butler, Hudibras

\subsection{Refraction and Reflection Work}

The two main seismic surveying methods are refraction and reflection. Refraction was the first of the two seismic techniques to be employed in petroleum prospecting. Prior to this it had been used by seismologists in the early twentieth century in determining the structure of the earth from earthquake records. The discovery of the Earth's core and its depth was made in 1912 by Gutenberg, using seismic refraction techniques.

Reflection is the most widely used of all geophysical techniques, as it provides structural descriptions of the sub-surface, comparable to the data taken from boreholes (Dobrin, 1981). Although a clear sub-surface picture is desirable, reflection work cannot determine accurate velocities or depth of layers. Conversely, refraction surveying does not detect small surface variations, but assumes a horizontally layered medium with velocity increasing with depth. In this case depth, dip and velocity can be accurately determined. For this reason, refraction work is the better of the two for determining the depth of sedimentary basins by mapping the surface of the basement (and upper layers of the basin), which should have a higher velocity than that of the sedimentary layers.

To show the physical difference between the two methods, we refer to Figure 2.1 showing the travel paths and velocities of seismic waves propagating through a two layer medium. The principle difference can be seen to lie in the geometry of the travel path of the waves. This geometry determines the time with which the waves travel back to the surface.

This has been a brief description of the two different seismic techniques to show the relevance of one as compared to the other for this study. The refraction method is pertinent to this particular work and shall be discussed forthwith.

\subsection{Basic Refraction Theory}

A seismic wave is refracted only from the boundary between layers of increasing velocity. The refraction at this boundary obey's Snell's Law:

$$
\frac{\sin i}{\sin R}=\frac{V_{1}}{V_{2}}
$$

where $\sin i$ is the angle of the incident wave, $\sin R$ is the angle of the refracted wave and $V_{1}, V_{2}$ 


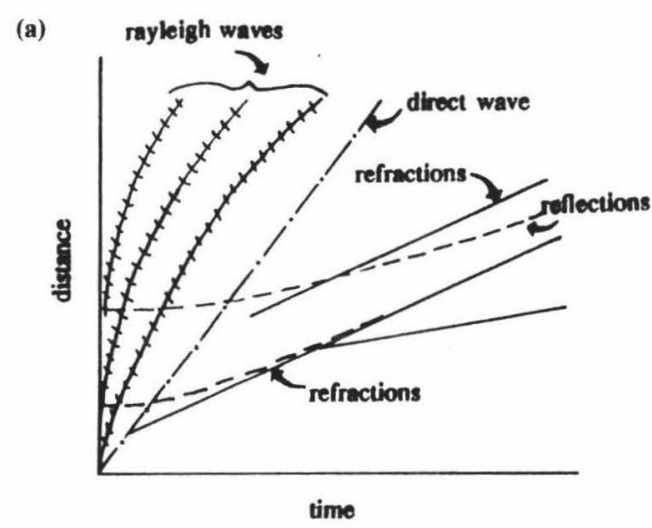

(b)

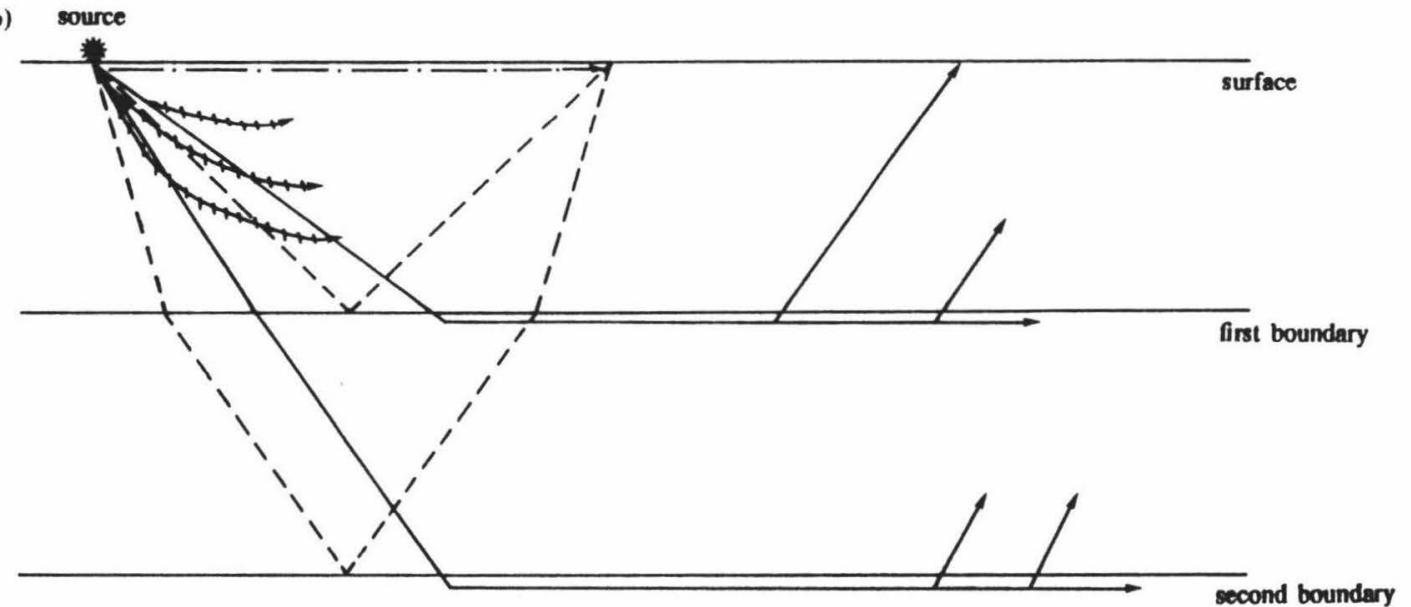

Figure 2.1 Velocities (a) and travel paths (b) of seismic waves (from Hales, 1958)

are the velocities of mediums 1 and 2 respectively, all shown in Figure 2.2. When energy is introduced into the ground by explosional or vibrational means, various factors such as ground velocity and density affect the travel path of the waves shown in Figure 2.1. In seismic refraction surveying, the interest is only in the refracted wave which travels along the interface between two different velocity layers. This particular wave is known as the head wave and occurs when $R=90^{\circ}$. For each interface there is a critical angle at which the energy is transmitted along this 


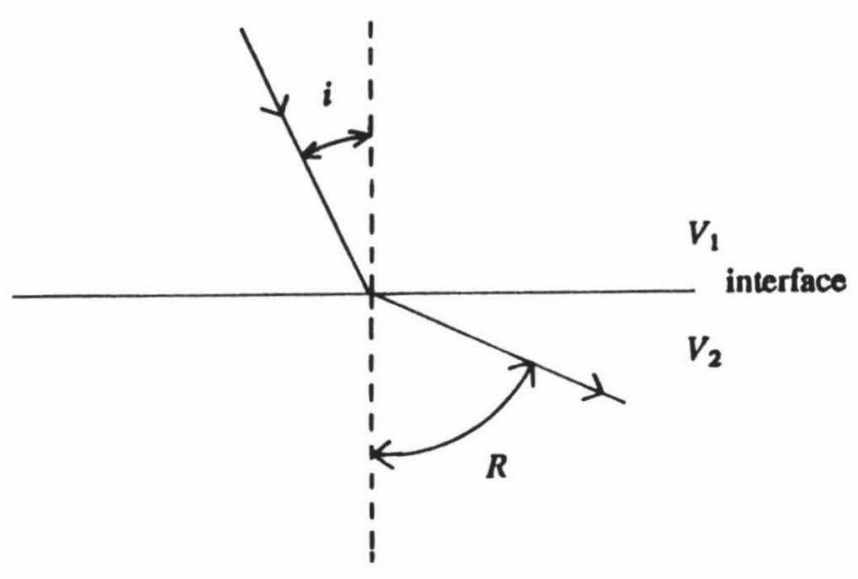

Figure 2.2 Physical geometry of a refracted wave

interface. Setting $\sin R=1$, Equation 2.1 becomes,

$$
i_{c}=\sin ^{-1}\left(\frac{V_{1}}{V_{2}}\right)
$$

where $i_{c}$ is the critical angle. If however $i>i_{c}$ no refraction occurs and the wave is totally reflected. Conversely, if $i<i_{c}$, the refracted wave will travel through to the next velocity layer where critical refraction may occur at a deeper interface.

In most refraction work only the initial arrival of seismic energy is recorded, although later arrivals are sometimes used if the conditions are favourable. The frequency of refraction signals tend to be lower than that of reflections because of the greater distance they have to travel. Further information on the refraction method can be found in Dobrin (1981) and subsequent data analysis in Mota (1954).

\subsection{Refraction Surveying}

A spread for seismic refraction surveying consists of geophones "planted" in the ground and connected along the seismic cable at "take-outs". One end of the spread is attached to the seismograph as shown in Figure 2.3.

There are four main positions for the shot point, but only the two used for this study, endshots and offset shots, shall be mentioned. End-shots are put as close to or actually at the position 


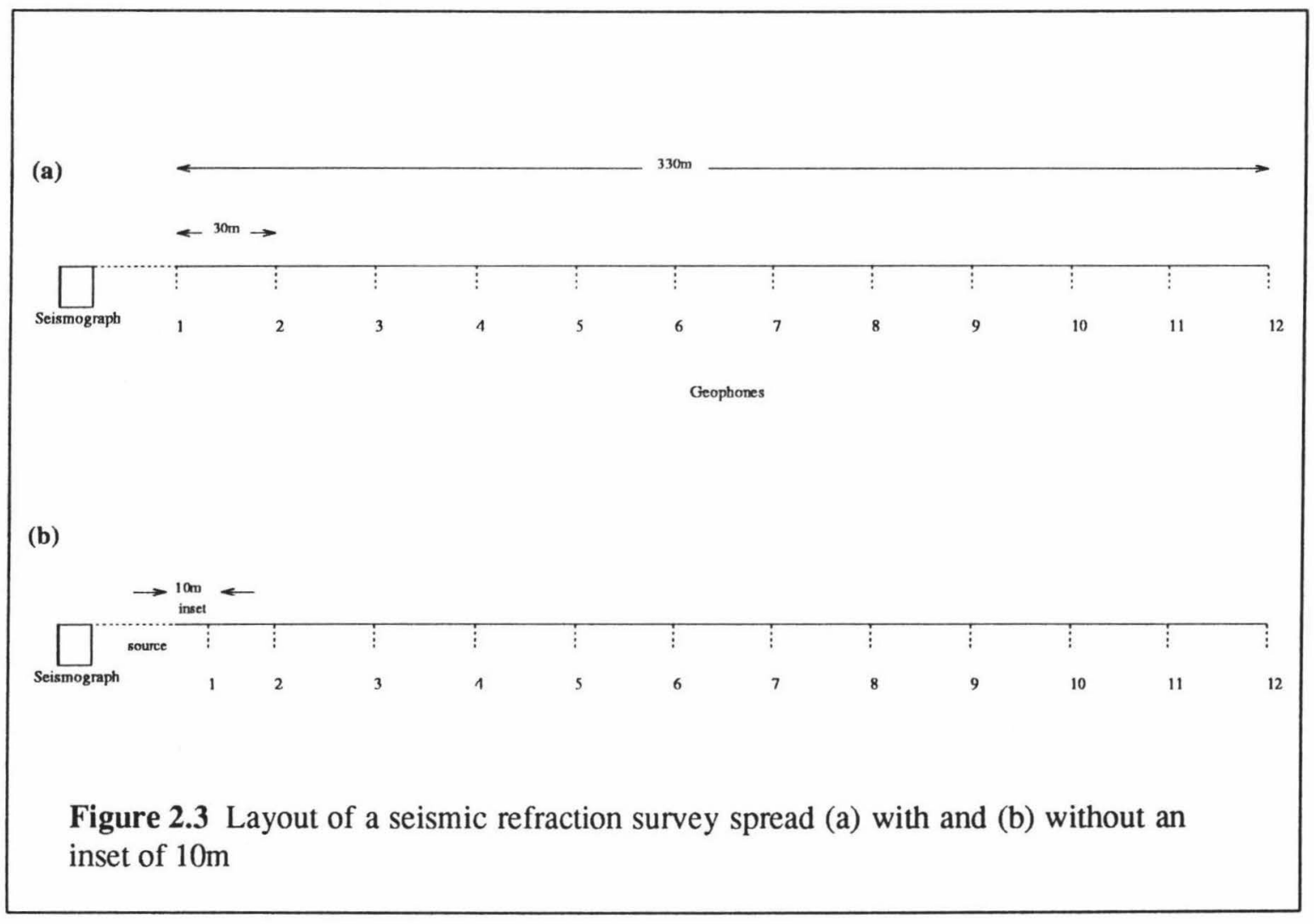

of the end geophone. For the latter case, this geophone is moved a distance between five and fifteen metres towards the next geophone in line, as shown in Figure 2.3. This inset results in the recording of the direct arrival through the surface layer, which provides the velocity of the layer so long as the "inset" distance has been measured.

The second shot position is the offset shot which enables the waves from deep refractors to be recorded as first arrivals. Obviously the larger the offset distance, the deeper the waves will travel into the ground before being refracted. Offset shots are made as close as possible to a straight line with the spread. Any deviation is noted and accounted for in subsequent analysis.

\subsection{Fieldwork}

The fieldwork involved with the seismic component of this study was carried out on two separate trips over a period of three days. For the first day of seismic work, two spreads were laid out either side of the Wharepapa River (see Figure 2.4). End and offset shots were recorded at Wharekauhau (WKH-S2), while at Wharepapa (WPP-S1) only end shots were recorded. The 
details for all the spreads and first arrival data is set out in Appendix B.

The second stage of the seismic work was carried out a few months later. A third spread, PN-S3, was laid out in a paddock further north from the previous two, near the site of PN1 (see Chapter 4). End shots and one offset shot were recorded with the Nimbus (see Section 2.5). After this the seismograph broke down and further work was abandoned whilst the $R S-44$ (see Section 2.5) was transported to the survey area. The following day was used to carry out the

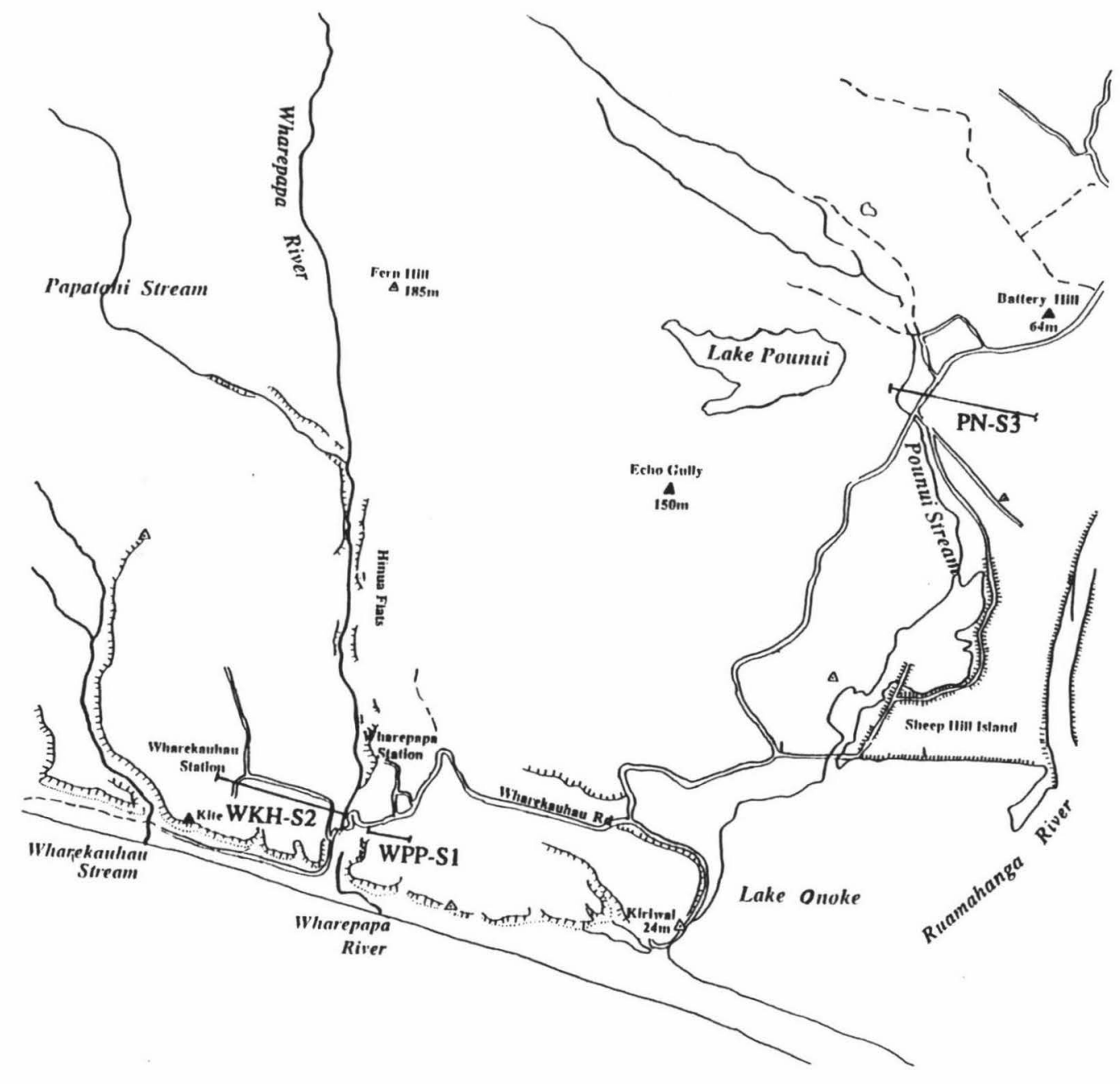

Figure 2.4 Locations of seismic spreads, WPP-S1, WKH-S2 and PN-S3 
reverse offset shot.

The primary reason for the seismic work, was to constrain the density values for the sediments used for the gravity modelling. With the spread length being just over $1 \mathrm{~km}$, we could not expect to see further down than $300 \mathrm{~m}$ which would give a good estimate of the upper layers. If the surface of the basement is $\leq 300 \mathrm{~m}$ deep, the velocity and depth of this structure could be determined.

Most shots were detonated in water found in streams or ponds, as the energy loss to sound is minimised and more is introduced into the ground as required, by this means. When there was no available natural water source, shot holes were drilled and filled with water. Depths of shot holes were always approximately one metre to ensure most available energy was directed into the ground.

\subsection{Instrumentation}

Two different seismographs were used for the seismic surveys. One being the $R S-4412$ channel seismograph and the other, the Nimbus ES-1210 multichannel signal enhancement seismograph. One seismograph was designated to each of the two spreads for the first survey. The Nimbus was used for the PN-S3 survey, but because of the break down had to be replaced by the $R S-44$ on the third day of surveying.

\section{Nimbus ES-1210}

This seismograph has an advantage over the $R S-44$ as well as a paper record, the seismic results can be stored on computer linked to the instrument. This allows for quicker interpretation of results in the field, which is advantageous if recordings need to be repeated. The main feature of this instrument is it's ability to allow the altering of trace signals and amplitudes before the final output is printed. The ES-1210 is designed specifically for shallow seismic exploration so was ideal for the work done for this study. Further details on this seismograph can be found in the operating manual, Gorman (1986) and Kleffmann (1992).

\section{RS-44}

The RS-44 seismograph is the second of the two seismic refraction instruments owned by VUW. As with the Nimbus, the RS-44 is a 12 channel seismograph. Records are recorded on 
light sensitive paper which is printed as soon as the seismic source is activated. Therefore, unlike the Nimbus, records are printed out immediately rather than stored for enhancement. The manual for the $R S-44$ again gives further details on this instrument.

\section{Cables and Geophones}

Each spread consisted of 12 geophones connected to the seismograph by seismic cable. Thirty metres separated each geophone making a total spread length of $330 \mathrm{~m}$.

\section{Shot Equipment}

The seismic source consisted of either TOVEX or AN-60 sticks, of quantity dependent on whether an end or offset shot was being detonated. The shot box with shot instant coder and decoder was operated by the shot firer who communicated with the seismograph operator by twoway radio.

\subsection{Methods and Theory of Data Analysis}

Analysis and proceeding interpretation of seismic data is subjective and a sound knowledge of the geology in a survey area must be assumed before refraction work can be carried out. All analysis of refraction data follows a set pattern and standard equations are applied to find the required information, whether done manually or by computer program. The following discussion will show the logical steps to the reduction of the seismic data collected during the study. All analysis was completed using computer programs rather than manually, for expediency and greater accuracy.

\section{Reading the Seismic Records}

Both the Nimbus and RS-44 seismographs produced permanent seismic records for later interpretation. Figure 2.5 shows an example of a seismogram from WKH-S2. Although the record shows arrivals from several different refractors and also reflectors, the important feature is time of the first break away from the theoretically flat trace. In reality the trace is rarely flat due to noise. Time is read along the vertical axis of the record and distance on the horizontal, with each trace representing the output of a single geophone. Once the shot instant has been established, the time taken for the signal to initially arrive at each geophone is noted. Sometimes 


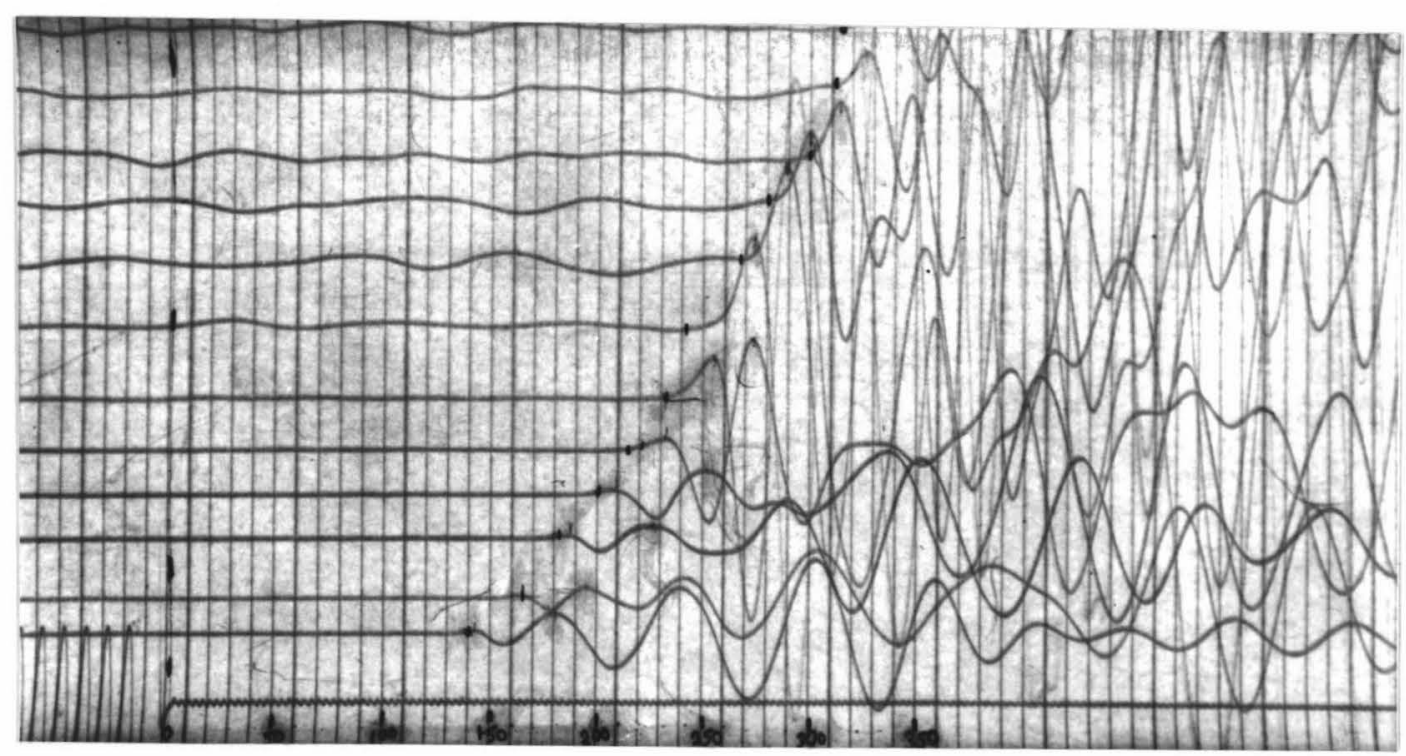

Figure 2.5 Example of a seismogram from the west end shot at WKH-S2

this "first break" is not clear and the first "peak" or "dip" of the wave is taken and subsequently corrected to the first break, by averaging the time difference on those traces where both features are visible. Most records from this study were clear enough for the first break to be read, but a few required either the first peak or dip to be read instead.

\section{Distance/Time Graphs}

The most easily obtained information to be gained from a refraction survey is the velocity of the sub-surface layers from which the scismic waves are refracted. Refraction surveying assumes the situation of a dipping plane multilayered Earth, with constant velocity throughout each layer and increasing downward.

The distances between geophones and shot point are all known, as is the time taken for the energy to reach each geophone, therefore the velocities of the waves travelling through the Earth can be determined.

For each spread, a time versus distance $(x-1)$ graph was plotted. The general rule is that the depth of penetration is approximately one third of the length of the spread including distance to the shot point. For the end shots, depth of penctration was up to $10 \mathrm{~m}$ and usually only detected 
two different velocity layers accurately. On an x-t graph, the scatter of data quite clearly shows the difference in gradient (or velocity) at the boundaries of the different layers as shown in Figure 2.6. The $\mathrm{x}$-t graphs of the offset shots show the velocities of layers up to twenty times deeper than those detected in the area between shot and first geophone.

For all interpretations in this study, the sub-surface structure under the end-shots was the same as that under the off-set shots.

The slope of the direct velocity $V_{0}$ passes through the origin and the following lines cut at some point along the time axis to give the time intercept $T_{i}$. The position where the forward and reverse profiles intercept is known as the tie time, $T_{c}$ This data is used in the following equations to determine the critical angle $i_{c}$, dip $a$, depth to refractors $z$ and true refractor velocities $V_{n}$, respectively.

$$
\begin{gathered}
i_{c}=\frac{1}{2}\left(\sin ^{-1} \frac{V_{0}}{V_{1 d}}+\sin ^{-1} \frac{V_{0}}{V_{1 u}}\right) \\
a=\frac{1}{2}\left(\sin ^{-1} \frac{V_{0}}{V_{1 d}}-\sin ^{-1} \frac{V_{0}}{V_{1 u}}\right) \\
z_{d}=\frac{T_{i d} V_{0}}{2 \cos i_{c}} \\
z_{u}=\frac{T_{i u} V_{0}}{2 \cos i_{c}}
\end{gathered}
$$

and

$$
V_{1}=\frac{V_{0}}{\sin i_{c}}
$$

The subscript $V_{1 u}$ denotes the velocity of the first refractor from the forward profile, and $V_{1 d}$ denotes the velocity for the reverse profile.

\section{Computational Analysis Programs}

\section{Seisview}

Seisview is the seismic refraction interpretation software (E G \& G Geometrics) used in the analysis of the seismic data. The program is able to read in files containing the time, distance and 


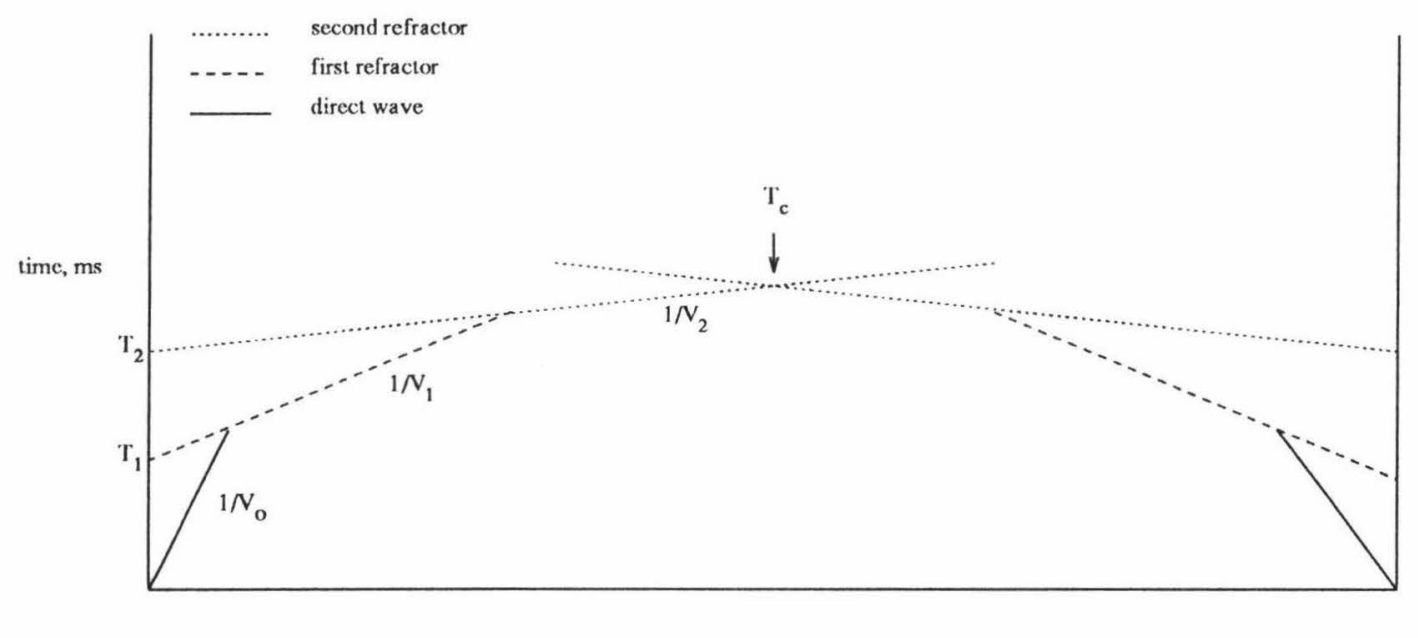

distance, $m$

Figure 2.6 Forward and reverse shots shown on an x-t graph

source data, and put them into the form of an $\mathrm{x}$-t plot. The user interactively selects points to which Seisview, by the method of least-squares, fits a line. This follows for each refractor the user analyses in both the forward and reverse profiles. Once the slopes for the velocities of the refractors have been found, the program interprets the data using Equations 2.3 to 2.7 and displays an output model. An output file gives the values of both the forward and reverse profiles for apparent velocity, time intercepts, slopes of the line segments $1 / \mathrm{V}$, dip to top of layer, thickness of layers and depth to the top of the layer.

Although Seisview's interpretation is based upon the standard equations used for manual computation, a few differences are applied to the data to make it compatible with Seisview's interpretational algorithm. One to be noted is the requirement for the interpretation of the end and offset shots. Seisview can only use an interpretation by which the surface structure under the end shots is extrapolated to be the same as under the offset shots. In reality this is an ideal situation, but for the spread distances used in this study of $1 \mathrm{~km}$ maximum, it is not an unreasonable assumption. However, for a truer representation of the model obtained from firing end and offset shots, the upper layers from the end shot analysis are combined with the lower layers from the offset shots. In this way the models are most representative of the true structure under the length of each spread. 
Seisview can also be used to examine the traces from the records recorded directly from the Nimbus.

\section{RAY84}

Once a satisfactory model had found using Seisview, it's fit to the observed data was determined using RAY84. RAY84 is a 2-D ray tracing package which shoots rays through a velocity model determined by the user.

Models are defined by two or more interfaces extending from left to right across the model. A layer is described by a pair of interfaces within which the velocity can be defined for both the top and the bottom of the layer. The ray tracing algorithm used, calculates the propagation of rays within a layer by the stepwise integration of the system of first order differential equations,

$$
\begin{gathered}
\frac{d x(t)}{d t}=V(x, z) \sin \theta \\
\frac{d z(t)}{d t}=V(x, z) \cos \theta \\
\frac{d \theta(t)}{d t}=\frac{d V}{d x} \cos \theta-\frac{d V}{d z} \sin \theta,
\end{gathered}
$$

where $\theta$ is the ray's angle from the vertical (Luetgert, 1985). By supplying definitions of $V(x, z)$ and initial values for $x, z, t$ and $\theta$, subsequent values of $x, z, t$ and $\theta$ can be calculated by simultaneously integrating Equations 2.8 to 2.10 over small steps in time.

The graphical output of RAY84 show the waves (type specified by the starting angle), travelling through the model and their comparison with the observed data. Examples of these are shown in Figures 2.8, 2.11 and 2.13. The three models were extended by ten metres either side of the offset shots, as RAY84 requires that shot points are within the model and not at its boundary.

The following discussion takes each of the three spreads independently and describes the individual analysis using Seisview and RAY84. The final models will be discussed briefly in the summary of this chapter. 


\section{Wharepapa Spread - WPP-S1}

Only end-shots were recorded at this spread with the end geophones being inset by $10 \mathrm{~m}$. The x-t graph of the first arrivals is shown in Figure 2.8. Analysis on Seisview was simple, with the differing velocity layers being easy to determine. The analysis of slope and time intercept is also shown in Table 2.1 The interpreted model was simple as can be seen in Figure 2.7.

Table 2.1 Values obtained from the $\mathrm{x}$-t graph in Figure 2.8

\begin{tabular}{|c|c|c|c|c|c|r||}
\hline \hline Seg & Slope & $V_{u}$ & $T_{a},(\mathrm{~ms})$ & Slope & \multicolumn{1}{|c|}{$V_{d}$} & $T_{d},(\mathrm{~ms})$ \\
\hline 1 & .00260 & 385 & 0.000 & .00260 & 385 & 1.000 \\
2 & .00069 & 1452 & 31.143 & .00092 & 1083 & 22.000 \\
3 & .00053 & 1887 & 64.200 & .00055 & 1814 & 62.000 \\
\hline
\end{tabular}

The sub-surface structure cannot be modelled by a plane layer case since the time intercepts do not agree. However the depths are correct and the dip was calculated from these and used for the model in the ray tracing. The rays shot through the final velocity model for WPP-S1 agreed well with the observed data, indicating the model was a good fit to the sub-surface in the region below the spread. The ray tracing interpretation is shown in Figure 2.8

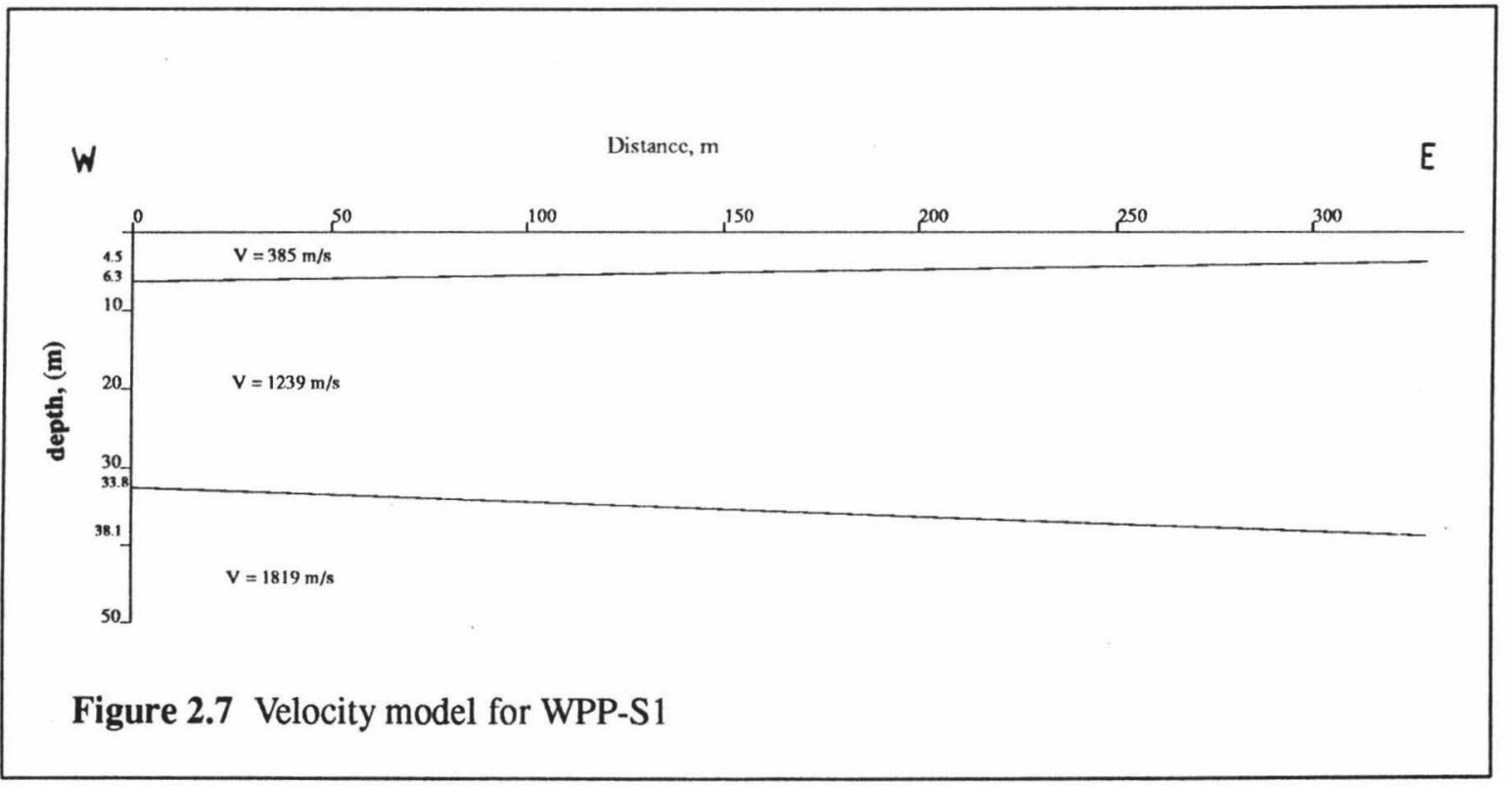




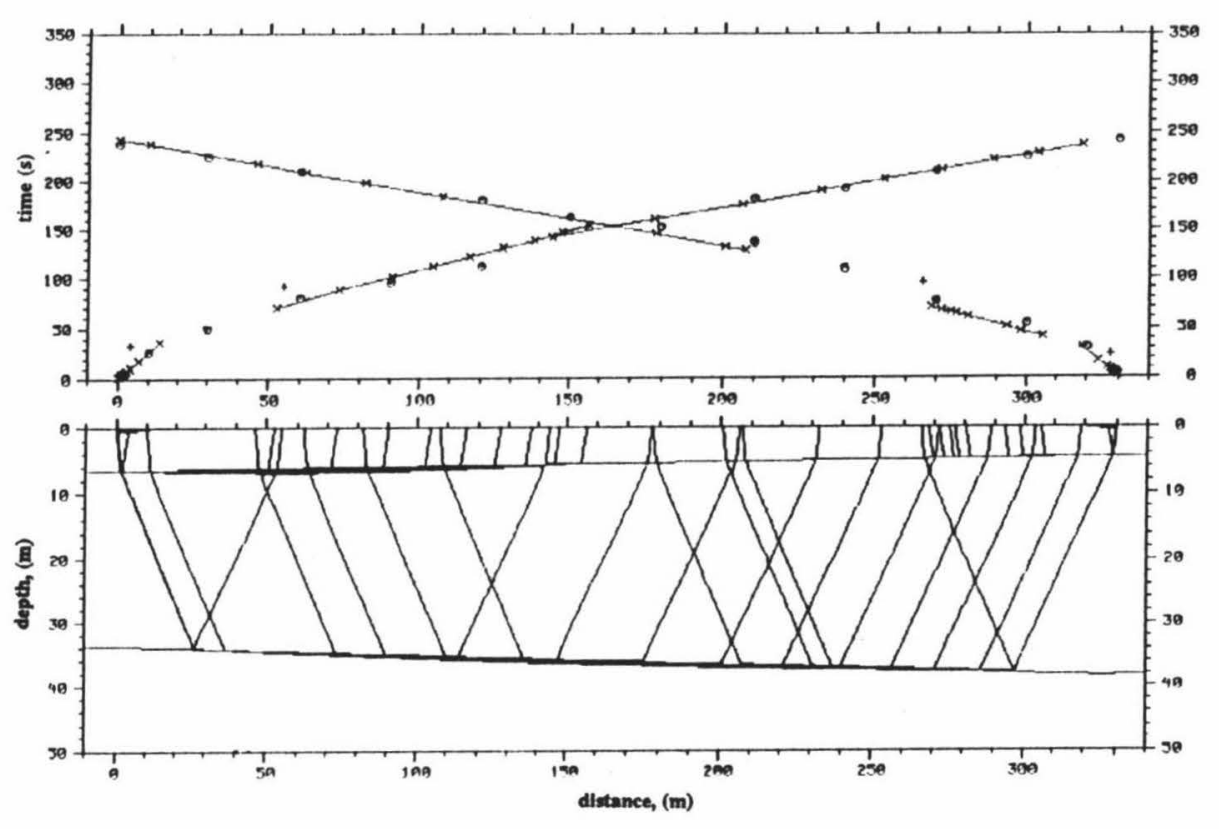

Figure 2.8 Ray tracing through the WPP-S1 velocity model

\section{Wharekauhau Spread WKH-S2}

The set up for this spread was somewhat more complex than either of the Wharepapa or Pounui spreads. Figure 2.9 shows the arrangement of the spread. Two end shots were fired without any insets, and two further offset shots were made giving the spread a total length of $979 \mathrm{~m}$. The western shot was made in a small pool in the Wharepapa River at a depth of $43 \mathrm{~m}$ below the spread level and the eastern shot in a small pond in a paddock behind the Wharekauhau homestead.

It became obvious that something was incorrect once the $x-t$ graphs were plotted. The arrival times for the east end shot were feasible, but those from the west end shot had a large delay time. The best explanation for these apparently late arrivals was a delay in the detonator. To accommodate for this problem, the readings were corrected to make the end time of $234 \mathrm{~ms}$ agree with thrtact thno eatsen offset shots, with three different velocity boundaries which had the calculated values shown in Table 2.2. 


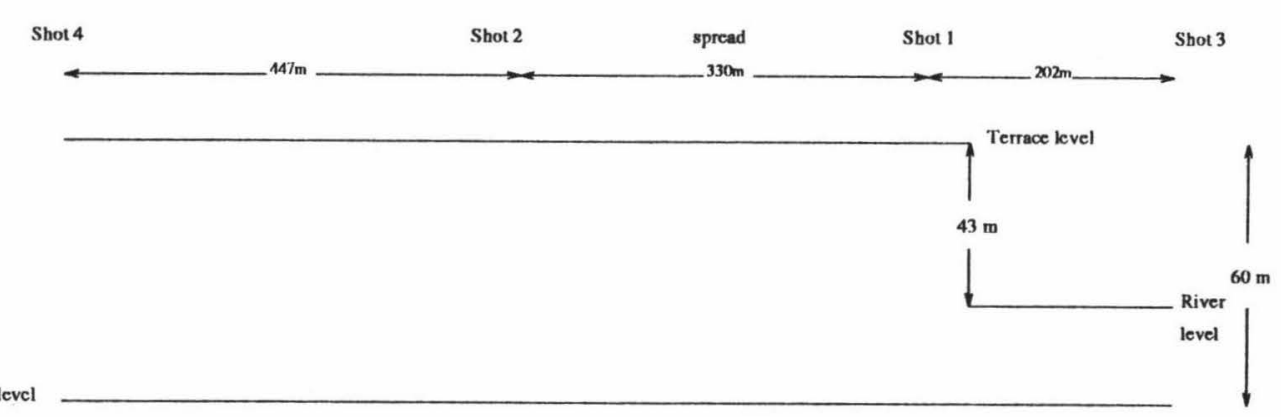

Figure 2.9 WKH-S2 refraction spread

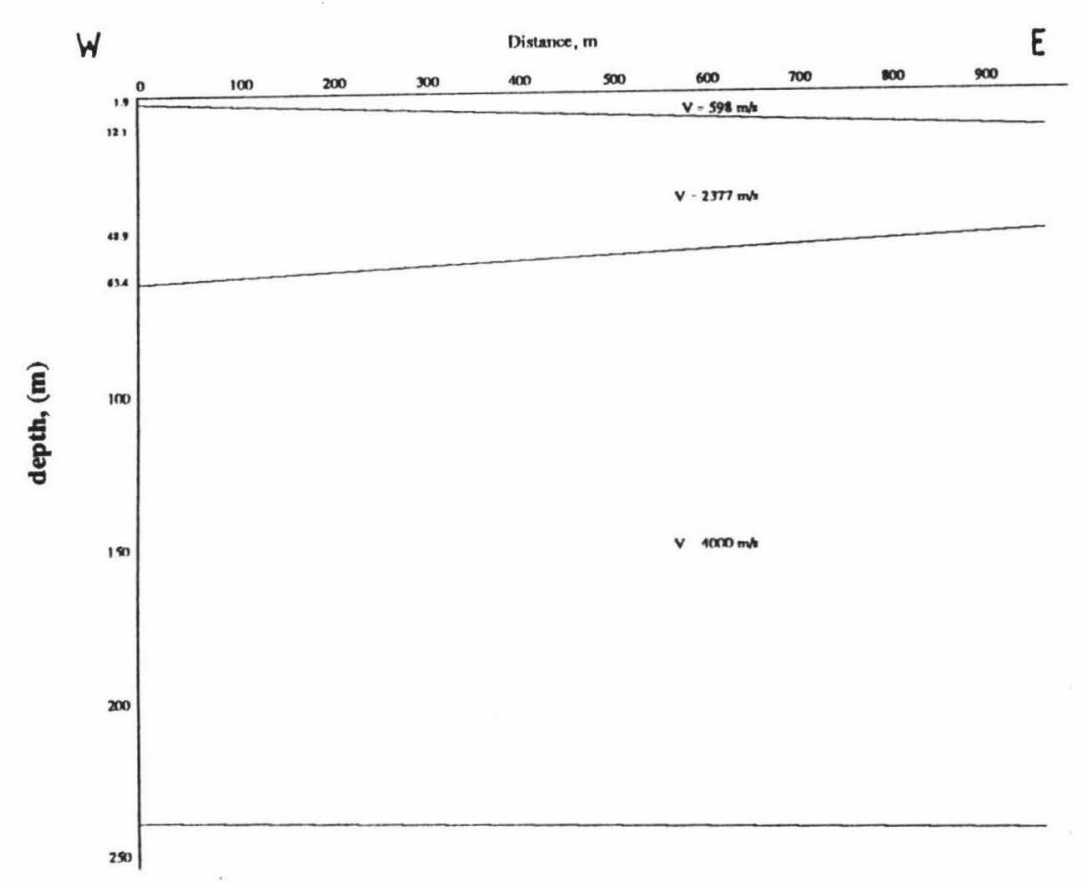

Figure 2.10 Velocity model for WKH-S2 spread 
Table 2.2 Values obtained from the x-t graph in Figure 2.11

\begin{tabular}{||c|c|r|r|l|r|r||}
\hline Seg & Slope & \multicolumn{1}{|c|}{$V_{u}$} & $T_{a},(\mathrm{~ms})$ & Slope & \multicolumn{1}{|c||}{$V_{d}$} & $T_{d},(\mathrm{~ms})$ \\
\hline 1 & .00168 & 595 & 0.000 & .00167 & 600 & -0.000 \\
2 & .00076 & 1313 & 18.921 & .00073 & 1369 & 30.831 \\
3 & .00042 & 2355 & 84.000 & .00042 & 2400 & 90.000 \\
3 & .00025 & 4000 & 217.750 & .00025 & 4000 & 222.000 \\
\hline
\end{tabular}

The readings from the offset shot fired at the east end of the spread also had to have elevation corrections made to them, as the shot position was below the spread level. This meant the arrival times were earlier for this shot than for the offset shot at the east end because the waves had at least $43 \mathrm{~m}$ less to travel before refraction. Compensation for this difference was calculated to be approximately $46 \mathrm{~ms}$ from the model generated by the interpretation from the end-shots. However only a correction of $25 \mathrm{~ms}$ was added to the arrival times, to make the end times agree. As the river shot was fired in river gravel, an initial delay could be explained by the slower travel of the wave through the gravels. Again the total correction for the east offset shot was chosen to make the reciprocal times agree.

A model consisting of 4 layers was the final interpretation found using Seisview, with the first two not quite reaching the datum level (taken as sea-level), as shown in Figure 2.10. A velocity layer possibly consistent with basement material is detectable at a depth of $250 \mathrm{~m}$.

Ray tracing proved the model fitted well considering the forementioned complications, see Figure 2.11. Although the fit did not appear as good as for the other two models, this was only to be expected from using a simplified model for a more complex situation The reverse shot does not detect the third boundary, because it is at a much closer distance to the spread. The forward shot has an offset of more than twice the distance of the reverse shot. As the river shot was fired in river gravel, an initial delay could be explained by the slower travel of the waves through these gravels.

\section{Pounui Spread}

The final of the three spreads to be analysed consisted again of the two end shots and two offset shots. As with WKH-S1, the offset shots were not an equi-distance away from the spread. The west end offset shots was at a distance $292 \mathrm{~m}$ while the east end offset shot was at a distance of $380 \mathrm{~m}$. The spread was inclined at an angle of $118.5^{\circ}$ from true north and this had to be taken 


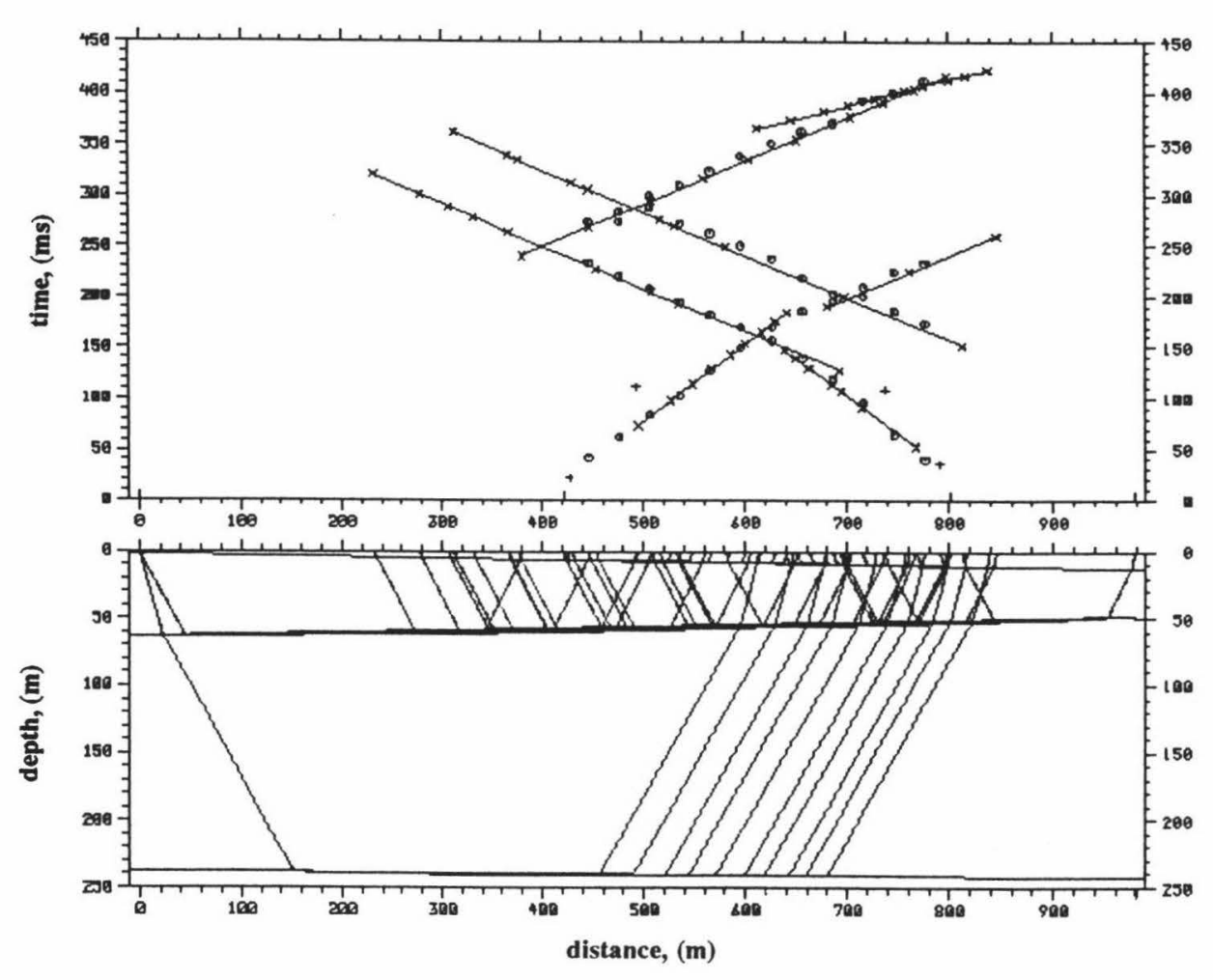

Figure 2.11 Ray tracing through the WKH-S2 velocity model

into consideration when determining the geophone distances from each shot point.

The $\mathrm{x}$-t graphs as shown in Figure 2.13 clearly showed three different velocity layers. The end times again were made to agree with each other, so the case being modelled was plane layered. The values determined from this graph are shown in Table 2.3. The angle of each layer dipped down towards the east to a final depth of $200 \mathrm{~m}$, again with a velocity consistent with basement material as shown in Figure 2.12.

Table 2.3 Values obtained from the x-t graph in Figure 2.13

\begin{tabular}{||c|c|r|r|l|r|r||}
\hline \hline Seg & Slope & \multicolumn{1}{|c|}{$V_{u}$} & $T_{a},(\mathrm{~ms})$ & Slope & $V_{d}$ & $T_{d},(\mathrm{~ms})$ \\
\hline 1 & .00220 & 455 & 0.000 & .00178 & 563 & -0.000 \\
2 & .00058 & 1728 & 19.180 & .00054 & 1839 & 31.154 \\
3 & .00046 & 2165 & 231.673 & .00040 & 2516 & 309.439 \\
\hline
\end{tabular}




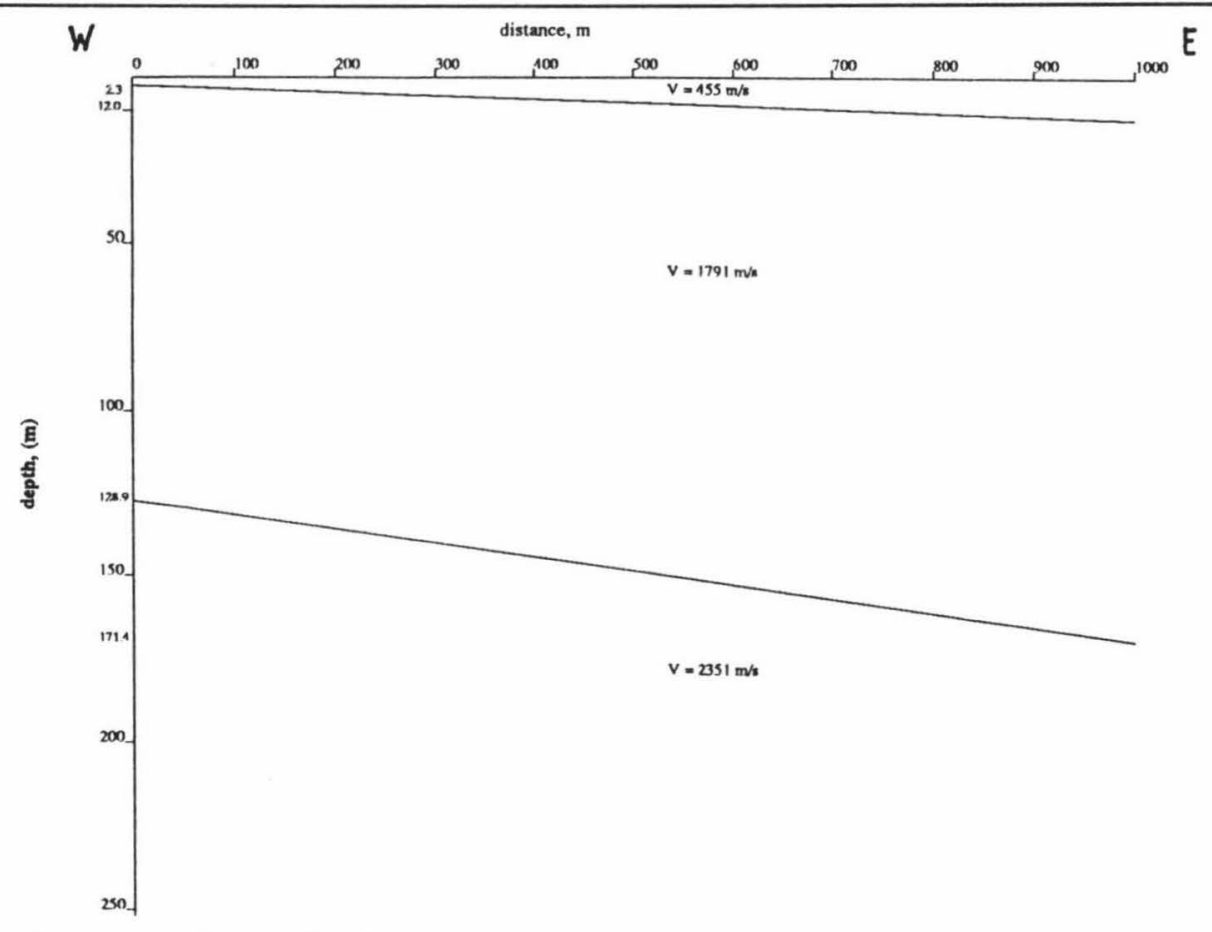

Figure 2.12 Velocity model for PN-S3

The rays shot through this velocity model are displayed in Figure 15 and show the model fits the observed very well.

\subsection{Uncertainties}

Rigorous error analysis was not applied to the seismic data analysis, because of the lesser significance of this survey to the study. However the range of error amd its source is worth noting to show the reality of the final models.

The two most significant and obvious points where error is introduced, are in the reading of the first break time of the seismograms and the second in the interpretation of the gradients of the $\mathrm{x}-\mathrm{t}$ graphs. Taking the first source, an error of $5 \%$ is easily introduced into the time value of the first break. When the record of first breaks cannot be accurately picked and the first dip or peak has to be read, further error can be introduced into the result. Some records have very clear breaks, but others are very difficult to read. The magnitude of error is therefore very much determined by the 'state' of the record. 


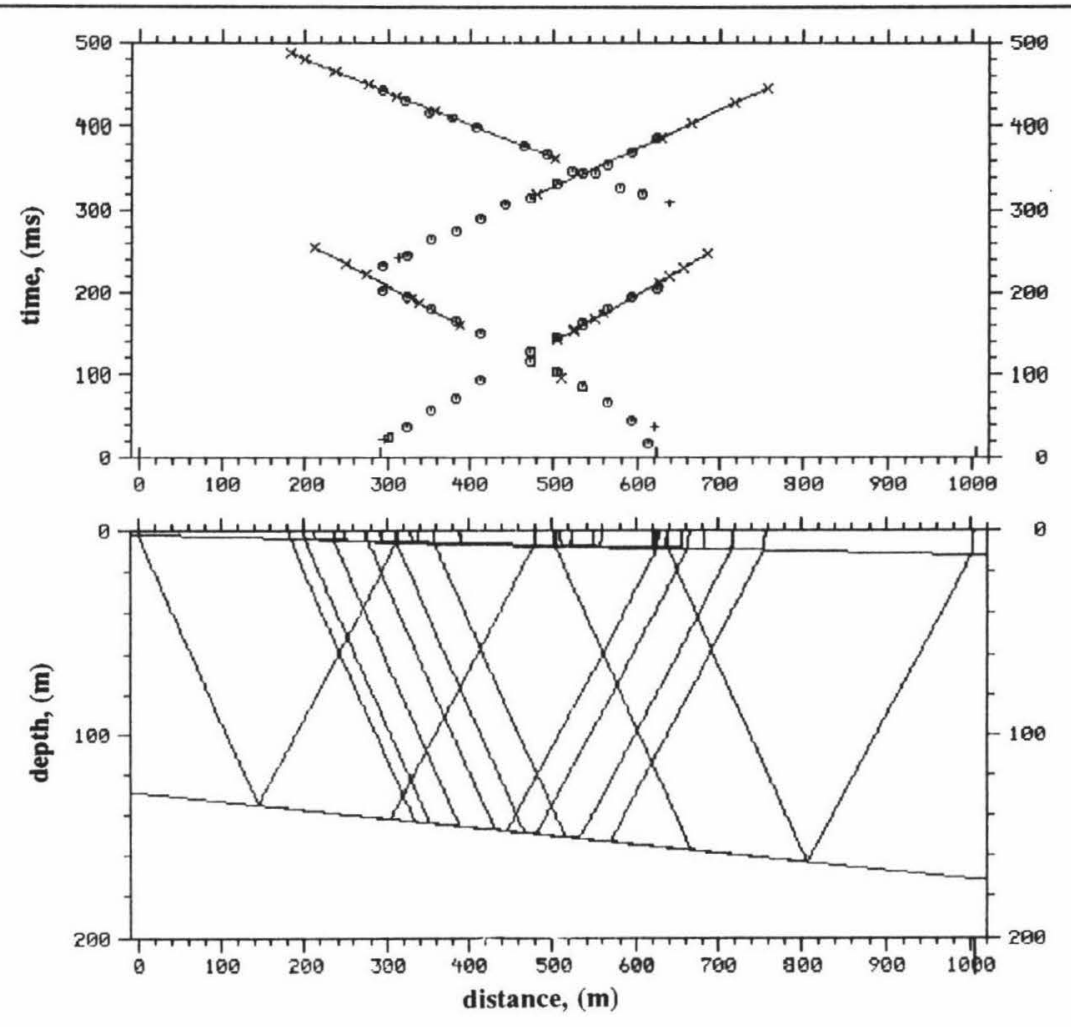

Figure 2.13 Ray tracing through the PN-S3 velocity model

The second error occurs in the interpretation of the gradients on the $\mathrm{x}-\mathrm{t}$ graphs, which determine the velocities of the corresponding layers. Table 2.4 displays the different velocity, dip and depth results from two different interpretations of gradient values. From these results it can be shown that a further $5 \%$ error is added to the final results. Obviously error analysis needs to be more complex when a greater accuracy is required in the results. However, as discussed above, this degree of accuracy was not necessary in this case. Overall it can be seen that an error in the region of $\pm 10 \%$ is expected in the results of the final model. 
Table 2.4 Two different interpretations of the x-t graph for PN-S3

\begin{tabular}{||c|c|r|r|c|r|r||}
\hline \hline Seg & Slope & \multicolumn{1}{|c|}{$V_{u}$} & $T_{a},(\mathrm{~ms})$ & Slope & \multicolumn{1}{c|}{$V_{d}$} & $T_{d},(\mathrm{~ms})$ \\
\hline 1 & .00220 & 455 & 0.000 & .00178 & 563 & -0.000 \\
2 & .00058 & 1728 & 19.180 & .00054 & 1839 & 31.154 \\
3 & .00046 & 2165 & 231.673 & .00040 & 2516 & 309.439 \\
\hline
\end{tabular}

\begin{tabular}{||c|c|r|r|l|r|r||}
\hline Seg & Slope & \multicolumn{1}{|c|}{$V_{u}$} & $T_{a},(\mathrm{~ms})$ & Slope & $V_{d}$ & $T_{d},(\mathrm{~ms})$ \\
\hline 1 & .00230 & 435 & 0.000 & .00170 & 588 & -0.000 \\
2 & .00060 & 1666 & 17.537 & .00055 & 1809 & 30.698 \\
3 & .00042 & 2400 & 67.583 & .00023 & 4286 & 123.767 \\
\hline
\end{tabular}

\subsection{Summary}

The complexity of the models varied with the length and situation of the spread. Models for both WKH-S2 and PN-S3 detected a boundary layer, possibly corresponding with the basement layer at depths of $200-250 \mathrm{~m}$. However a velocity of $4000 \mathrm{~ms}^{-1}$, taking uncertainties into account, is bordering on the velocity value for unconsolidated greywacke. Unconsolidated greywacke has a value of $4.42 \mathrm{kms}^{-1}$, and consolidated greywacke is $5.43 \mathrm{kms}^{-1}$. So this layer cannot be categorically defined to be the depth to basement. The deeper the sub-surface layer is, the more compacted the material making up the layer becomes, and therefore the velocity increases. This reasoning could be applied to explain the high velocities found at these shallow layers. The results from the following two chapters will confirm whether it is appropriate to define this $200-250 \mathrm{~m}$ layer as the surface of the basement material. 
- 44 - 


\section{Chapter 3}

\section{Gravity Survey}

Gravity was one of the more important of the three surveys carried out, as the 122 stations surveyed encompassed the entire study area.

The gravity should therefore give an overview of the sub-surface structure in the south-western part of the Wairarapa under study. This structure will then be used in conjunction with the results from the other methods chosen for this study, to determine the final model. 
"Its not the figures themselves", she said finally, "it's what you do with them that matters" - K.A.C. Manderville, "The Undoing of Lamia Gurdlene:k"

\subsection{Introduction}

In the mid-19th century, Sir George Everest carried out a triangulation survey of northern India. He determined the precise distance between two towns using both astronomical and land measurements. He calculated a difference of $150 \mathrm{~m}$ in approximately $600 \mathrm{~km}$, between the results determined using both methods. Everest concluded that the Himalayas must have been exerting a gravitational attraction on the plumb bob, used in the astronomical measurements, and pulling the line away from the vertical. Pierre Bouguer made a similar discovery in the Andes a century before (Hutchinson, 1986).

As a result of these discoveries, along with others, mountains were postulated to have low density roots, which produced a measurable effect on the local gravity field. This principle, known as isostasy, led to the idea of gravity surveying, where observations of changes in gravity could be used to provide information on sub-surface rock bodies. Everest's discrepancy of $150 \mathrm{~m}$ should have been closer to $450 \mathrm{~m}$ if the Himalayas did not have a root system.

The gravity method makes use of a natural potential field, unlike magnetic and electrical methods which measure induced fields in the Earth. In gravity surveying, the measurement is not of the value of gravitational attraction, but is of its variation from one point to another (Dobrin, 1981). In this surveying method, the location of inhomogeneities and density contrasts are being sought in the area under investigation. In this way, a description of features which in some way depart from uniformity are found.

The acceleration due to gravity at a particular station depends upon the following six quantities:

i) mass of the Earth,

ii) shape and size of the geoid,

iii) rotation of the Earth,

iv) height of the gravity station above the geoid,

v) topography, density and structure of rock above the geoid and 
vi) density and structure to about $120 \mathrm{~km}$ below the geoid.

A gravity anomaly indicates that a body of rock or some other type of structure of a different density to the rock surrounding it, exists beneath the surface of the anomalous region. Measuring gravity anomalies above a sub-surface feature and comparing these measurements with a reference site (usually taken to be sea level), should in theory give details of the size and shape of the body. In reality, the gravity difference between two points depends on the features listed above, as well as the presence of density variations. Therefore before the true anomaly can be calculated, these effects must be eliminated from the gravity measurements made in the field. These shall be discussed in the following sections.

Although gravity anomalies can demonstrate existence of a sub-surface feature, there are an infinite number of possible combinations of size, shape, depth and density to explain these anomalies. It is not possible to make a detailed structural analysis solely from gravity results, but when used in conjunction with seismic data, boreholes and other geophysical methods, enough information is available to make accurate profiles of surveyed areas.

As anomalies cannot by themselves be interpreted uniquely in terms of structure, progress in interpretation is often made by trial and error. The principle method of interpretation arises from the comparison of the measured anomalies with those calculated from simple structural models. Figure 3.1 shows the gravity anomaly caused by a sub-surface sphere.

Sub-surface geological structures are rarely of simple and regular shape. However it is possible to approximate structures by regular shapes alone or in combination, for a large number of cases. But as has already been mentioned, even when measured anomalies have been closely simulated by those of a known shape, this shape does not necessarily describe the sub-surface feature under investigation. Figure 3.2 shows the situation of an attraction of a faulted slab with an infinite throw.

\subsection{Gravity Anomalies}

There are three basic anomaly calculations associated with gravity surveying. Each one gives different information, and which one to be used, depends upon what is required from a particular survey. Anomalies have different meanings depending on the Earth model which has been assumed. To explain the different anomalies we must first briefly look to the basis of all gravitational studies, Newton's law of attraction: 


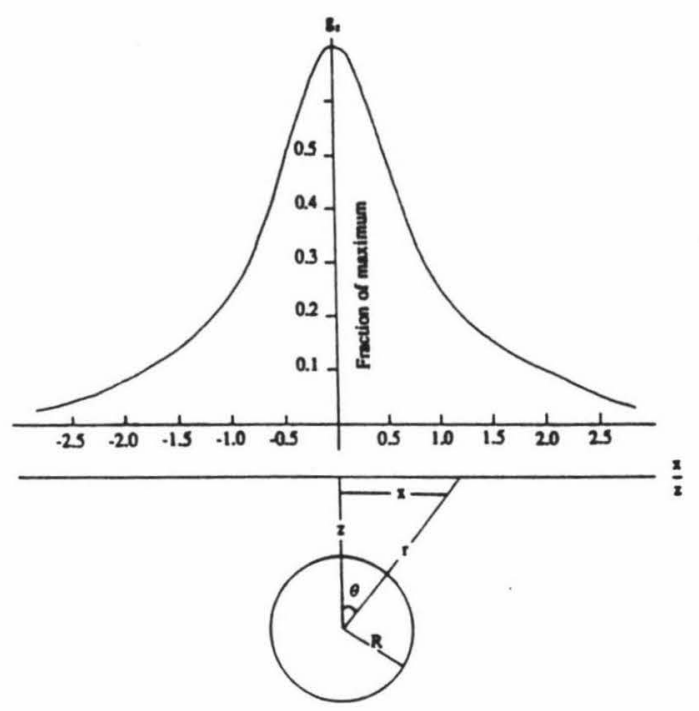

Figure 3.1 Gravity anomaly caused by a sub-surface sphere

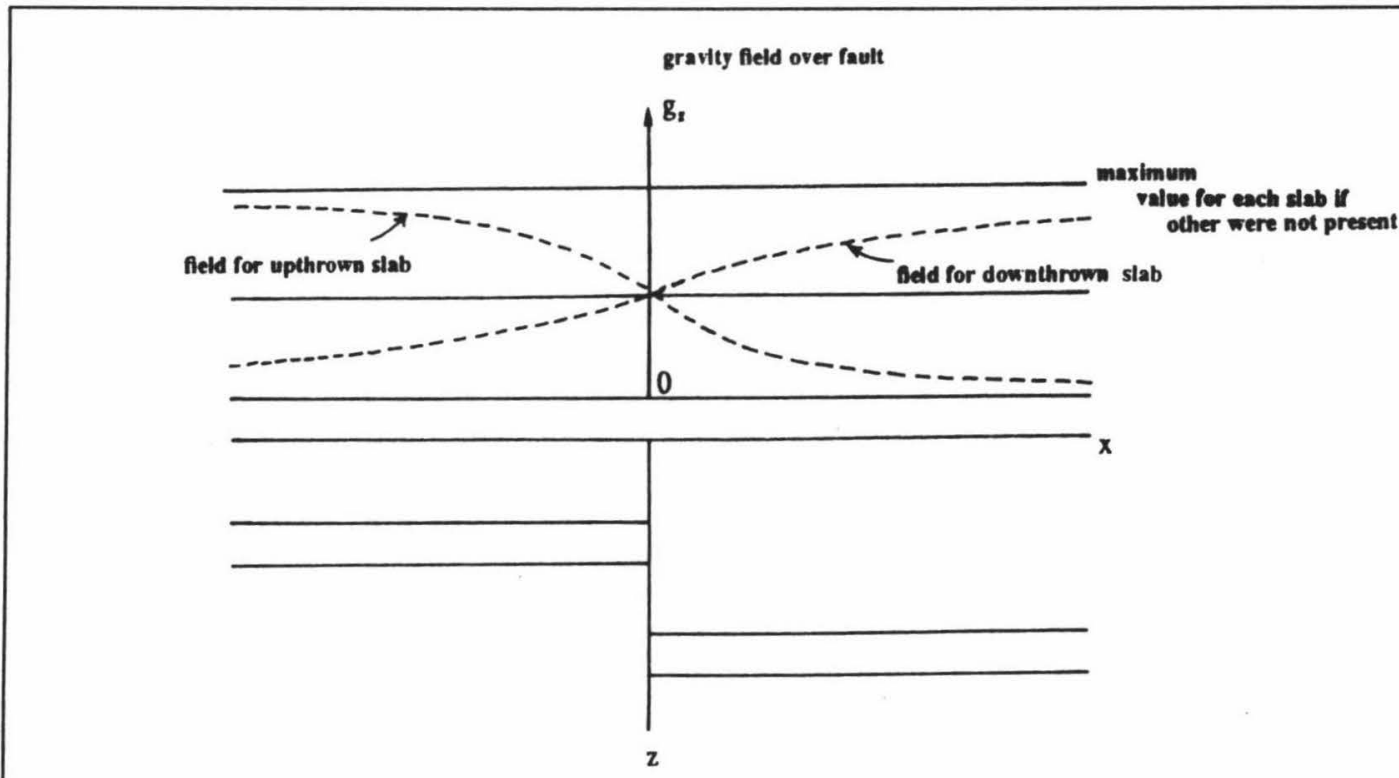

Figure 3.2 Attraction of a faulted slab having infinite throw (from Dobrin, 1981)

$$
F=\frac{-G M m}{R^{2}}
$$

where $G$ is the universal constant of gravitation, $M$ is the mass of the Earth, $R$ is the radius of the 
Earth and $m$ is a mass.

This force is due to the gravitational pull on the body at the Earth's surface. Since the force due to gravity on a mass $m$ is,

$$
F=m g \text {, }
$$

we can equate Equations 3.1 and 3.2 to get the acceleration due to gravity,

$$
g=\frac{-G M}{R^{2}}
$$

The gravitational potential is the work per unit mass done in bringing a mass $m$ from infinity to a radius $r$ from $M$,

$$
U=\int_{\infty}^{r} \frac{G M}{r^{2}} d r=\frac{-G M}{r}=\int_{\infty}^{r} g d r .
$$

Obviously the first vertical derivative of the gravitational potential is gravity itself,

$$
\frac{d U}{d z}=g
$$

The second vertical derivative is called the vertical gradient of $g$ or the free-air (FA) correction,

$$
\frac{d^{2} U}{d z^{2}}=\frac{d g}{d z}
$$

The third vertical derivative is the FA correction gradient,

$$
\frac{d^{3} U}{d z^{3}}=\frac{d(F A)}{d z}=\frac{d}{d z}\left(\frac{d g}{d z}\right) .
$$

Free-air corrections take into account the elevation of the gravity station above or below the reference spheroid (geoid), since gravitational attraction is based upon the distance of a point from the centre of the Earth. The disadvantage with these corrections is that they are not accurate enough in mountainous or geologically active areas (Daly, 1938). They are however easy to calculate and are independent of geological theories. Free-air anomalies are one of the simplest anomalies, measuring the difference between the masses of a unit area from the station to the Earth's centre and a similar column of the ellipsoid model of the Earth. 
The FA anomaly is:

$$
g_{\text {meas }}-[g(\phi)-\Delta g(F A)]
$$

where $\mathrm{g}(\phi)$ is the value of gravity at latitude $\phi$ (latitudinal correction), calculated from the International Gravity Formula (IGF), $g_{\text {meas }}$ is the measured value of gravity, and $g(F A)$ is the FA correction in Equation 3.7. The FA correction is used to correct $\mathrm{g}(\phi)$ to the height of the gravity station, considering the vertical gradient varies with latitude, height and geology to some extent.

The FA correction only takes elevation into consideration and ignores the material lying between the station and the reference spheroid. To correct for this mass, the FA anomalies can be further modified to obtain Bouguer anomalies.

Mass, shape, rotation, elevation, topography and density of the Earth are all measurable. For Bouguer anomalies, the model is fitted as closely as possible to the forementioned features above the reference spheroid. The Bouguer anomaly is thus:

$$
d g=g_{\text {meas }}-[g(\phi)-\Delta g(h)-\Delta g(T)]
$$

where $\Delta g(h)$ is the combined FA and Bouguer corrections (both of which will be discussed later in this section) and $\Delta g(T)$ is the terrain correction.

Bouguer anomalies are universally used for geophysical prospecting. This is due to their ability to provide good data for analysis of sub-surface structure without the complications isostasy creates. One of the disadvantages with Bouguer anomalies is that they tend to be relatively large, so smaller variations can become undetectable. This problem however can be solved with careful calculations of the regional gradient.

The third and final anomaly to be briefly discussed is the isostatic anomaly. This anomaly is an adaption of the Bouguer anomaly with an isostatic correction being made. The isostatic anomaly is usually removed as part of the regional trend, except in surveys over broad and anomalous regions (Grant and West, 1985). Bouguer anomalies are more useful for land measurements, whilst isostatic anomalies are used when measurements at sea are also involved. 


\subsection{Fieldwork}

Gravity measurements were taken at 122 stations in total. Stations 1 to 35 were occupied in the early months of 1990 , whilst the remaining stations were occupied at various stages throughout 1991 . Figure 3.3 is a locality map of the 122 new stations comprising the gravity survey. Surveys were made where possible on calm days, but on several occasions winds were strong causing greater time spent reading the gravity meter to ensure accurate measurements were made.

The ruggedness of the terrain can be seen from the aerial photograph in Figure 1.7. Several places were desirable to establish gravity stations, but could not be accessed easily. Due to this, there are a few 'holes' in the otherwise consistent spread of stations.

As the existence of a fault running down the Wharepapa River, as mapped by Kingma (1967) was one aspect of the investigation in the study area, stations were located either side of the stream, and as far west as Wharekauhau Stream, the first visible sign of greywacke outcrops in the area. Station position was chosen with accessibility in mind, and also the spacing pattern necessary to detect the detail of the feature under study.

The closest benchmark to the study area was K46 located at (106548.4 N, and 138712.7 E). As it is desirable to include at least two benchmarks in a survey of this size, a further benchmark at Camp Road, used by Gresham (1967) and Maddocks (1970), was included at the beginning of 1991. All height and absolute gravity measurements were then tied to these two stations. As both benchmarks were a considerable distance away from the study area, in terms of travel time, two further bases were established, Station 1 for the surveys in the Lake Pounui region, and Station 61 for those near Palliser Bay. The base stations were occupied at least once a day to determine the drift of the gravity meter. A looping survey was not feasible because of the type of terrain and accessibility, and also cost and time factors. Although a looping survey results in very precise data, the method of reoccupation of a set number of base stations during the day, achieved results within the desired range of accuracy for this study.

Theodolitic measuring is the most accurate means of determining the elevation of gravity stations. However barometric levelling is adequate and is frequently used in surveying. It was this latter means of elevation determination which was used for this study. When using this type of levelling, factors that may cause pressure fluctuations, such as wind, will lead to error in the measurements which have to be taken into consideration in the final results. All heights were 


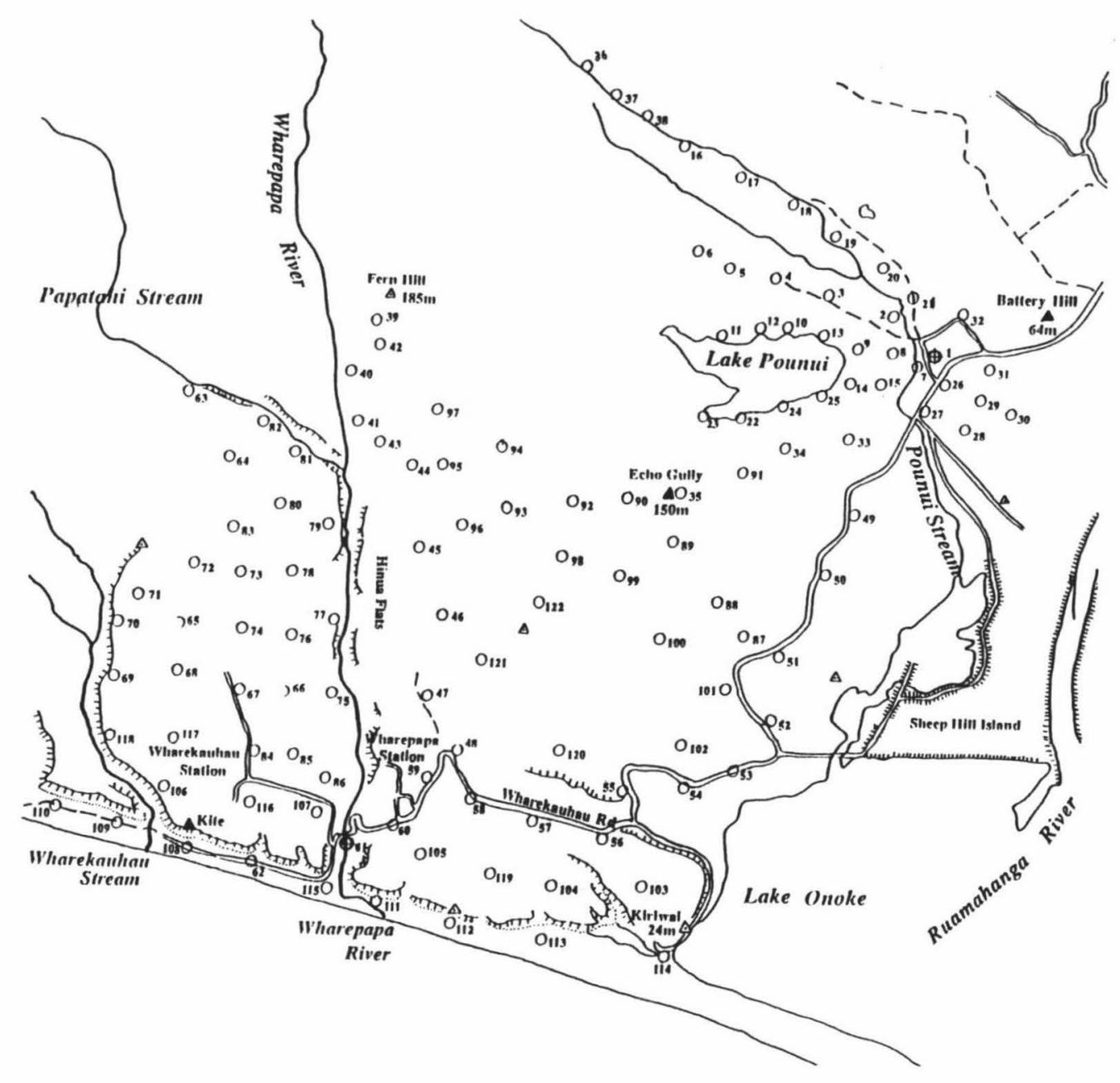

Figure 3.3 Localities of gravity stations in the study area

then tied to the two established benchmarks.

\subsection{Instrumentation}

When a hand held gravity meter is used, gravity surveying requires the most compact, and least amount of equipment, compared to many other geophysical surveying methods. This 
section contains the description of the instruments used for the surveying work.

\section{Gravity Meter}

The La Coste and Romberg gravity meters \#179 and \#519 were used in the surveys, with accompanying power pack. Both meters came in a transportable metal case with room for the battery supply, which was essential as much of the survey was conducted on foot. The meter operates on the principle of a spring balance which is outlined in the instruction booklet supplied with each meter. A small circular levelling disc was used to place the meter upon. Once levelled longitudinally and latitudinally with levelling screws, meter readings could be taken.

\section{Temperature gauge and Barometers}

The wet and dry temperatures were taken using two separate Celsius thermometers. The wet thermometer had a small fan attached to circulate air around the thermometer, to give accurate wet temperature readings.

Two barometers were used which consistently gave differing results. As it was impossible to determine which barometer gave the correct pressure reading, an average of the two results was used in the analysis. In barometric surveying the heights determined are relative, therefore because the differences between the barometers was consistent, the fact that absolute pressure was not obtained did not matter.

\section{Time Recorder}

An ordinary digital wrist watch was used to read the time that the gravity readings were taken to later calculate the drift rate. The seconds were read to the nearest half minute or minute.

\subsection{Gravity Data Reduction}

Gravity data is relatively simple to collect, but the analysis must be done with great care and is very time consuming because many corrections need to be made to the original data collected in the field, before any useful information can be extracted. Computer reduction minimises a lot of the work, but there is still preliminary reduction that must be carried out before the data can be further analysed by computer. For this study the data has been reduced both manually and by computer at the various different stages. In this section the methods of data analysis will be 
detailed. All numerical results from the gravity analysis are displayed in Appendix C.

\section{Drift}

All measuring instruments are prone to drift unless factors such as temperature, pressure, magnetic field and humidity remain constant (Rymer, 1989). As these conditions are idealistic, corrections must be made for instrument drift. The La Coste and Romberg gravity meters have been equipped with thermostat and pressure compensators and the casing around the spring and level systems of the meters are sealed and insulated, so the physical characteristics of the meters are as close to constant as practicable. However, the spring in the meter "creeps" with time, and knocks or taps during transport can disturb the complex lever system, so the actual dial reading taken at any one station will change with time.

Drift in the barometers is caused by:

(i) changes of pressure with time,

(ii) horizontal pressure gradient,

(iii) calibration errors causing drift to be proportional to height,

(iv) hysteresis of the barometer causing rapid drift after rapid change of height, and

(v) mechanical faults causing erratic 'drift'.

Drift in the thermometers is caused by (i), (ii), (v) above and also by changes in temperature with time.

The drift rates for the barometers and gravity meter were calculated for each individual survey. The drift rates were then used to correct the pressure and gravity readings at each station to get the true values.

\section{Barometric Levelling}

The elevation of each gravity station had to be known to determine the FA correction. The height was not known at the time of survey, except that of the benchmarks. To determine station height levelling was not considered necessary, as this type of accuracy would be lost in the realms of uncertainty in the final results of this type of survey, where we are only working to one decimal place accuracy. Instead the pressure and temperature readings were used to calculate the height differences between successive stations using Babinet's formula, 


$$
\Delta h=C \cdot \frac{B_{1}-B_{2}}{B_{1}+B_{2}},
$$

where $B_{1}$ and $B_{2}$ are the barometric pressures at Stations 1 and 2 respectively, and $C$ is the coefficient which depends on the average virtual temperature of the air column between stations 1 and 2. Virtual temperature is the temperature of dry air which has the same density as the actual humid air column. In New Zealand the virtual temperature averages two degrees less than the actual temperature. $\mathrm{C}$ is calculated from,

$$
C(\text { metres })=16000\left[1+2\left(t_{1}+\frac{t_{n}}{1000}\right)\right]
$$

where $t_{n}$ is the temperature at station $n$.

As Stations 1 and 61 were established as base stations, their values had to be set before the heights of the remaining 120 stations could be determined. For each separate survey day, the values of elevation and gravity for Stations 1 and 61 were determined after correction was made for drift. These values were then tied to these values of the benchmarks, averaged and then adopted as the elevations and gravity readings of the two base stations.

All heights were calculated using the height differences determined from Equation 3.11 with no decimal place accuracy, as any greater precision in barometric levelling is unrealistic. All pressure readings were made to an accuracy of 0.05 millibars, which is equivalent to an accuracy of 0.5 metres in elevation. As pressure is very variable, especially in hilly and often windy regions, such as in the study area, inaccuracies develop because of the difficulty in determining pressure variations with position, not of the inaccuracy of pressure measurement. Woodward (1982) estimates the accuracy of height determined by barometric levelling to be approximately $\pm 5 \mathrm{~m}$.

\section{Correction of Gravity Meter Readings}

Gravity measurements are not absolute but are of the variation in gravity from one station or point on the earth to another. Each gravity meter will give different readings because the meters have different calibrations. Before the gravity readings could be of further use, they had to be converted from dial units to milligals (mgals) using the conversion chart in the hand book associated with that particular meter. 


\section{Terrain Corrections}

From the physical theory behind gravity surveying, we know that rock deficit or mass near a gravity station will affect the attraction of gravity at that particular station. The affect of a mountain even several kilometres away will exert gravitational attraction at a station and this must be accounted for. Therefore all gravity readings must be corrected for terrain variation, as the Bouguer correction assumes the topography around the gravity station to be flat, and this is very rarely so.

Terrain corrections remove the effects of valleys and hills in the area surrounding a point where gravity values are being read. The corrections compensate for valleys by adding the gravitational attraction the area would exert if the valley were filled in. By the same reasoning the effect of a hill is removed by adding its upward attraction at the station.

The terrain was quite variable in the study area with stations ranging in height from 0 to $150 \mathrm{~m}$ above sea-level. Hammer zones A to $\mathrm{D}(0 \mathrm{~m}$ to $170 \mathrm{~m})$ were calculated in the field, zones $\mathrm{E}$ to $G(170 \mathrm{~m}$ to $1.53 \mathrm{~km})$ were calculated manually using a graticule and zones $H$ to $M(1.53 \mathrm{~km}$ to $21.93 \mathrm{~km}$ ) were calculated using a gravity reduction program developed by Woodward (1982). A description of the method used for terrain correction is described by Hammer (1939). For this analysis his tables were converted from feet into metres.

The manual method of computing the inner-terrain effects by graticule, uses the following formula:

$$
T=0.4191 \times 10^{-3} \frac{\rho}{n}\left(r_{2}-r_{1}+\sqrt{r_{1}^{2}+z^{2}}-\sqrt{r_{2}^{2}+z^{2}}\right)
$$

where $n$ is the number of components in zone of graticule, $r_{1}$ is the inner radius of zone (m), $r^{2}$ is the outer radius of zone $(\mathrm{m})$ and $z^{2}$ is the modulus of elevation difference between observation point and mean elevation of compartment $(\mathrm{m})$.

This degree of accuracy is not required out to large distances ( $>20 \mathrm{~km}$ ) from the gravity station. For these areas the topography can be averaged within a rectangular grid. The topographic effects can be calculated at any point within the grid by summing the effects of the right rectangular prisms defined by the grid squares and their elevation difference with the gravity station. This is the principle used in the gravity reduction program for this study, to analyse the outer terrain corrections. 


\section{Latitudinal Corrections}

The shape of the Earth is best described as an ellipsoid of revolution. It is therefore obvious that at different latitudes on the Earth, the shape and size of the geoid, one of the quantities for which the gravity at a station depends, will vary. The value of gravity at the poles would be the same at the equator as it would at any point on the Earth's surface, if the Earth was a perfect sphere, but because of the forementioned discrepancy, the latitude of each gravity station must be taken into consideration and the gravity measurement corrected to account for it. The rotation of the Earth also affects this correction. The correction for latitude is made using the International Gravity Formula (IGF), which gives the theoretical value for gravity at a given latitude, without taking rock density, elevation and so on, into consideration.

The IGF was determined by fitting values of $\mathrm{g}$ measured at spaced stations, reduced to sealevel with the free-air reduction (i.e only elevation is taken into consideration), to the formula,

$$
g(\phi)=g(0) \sum a_{n} \sin ^{2}(n \phi),
$$

where $g(\phi)$ is the value for $g$ at sea-level and altitude $\phi, g(0)$ is the value for $g$ at sea-level on the equator, $a_{n}$ is the $n t h$ coefficient and $n$ is a positive integer.

It was found that only the first three coefficients $a_{0}, a_{1}$ and $a_{2}$ were significant, because of the Earth being very nearly an ellipsoid of revolution. So once $a_{0}, a_{1}$ and $a_{2}$ are determined,

$$
g(\phi)=9.78049\left(1+0.0052884 \sin ^{2} \phi-0.0000059 \sin ^{2} 2 \phi\right) \mathrm{N} / \mathrm{kg}
$$

As part of the gravity reduction program, the latitude was calculated from the easting and northing map co-ordinates of each station, and applied to Equation 3.14 to find the theoretical value of gravity at each station.

\section{Elevation Corrections}

Since gravity varies proportionally to the inverse of the radius from the centre of the Earth, we must choose a reference or datum surface for which to refer all gravity values and correct them relative to this surface. This reference surface is most commonly taken to be sea-level and for this survey all data is corrected relative to this datum surface. There are two different effects which must be taken into consideration when correcting for elevation. The first is the FA effect which is due to the vertical gradient of gravity and the second is the Bouguer effect which is the 


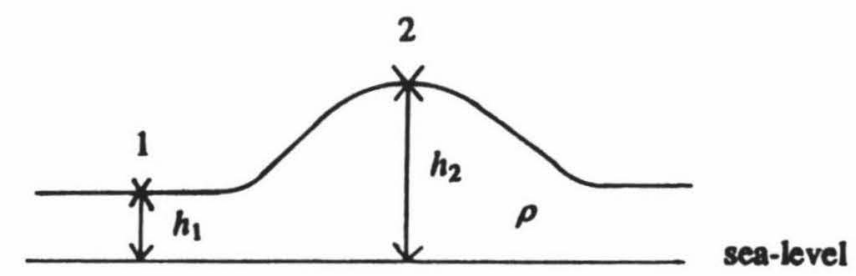

Figure 3.4 Topographic section illustrating Bouguer corrections

measure of the attraction of the material between a particular station and the chosen reference surface, as described in Section 3.2. Figure 3.4 illustrates this second point, that Station 2 at a greater elevation than Station 1, will be subject to a greater attraction because of the thicker sheet of material below it. The total elevation correction is thus a combination of the free-air and Bouguer effect. The elevation correction using the standard density of rock, $2.67 \mathrm{Mg} / \mathrm{m}^{3}$ and sea-level datum is,

$$
\Delta g(h)=(0.094-0.01276 \times 2.67) h,
$$

where $h$ is the height of the station above sea-level.

\section{Rock Density Measurements}

The Bouguer anomaly is the same as the FA anomaly but takes into consideration the density of the rock below the gravity station. The choice of density values is an important factor in determining the elevation correction. Figure 3.5 shows the variation of the elevation factors in both $\mathrm{mgals} / \mathrm{foot}$ and $\mathrm{mgals} / \mathrm{m}$, with density. Knowing the density of the rock beneath the gravity station is essential in determining the Bouguer anomaly. Where borehole data is not available, densities of the supposed sub-surface rocks have to be introduced into the modelling program to try and estimate the actual densities.

In the Wairarapa region, most authors use a density contrast near $-0.5 \mathrm{M} \mathrm{g} / \mathrm{m}^{3}$. Heine (1964) assumed an exact contrast of $-0.5 \mathrm{Mg} / \mathrm{m}^{3}$ for the modelling of the Wairarapa region, whilst the gravity modelling done in the Wairarapa by Woodward et al.. (1978), used the values for density of Cenozoic material relative to the surrounding Mesozoic basement shown in Table 3.1. 


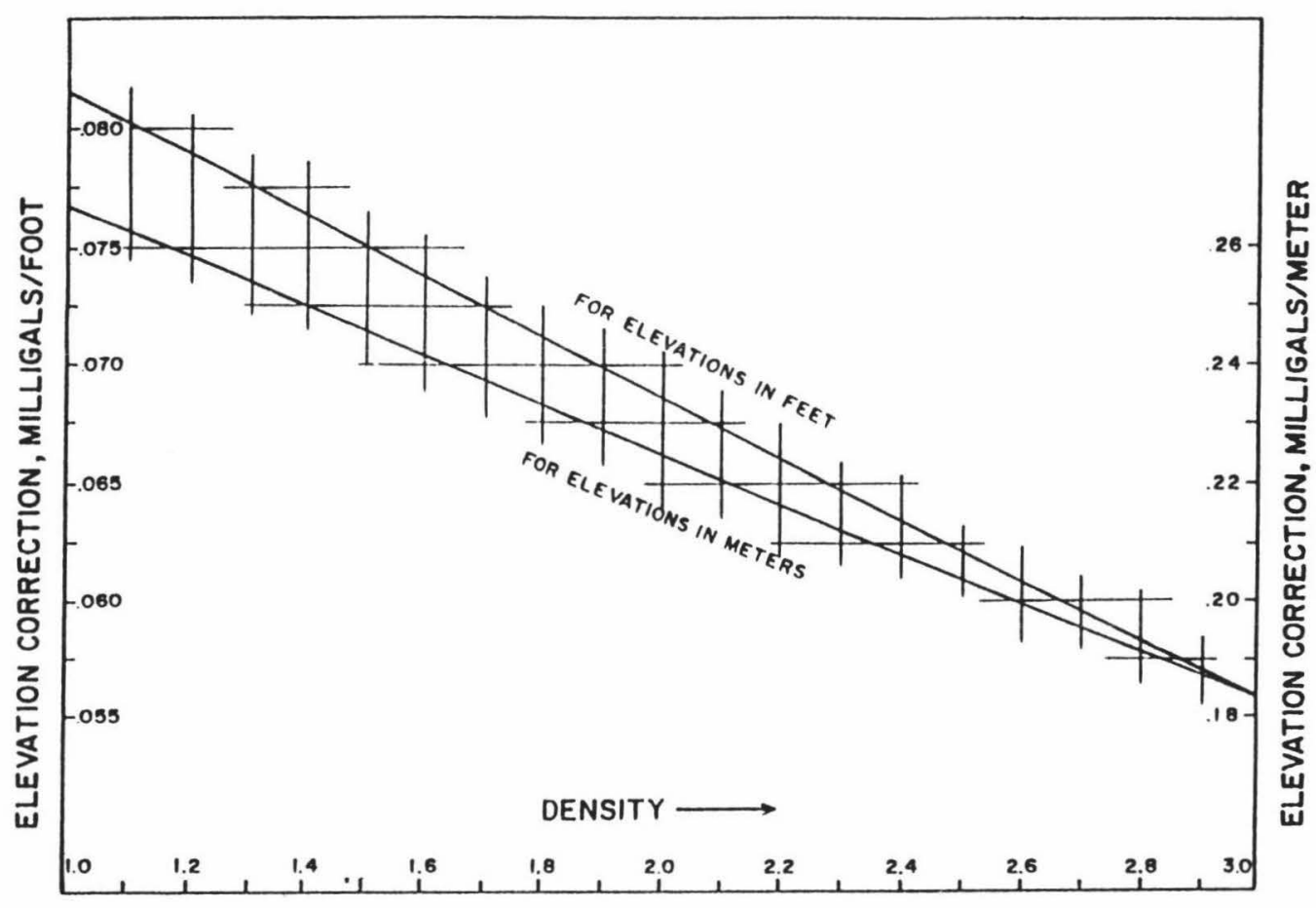

Figure 3.5 Variation of elevation factors with density (from Nettleton 1971) where $f$ $=(0.3086-0.04185 \sigma) \mathrm{h}$ mgal for $h$ metres

Table 3.1 Density Contrasts Adopted by Woodward et al. (1978)

\begin{tabular}{||l|l|l||}
\hline Depth $(\mathrm{km})$ & Density, $\mathrm{Mg} / \mathrm{m}^{3}$ & Density Contrast, $\mathrm{Mg} / \mathrm{m}^{3}$ \\
\hline $0-0.5$ & 2.2 & -0.47 \\
$0.5-1.0$ & 2.26 & -0.41 \\
$1.0-1.5$ & 2.35 & -0.32 \\
below 1.5 & 2.47 & -0.20 \\
\hline
\end{tabular}

In this study we are looking at an area with basement rock of greywacke of Jurassic age, and Tertiary mudstone in the sedimentary basin. Jurassic to Permian greywackes have a wet density of $2.65 \mathrm{Mg} / \mathrm{m}^{3}$, whilst Tertiary mudstone has a density of $2.15 \mathrm{Mg} / \mathrm{m}^{3}$, which gives the density contrast of $-0.5 \mathrm{Mg} / \mathrm{m}^{3}$. This value was also used by Maddocks (1970) in his gravity 
modelling of the same area of study.

The values in Table 3.1 were estimated by Woodward et al. (1978) from density-depth curves summarised by Hunt (1969) in an intensive study of the relationship between density and depth of New Zealand rocks. A graph of uncertainties in rock densities (after Hatherton and Leopard, 1964), is shown in Figure 3.6, to give an idea of the large range of uncertainties of these values. The crosses represent the mean wet densities of Cretaceous, Tertiary and Pleistocene sedimentary rocks, the vertical lines show the spread of densities, whilst the circles and squares represent the mean density of the higher and lower density group respectively.

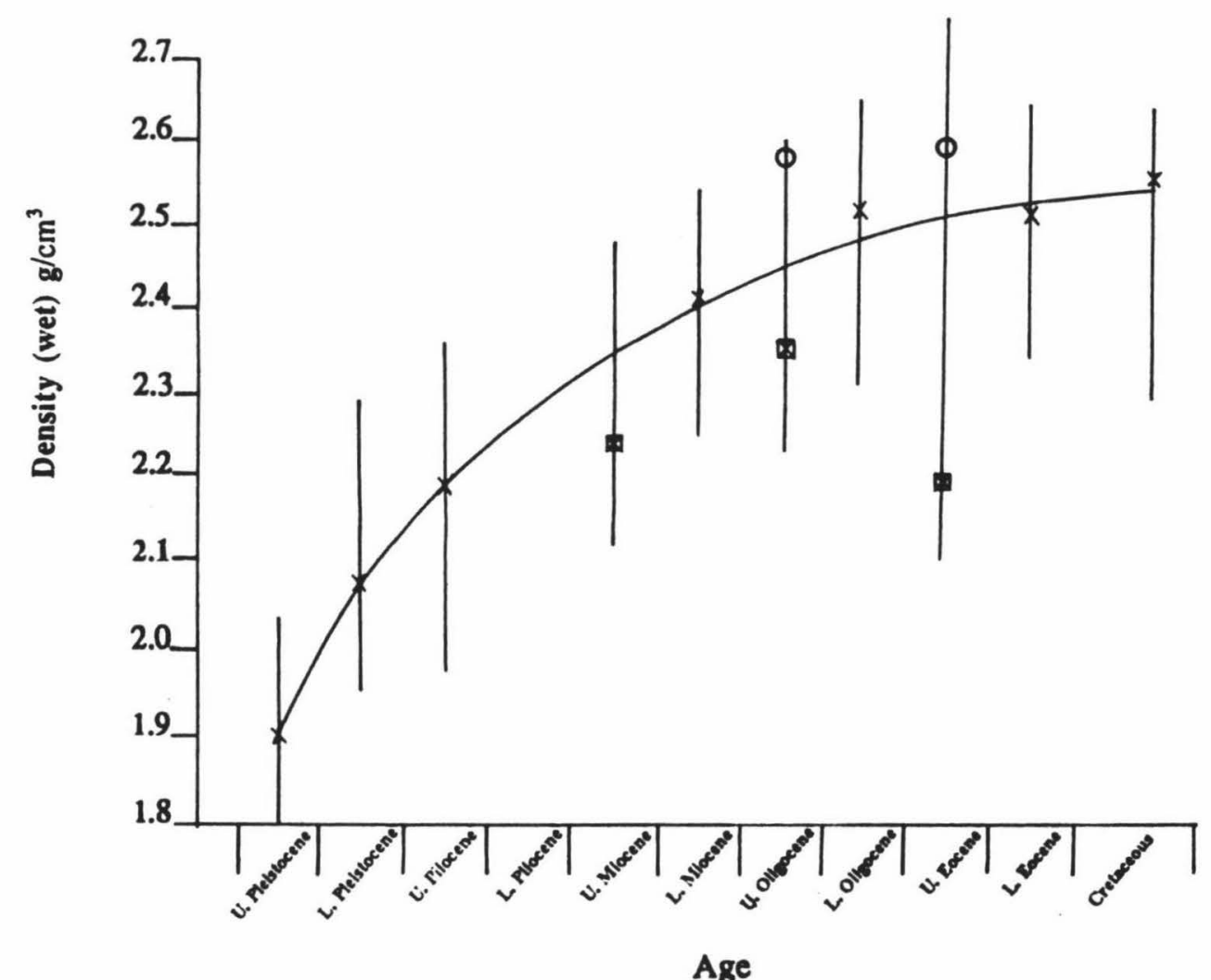

Figure 3.6 Graph of rock densities and their uncertainties 
As no bore-hole data was available and the work done by Woodward et al. (1978) was further north of the study area where the rocks are not of such a young age as we are dealing with, different density values were experimented with (see Section 3.10 ). The density values used in the final model are shown in Table 3.2. The density of the upper layers $(\leq 300 \mathrm{~m})$ was most questionable, because of the age as opposed to the older values dealt with by Woodward et al. (1978). However, the values obtained from the seismic velocities in Chapter 3 were used to help isolate the density value for this surface layer. The Nafe-Drake relationship (Talwani et al. 1959),

$$
\rho=0.379 \alpha+0.252
$$

where $\rho$ is the density and $\alpha$ is the P-velocity, gives a value for density using the P-wave velocity. Using the approximate velocity value of $4000 \mathrm{~ms}^{-1}$ at a depth of $200-250 \mathrm{~m}$ in the area, a density value of $1.8 \mathrm{Mg} / \mathrm{m}^{3}$ is derived from Equation 3.16. Given that the above relation is not as reliable in surface layers, because of the greater variation in the nature of sedimentary materials, this value is consistent with the density value of $2 \mathrm{Mg} / \mathrm{m}^{3}$ adopted for the corresponding depth in the gravity models. It confirms the choice of a lower density value than that used by Woodward et al. (1978).

Table 3.2 Density contrasts adopted in final model

\begin{tabular}{||l|l|l||}
\hline Depth $(\mathrm{km})$ & Density $\left(\mathrm{Mg} / \mathrm{m}^{3)}\right.$ & Density Contrast $\left(\mathrm{Mg} / \mathrm{m}^{3}\right)$ \\
\hline $0-0.21$ & 2.00 & -0.67 \\
$0.21-0.5$ & 2.2 & -0.47 \\
$0.5-1.0$ & 2.26 & -0.41 \\
$1-1.5$ & 2.35 & -0.32 \\
below 1.5 & 2.47 & -0.2 \\
\hline
\end{tabular}

\subsection{Removal of the Regional Gradient}

Any geophysical data collected from a particular area can be separated into two components. The first part being of a regional nature and the second part due to local deviations from the regional. In general we are aware of the geological features causing regional trends. We want to separate this regional effect from the field data in order to detect the local fluctuations. For example, in the case of a fault running through a sedimentary basin, the gravitational effect of the basin must be first removed from the observed data in order to see the much smaller 
gravitational effect due to the fault. The effect of these long wavelength features on the gravitational field is usually greater than the effect of the local short wavelength features (Hughes, 1984).

There are many different methods of separating these two gravity components, referred to collectively as 'trend analysis'. The two methods investigated for the analysis of the survey data in this project were of a geological and a mathematical nature. The mathematical solution to trend analysis is the use of trend surfaces made up from the solutions from least squares data fitting. This method is subjective and polynomial orders can become increasingly higher as a greater degree of fit is sought. Its main downfall, is determining which order polynomial is best representative of the regional effect. Trend analysis is an adaption of the statistical field of multiple regression, from which the techniques have been 'borrowed'. The trend surface of polynomial order one is merely a plane surface, and this may be a quite adequate interpretation for some data, however some very complex surfaces can be matched to the data as the polynomials are expanded to a sufficiently high order. Of course geological processes are not polynomial functions, and can only be approximated by them.

Trend surfaces up to degree 6 were attempted. Beyond degree 4 , the trend surfaces started to exhibit unrealistic characteristics and so with the geology in mind, an attempt was made to interpret the trend surfaces. It became increasingly obvious that trend analysis was not the best approach for the regional analysis as the large anomalies within the region were unduly affecting the trend surfaces calculated by this method. Another problem was also the non-uniformity of the sub-surface structure in the area. We were not only faced with working on sediment, but over an area of varying material, and therefore a varying range in density contrasts. The density contrasts ranged from $-0.2 \mathrm{Mg} / \mathrm{m}^{3}$ to $-0.67 \mathrm{Mg} / \mathrm{m}^{3}$ in a small area, which caused some of the problems encountered with the trend analysis, which is only effective in areas of uniform density.

With this in mind, the most obvious approach was that used by many authors such as Woodward and Hicks (1978) and Bekesi (1989), where the regional is determined using a combination of geological and mathematical techniques. This combination constructs a fit to the gravity field where it is least disturbed by local effects (Stern, 1979). The best areas to use are the Torlesse Group outcrops which are common throughout New Zealand, and have an almost negligible density variation. For this method we can use the Bouguer anomalies over these uniformly outcropping greywackes to determine the regional anomaly. In basement investigation, 
regional determination must assume the following:

(i) the basement is homogeneous in density

(ii) the Cenozoic material is homogeneous in density

(iii) the regional anomaly is of a deeper origin than the residual.

The Bouguer anomalies on the outcropping greywackes within $40 \mathrm{~km}$ of the study area were supplied from the DSIR's database, and contoured to determine the regional effect. Throughout the study area, the regional ranged in value between 200 and $300 \mu \mathrm{N} / \mathrm{kg}$, which was consistent with the Bouguer anomaly maps by Doone and Ferry (1974). Removal of these regional values was done using a GIS program, called GES, in which the surface is built of the regional values and another of the Bouguer values. The difference between the two surfaces is taken as the Bouguer residual.

Removal of the regional is the most important aspect in gravity data analysis, for meaningful and accurate results. Poor regional analysis can completely ruin any hope for accurate interpretation. With this in mind, a FORTRAN program was constructed to determine the trend surface at each individual gravity station for whatever degree was required, using the greywacke data, instead of the previous method using GES of building surfaces using more generalised trend fitting. After further experimentation, a trend surface of order 2 was judged to be the most representative of the overall regional. The trend at each station was then subtracted as the final step in data reduction, to give the Bouguer residuals which were then used for the modelling. This further stage also meant that the data could be used for taking cross-sections across the area, rather than just profiles, which are more limiting in terms of modelling. Figures 3.7, 3.8 and 3.9 show the first, second and third degree trend surfaces for the regional data and their associated Bouguer residuals, determined from the subtraction of the individual trend surfaces from the Bouguer anomalies.

\subsection{Uncertainties}

\section{Possible sources of error in gravity surveying}

Any form of surveying and computation is open to some form of error, whether it be human or mechanical. Gravity surveying, as has already been discussed in Section 3.5, uses instruments which are prone to drift. Fortunately this source of possible error is minimised by 

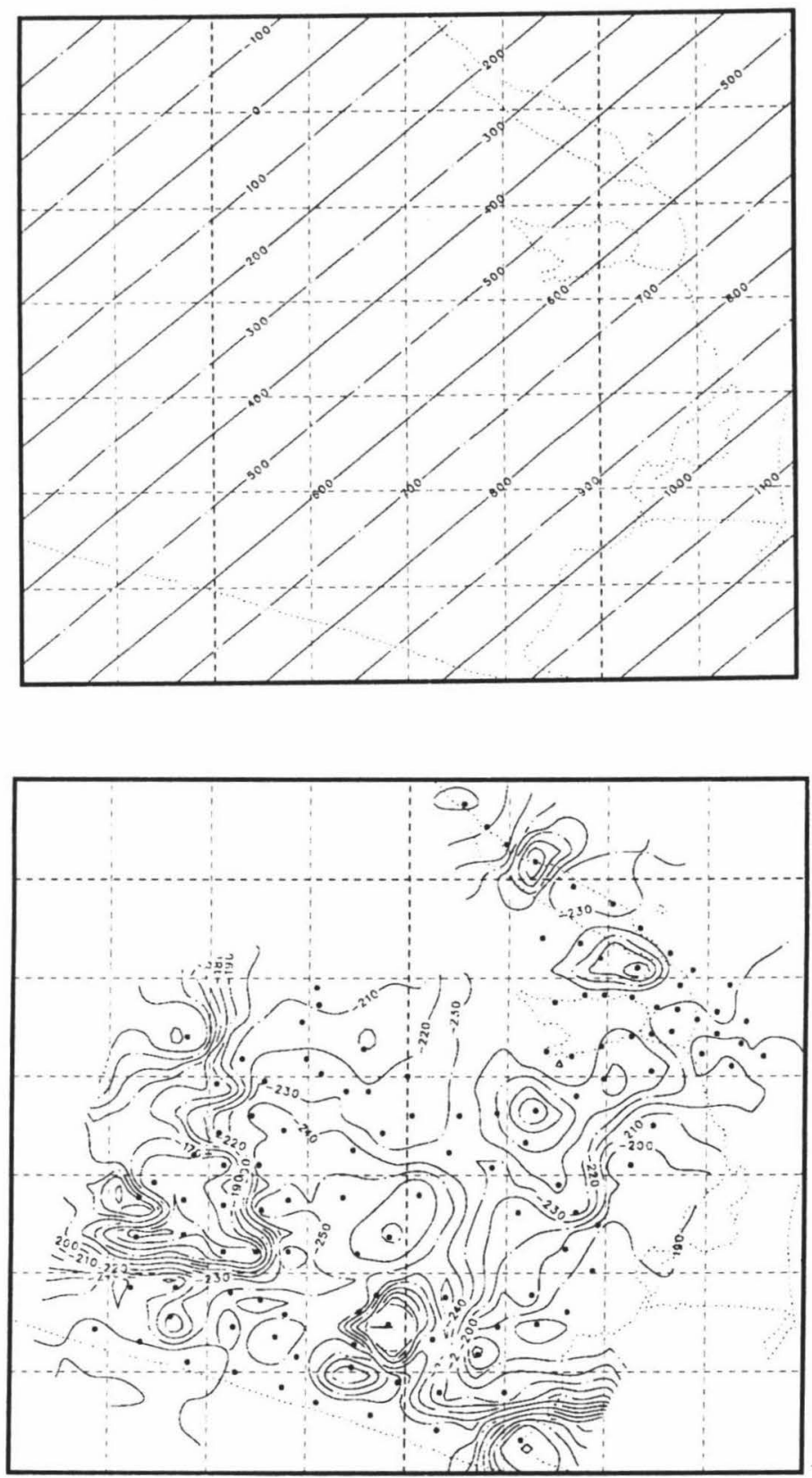

Figure 3.7 Regional trend surface 1 and the corresponding Bouguer residual 

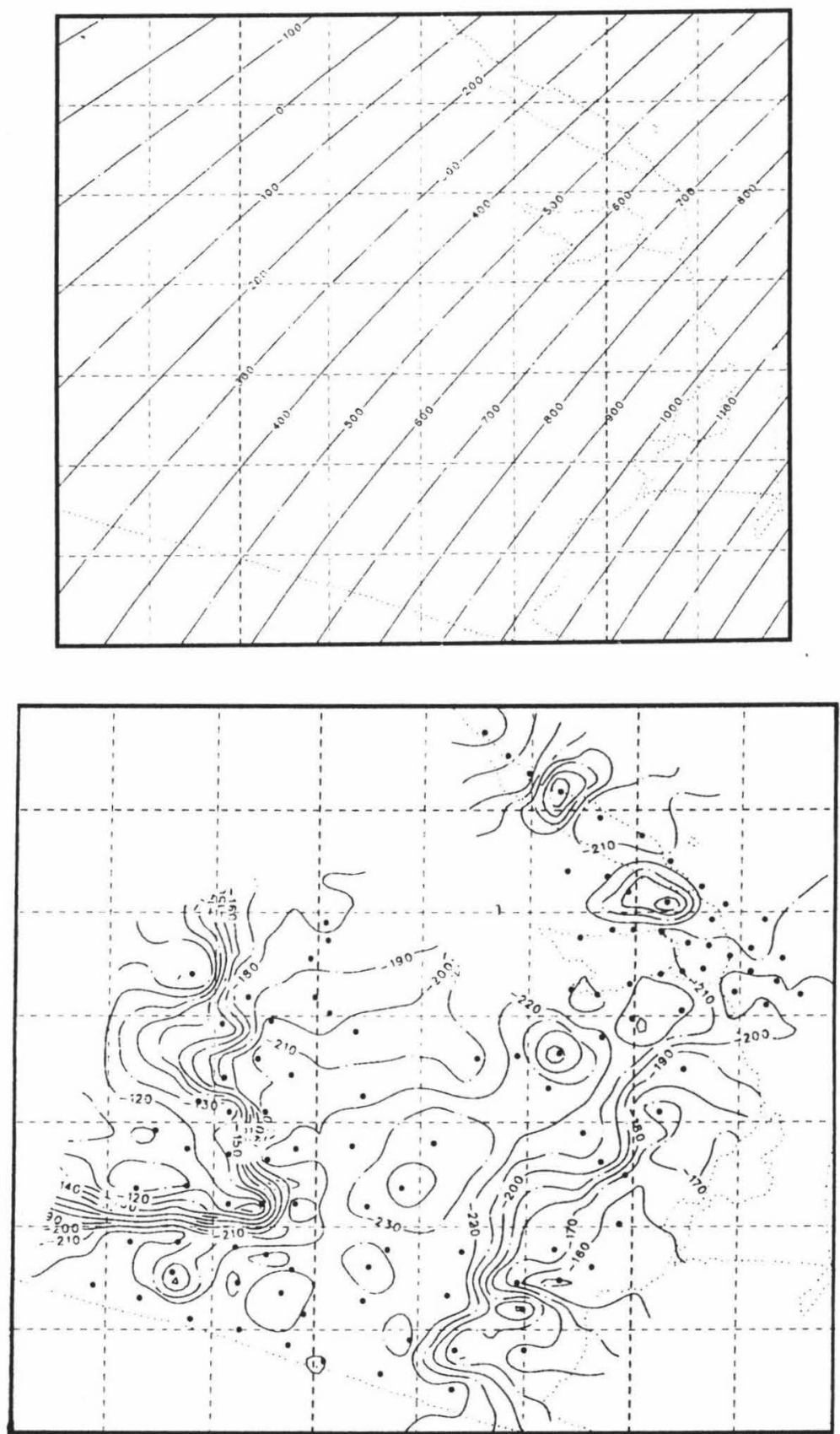

Figure 3.8 Regional trend surface 2 and the corresponding Bouguer residual 

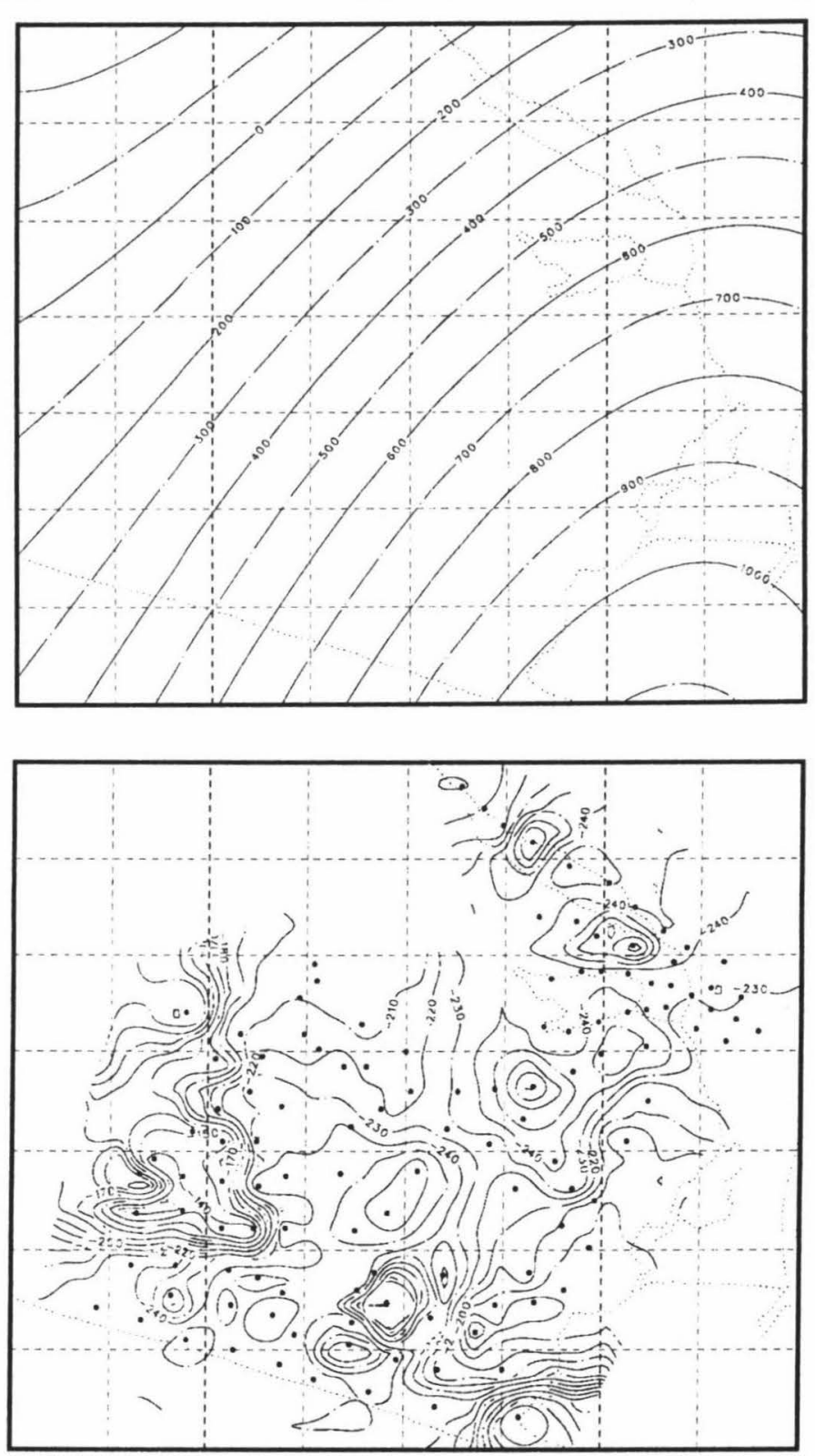

Figure 3.9 Regional trend surface 3 the corresponding Bouguer residual

correcting the results from the particular instrument for drift. All calculations done by hand in the analysis were double checked to ensure that no error was introduced by this way to the final results. Rymer (1989), discusses the principle causes of gravity errors encountered while surveying, and her findings are summarised in Table 3.3. 
Table 3.3 Possible sources of error in gravity measurements, from Rymer (1989)

\begin{tabular}{|c|c|c|c|}
\hline CAUSE & COMMENTS & $\overline{(E(\max ))}$ & $\overline{(E(\min ))}$ \\
\hline $\begin{array}{l}\text { EXTERNAL } \\
\text { a) Earth tide }\end{array}$ & Effect is always significant but depends & $<200 \mu \mathrm{gal}$ & $<20 \mu \mathrm{gal}$ \\
\hline & $\begin{array}{l}\text { on the precision of the time, latitude, } \\
\text { longitude and elevation measurement. } \\
\text { Greatest effect is a change of approx. } \\
50 \mu \mathrm{gal} \text { per hour. }\end{array}$ & & \\
\hline i)gravimetric factor & $\begin{array}{l}\text { Value ranges from } 1.155-1.165 \text { depend- } \\
\text { ing on Love numbers and latitude. }\end{array}$ & $<2 \mu$ gal & $<2 \mu \mathrm{gal}$ \\
\hline ii)phase lag & $\begin{array}{l}\text { Observed and predicted tides may be out } \\
\text { of phase by }-6^{\circ} \text { to }+3^{\circ}\end{array}$ & small? & $<1 \mu$ gal \\
\hline iii)ocean loading & $\begin{array}{l}\text { Caused by tilting of plates and the gravi- } \\
\text { tational attraction of varying masses of } \\
\text { water in the adjacent oceans. }\end{array}$ & $<10 \mu$ gal & $<1 \mu \mathrm{gal}$ \\
\hline b)Noise & $\begin{array}{l}\text { Low frequency, }(1-50 \mathrm{~Hz}) \text { disturbances } \\
\text { cause beam to swing, also produce tares. }\end{array}$ & $<50 \mu \mathrm{gal}$ & $<1 \mu \mathrm{gal}$ \\
\hline $\begin{array}{l}\text { READER } \\
\text { a)Leg Length }\end{array}$ & Height of meter is varied by changing & $<9 \mu \mathrm{gal}$ & $<1 \mu \mathrm{gal}$ \\
\hline & $\begin{array}{l}\text { leg lengths, and gravity changes accord- } \\
\text { ing to the free air gradient as }-3 \mu \mathrm{Gal} \text { per } \\
\mathrm{cm} \text {. }\end{array}$ & & \\
\hline b)Sensitivity and levelling & $\begin{array}{l}\text { Sensitivity can be varied manually, but } \\
\text { drifts with time. Failure to level, espe- } \\
\text { cially along the long level, effectively } \\
\text { changes the reading line and changes the } \\
\text { sensitivity. }\end{array}$ & $<20 \mu$ gal & $<1 \mu \mathrm{gal}$ \\
\hline c)Dial movements & $\begin{array}{l}\text { Slack in the gears will cause errors un- } \\
\text { less the reading is approached from the } \\
\text { same side each time. }\end{array}$ & $<40 \mathrm{mgal}$ & $<1 \mu \mathrm{gal}$ \\
\hline d)Timing & $\begin{array}{l}\text { So long as the reading is steady there is } \\
\text { no evidence that there is an advantage in } \\
\text { waiting before making a reading. }\end{array}$ & Negligible & - \\
\hline \multicolumn{4}{|l|}{$\begin{array}{l}\text { INSTRUMENTAL } \\
\text { Evidence }\end{array}$} \\
\hline & $\begin{array}{l}\text { The r.m.s deviation about the mean } \\
\text { reading when the gravity meter is } \\
\text { moved and reset between readings is } \\
\text { greater than if it is not moved between } \\
\text { readings. }\end{array}$ & & \\
\hline a)Meter Calibration & $\begin{array}{l}\text { Polynomials can be used to model the } \\
\text { calibration features. There are periodic } \\
\text { terms due to the way the meter is con- } \\
\text { structed, but over small ranges the effect } \\
\text { can be kept down to a few gals. }\end{array}$ & $0.1 \%$ & $<1 \mu \mathrm{gal}$ \\
\hline $\begin{array}{l}\text { b)Tares } \\
\text { i)Thermal instabilities }\end{array}$ & $\begin{array}{l}\text { Low battery power or a sudden change } \\
\text { in external temperature may cause a }\end{array}$ & ca.10 mgal & $<1 \mu \mathrm{gal}$ \\
\hline We & $\begin{array}{l}\text { thermal shock to the measuring system. } \\
\text { If the internal temperature is allowed to } \\
\text { fall to room temperature, the effect is } \\
\text { much larger. }\end{array}$ & & \\
\hline \multirow[t]{2}{*}{ ii)Mechanical instabilities } & $\begin{array}{l}\text { Physical jolting of the spring system and } \\
\text { possible hysteresis effects can cause } \\
\text { tares of almost any magnitude. }\end{array}$ & ca.10 mgal & $<1 \mu \mathrm{gal}$ \\
\hline & TOTALS & $>50 \mu \mathrm{gal}$ & $<10 \mu \mathrm{gal}$ \\
\hline
\end{tabular}


From this table it is clearly evident how easy it is for errors to be introduced cumulatively throughout a gravity survey. For the surveys however, within the range of uncertainty, these types of errors discussed by Rymer would not contribute a significant enough amount to alter the final results. Care was taken however, to always read the reading line of the gravity meter from the same side, protecting the meter from direct sun (so its temperature was the least affected), protecting the meter as much as possible from the wind as readings were being taken, and taking special care when levelling the meter on the levelling disc. Most of the sources of error in Table 3.3 were able to be successfully neglected for surveying, however errors introduced in the actual gravity reduction could not be avoided.

\section{Error Analysis from Data Reduction}

Not accounting for error involved with misreading the gravity meter, barometer dials or time recorder, so that instrument readings and drift rates are inaccurate, the greatest source of error comes from elevational inaccuracies. An analysis of uncertainties in scientific measurement is of prime importance because all field measurements are subject to experimental error. Errors are cumulative and can result in quite large variations in uncertainty of the final result. This pertains especially to the concluding models, where a fit might seem poor if the uncertainties were not taken into account.

The errors for Bouguer anomalies can be estimated by,

$$
X=\sqrt{\sum x_{i}^{2}}
$$

where, using the expression for the Bouguer anomaly in Equation $3.9 x_{1}$ is the error in $g_{\text {meas }}, x_{2}$ is the error in $g(\phi), x_{3}$ is the error in $\Delta g(h)$ and $x_{4}$ is the error in $g(T)$.

The greatest error is found in $\Delta g(h)$, where there is an affect of elevational errors from the barometric levelling. This is accumulated also into the topographic corrections, where error is incurred from incorrect station elevation. Taking Station 49 for example, which has a height of $43.3 \mathrm{~m}$, the total gravity correction for zones $\mathrm{E}-\mathrm{H}$ is $50.9 \mu \mathrm{N} / \mathrm{kg}$, whereas if its height were $25 \mathrm{~m}$, the correction for the same zones would be $58.3 \mu \mathrm{N} / \mathrm{kg}$, which is approximately a $13 \%$ increase.

Figure 3.5 shows the variation of elevation correction with density. Unless borehole data is available, the uncertainty in density assumptions is very great. However this uncertainty is not dealt with in error analysis, but instead is compensated for in the final model. 
Error in $g_{\text {meas }}$ is only in the order of $10^{-4} \%$, which is negligible in terms of the accuracy required for this study, and for $g(\phi)$ is even less. We are therefore dealing with the case in which $x_{3}+x_{4} \gg x_{i}$ so,

$$
X=\sqrt{x_{3}+x_{4}}=\sqrt{2} x_{3}
$$

As discussed earlier in this chapter, barometric levelling is not a very accurate means of calculating station elevation. Theodolitic measurements or other similar methods, are too time consuming and involved for this type of research. Instead the errors involved with the barometric levelling must be faced and accounted for in the final results.

The study region was very exposed and hilly, resulting in the quite rapid pressure changes, thus interfering further with the accuracy of the levelling. In a few areas the heights were obviously inaccurate by approximately $20 \mathrm{~m}$, but as a rule, Woodward's estimate of $5 \mathrm{~m}$ is a good guide to the range of error. The error varied between 2 and $20 \mathrm{~m}$, with most falling at the lower end of the scale.

Assuming an error of $5 \mathrm{~m}$ in the barometric levelling, the error to be expected in the Bouguer anomaly is approximately $15 \mu \mathrm{N} / \mathrm{kg}$. However, strictly speaking the error is larger than this, because the heights of the base stations themselves were determined by barometric levelling. To allow for this, a fairer estimate of the uncertainty in the final values would be $20 \mu \mathrm{N} / \mathrm{kg}$. At this point it should be noted that the units for gravity in this thesis are in $\mu \mathrm{N} / \mathrm{kg}$, except for any modelling diagrams output by $S A K I$, which only runs in milligals. The next stage of regional removal also involves error, but this is harder to estimate. To compensate for this, floating is used in the modelling programs.

\subsection{Contouring}

Once all corrections had been applied to the gravity data, the next stage before an attempt was made at modelling was to contour the Bouguer residuals to see their general trend. The trend of the residual data lies in the north-west direction, as shown in Figure 3.10, with the most obviously anomalous region showing in the south-west portion of the study area. Another steep anomaly but with a more gradual gradient than the former, is associated with the region slightly to the west of Lake Onoke, where several faults have been mapped (see Figure 1.7). 
The area in the middle of the study area is relatively uniform, which is to be expected over a sedimentary basin. A small anomaly is showing up around the Lake Pounui region, caused by the lake itself. The region of most interest however, is to the west of the region. There is presumably a feature causing this anomaly, such as a 'bulge' of greywacke coming to the surface, but a full interpretation is not easy without data from even further west. Time limitations involved with a study of this nature unfortunately prevented the required amount of extra data to be gathered, mainly due to difficult access.

As the best efforts had been made to remove the regional effect from the Bouguer anomalies, the information relayed in Figure 3.8 should be solely due to unconformities in the sub-surface of the study area. The best ways to approach modelling, was decided from the contour map and these shall be discussed in Section 3.10.

\subsection{Modelling Programs}

\section{Saki - 2-D Modelling Program}

Two separate modelling programs were used in the analysis of the gravity data. The first stage of modelling was to find a two dimensional structure which would best describe the subsurface of the study area. Standard 2-D gravity modelling uses the method of least squares to fit the theoretical gravity response of a geological structure to a profile of observed data. More often than not, a model is constructed by linking together a series of polygons. SAKI (Webring, 1985), the 2-D modelling program used in this study, works in this manner. It's advantage over other types of similar modelling programs, is that it is semi-automated. This allows for user interaction and as well as speeding up the modelling process, the user is also able to adjust the model and observe the effect on the calculated anomalies. SAKI is a FORTRAN program for "generalised linear inversion of gravity and magnetic profiles." The user begins with a simple model. Figure 3.11 shows an example.

An ASCII model file is set up with the vertices of each body, their individual density and the density of the background body, which is usually taken to be the Bouguer reduction density of $2.67 \mathrm{Mg} / \mathrm{m}^{3}$. The models must extend beyond the profile ends by five to ten times the depth of the deepest body, to minimise the edge effects. The strike lengths, or third dimension of the model, extend at a right angle to the cross-sections, follow the same reasoning. This model is then read 


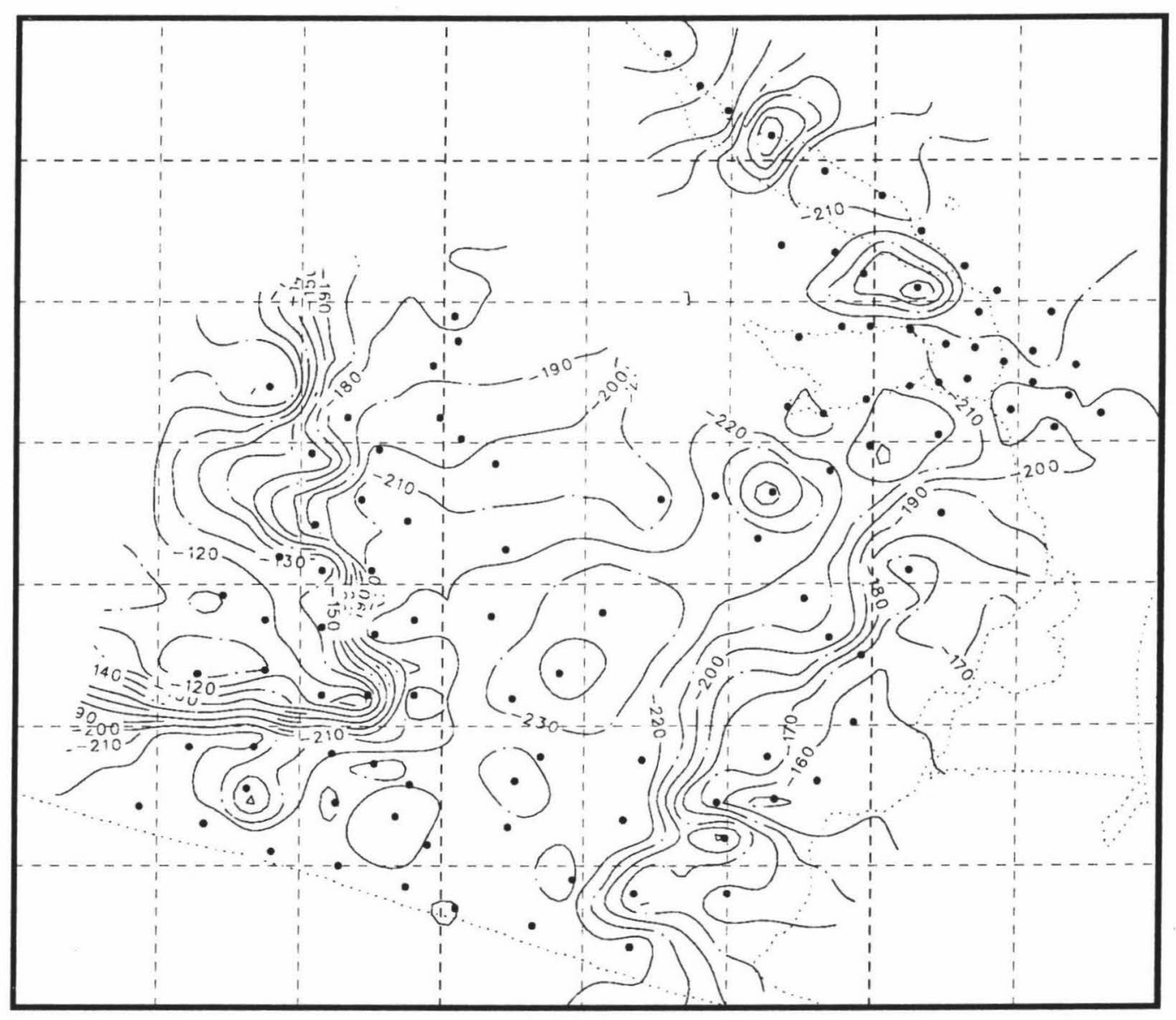

Figure 3.10 Contour map of the Bouguer residual anomalies 


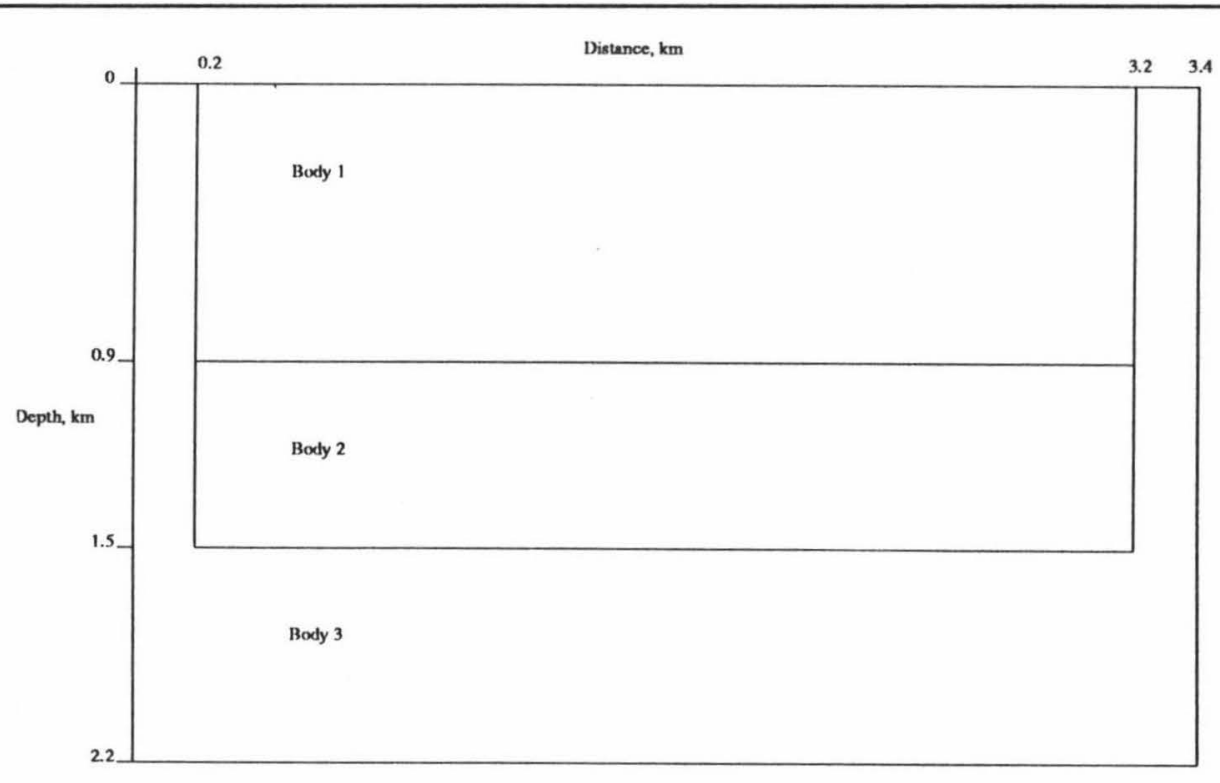

Figure 3.11 Example of a starting model used in SAKI

into $S A K I$ with the option of also being able to read in a file of observed gravity data. The gravity anomaly caused by the model is then shown against the observed data, so the fit can be analysed. The user can then interactively alter the positions of the vertices (nodes) of whatever body is chosen, and also its density. After this alteration the better fit, or otherwise, of the model can be seen.

Once a reasonable fit to the observed data is found, the model can be inverted. SAKI's generalised linear inversion uses a modified Marquardt (1963) algorithm, to improve the model parameters. A good fit can often be achieved by a quite unsuitable geological model. The user must be subjective with the geological interpretation and not rely on a good model found by inversion, just because the root mean square (rms) error is small. By selecting which parameters are free for inversion, the user can control whether set layers are to remain at certain depths and so on. When a geologically feasible structure is defined in the first layer of a two layer model for example, it may only be necessary to invert the model representing the second layer. In this way, the depths of certain boundaries or body densities can be constrained.

One of the first decisions the user must make is whether the data is to be floated or not. It is a good idea, and recommended in the open file report to $S A K I$, that data be floated unless the user believes the regional removed is perfect. Floating data requires the use of a floating datum level 
in which local anomalies, rather than those on a regional scale are of most importance. This step in SAKI involves automatic DC average removal from the calculated data, with the average being the difference between the calculated and observed data.

Again it is to be noted, that gravity models are non-unique, but with careful thought and knowledge of the regional geology of an area, SAKI provides the user with a useful tool to evaluate models describing cross-sectional areas.

\section{GRAV3D - 3D Modelling Program}

The second stage of modelling described the sub-surface structure of the study region three dimensionally. The program chosen at this stage was made available to the author by the DSIR. GRAV3D (Paintin, 1989) evaluates the gravity effect of one or more bodies, using an algorithm developed by Talwani and Ewing (1960). Modifications have since been made to the program. One of particular importance allowed for laterally-varying density contrasts.

The theory behind the algorithm becomes one of integration. The 3-D body is represented by a series of contours, each of which is replaced by a horizontal irregular n-sided polygonal lamina. The gravity effect of each lamina can be determined analytically and plotted as a function of the contour elevation (i.e lamina height). Figure 3.12 shows a 3-D body represented by contours. The body $\mathrm{M}$ is divided into three lamina and the gravitational effect at point $\mathrm{P}$ is determined. This effect is:

$$
\Delta g_{\text {total }}=\int_{z_{\text {bot }}}^{z_{\text {top }}} V d z
$$

The fit of the contours by the polygons can be as close as desired, depending upon the number of sides describing the polygon. Laminae are described by the vertices of a polygon, using a righthanded orthogonal Cartesian co-ordinate system. Each lamina of a specified density contrast, can be further sub-divided into a number of discrete groups of laminae.

An important feature of $G R A V 3 D$ is that the program sums the effect of each lamina, without noting the distribution of previous lamina. This means for example, in the case of a fault in a sedimentary basin, the sediments can first be modelled rather than modelling the anomalous region. Then the fault causing density contrasts can be modelled and the summation of the two contrasts models the actual combination of these bodies. 

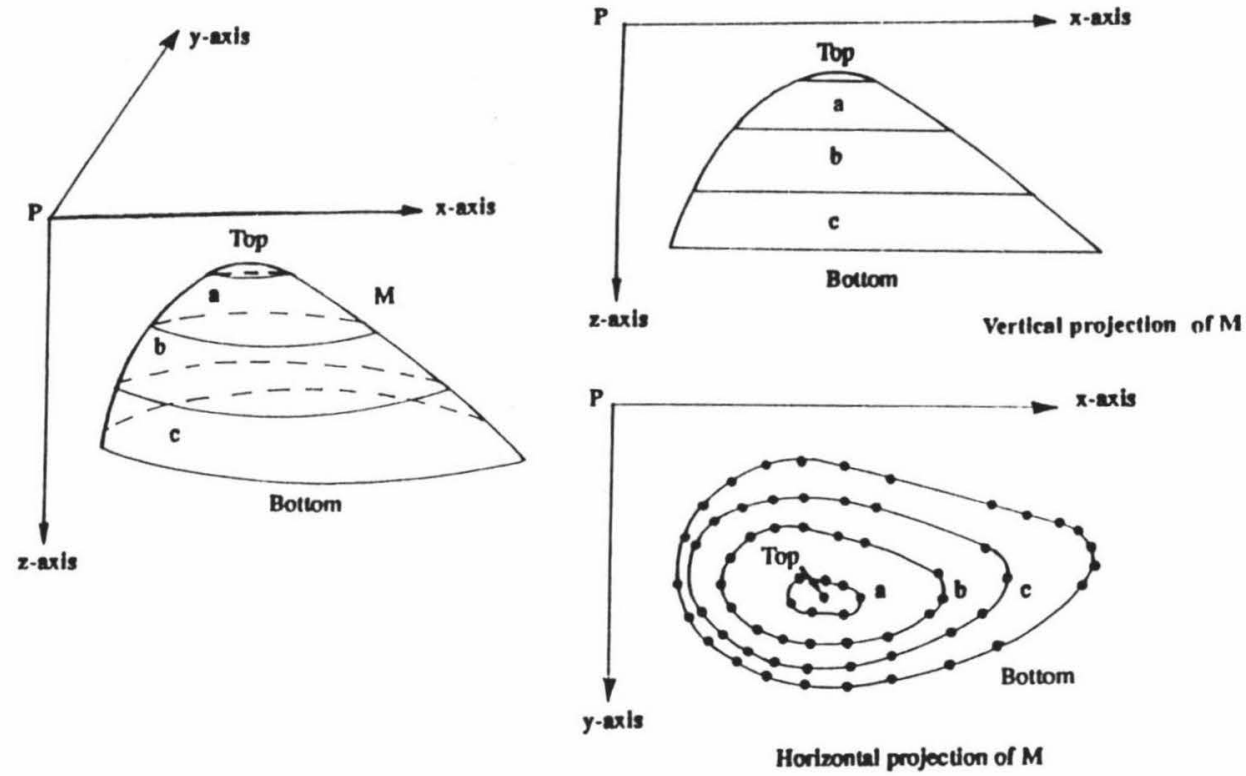

Figure 3.12 3-D Model from Talwani and Ewing (1960)

Unlike $S A K I, G R A V 3 D$ is not an iterative modelling program. A model file containing the vertices of each lamina of n-number of bodies is read by $G R A V 3 D$, along with an input file containing the $\mathrm{x}, \mathrm{y}$, and $\mathrm{z}$ co-ordinates of the gravity station and gravity anomalies. An output file is produced by the program containing the effect of the model. Graphics are available with the program, but were not suitable for the author's requirements. Instead a FORTRAN program was written to contour the residual values obtained from the difference between the observed gravity values and those calculated from the 3-D model. From these contours, it can be seen where the model is not fitting the data well, and the model file can be adjusted and run through GRAV3D again. This process continues manually until a satisfactory fit is achieved.

\subsection{Modelling}

Once the anomalies had been described in a contour plot the next stage was to take profiles or cross-sections through the area, a step necessary for 2-D modelling. Contouring is also a good 
starting basis for modelling, because it helps to smooth out inconsistencies in the data. The first attempt at modelling was to draw the Profiles A-A', B-B', C-C' and D-D' running in the direction perpendicular to the trend as shown in Figure 3.13. The residuals vary by a difference of $100 \mu \mathrm{N} / \mathrm{kg}$ along A-A', $130 \mu \mathrm{N} / \mathrm{kg}$ along B-B', $40 \mu \mathrm{N} / \mathrm{kg}$ along C-C' and $60 \mu \mathrm{N} / \mathrm{kg}$ along D-D'. So in each profile there is a significant gravity variation along its length. The $2 \frac{1}{2} 2$-D modelling program, SAKI, discussed in Section 3.9, was used to model each individual profile. A simple model consisting of two separate rectangles was the starting point for the model of Profile A. Once a suitable model had been found for this profile it was then used as a starting model for Profile B and this step was repeated for the remaining two profiles, which provided consistency through the different models. The density contrasts used in these preliminary models were those determined by Woodward et al. (1978) shown in Table 3.1. The reference point was taken to be at approximately 2677000 on the NZMG R27 map, so the profiles were rotated parallel to the map grid lines to find distances consistent for the four profiles.

Model A, was the most complex of the four models, consisting of two discrete bodies. The models became less complicated as progression was made up the valley. Figures 3.14 and 3.15 show models A to D, the models for Profiles A to D respectively, and their fit to the observed data. For Model A it was not possible to fit the large dips in the anomaly between 2 and $2.5 \mathrm{~km}$ along the profile. Deepening the fourth layers of the bodies to greater depths $(>10 \mathrm{~km})$, made little difference to the model fitting the observed values at this point. However, when the uncertainty determined in Section 3.8 was included, the model fits the minimum in Model A. Each of the four models consistently showed a fault appearing in the vicinity of 1 to $1.5 \mathrm{~km}$ from the reference point which corresponds with the Wharepapa River channel. Eastwards along the profiles the models spread gently out into a basin type structure with the effects of Lake Pounui, showing in Profile D. For this latter profile, the anomaly in the region of the fault is much less than that caused by Lake Pounui. The smaller fault at $3.5 \mathrm{~km}$ is consistent with the Battery Hill fault (Ghani, 1974) in this region.

When modelling these four profiles the fit for each model with the observed data was good. At this point however it should be noted that the data was floated. By floating the data, it becomes easier to see how good a fit the model is.

Contouring can be quite subjective when done manually. However by computer, edge effects can distort the true data in the outer areas. This is the most likely explanation for the 


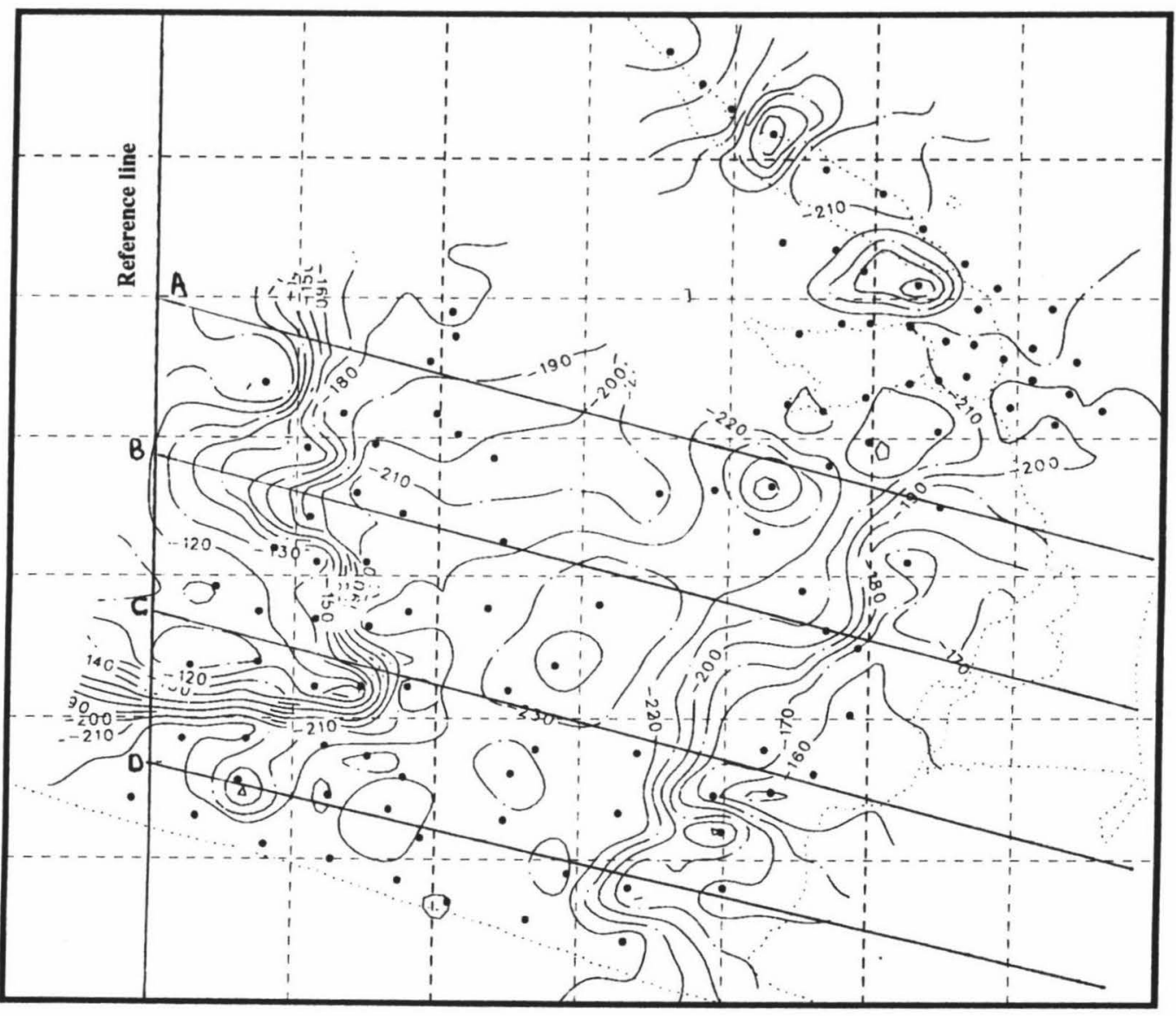

Figure 3.13 Position of Profile lines A to D 

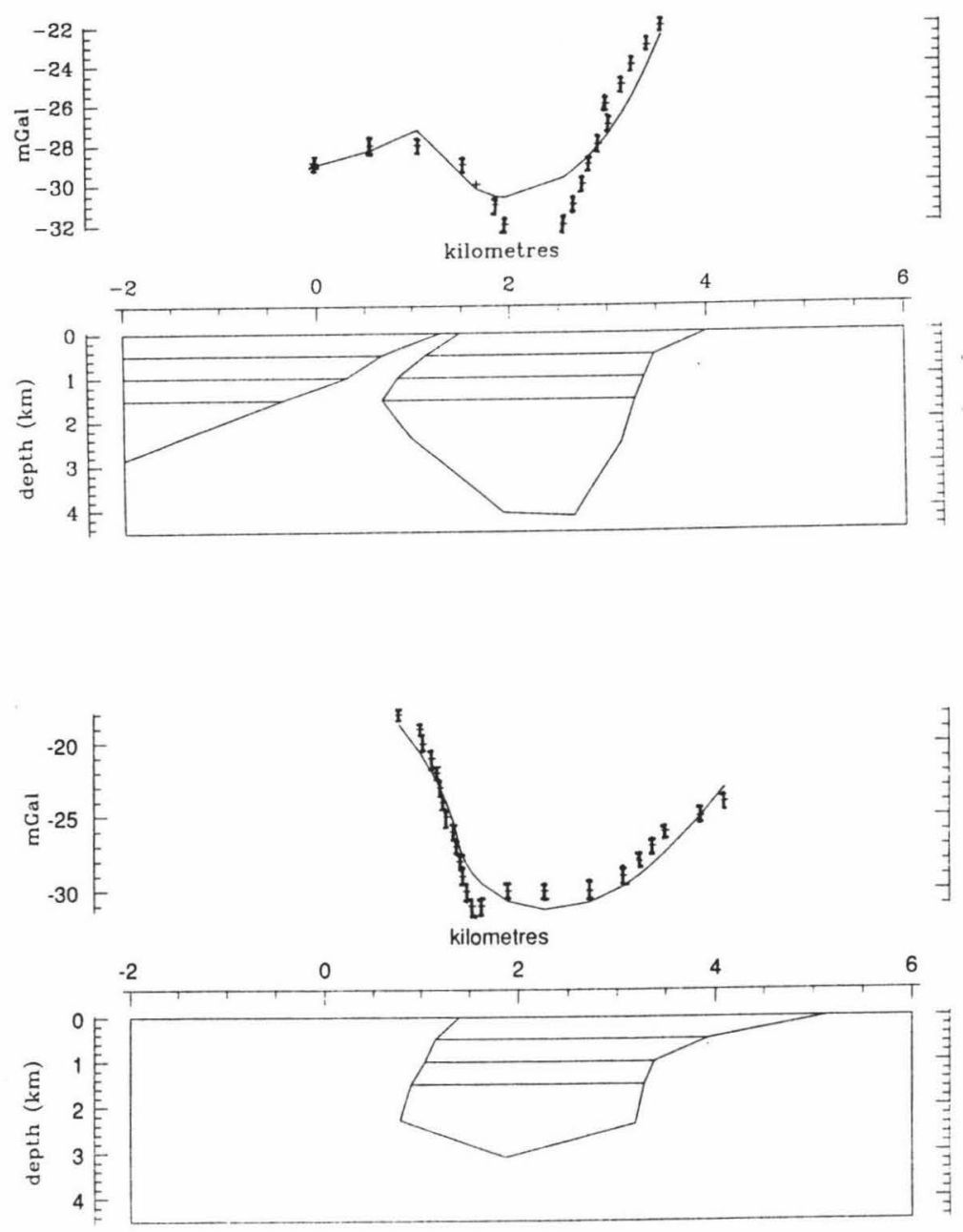

Figure 3.14 Models A and B corresponding to Profiles A and B 

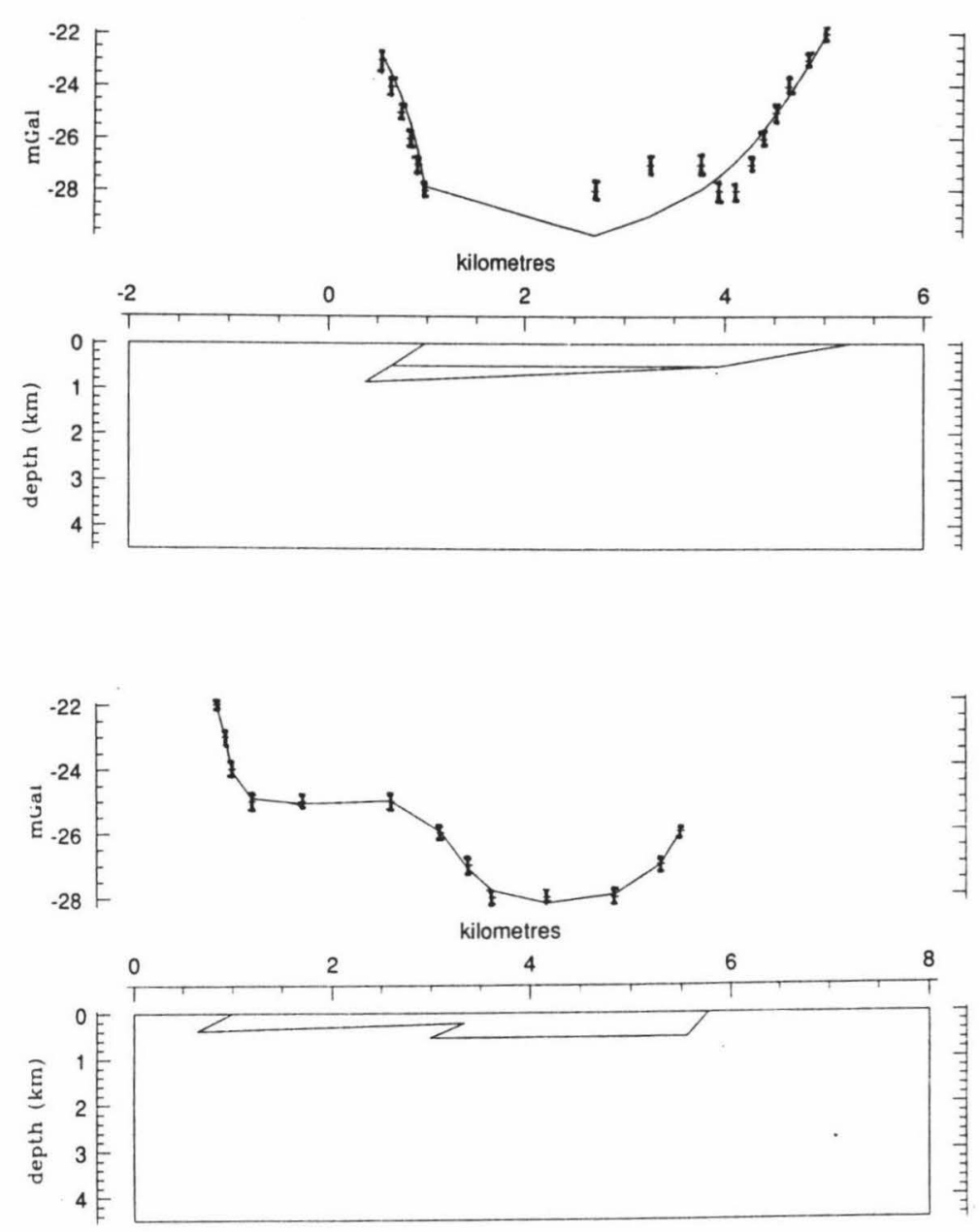

Figure 3.15 Models C and D corresponding to Profiles C and D

minimum in the observed data for Profile A. Although the fits of Models A to D inclusive, were good, it was decided that a better representation of the data could be achieved by taking the regional value off from each individual datum point and taking cross-sections through the area. This gave a total of 6 cross-sections E, F, G, H, I and J, as shown in Figure 3.16. Another problem with taking profiles directly from the contours is the uncertainty in the contours are unknown. Models A $\mathrm{n}$ chnwed a fault minnina through the moginn of the river on it 
was decided to make the cross-sections along the grid lines $1 \mathrm{~km}$ apart starting at 2682000 , perpendicular to the supposed fault. Stations up to $1 / 2 \mathrm{~km}$ either side of the cross-sectional line were included in each cross-section. A further cross-section, was made to coincide with the line of MT sites, and again stations were projected $1 / 2 \mathrm{~km}$ either side of the cross-section.

After using this method it became clear that the minimum in the data for Profile A must have been due to edge effects in the contouring. Models $\mathrm{E}, \mathrm{H}, \mathrm{I}$ and $\mathrm{J}$ gave quite good fits to the

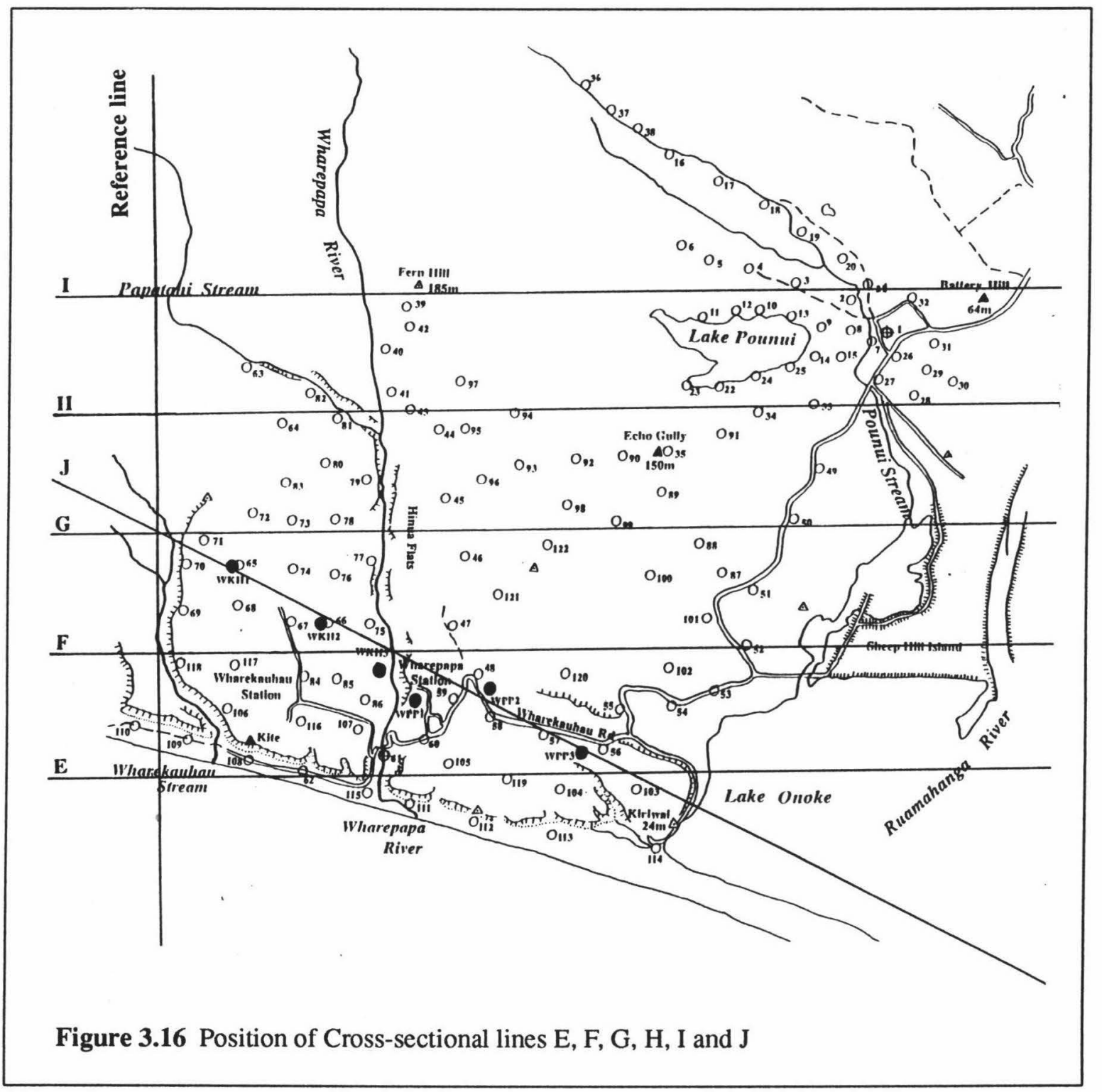


data of the respective Cross-sections E, H, I and J. However difficulties became apparent as soon as models for $\mathrm{F}$ and $\mathrm{G}$ were attempted. The steep gradient in Figure 3.13 of $100 \mu \mathrm{N} / \mathrm{kg}$, is transected at the western end of the cross-sections, whilst at the eastem end, there is a gradient of $50 \mu \mathrm{N} / \mathrm{kg}$ over a larger area. This caused a large scatter in the data for Cross-section F and G. As each cross-section was near one of the profiles, the respective models A through to D were used to model the cross-section data. Models for F and $\mathrm{G}$ could accurately modelled by either Model A or B, depending on whether the steeper gradient was taken into consideration or not. Traverse J was modelled well by Model B. Cross-sections E, F, G and H were then once again modelled using SAKI to get the best fit models shown in Figures 3.17 and 3.18. Although these models appear to be of quite a reasonable goodness-of-fit, when taking the uncertainty into consideration, there was still too much noise in the data to be able to realistically use these as the final models. However because the structure found in the models for the cross-section was better defined than from the models of the profiles, it was decided to refine the method by which data was chosen for modelling.

The second modelling attempt was the final to be used as it gave a better representation of the data than the first. However, another problem ensued with a lot of noise showing up in the data. The only resolution for this problem was to stay with the idea of cross-sections and using Bouguer residuals where the regional was taken from each individual datum point, but projecting stations onto the cross-sectional line from a maximum distance of $100 \mathrm{~m}$ either side. Rather than using equispaced cross-sectional lines across the study area, seven lines were made to ensure the greatest number of stations were near each line as shown in Figure 3.19. The reference point for these lines was at the map grid line 2682000 . The station positions were taken from their grid locations rather than by measurement along the lines, to ensure greater accuracy. The distance from the reference point was then multiplied by the appropriate angle $(\cos \theta)$ that each line made with the horizontal. SAKI was then used to model each cross-section. Through the course of modelling, it became evident that the values measured at a few stations were suspect, namely at stations 70, 56 and 114. These stations were excluded from further analysis, but station 56 was replaced by Station 123, a station from the DSIR data base, very near to 56 and comparing well with the other values in the immediate vicinity. Line $T$ was later removed also, as there was an oscillation occurring in the data along this section, possible due to uncorrected errors occurring on one of the survey days. Data along this line was collected on separate days, but variations 

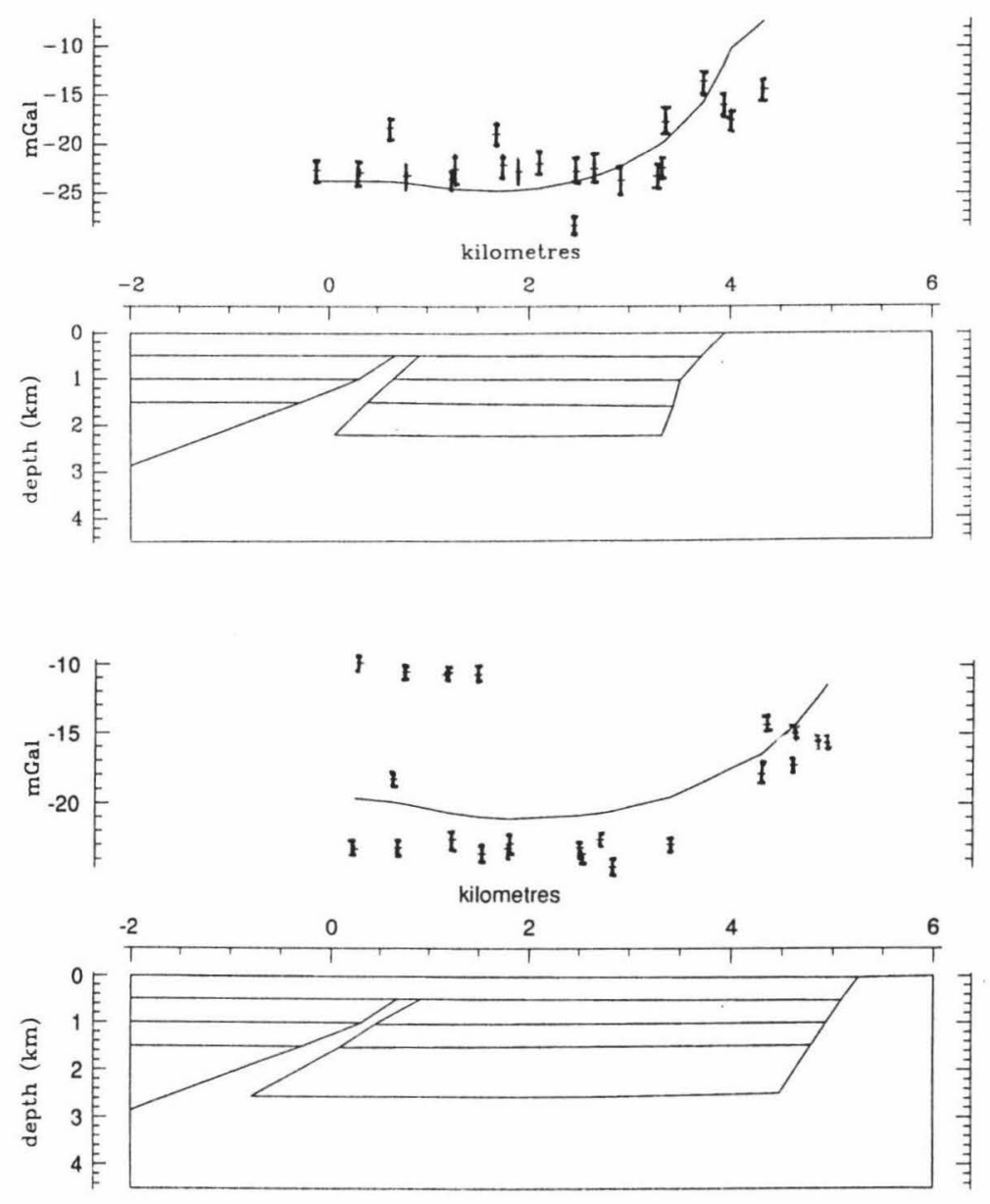

Figure 3.17 Models E and F for Cross-sections $\mathrm{E}$ and $\mathrm{F}$ 

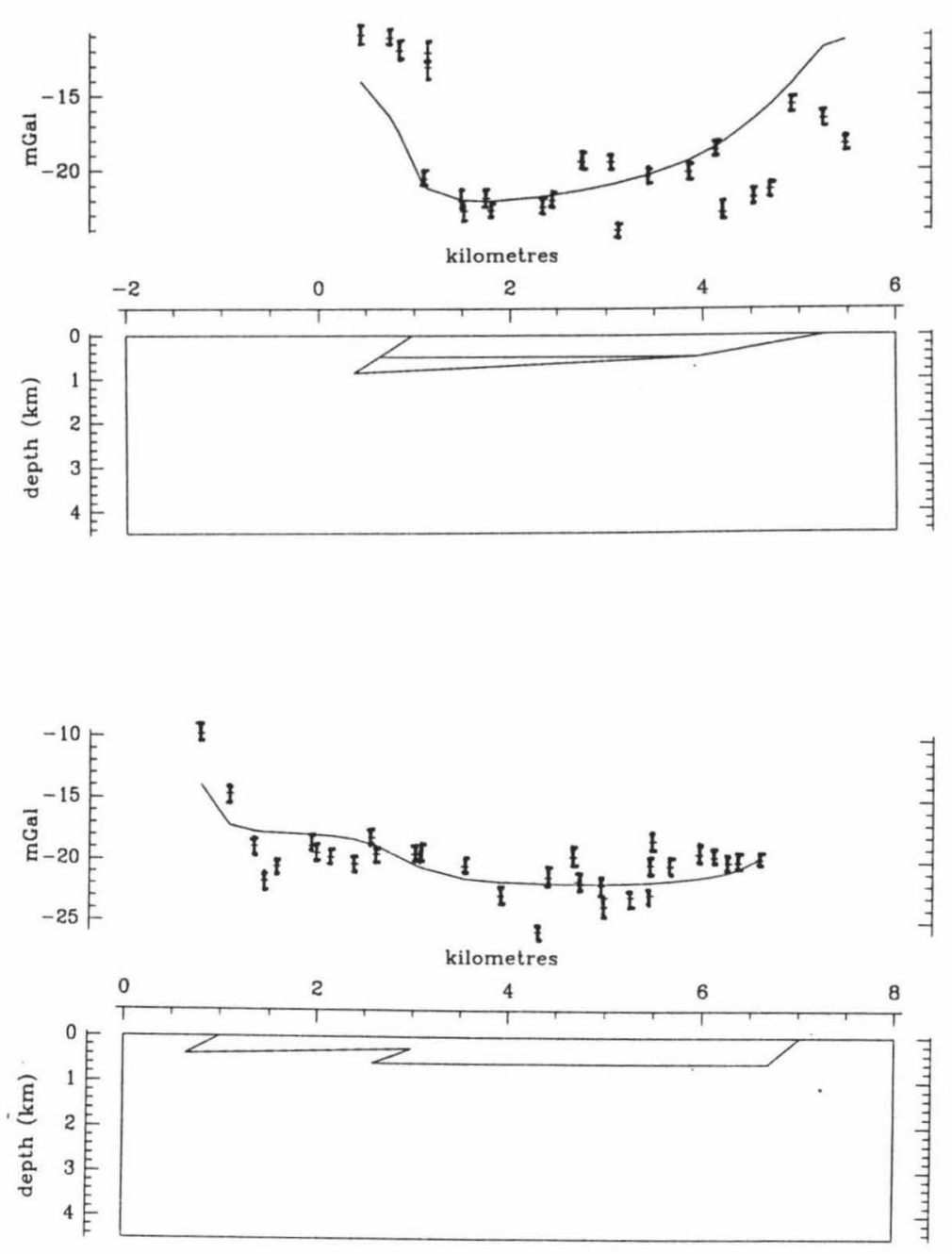

Figure 3.18 Models $\mathrm{G}$ and $\mathrm{H}$ for Cross-sections $\mathrm{G}$ and $\mathrm{H}$ 


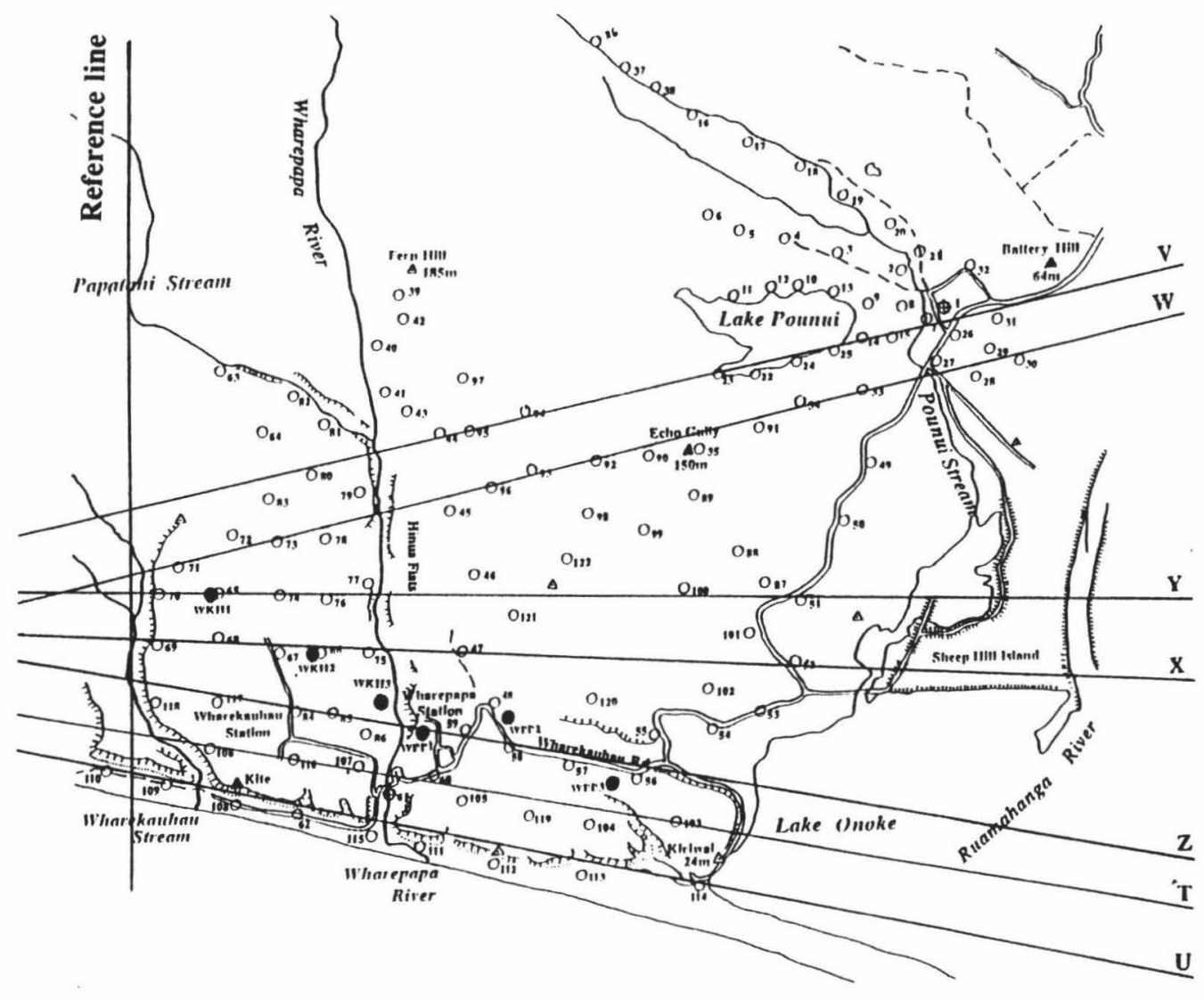

Figure 3.19 Locality of gravity Cross-sections T, U, V, W, X, Y and Z

only seemed to occur in this area. One possibility is that a few station heights in the area appear to be inaccurate, which as discussed in Section 3.7, introduces sizeable variation. However, this does not explain the oscillating variation which is also unlikely to be caused by drift, that has not been sufficiently corrected for in calculations. This cross-section was thus abandoned and the remaining six were modelled.

At this stage of the modelling, it was decided to change Woodward's density contrasts previously used. The material in the study area is very young and the density contrasts after research into the geology of the area and experimentation in modelling were adopted as those 
shown in Table 3.2 .

In modelling, the depths of the various boundaries of the density contrasts has to be made. With no borehole data available in the area, but from the seismic data obtained in this study and experimentation with the modelling program, a depth of $210 \mathrm{~m}$ was decided upon for the upper layer. Woodward's example of separating the deeper layers up to $1.5 \mathrm{~km}$ by $0.5 \mathrm{~km}$ was then followed. As soon as a model dipped below a $500 \mathrm{~m}$ boundary, the layer was separated into two or more corresponding density layers and the appropriate density contrasts assigned to them.

As models for Cross-sections U, V and Z were all based on a variation of 10 or $20 \mu \mathrm{N} / \mathrm{kg}$, they could not be regarded as significant, as this variation is within the range of uncertainty. However the models fitted to these cross-sections were of importance because the structures showed similar features to the significant models of Cross-sections W, X and Y.

Models $\mathrm{W}, \mathrm{X}$ and $\mathrm{Y}$ were the three cross-sections which gave the best representation of the data in the area and are shown in Figure 3.20, 3.21 and 3.22. Model W fits the observed data well and defines a fault in the vicinity of the Wharepapa River channel, and a sedimentary basin extending east. These three important models are in areas of the steepest anomaly gradients.
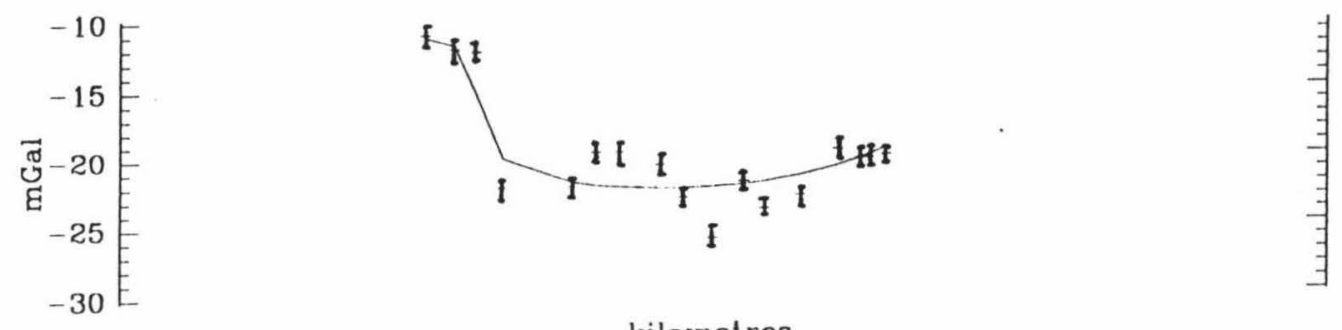

kilometres

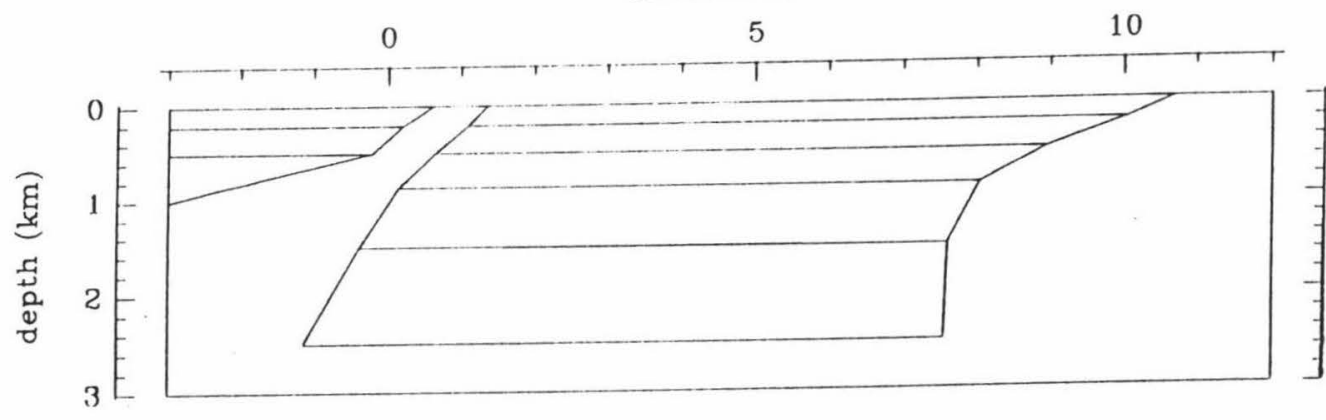

Figure 3.20 Model W 


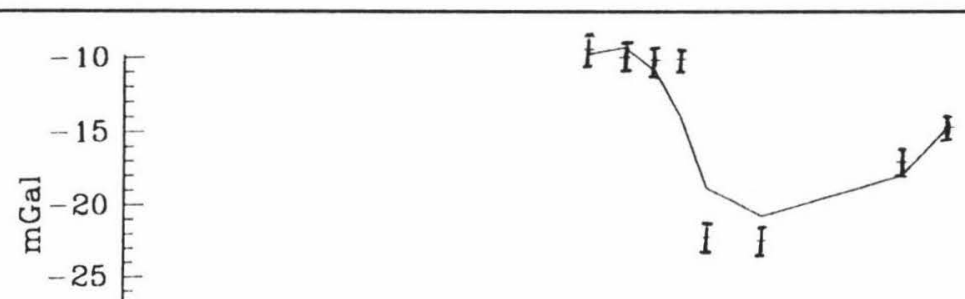

kilometres

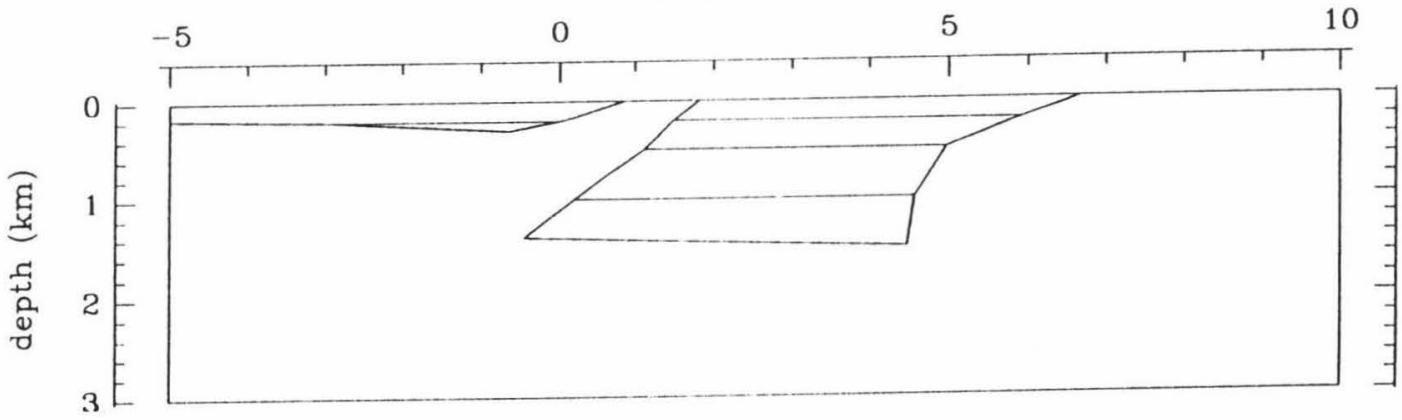

Figure 3.21 Model X

$$
-10 \text { E }
$$

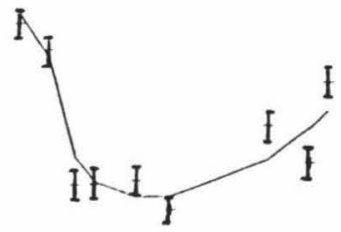

kilometres

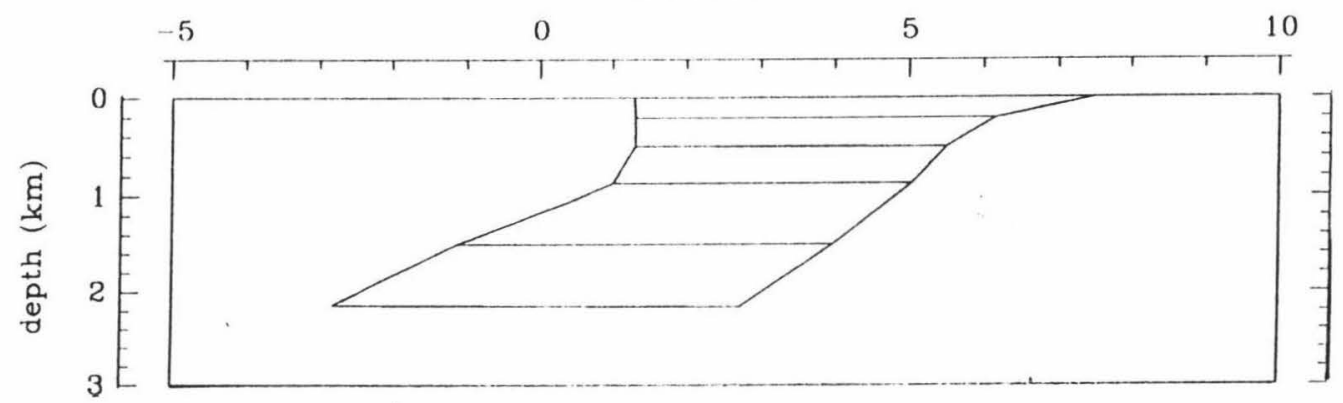

Figure 3.22 Model Y

Model $\mathrm{X}$ is a variation of $\mathrm{W}$. We are not seeing such an effect at greater depths of either of the two discrete bodies. The fault lies within a region of $400 \mathrm{~m}$ which is covered in the range of uncertainty. The gravitational effect in this area is therefore affected by the shallower structure. 
Increasing the depths of these two bodies in Model X made insignificant changes to the goodnessof-fit.

In Model $\mathrm{Y}$ we see no effect from a second body in the region. We do however see an effect of a sedimentary layer on top of the fault. When the model was made, so the fault came to the surface, the fit altered dramatically with the observed data. So it appears in this region that the fault trace is buried under at least $100 \mathrm{~m}$ of sediment. This model does however extend deeper than the other five, and alteration of this depth in terms of shallowing, again quite significantly alters the goodness-of-fit with the observed data.

In all 2-D modelling we are in fact modelling a $2 \frac{1}{2} 2$-D structure, as each model is also represented as extending out in a direction at right angles to the cross-section. For SAKI modelling, the standard value to extend the model out to is $\pm 20 \mathrm{~km}$. As the region under study has a variable and undefined sub-structure, the models were only extended to $\pm 10 \mathrm{~km}$.

Modelling in 2-D gives a clear indication of the sub-surface structure, however to go that one step further and model in 3-D would be even more indicative of the structure under the region. It is also a good way of confirming the 2-D modelling.

As was to be expected, the 3-D modelling was made easier by having first attempted the 2-D modelling, but because the program was not iterative, it became a very time consuming part of the modelling process. The first stage was to draw up a map of the study area to determine where the various layers from the 2-D models came to the surface. It became obvious early on, that the fault detected from the 2-D modelling ran up or very near the Wharepapa River. The 3-D model constructed from this information detected the fault running further west than that from the 2-D modelling, but within the range of uncertainty the two models agreed well.

The 3-D model consisted of two discrete bodies, as shown in Figure 3.23. The symbols on the gradually deepening layers, correspond with the five values of density contrasts in Table 3.3. The'steepness of the anomaly became the most difficult aspect to model. After much experimentation of extra layers, steepness of the sides of the model and so on, it became obvious that without further help from extra data made available in this region, successful modelling of this area was not possible.

The rest of the area modelled, fitted well enough to be able to say that the study area represents a sedimentary basin, dipping east under Lake Onoke and to the west, a reverse fault 


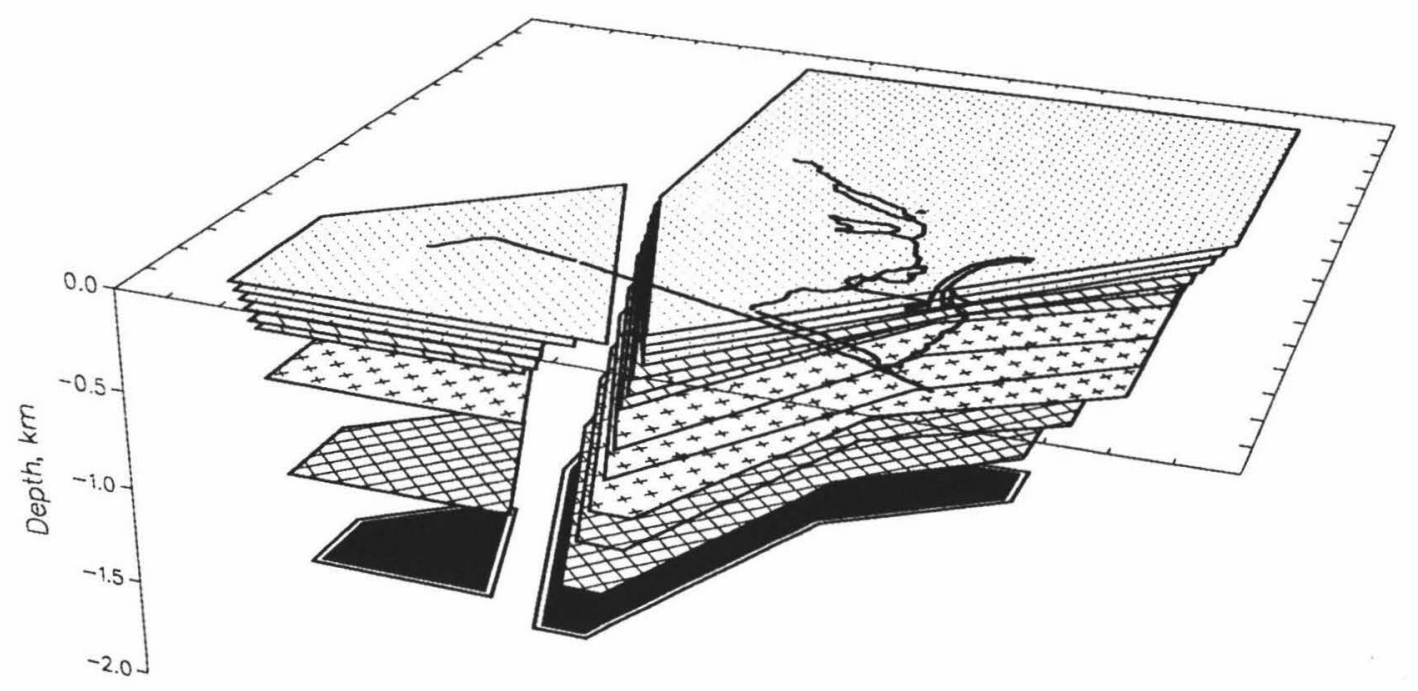

Figure 3.23 3-D gravity model of the study area

sharply dipping further west, with an underlying area of material being forced up to the surface in the region between the Wharekauhau Stream and Wharepapa River. The fit of the 3-D model is shown in the contour plot of the calculated gravity due to this model in Figure 3.24, and the residuals bewteen the observed gravity and the calculated gravity is shown in Figure 3.25 can be compared with those in Figure 3.9.

\section{Summary}

The 2-D modelling described the study region well, giving a believable value for the depth to basement, which was shown to be approximately consistent in value throughout the entire region. The gravity data could only be modelled by a fault in the region of the Wharepapa River channel. The consistency of this interpretation was evident throughout the entire modelling process for all cross-sections and profiles taken over the study area. The fit achieved in the 3-D modelling confirmed the results in the 2-D form. The final model shown in Figure 3.23 gives an 
easily accessible interpretation of the sub-surface of the study area.

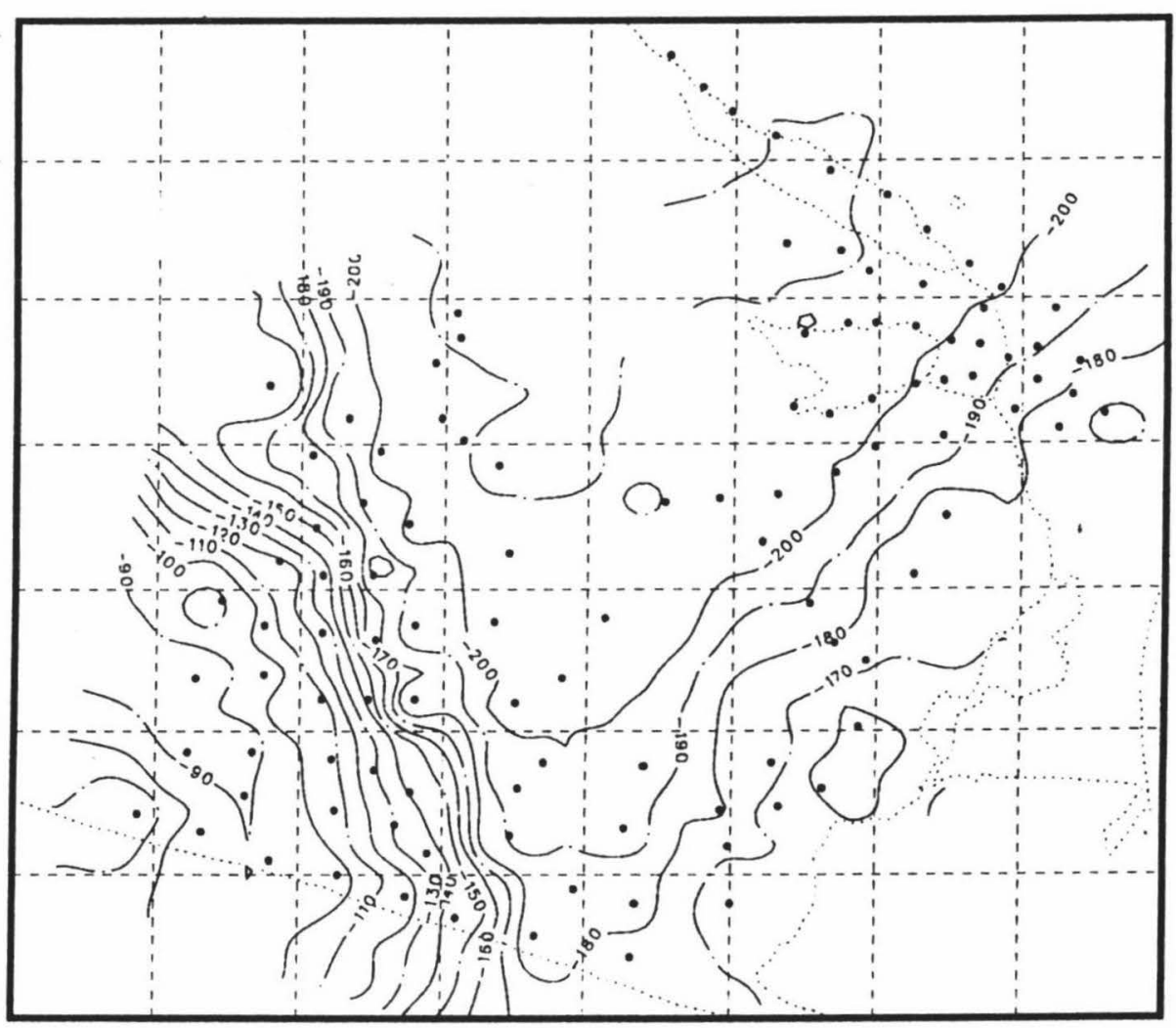

Figure 3.24 Calculated fit of the 3-D model 


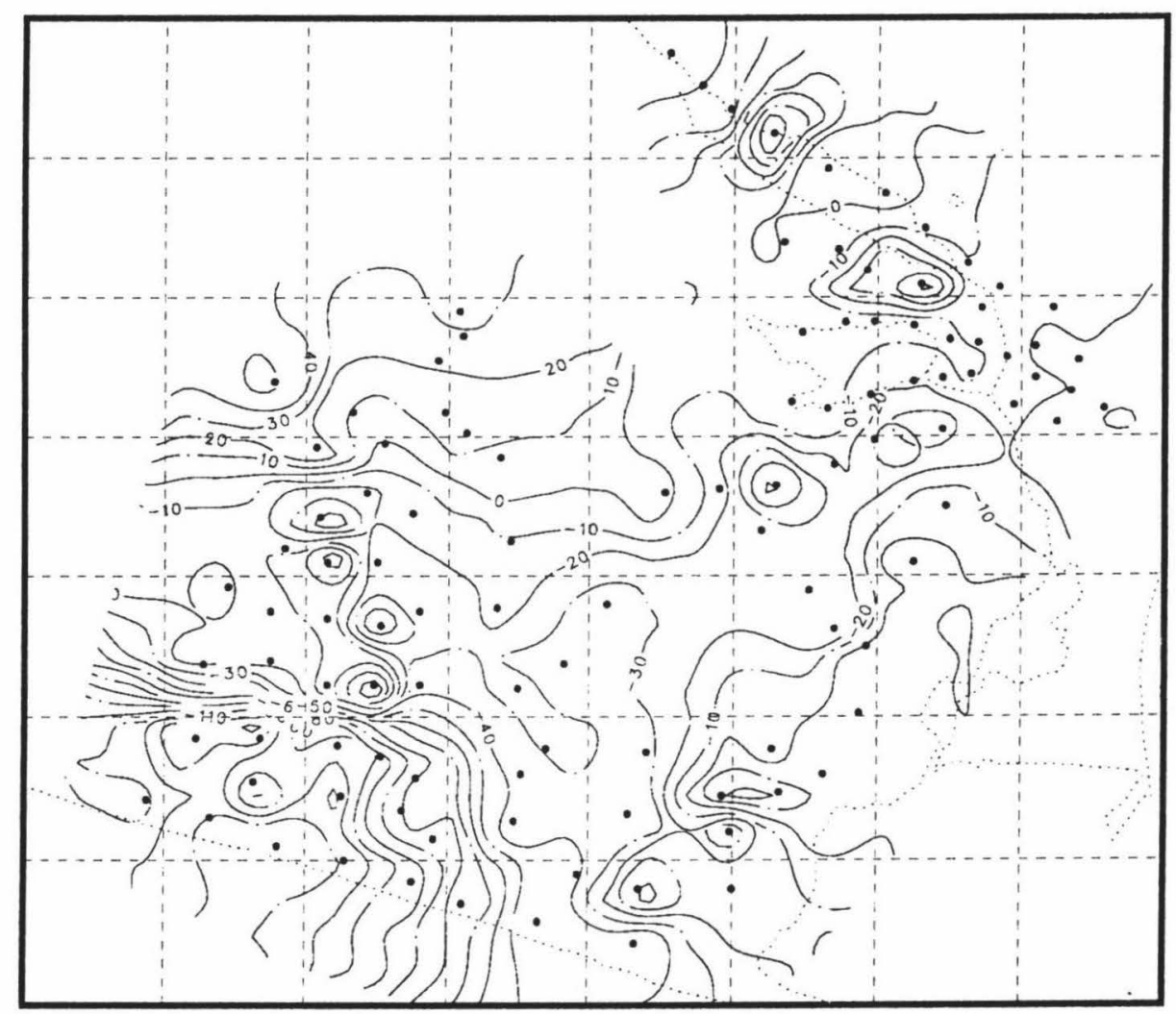

Figure 3.25 Residuals of the calculated and observed values for the 3-D model 


\section{Chapter 4}

\section{Magnetotelluric Survey}

The MT surveys were the second most comprehensive of the three surveys carried out in the study area. This chapter introduces the theory of magnetotellurics and describes the surveying techniques and complex data analysis used to reduce the data collected for this study. Finally modelling is discussed with a conclusive model determined at the close of the chapter. 
"If you torture the data long enough, it will confess." - Ronald Coase

\subsection{Theory of Magnetotellurics}

The magnetotelluric method for determining resistivity is a relatively new geophysical prospecting technique, and its methods and theories are continually being developed. It was introduced by Caignard (1953) following development of the original work done by Schlumberger (Leonardon, 1928). He showed that the ratio of an alternating magnetic field to an alternating electric field measured at the surface of the Earth can show the variation of resistivity with depth within the Earth, when plotted as a function of frequency.

The magnetic field used in magnetotellurics, is the time varying portion of the Earth's magnetic field which induces current flow in the Earth (Keller and Frischknecht, 1966). Induction of electric currents in rocks using a magnetic field, is the general idea of magnetotellurics (MT). By treating the time varying magnetic field as a plane wave, a simple relationship between the magnetic field changes, the voltage gradients induced in the Earth and the Earth resistivity can be shown to exist. In MT surveying, time varying electric and magnetic fields are simultaneously measured at a particular location, over a range of frequencies. The lower frequencies penetrate deeper into the Earth than the higher frequencies, and therefore distinguish resistivity structures at greater depths.

The electric and magnetic fields are measured perpendicular to each other. The fields are most commonly measured in the east-west, north-south and vertical directions. MT measurements cover a wide range of frequencies depending upon the depth of penetration being studied. This comes from the general knowledge that the depth of penetration of a current is inversely proportional to the square root of the frequency of its induction. Audiomagnetotellurics (AMT) uses a specific range of frequencies in the audiofrequency range between $1 \mathrm{~Hz}$ and $20 \mathrm{kHz}$.

The physical theory of MT/AMT begins with the basis of all electro-magnetic theory, Maxwell's equations, since they take the existence of induction currents into consideration,

$$
\begin{gathered}
\nabla \times \mathbf{E}=\frac{-\partial \mathbf{B}}{\partial t} \\
\nabla \times \mathbf{H}=\mathbf{J}+\frac{\partial \mathbf{D}}{\partial t}
\end{gathered}
$$




$$
\begin{aligned}
& \nabla \cdot \mathbf{B}=0 \\
& \nabla \cdot \mathbf{D}=0
\end{aligned}
$$

where $\mathbf{E}$ is the electric field vector, $\mathbf{H}$ is the magnetic field vector, $\mathbf{B}$ is the inductive field vector, $\mathbf{D}$ is the displacement vector and $\mathbf{J}$ is the electric current density.

Defining $\mathbf{D}$ and $\mathbf{J}$ in terms of $\mathbf{E}$ and $\mathbf{H}$, Maxwell's equations become:

$$
\begin{gathered}
\nabla \times \mathbf{E}=-\mu \frac{\partial \mathbf{H}}{\partial t} \\
\nabla \times \mathbf{H}=\sigma \mathbf{E}+\varepsilon \frac{\partial \mathbf{E}}{\partial t} \\
\nabla \cdot \mathbf{H}=0 \\
\nabla \cdot \mathbf{E}=0
\end{gathered}
$$

where $\mathbf{D}$ is the displacement vector and

$$
\mathbf{D}=\varepsilon \mathbf{E},
$$

$\varepsilon$ is the dielectric constant of free space, $\mathrm{J}$ is the electric current density, $\mu$ is the permeability of free space and $\sigma$ is the conductivity of the medium.

Assuming that the physical properties of the medium are isotropic and independent of time, the magnetic field intensity is eliminated from the expressions in Equation 4.5 and Equation 4.6 by taking the curl of Equation 4.5 and differentiating Equation 4.6 with respect to $t$. Multiplying through by $\mu$ the following equations are obtained:

$$
\begin{gathered}
\nabla \times(\nabla \times \mathbf{E})=-\mu \nabla \times \frac{\partial \mathbf{H}}{\partial t} \\
-\mu \sigma \frac{\partial \mathbf{E}}{\partial t}-\varepsilon \mu \frac{\partial^{2} \mathbf{E}}{\partial t^{2}}=-\mu \nabla \times \frac{\partial \mathbf{H}}{\partial t} .
\end{gathered}
$$

Subtracting Equation 4.11 from Equation 4.10, gives,

$$
-\nabla \times \nabla \times \mathbf{E}=\mu \sigma \frac{\partial \mathbf{E}}{\partial t}+\varepsilon \mu \frac{\partial^{2} \mathbf{E}}{\partial t^{2}}
$$

and using the vector identity, 


$$
\nabla \times(\nabla \times \mathbf{E})=-\nabla \cdot(\nabla \cdot \mathbf{E})-\nabla^{2} \mathbf{E}
$$

Equation 4.11 becomes,

$$
\nabla^{2} \mathbf{E}=\sigma \mu \frac{\partial \mathbf{E}}{\partial t}+\varepsilon \mu \frac{\partial^{2} \mathbf{E}}{\partial t^{2}}
$$

Typical values of $\sigma$ within the Earth are $10^{-5}$ to $10^{-1} \mathrm{Sm}^{-1}$ and of $\varepsilon$ are approximately $9 \times \varepsilon_{0}$, where $\varepsilon_{0}$ is the permittivity of free space $=8.85 \times 10^{-12} \mathrm{Fm}^{-1}$. For the periods of magnetic field variations involved in both AMT and MT work, $\mathrm{T} \geq 0.01 \mathrm{~s}$ so,

$$
\left|\sigma \frac{\partial \mathbf{E}}{\partial t}\right| \gg\left|\varepsilon \frac{\partial^{2} \mathbf{E}}{\partial t^{2}}\right|
$$

and therefore Equation 4.14 becomes,

$$
\nabla^{2} \mathbf{E}=\mu \sigma \frac{\partial \mathbf{E}}{\partial t}
$$

Equation 4.16 is the diffusion equation, so in MT work we are dealing with a problem of diffusion of the incident field into the Earth. The extension to a non-uniform resistivity modifies this equation, but the basic result that a time-varying field diffuses into the Earth remains the same. The mathematical theory of MT is rigorously treated in Keller (1966). In finding solutions for Equation 4.6 he considers the general solution,

$$
E_{x}=A e^{i \omega t+\gamma z}+B e^{i \omega t-\gamma z}
$$

where $\gamma$ is the wave number and

$$
\gamma= \pm\left[i \omega \frac{\mu}{\rho}\right]^{\frac{1}{2}}
$$

This electric field will cause current flow in a conductive medium, which will in turn generate a time variant horizontal component of the magnetic field,

$$
H_{y}=-\frac{\gamma}{i \mu \omega}\left[A e^{i \omega t+\gamma z}-B e^{i \omega t-\gamma z}\right]
$$

A vertical component is also generated, but it is the ratio of the horizontal magnetic and electric fields, which is used in MT. This ratio is defined to be the wave impedance of the medium. 
Taking the ratio of Equation 4.17 and Equation 4.19, the wave impedance is,

$$
Z=\frac{E_{x}}{H_{y}}=\frac{-i \mu \omega}{\gamma} \frac{A e^{\gamma z}+B e^{-\gamma z}}{A e^{\gamma z}-B e^{-\gamma z}},
$$

where $A$ and $B$ are arbitrary constants. It is possible to further simplify $Z$, but at this point it is more important to consider how impedance is used to represent MT data.

The conversion of frequency, $f$, to the depth of penetration $\delta$ for resistivity $\rho$, is based on the skin-depth relation,

$$
\delta=\sqrt{\frac{2 \rho}{\omega \mu}} .
$$

MT data is generally presented as a graph of apparent resistivity $\rho_{a}$ versus phase, $\phi$. In terms of the impedance,

$$
\rho_{a}=\frac{1}{\mu_{0} \omega}|Z|^{2}
$$

and

$$
\phi=\tan ^{-1} \frac{\operatorname{Im}(Z)}{\operatorname{Re}(Z)}
$$

where $\operatorname{Im}(Z)$ and $\operatorname{Re}(Z)$ are the imaginary and real parts of $Z$, respectively. The maximum and minimum $\rho_{a}$ and $\phi$ are calculated for all $\omega$ or T. In the case of non-uniform resistivity $E_{x}$ is not related solely to $H_{y}$, but also to $H_{x}$. Thus rather than a single impedance $\mathbf{Z}$ in general, an impedance tensor is found which relates the vector electric field $\mathbf{E}$ to the vector magnetic field $\mathbf{H}$,

$$
\mathbf{E}=\mathbf{Z H}
$$

The analysis and modelling of the MT data will be discussed in the appropriate sections, rather than generally at this stage. There are numerous different techniques for analysis, so only those pertinent to this study shall be considered.

\subsection{Fieldwork}

A total of eight MT sites were set up over three separate time periods. Two sites were located in the region of Lake Pounui, PN1 and PN2, whilst the remaining six, WKH1, WKH2, WKH3, WPP1, WPP2 and WPP3 were situated, three each side of the Wharepapa River. The 
Wharepapa sites were chosen so as to from a near perpendicular line across the stream down which a branch of the Wairarapa fault has been mapped. Any electrical structure associated with a fault should become obvious as a marked contrast between the data gathered from the two opposite sides of the stream. The two Pounui sites were made to compare the structure of the southern part of the study area with the region near Lake Pounui, where a large proportion of the gravity stations were sited.

Table 4.1 gives the grid references for each of the eight MT sites, which are shown in Figure 4.1. It was not possible to use data from all eight sites for the following reasons. At PN1 and WPP1, there was a large amount contamination from mains and electric fences present. This made data unusable even after additional digital notch filtering. At WKH1 there was considerable distortion of the signal due to the cables acting as aerials, which again made the data from this site unusable. The other major problem with the data from some of the sites was a very low signal to noise ratio in part of the frequency range.

Table 4.1 Grid co-ordinates for the MT sites

\begin{tabular}{||c|c|c||}
\hline Station name & Easting position & Northing position \\
\hline & & \\
WKH1 & 2682750 & 5980750 \\
WKH2 & 2683476 & 5980225 \\
WKH3 & 2683774 & 5979899 \\
WPP1 & 2684299 & 5979574 \\
WPP2 & 2684524 & 5979625 \\
WPP3 & 2688449 & 5979170 \\
PN1 & 2687699 & 5982750 \\
PN2 & 2687899 & 5982562 \\
\hline
\end{tabular}

The fieldwork for the MT work involved some complications in the fact that it was carried out in farmland. Fifty hertz frequencies generated by mains supplies and pulses caused by electric fences, are always hazards that one has to deal with when surveying in farmland. For most of the time, it was possible to turn the fences off in the near surrounding area, and later data analysis removed a fair amount of $50 \mathrm{~Hz}$ noise. Wind was another factor which could cause problems, but it is hard to estimate how serious this was. When laying out the MT spread, it is essential to get correct N-S, E-W orientation of the electrodes and N-S orientation of the electrodes. In windy conditions the coils can be buffeted, which means that true $\mathrm{H}$ and $\mathrm{D}$ field 


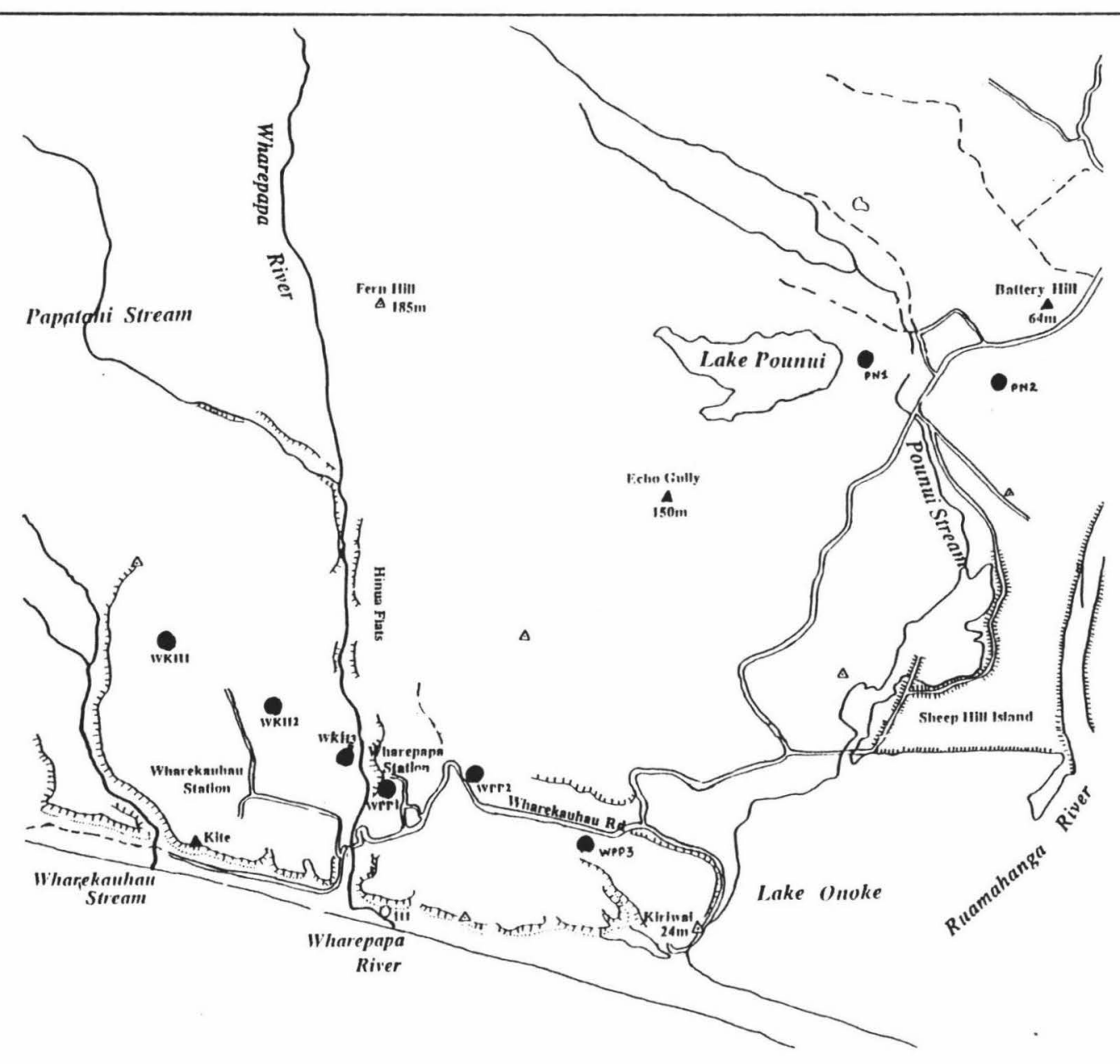

Figure 4.1 Locality of MT sites in study area

components are not being measured. However the noise associated with this problem will be lesser than that introduced by electric fences and mains supplies.

Only frequencies between 500 and $0.1 \mathrm{~Hz}$ were ever recorded at any of the MT sites in this study, as we were not interested in the depths to which lower frequencies might penetrate. The depth to basement, which was one point of the investigation, could be estimated at $2 \mathrm{~km}$ maximum. 


\subsection{Instrumentation}

The magnetotelluric system used for the field work was built by E. Broughton at Victoria University of Wellington. This system (as is the case for all magnetotelluric systems) is continually being modified and developed further as demanded by changing requirements, for example greater resolution at various depths and easier portability.

In 1987 new high frequency AMT equipment was developed, and it was partly tested by Ellis (1987). This equipment has since been modified to record signals in a frequency range of $500 \mathrm{~Hz}$ to $0.01 \mathrm{~Hz}$ and taking into account some of the improvements suggested by Ellis, such as;

(i) a system of direct transferal from FM tape to digitiser has been found,

(ii) a battery powered multimeter is now used in the field to examine the AMT signals,

(iii) notch filter adjustment controls have been made more accessible and components are now temperature independent.

This system used in Ellis's project was the basis of that used in this study.

Figure 4.2 shows a block diagram of the field setup for the MT equipment used in both high and low frequency recording, allowing for the fact that the induction coils used in the high frequency work were replaced at some sites by fluxgate magnetometers for the low frequency recordings.

The preamplifier aside, all electronic parts of the system were operated from the back of the Land Rover (which provided transport to and any additional power needed at the sites). All necessary power was supplied by $12 \mathrm{~V}$ batteries.

The equipment used to make recordings at the two Pounui sites was slightly different to that used for the later work. The differences shall be discussed in the individual equipment descriptions below.

\section{Schonstedt Fluxgate Magnetometers}

The fluxgate magnetometers were only used for the low frequency recordings at the Pounui sites. Two fluxgate magnetometers are aligned orthogonally in a single box, which is then aligned to magnetic north by rotating. The alignment is correct when there is no eastward field component. This is far more accurate than simply using a magnetic compass. The operation of the fluxgate is outlined in Ellis (1987). 


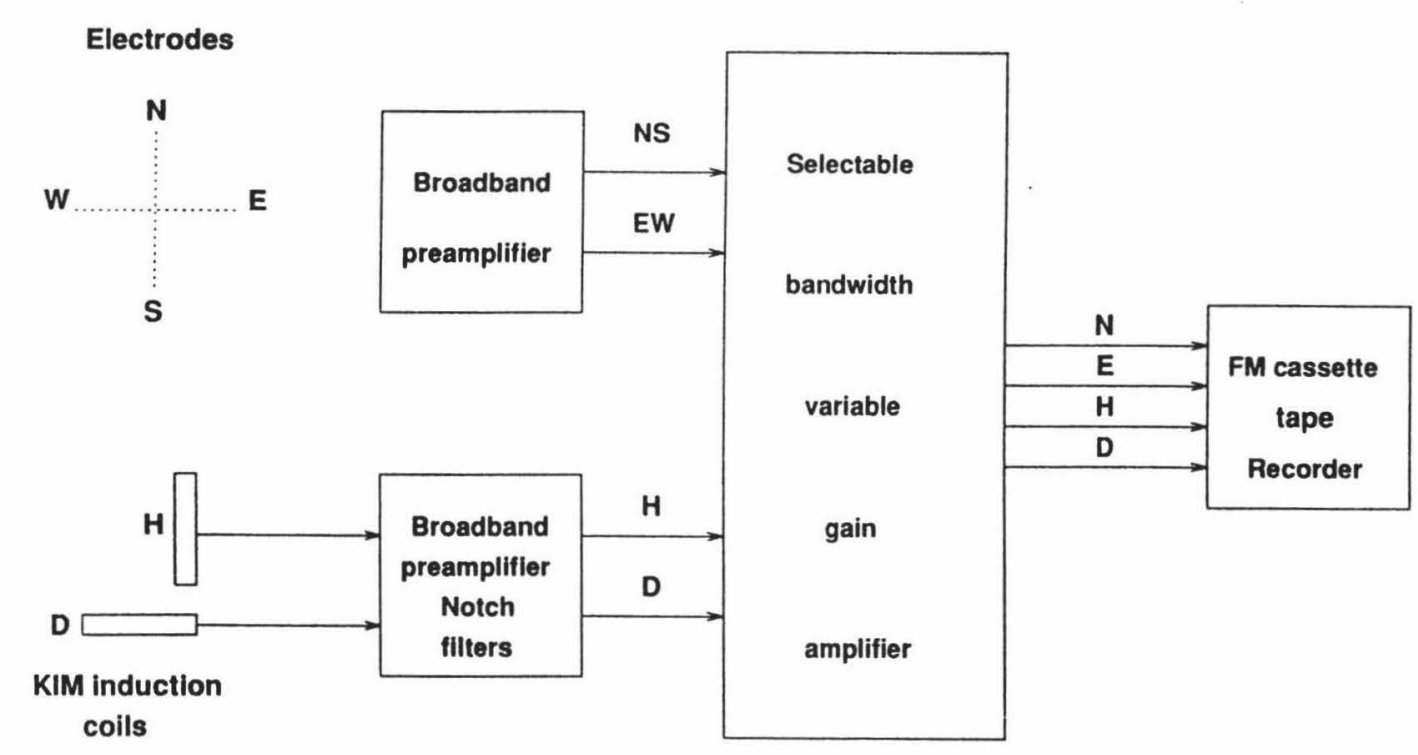

Figure 4.2 Block diagram of the MT field set-up used in this study

\section{Induction Coils}

The fluxgate magnetometer can not be used in high frequency work because its response at high frequencies is much less sensitive than at low frequencies. To counter this, more sensitive instruments must be used, thus two induction coils replaced the magnetometers for the recording of the higher frequencies at PN1 and PN2. The induction coils used for the WKH and WPP sites were new, with the advantage over the old ones used at Pounui, being that they covered the whole frequency range. Therefore induction coils were used for the recordings at all six WKH and WPP sites.

The induction coils were in long plastic cylinders which were orientated to magnetic North and East. Both coils were assumed to be identical for all practical purposes.

\section{Preamplifier}

The preamplifier part of the MT system buffers the signals. Modifications were made to the preamplifier between the two different main time periods of recording. The telluric and induction coil amplifiers had no notch filters in the old system, however there are four different ones on the modified version which can filter out most of the $16 \frac{2}{3}, 50,150$ or $250 \mathrm{~Hz}$ signals. The equipment 
also has chopper capabilities, which have the effect of reducing internal noise at the amplification stage and converting the low frequency signal $(<30 \mathrm{~Hz})$ from $\mathrm{DC}$ to $\mathrm{AC}$, so filtering is possible (Reeves, 1991).

\section{Amplifier}

The telluric and magnetic signals are passed from the preamplifier to the main amplification system. The system consisted of four amplifiers which covered a range of four bands. The overall bandwidth was $1 \mathrm{kHz}$ to $0.01 \mathrm{~Hz}$. With band 1 recording $1 \mathrm{kHz}$ to $10 \mathrm{~Hz}$, band 2, 100 $1 \mathrm{~Hz}$, band 3,10 to $0.1 \mathrm{~Hz}$ and band 4,1 to $.01 \mathrm{~Hz}$. The old system used at Pounui did not catergorise the range of frequencies into bands 1 to 4 , but used wide band $(500-3 \mathrm{~Hz})$, narrow band $(100-3 \mathrm{~Hz})$ and low frequency $(0.5 \mathrm{~Hz}$ and below).

The notch filters on the amplifiers were used, but rather unsuccessfully, to cut out the noise due to the $50 \mathrm{~Hz}$ signal from the mains near the sites. As a rule, notch filters were turned on for the recording of bands 1 and 2 data, and only the variable gain amplifier notch filters were switched on for band 3. Although the notch filters are designed to filter out most of the $50 \mathrm{~Hz}$ noise from the main supply, one of the major problems lies in the fact that mains frequency is not constant at $50 \mathrm{~Hz}$, but varies between 47.5 and $52.5 \mathrm{~Hz}$. Therefore the filters 'miss' the variation of frequency either side of $50 \mathrm{~Hz}$, which contributes to contamination of the data.

\section{Electrodes - steel and copper sulphate}

For the 1-10 second period range, the natural signal is low, so copper sulphate electrodes are preferable to steel. However the choice of copper sulphate over steel electrodes is more importantly to avoid polarisation effects at the electrodes. The copper sulphate electrodes were used to reduce noise for low frequency recording and to increase electrical contact with the ground. The steel electrodes were only used for the recording of the lower period data at PN1.

Four electrodes were formed into a cross configuration with a electrode at each apex, measuring the north-south and cast-west electric fields. A distance of approximately $50 \mathrm{~m}$ separated the electrode pairs. See Figure 4.1 for electrode configuration. 


\section{FM Recorder}

Once the telluric and magnetic signals had been amplified and filtered, they were passed to the FM recorder. The recorder used was a TEAC R-61 cassette data recorder, the data being stored by the recorder onto 45 minute TEAC heavy duty instrumentation tape. The R-61 records and plays back tape at a constant speed of $4.76 \mathrm{~cm} / \mathrm{s}$.

\subsection{Data Analysis}

Similarly to gravity, MT data requires several different stages of analysis. Each separate stage will be discussed, including details of the computer programs used to interpret the data. The mathematical and physical concepts surrounding MT work are very complex. Equations and some techniques are standard and so will only be dealt with briefly. However, any non-standard techniques shall be discussed more fully. Unless stated the programs used in the first stages of analysis were written by Dr M. Ingham of VUW. No MT data could be analysed on site during surveys with the equipment used. This was a drawback as shown by the lack of signal power at some sites. Further data could have been recorded at these particular sites with the required modifications, if partial analysis could have been done on site.

The first step was to digitise the data from the magnetic tapes used for recording in the field. The analogue to digital converter is controlled by a program MTAUTO which stores sections of digitised data from a length of tape varying according to which frequency band is being converted. These specifications are standard and are set out in Table 4.2 for bands 1,2 and 3. For all bands each section is digitised into 1801 points.

Table 4.2 Digitising Specifications for Bands 1, 2 and 3

\begin{tabular}{||l|l|l|l||}
\hline Frequency Band & Channel(Hz) & Overall rate(Hz) & Section length(s) \\
\hline 1 & 3000 & 12000 & 0.6 \\
2 & 300 & 1200 & 6 \\
3 & 30 & 120 & 60 \\
\hline
\end{tabular}

Less events are obtained from band 3 and higher. If after subsequent analysis, more events are required, a certain number may be obtained by re-digitising from a different starting point. This is possible because data sections overlapping up to $50 \%$ have basically different power spectra. The components $\mathrm{H}, \mathrm{D}, \mathrm{N}$ and $\mathrm{E}$ being digitised have a time lag between each one 
varying in length between $1 / 12000$ s for band 1 to $1 / 120$ s for band 3 , because they are not converted simultaneously due to multiplexing. This phase difference in the components is accounted for and corrected in a subsequent program.

Following digitisation, each event is examined on computer using DADISP, a graphical spreadsheet package. This ensures that every event is vetted for extraneous noise or other irregularities which may may not be discarded by subsequent analysis programs, thus yielding erroneous results. These programs have inherent selection criteria to discard data of inferior quality, but manual checking is still advisable, due to data spikes (see later on in this section). This stage was particularly important for all the MT data collected in this study, which was plagued by spikes due to electric fences, rendering a large proportion of the data useless. Selection using DADISP often had to waive some poorer quality data to ensure there were enough events for analysis.

A minimum of 30 events is desirable for analysis, although eventually the quality of the data dictates the final number. For the majority of bands at all sites, at least 40 to 50 events could be selected.

The following notes of the operation of the programs AMT2 and AMTAV were outlined by Ingham (pers. comm.), and used by Reeves (1991).

The group of events selected is then used for the next stage of analysis which applies amplification factors, filters to the data, spectrally analyses each component and calculates an estimate of the impedance tensor $\mathbf{Z}$ at each frequency. These operations are carried out by the program $A M T 2$ which works in the following manner.

(1) A linear least squares line is subtracted from the data to remove any underlying long period trend in each component.

(2) To reduce power leakage into the side lobes of the FFT, a cosine bell is applied to the first and last $10 \%$ of the data points of each component.

(3) A fast Fourier transform (FFT) is performed on each component. Before this can be done, the FFT algorithm requires data must have a series of zeroes added to bring the total number of data points to $2^{m}$.

(4) Each component is calibrated for the amplifier and preamplifier responses. Phase corrections, due to multiplexing at the digitisation stage is also applied. 
(5) All components are rotated into geographic co-ordinates.

(6) Auto and cross-power spectral estimates of the components are calculated and averaged over four adjoining band estimates.

(7) The spectral estimates are then used to calculate the following four parameters.

(i) Upward and downward biased impedance tensors estimating $Z_{x x}, Z_{x y}, Z_{y y}$ and $Z_{y x}$ for each frequency (discussed later in this chapter). (ii) Signal to noise ratio for each estimate. (iii) A ratio indicating where the phase estimate is within an allowable range. (iv) Ratio of the predicted coherency between the measured $\mathrm{N}$ and $\mathrm{E}$ field with $\mathrm{N}$ and $\mathrm{E}$ calculated from the impedance tensor, and the measured $\mathrm{H}$ and $\mathrm{D}$ fields.

When the data has been enhanced by the proceeding features with irregularities and distortions had been removed, the output from $A M T 2$ was complete and ready to be run through the next program $A M T A V$. This program takes multiple estimates of $\mathbf{Z}$ and averages them to get $\mathbf{Z}$ as a function of period and calculates apparent resistivities, phases, azimuthal directions, dimensionality indices and skew. Although poor quality data has been discarded by this stage each event had to go through a further selection process to choose whether it should be used in the final averaging. Events not strictly following these guidelines are rejected. The three criteria for selection are:

(1) The predicted coherency for the estimate must be $\geq 0.8$.

(2) The estimate of the phase of the off diagonal impedance tensor elements must be within physically realistic limits.

(3) A signal to noise ratio must be greater than the minimum acceptable level. This had to be set low to allow sufficient data in some of the bands for several of the sites.

The events which pass these criteria are averaged over a range in period between $0.00115 \mathrm{~s}$ and $8.659645 \mathrm{~s}$, giving eight values per decade of frequency. In the original visual inspection of the data using DADISP, narrow sharp spikes of data were found on many events. This was caused by $50 \mathrm{~Hz}$ contamination and overscale readings. Events with a small amount of this spiking were selected although if it occurred in more than $10 \%$ of the data, the particular event was discarded. The reason some of this data could be used was due to an averaging algorithm in AMTAV which progressively downweights estimates which are far from the average. This prevents distortion resulting from these outliers, so can be considered analogous to robust spectral analysis (Ingham, 
pers.comm), which calculates an average estimate based on a distribution of estimates rather than a simple least-squares average.

The averaged values of the impedance tensor were then used by AMTAV to calculate the following parameters:

(1) Maximum and minimum apparent resistivities and phases. $\mathrm{E}$ and $\mathrm{H}$ polarisations are defined from an initial input of strike direction into the program.

(2) The azimuth corresponding to the maximum apparent resistivity.

(3) Skew and dimensionality indices of Kao and Orr (1982), which give an indication of the complexity of the structure under study. The skew should be approximately zero in a 1-D case, making allowances for some noise.

(4) Apparent resistivity and phase calculated from the determinant impedance defined by Ranganayaki (1984).

(5) A simple 1-D inversion of the determinant apparent resistivity and phase, developed by Bostick (1977).

These parameters as output from $A M T A V$ are displayed in Appendix D.

\section{Subsequent Analysis of AMTAV Output}

For each site, AMTAV output downward and upward biased results for bands 1,2 and 3 . Usually only one of the upward or downward biases are used. In the presence of coherent noise in the telluric field upward biased estimates give an over-estimation of the tensor elements. In the presence of coherent noise in the magnetic field the reverse is true for downward biased estimates. The true value of the tensor elements should lie between these two estimates. To explain how AMTAV achieves the two different biasings consider the following. N, E, H and D are defined using the respective electric and magnetic components measured in the field, in terms of the admittance tensor $\left(Z^{-1}\right)$ by,

$$
\begin{aligned}
& N=Z_{x x} H+Z_{x y} D \\
& E=Z_{y x} H+Z_{y y} D
\end{aligned}
$$




$$
\begin{aligned}
& H=A_{x x} N+A_{x y} E \\
& D=A_{y x} N+A_{y y} E .
\end{aligned}
$$

A is defined by,

$$
H=\mathbf{A} E
$$

and therefore

$$
\mathbf{A}=\mathbf{Z}^{-1}
$$

The downward bias estimates are based upon $Z_{i j}=\frac{E_{i}}{H_{j}}$, so there are four separate expressions for the impedance tensor. The expansion of one of these in terms of the average cross power spectra is:

$$
Z_{x y}=\frac{\left\langle N D^{*}><H H^{*}>-<N H^{*}><H D^{*}\right\rangle}{<H H^{*}><D D^{*}>-<H D^{*}><D H^{*}>}
$$

where * represents a complex conjugate of the value. If coherent noise exists in the magnetic components, the denominator in Equation 4.30 becomes larger than the numerator which results in the value of all $Z_{i j}$ being underestimated.

For the case of upward biasing, the estimates of $\mathbf{A}$ are calculated initially from Equations 4.26 $\mathrm{A}$ is calculated from the inverse of the impedance tensor and 4.27. $\mathrm{Z}$ is then calculated from the inverse of the admittance tensor. The corresponding expression to $Z_{x y}, A_{x y}$ is defined by,

$$
A_{x y}=\frac{\left\langle N N^{*}><H E^{*}>-<N E^{*}><H N^{*}\right\rangle}{\left.\left.\left\langle N N^{*}\right\rangle<E E^{*}>-<N E^{*}\right\rangle<E N^{*}\right\rangle} .
$$

When the electric components are plagued by noise, $A_{x y}$ is underestimated and the elements of $\mathbf{Z}$, being the inverse tensor, are overestimated. From this argument it is obvious the bias estimates will be equal when there is no coherent noise present. This seldom occurs especially in built up areas where $50 \mathrm{~Hz}$ frequencies plague both the electric and magnetic components.

Some of the data from this study presented a good example of a large difference between the two bias estimates. Noise can be non-random, random or coherent and affect the results differently. For the all the MT data, the noise is generally coherent rather than random, and so true values of the impedance tensor lie between the two sets of estimates. 
The data was such that the best estimates and those with the most power in the $\mathrm{E}$ and $\mathrm{H}$ polarisation values were chosen for the modelling. On the whole it was apparent that much of the mains interference was entering the system through the telluric field and the downward biased values were therefore chosen as the more reliable estimate to the true data values. Even so, in reality the true values probably lie somewhere between the upward and downward estimates.

A range of 28 periods varying from $0.00205 \mathrm{~s}$ to $8.659645 \mathrm{~s}$ were used. AMTAV also calculated values for periods of $0.00115 \mathrm{~s}$ and $0.00154 \mathrm{~s}$, but these were outside the normal range of the tape recorder and were discarded. The overlap between the three bands ensures a better estimate of the values at the overlapping frequencies.

When the eight sites had been finally analysed, it became obvious that the data at WPP1 was too contaminated by $50 \mathrm{~Hz}$ to be of further use. The data at WKH1 and WKH3 both lacked power and were essentially in the same situation as WKH2. Therefore to save repetition of results, only WKH2 was used for modelling to represent this particular region.

\section{Presentation of Results Prior to Modelling}

Results were presented in the form of two plots per MT site. One plot was of $\log _{10}$ of both $\mathrm{E}$ and $\mathrm{H}$ polarisation apparent resistivity against $\log _{10} T$. E and $\mathrm{H}$-polarisation refer to orientations of the impedance tensor in which its principal axes are parallel and perpendicular to the strike of the structure under investigation. After calculation of $\mathbf{Z}$ in the measurement axes, the tensor was mathematically rotated into the $\mathrm{E}$ and $\mathrm{H}$-polarisation directions. These plots are presented in Figures 4.3 to 4.6 for the four sites used in the modelling.

The effective depth of penetration into a conductor is given by the skin depth $\delta$, as shown in Equation 4.21. This application is only applicable to uniform conductors, but is also used to visualise what happens when $\rho$ varies with depth. Therefore, the plots of $\log _{10} \rho_{a}$ vs $\log _{10} T$ give some indication of the approximate variation of resistivity with depth. From these initial results, it seems probable that the structure under the sites WPP2, WPP3 and WKH2 is of a resistor/conductor/resistor and under Pounui is of a conductor/resistor/conductor.

\subsection{Modelling}

AMTAV gives values for a simple and approximate 1-D inversion model (Bostick, 1977), as previously discussed, but thesc results were not used at all in the modelling. Instead the 

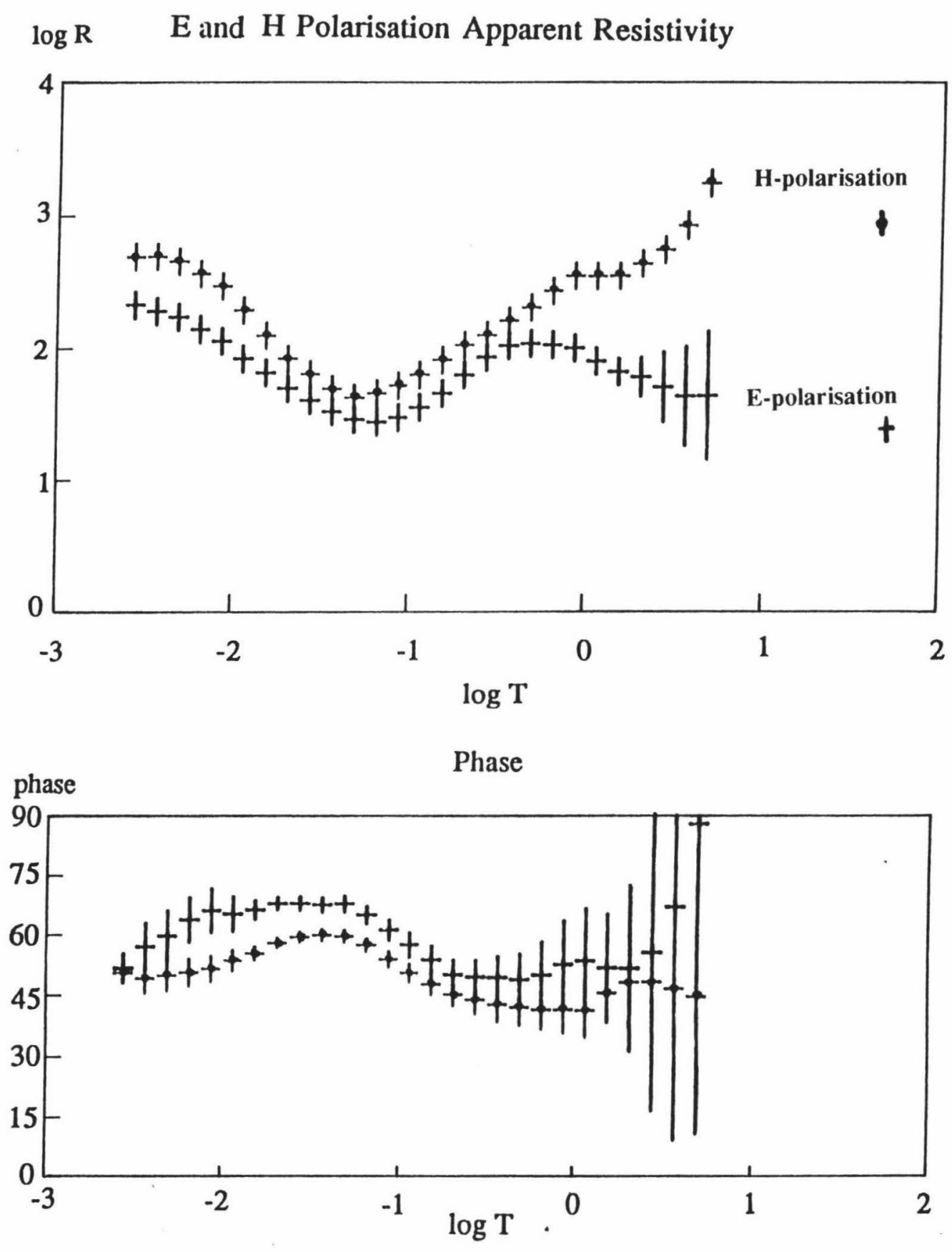

Figure 4.3 Plots of period vs apparent resistivity and phase at WKH2 


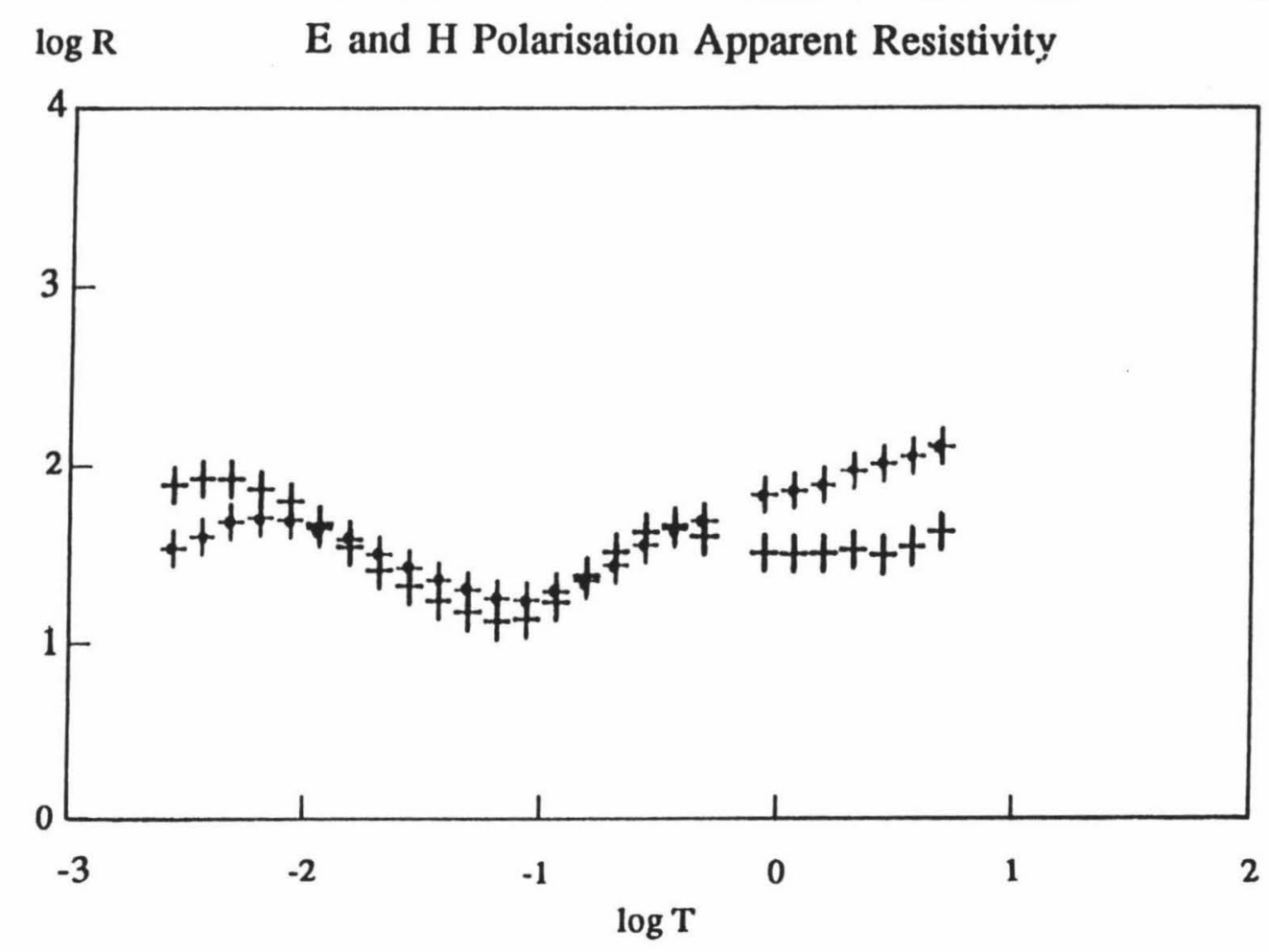

Phase

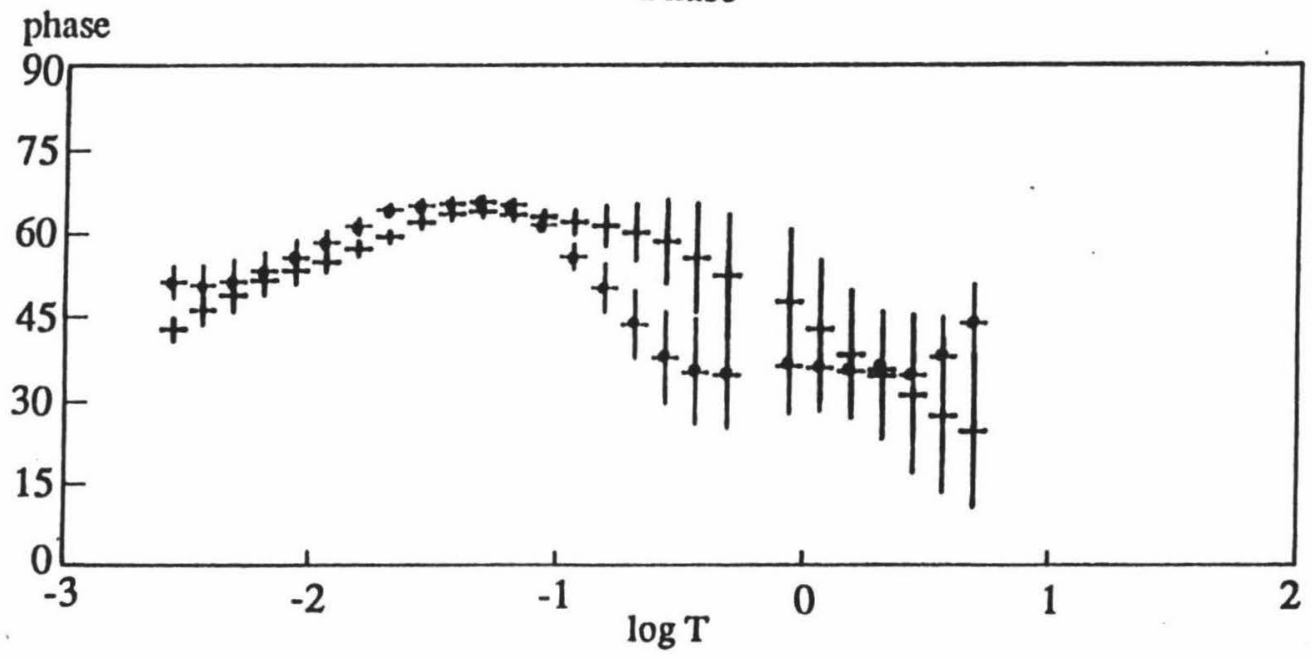

Figure 4.4 Plots of period vs apparent resistivity and phase at WPP2 

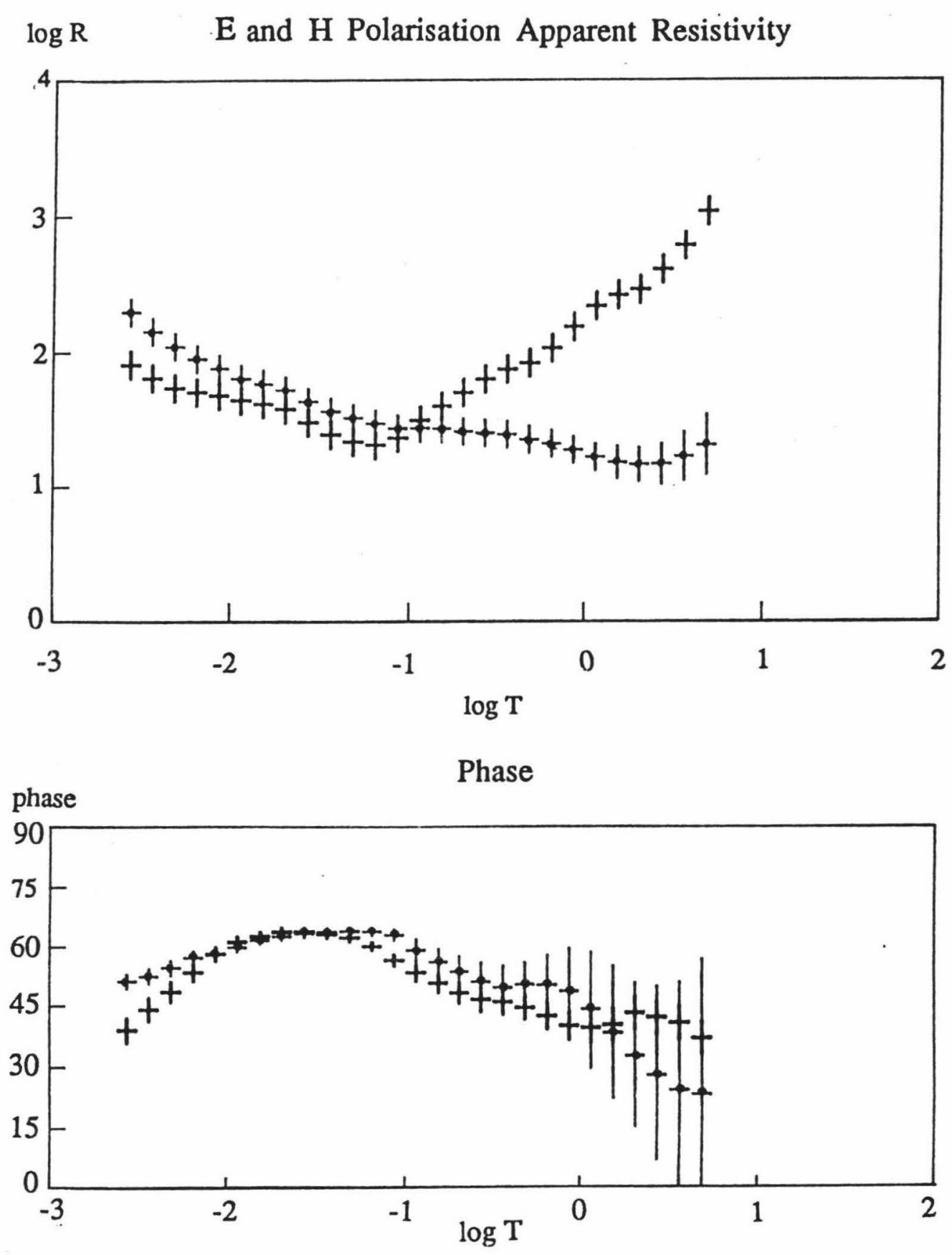

Figure 4.5 Plots of period vs apparent resistivity and phase at WPP3 


\section{$\log \mathrm{R} \quad \mathrm{E}$ and H Polarisation Apparent Resistivity}

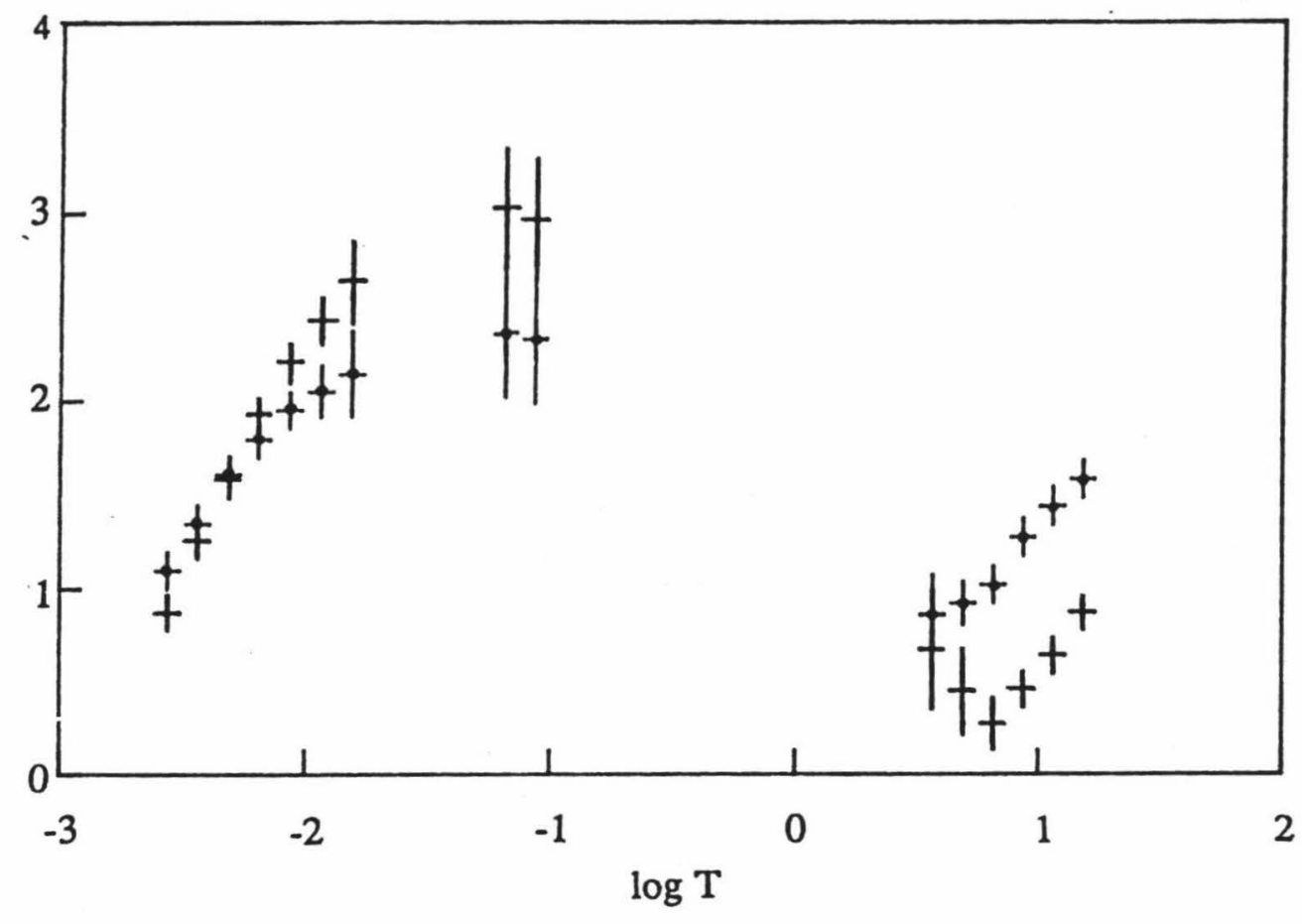

Phase

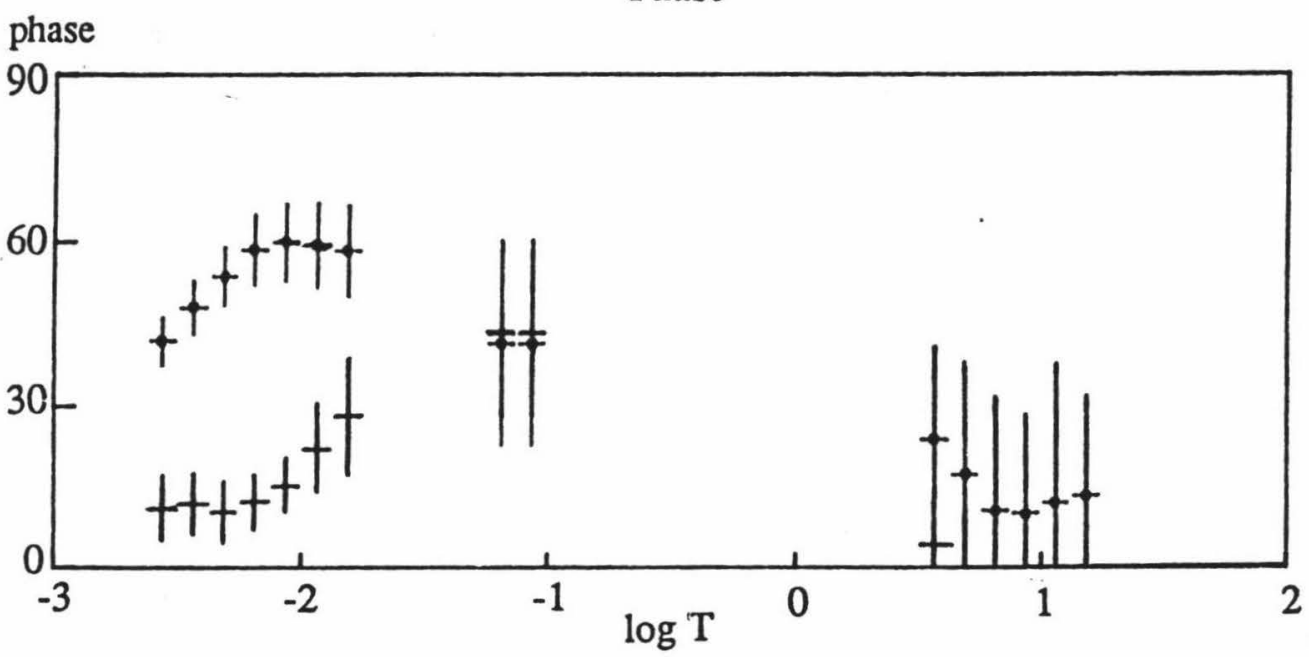

Figure 4.6 Plots of period vs apparent resistivity and phase at PN2

determinant apparent resistivity and phase (Ranganayaki, 1984) output were used for 1-D interpretation. The determinant apparent resistivity and phase are calculated from the impedance defined by, 


$$
Z_{\text {det }}=\sqrt{Z_{x x} Z_{y y}-Z_{x y} Z_{y x}}
$$

This parameter has the property that it does not depend on the orientation of the measuring axes, and can therefore be thought of as sensitive primarily to 1-D structure. With quality data available only from a limited number of sites, it was not possible to attempt anything beyond 1-D modelling for each individual site. Only for 1-D conductivity structures do analytical solutions to the problem of electromagnetic induction exist.

The process of MT data analysis (after the stages discussed in the previous section) was achieved in two separate stages. The first stage of modelling was carried out using a program called $P R I D P C$ which is specifically for modelling 1-D data. This program models the data by the method described by Fischer and Le Quang (1981) and Fischer et al. (1980). Values of apparent resistivity, phase and period are input into the program and the user interactively chooses a starting model specifying the number of layers and the depth and restivity of each layer. The program searches the parameter space of models and eventually, after many iterations, outputs a model (with the same number of layers as the initial model) and gives a value for $\varepsilon$, the indicator of the degree of fit between the field measurements and the calculated model response (Fischer and Le Quang, 1981).

The fit of this final model is shown on a plot of $\log _{10} \rho_{a}$ vs $\log _{10} T$, so the user can interactively get a feel for how the model needs to be altered to achieve the best fit. It was found that models with only three or four layers at the maximum, were better to use as starting models, rather than trying to use complex models to model every turn in the data.

MT modelling seeks to minimise the difference between the observed response function and a theoretical model response function (Fischer and Schnegg, 1980). The modelling process is non-unique and although $P R I D P C$ gives a single model which fits the data, it is necessary to investigate how much this model can be varied without substantially altering the goodness-of-fit. This is achieved using the Monte-Carlo inversion program, MONTYC. The final models from PRIDPC were used as the starting models. These starting models with values of depth $h$ and resistivity $\rho$ are used to generate a series of random models, with resistivity values,

$$
\rho=\rho_{i} \times 10^{n}
$$

and depth 


$$
h=h_{i} \times 2^{n}
$$

where $\rho_{i}$ and $h_{i}$ are the values for each layer of the initial model and $n$ is a random number. A specific number of iterations, usually chosen to be greater than 10,000 , are performed to randomly generate models and whenever a model giving an improved fit is found it is then used as the initial model to generate further models. This process was continued until the range of models satisfying the data was clearly defined. The goodness-of-fit is output, as are the best twenty models for the data. Like most data derived from nature, no one model can be categorically described as fitting the data perfectly. MONTYC thus gives a good estimate of the range of uncertainty and how well the data constrains the model.

The best model from the twenty models for each site was chosen as the final representation of the structure beneath and surrounding the site, as shown in Figure 4.11. Figures 4.7 to 4.10 show the best twenty models for the data. The fit of the final models is shown on the plots of invariant phase and apparent resistivity in Figures 4.12 to 4.19.

One problem with modelling apparent resistivity data is that it can be affected by static shift, which means that it does not give an accurate evaluation of the conductivity structure. This problem occurs because small inhomogeneities in conductivity between the electrodes in the field, cause distortions in the electric field, the result of which is that the apparent resistivity curve is shifted up or down. While the overall shape of the curve is consistent, this shift results in depth and resistivity inaccuracies. However, the fact that the near surface resistivity structure at the sites was so similar, suggests that static shift was not a problem in this study.

Even in the presence of static shift one way to get a qualitative indication of the structure is to take pseudosections of determinant phase across a number of MT sites. These are a plot of the determinant phase against the log of the period at the various sites. The reason for this being that the impedance phase is not affected by static shift. Although static shift did not appear to be a problem, a pseudo-section of the three sites across the Wharepapa River is shown in Figure 4.20, to give a tentative glance at the structure in the study region. PN2 could not be used in a pseudosection, as there were no other sites with data available in the area. At least three sites are needed for a meaningful pseudo-section. The uniformity of the pseudosection is a good indication that the structure is relatively uniform beneath the three sites WKH2, WPP2 and WPP3. 


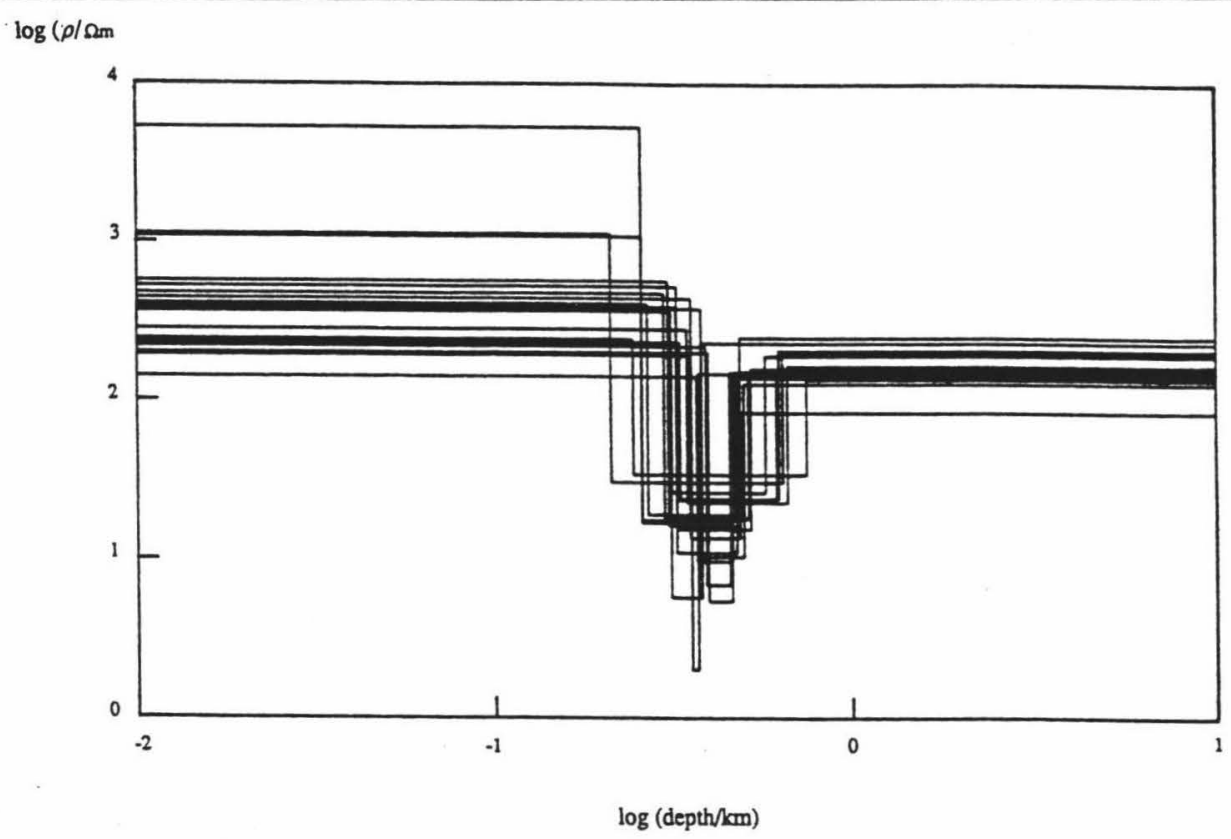

Figure 4.7 Best 20 Monte-Carlo models for WKH2

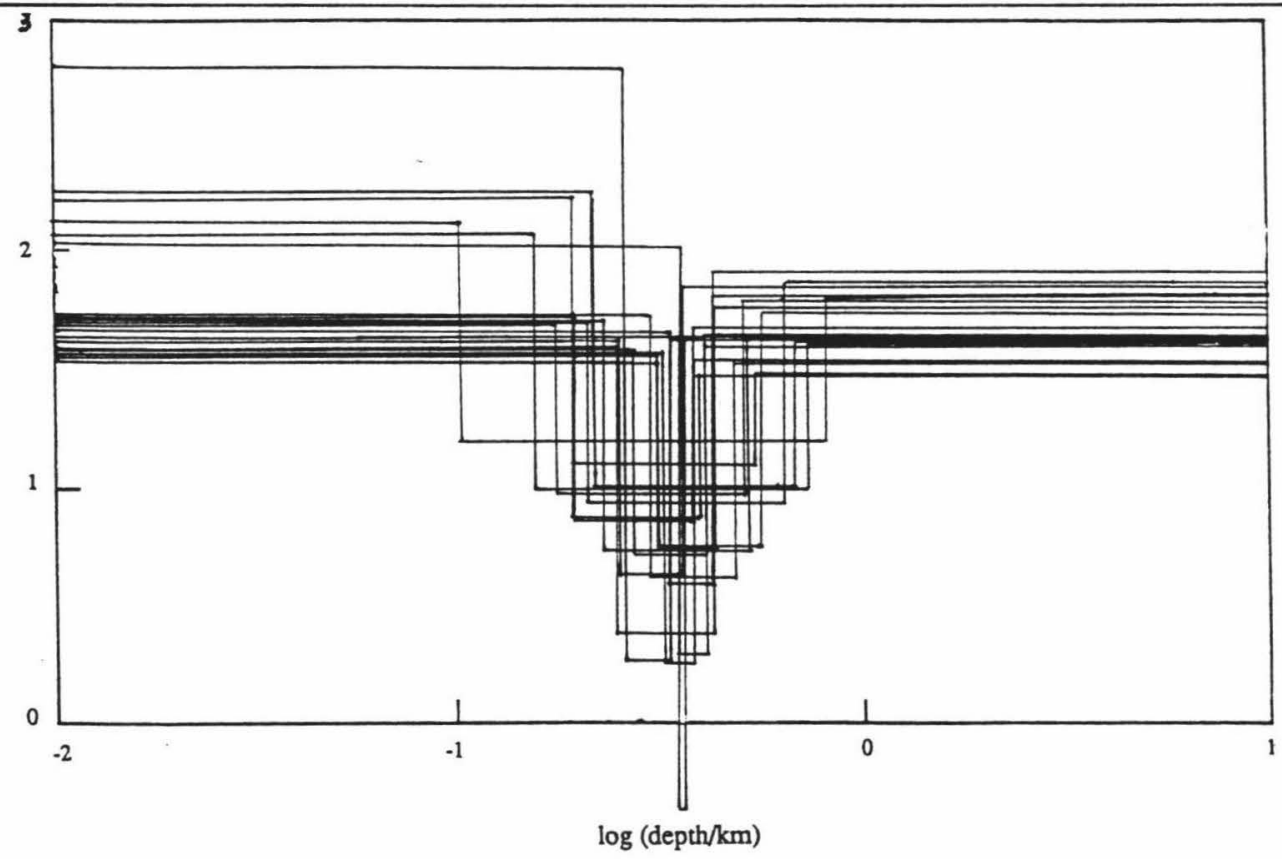

Figure 4.8 Best 20 Monte-Carlo models for WPP2 
$\log (\rho / \Omega \mathrm{m}$

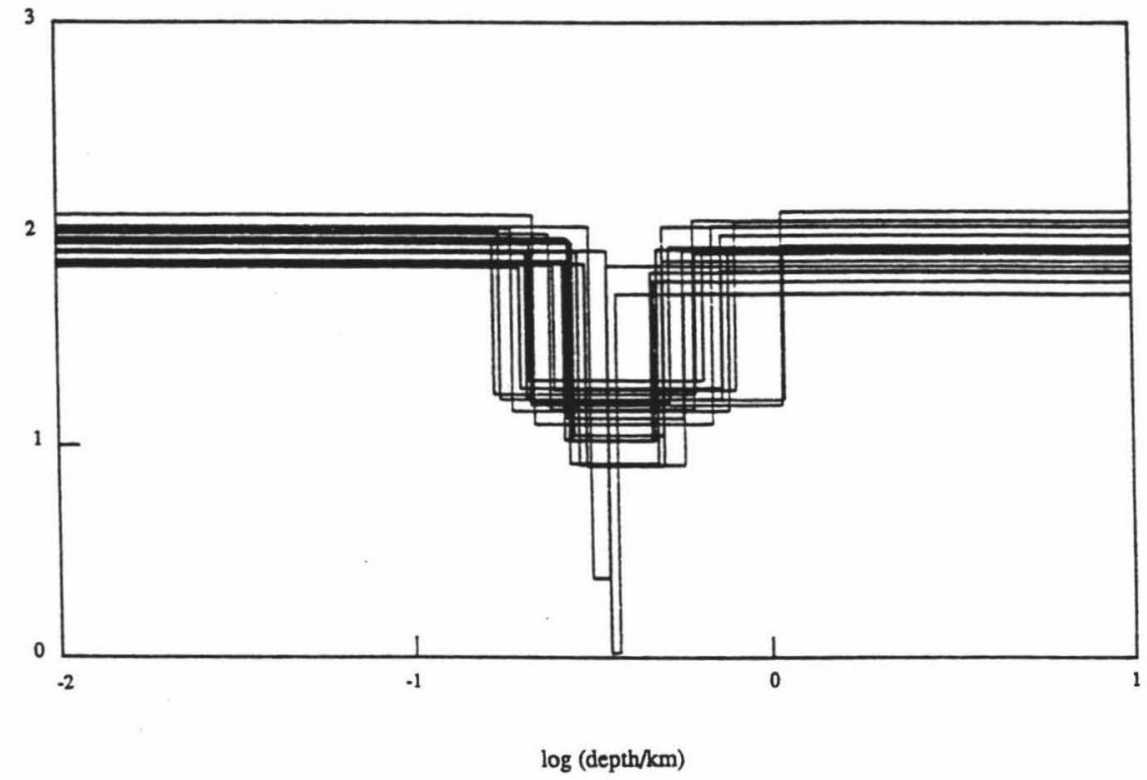

Figure 4.9 Best 20 Monte-Carlo models for WPP3

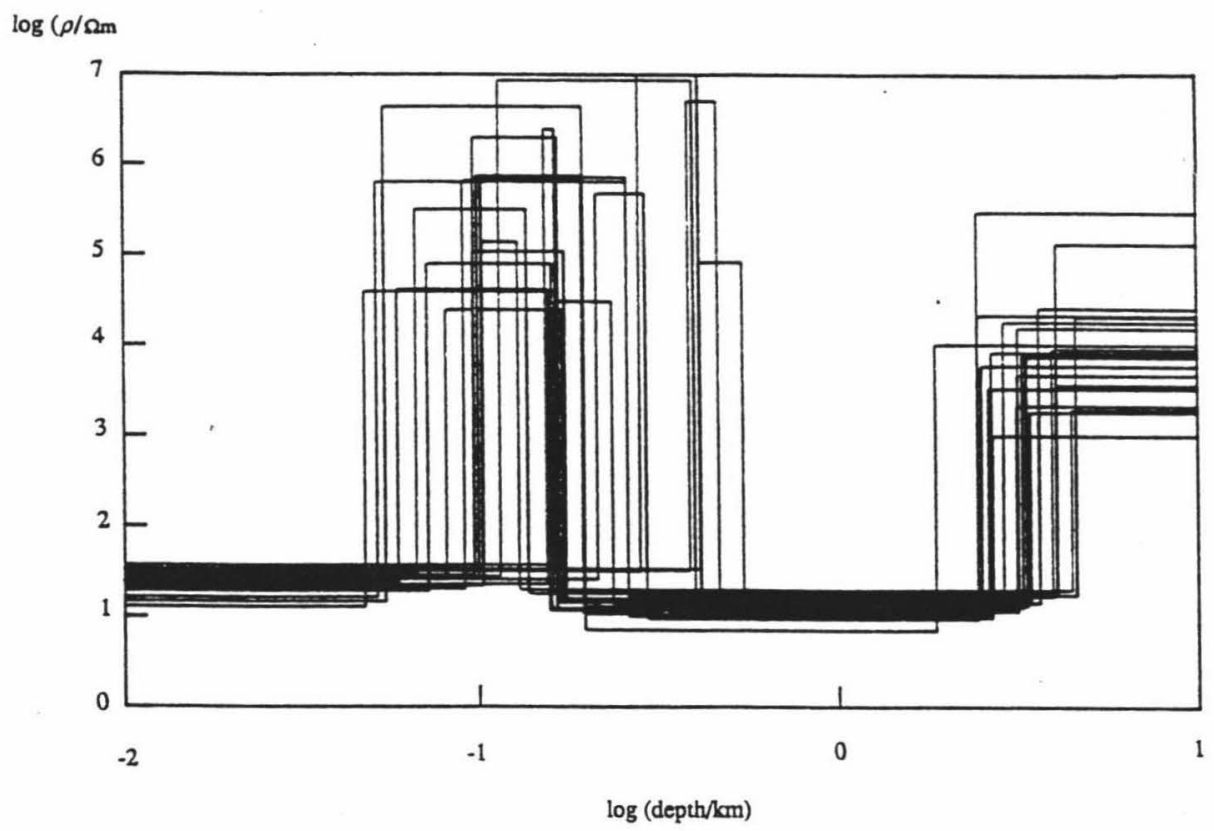

Figure 4.10 Best 20 Monte-Carlo models for PN2 
Chapter 4 - Magnetotelluric Survey

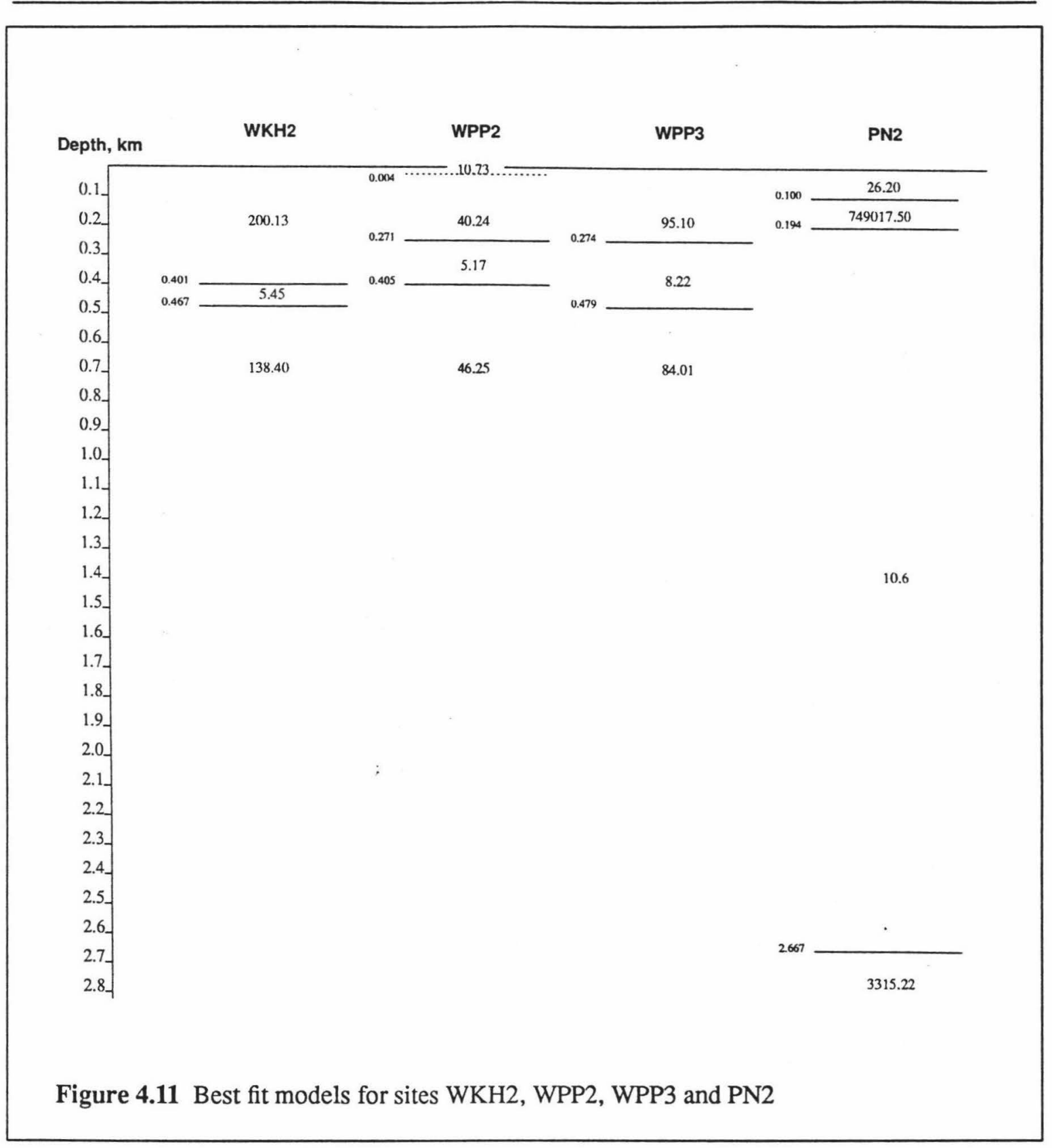




\section{Phase}

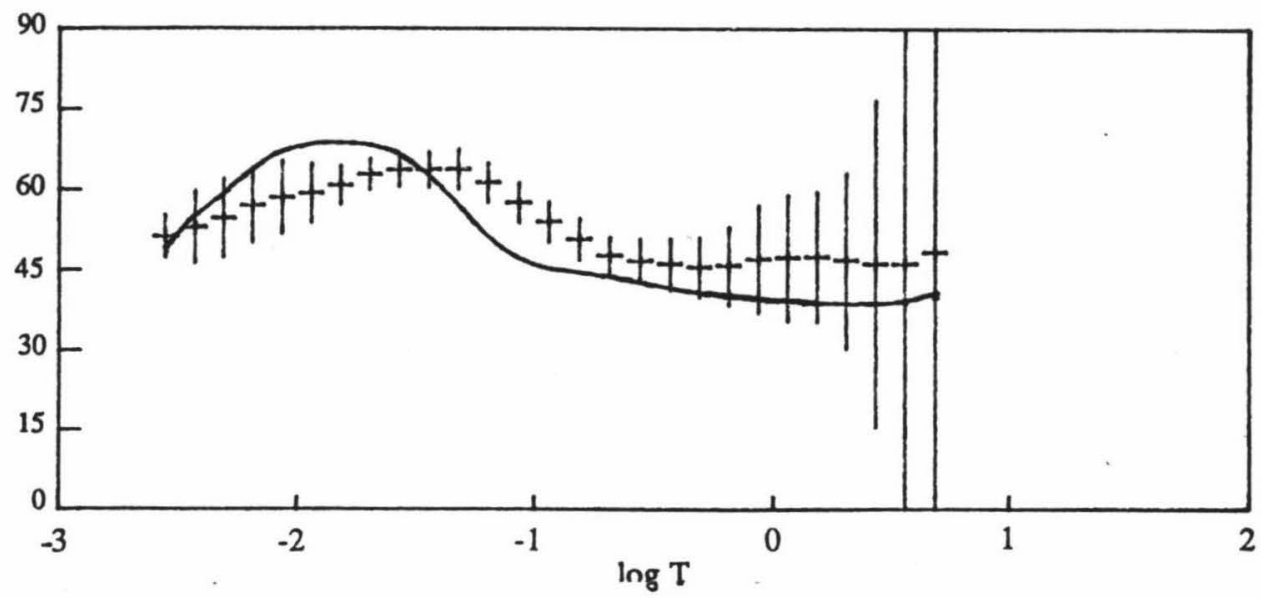

Figure 4.12 Plot of invariant phase vs period and best fit model, WKH2

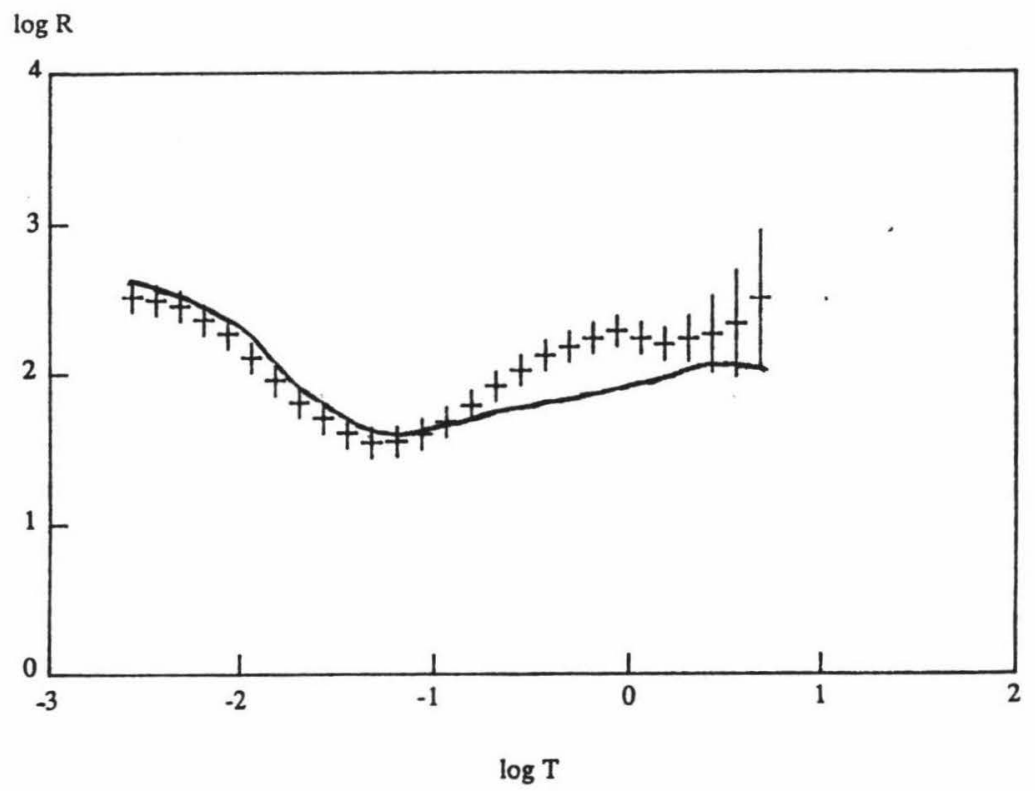

Figure 4.13 Plot of invariant apparent resistivity and best fit model, WKH2 


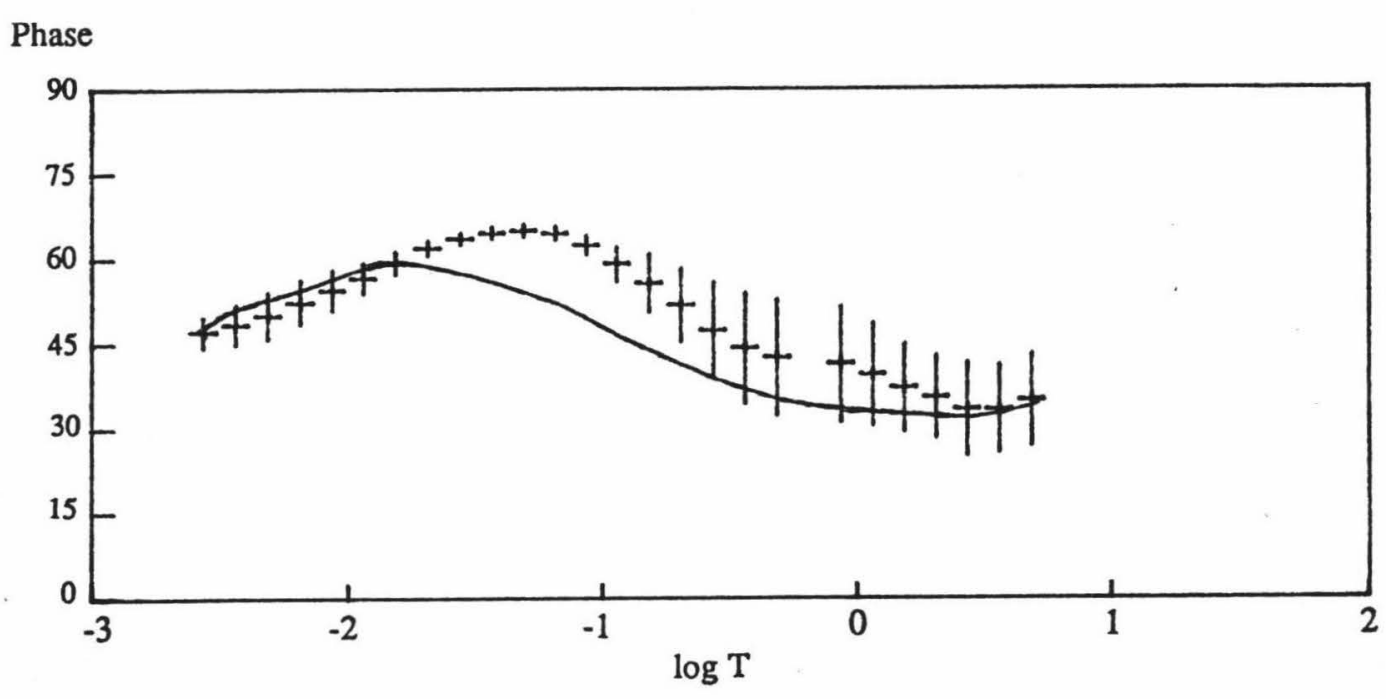

Figure 4.14 Plot of invariant phase vs period and best fit model, WPP2

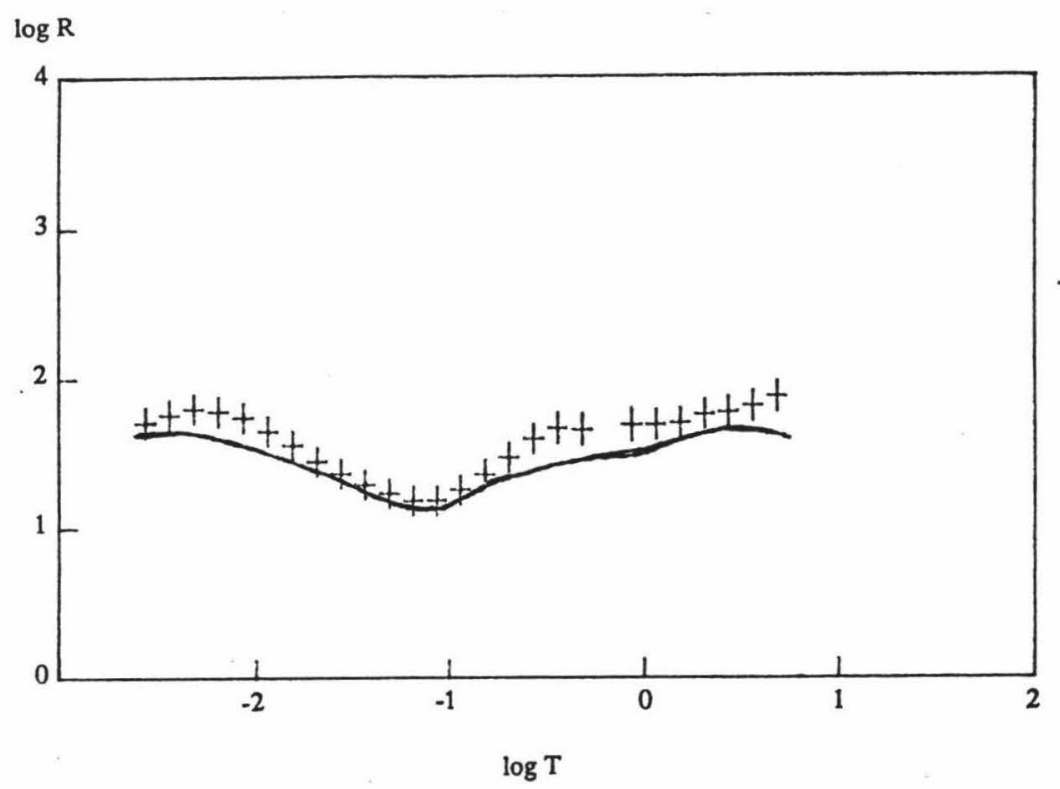

Figure 4.15 Plot of invariant apparent resistivity and best fit model, WPP2 


\section{Phase}

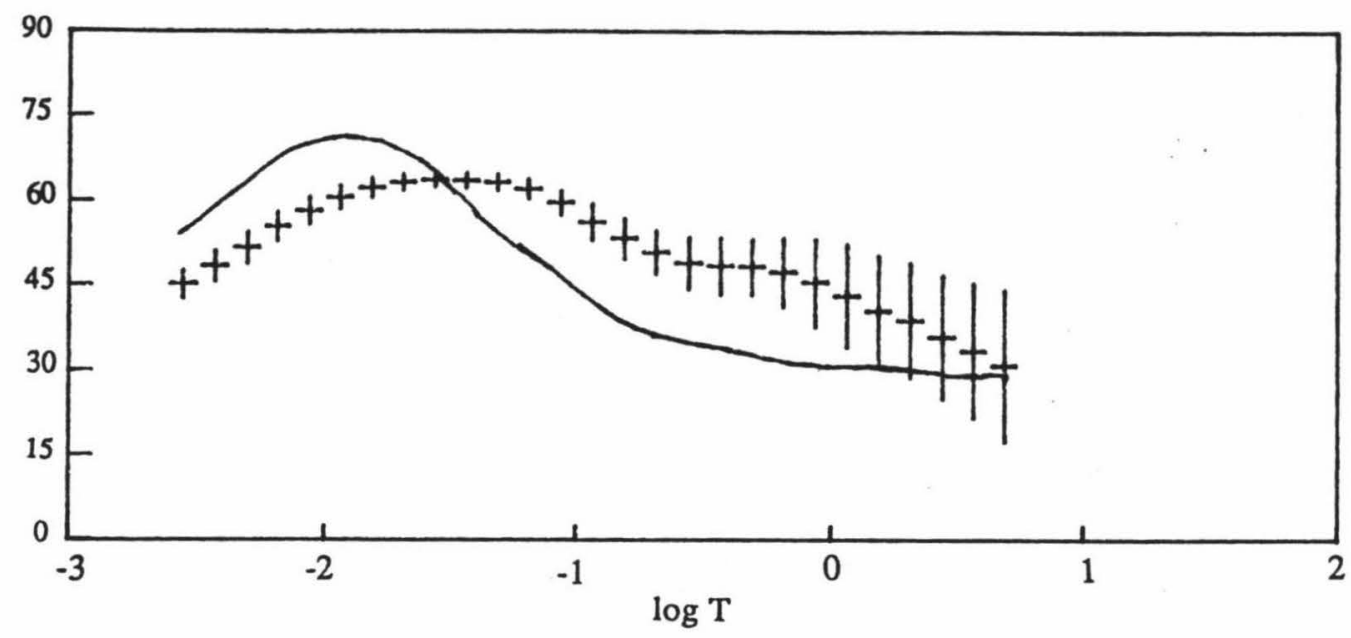

Figure 4.16 Plot of invariant phase vs period and best fit model, WPP3

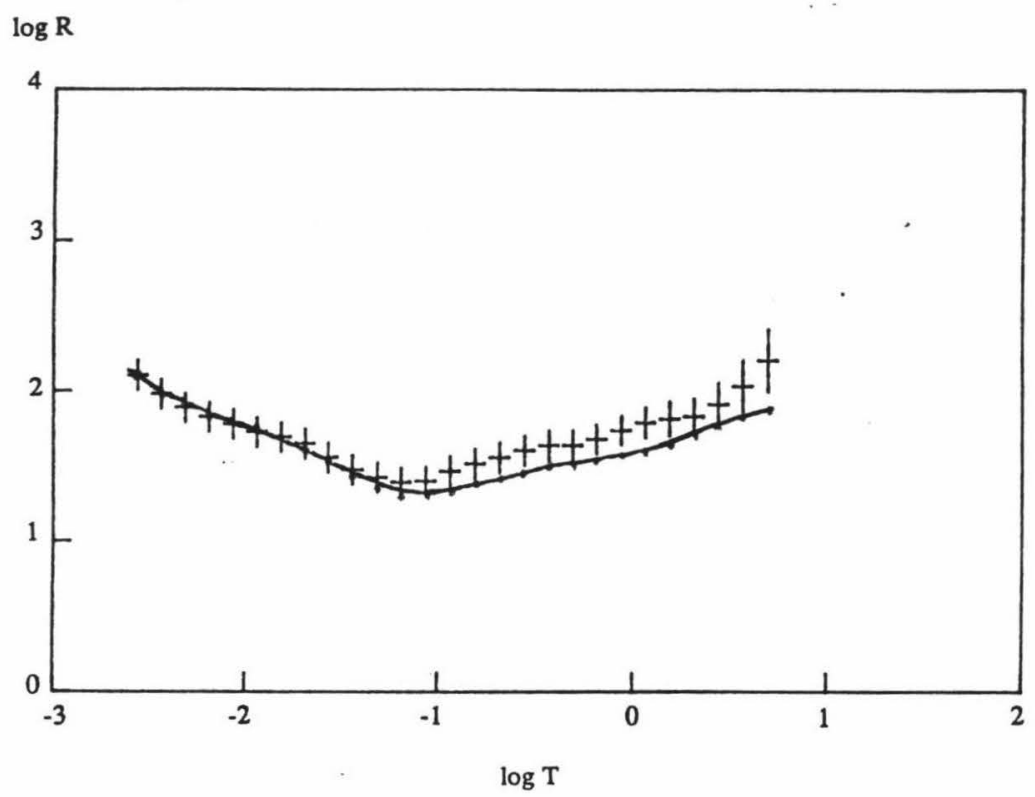

Figure 4.17 Plot of invariant appparent resistivity and best fit model, WPP3 


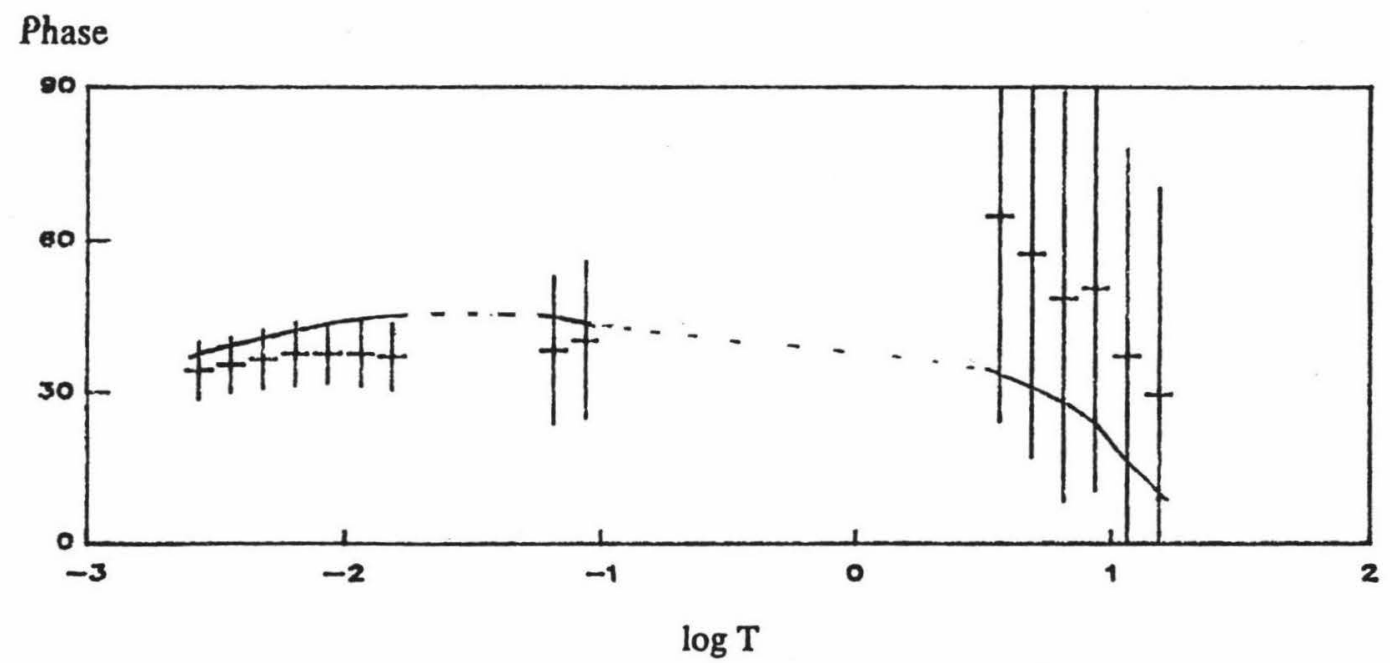

Figure 4.18 Plot of invariant phase vs period and best fit model, PN2

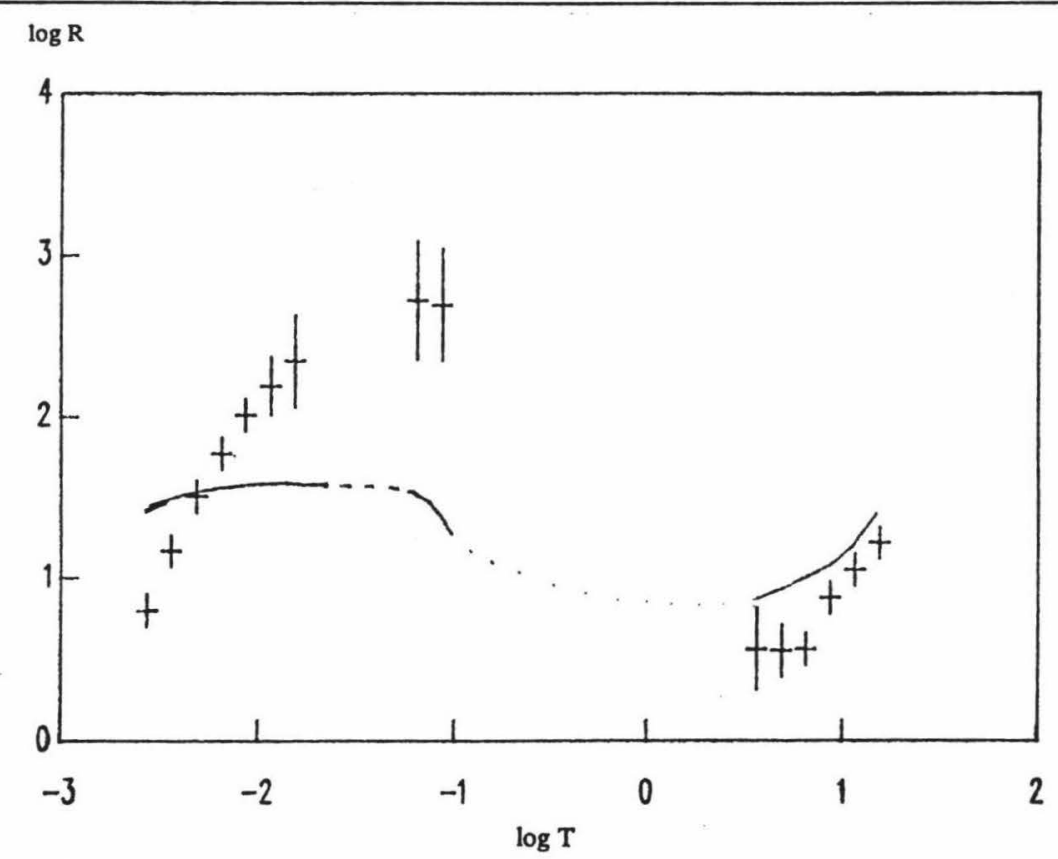

Figure 4.19 Plot of invariant apparent resistivity and best fit model, PN2 


\subsection{Uncertainties}

The output from AMTAV also gives statistical uncertainties in the values for $\mathrm{E}$ and $\mathrm{H}$ polarisation, apparent resistivity and phase. Uncertainties never exceeded $1 \%$ in the apparent resistivity values or $10 \%$ in the phase values, reflecting the greater degree of difficulty in obtaining good phase data. The uncertainties are all included in Figures 4.3 to 4.6 and the uncertainty in the final model is given by the range of models found in the Monte-Carlo inversion.

\subsection{Summary}

The results from the MT surveys to not give a clear indication of the basement depth as the gravity data does, because we are not 'seeing' down to such a great depth. However the main conclusion that can be drawn from the data is the consistency in the models on either side of the Wharepapa River, the supposed region of a fault. The consistency gives a firm indication of the fossil nature of the fault detected from the gravity data. Obviously the fault cannot have moved since the time of creation of the marine benches, which are at least 10,000 years old. A schematic diagram of the models from the four sites is shown in Figure 4.16 Obviously the un-naturally resistivity value for the second layer of the PN2 model lowers the third layer to a depth considerably lower than it should be. If this resistivity value was more in keeping with the values for the other three models, this third layer would indeed be of a similar value for all three models. It is not unrealistic to concede that the same boundaries for the layers of the models are also being seen in the gravity model. This idea shall be discussed in Chapter5, where the data from the three separate surveys shall be tied together. 


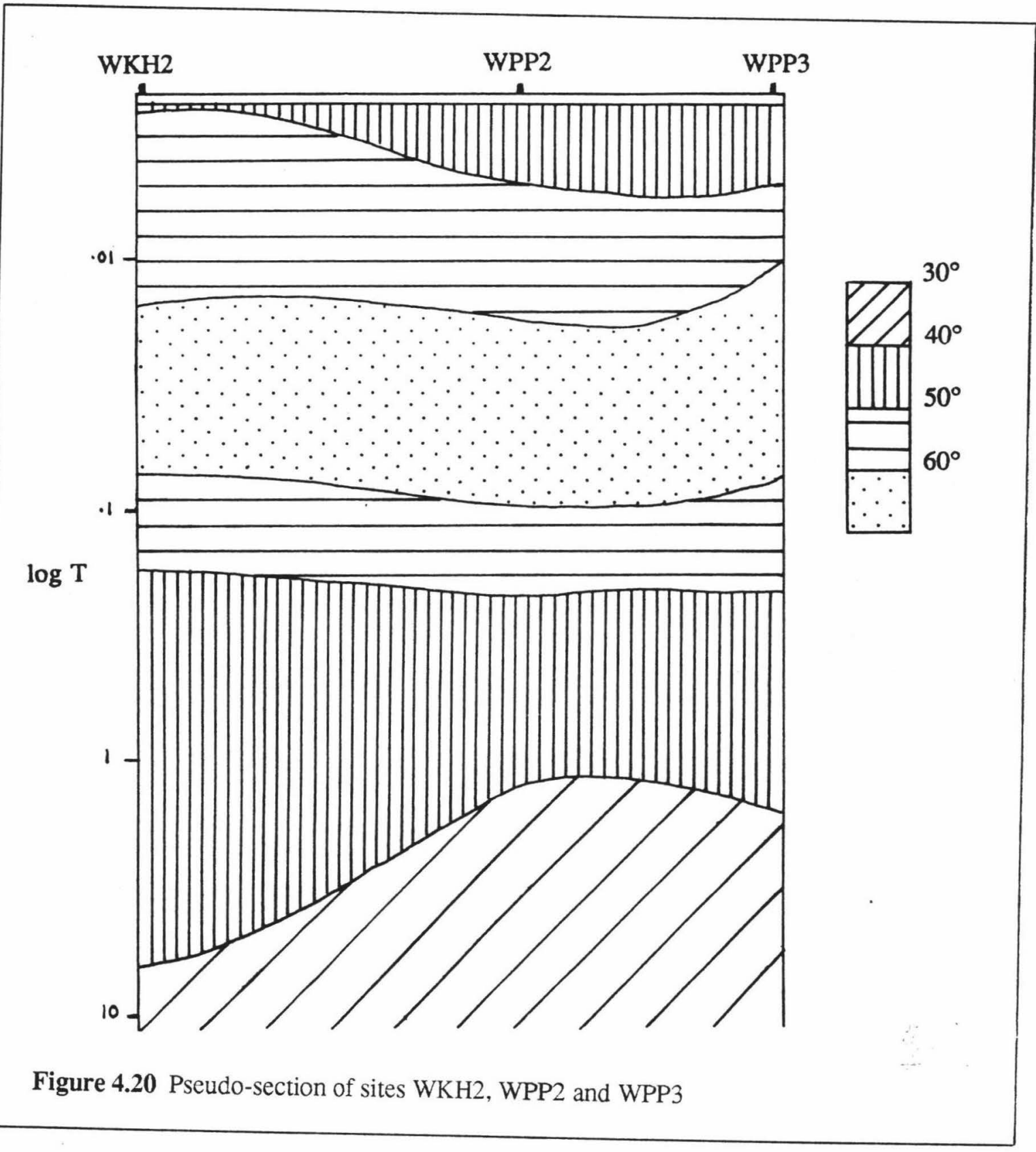




\section{Chapter 5}

\section{Final Model}

The results discussed thus far, are combined in this penultimate chapter and presented as a final model of the sub-surface for the study area. These previous results have been carefully considered,

and the final model has been chosen as the best representation of these and also to include the physical relevance of the geological situation in the area. 
In Nature's book of secrecy a little I can read - Shakespeare, "Antony and Cleopatra"

\subsection{Discussion of Previous Results}

From each of the three survey methods used in this study, a model has been found as detailed in the relevant preceding chapters. The results from the separate surveys showed a similar trend, although understandably the results varied especially in terms of the depths of the sub-surface layers. It is debatable whether the MT model was able to detect the fault down the Wharepapa River. The accuracy of detection as opposed to the gravity method, was certainly not as good, particularly in the absence of 2-D numerical modelling. This was because there was no significant change in the structure of the terraces either side of the river and the MT did not detect depths to nearly the extent that the gravity was able to. With just the MT data to go by, no obvious evidence can be given to suggest a fault lies along the Wharepapa River, except for the fact that beyond a depth of $500 \mathrm{~m}$, the layer becomes more conductive than the upper layers. and WPP2. However in conjunction with the gravity results, it is quite apposite to suggest that the fault can be similarly detected from the MT results. Figure 5.1 shows gravity Profile W (Figure 3.20) with the positions of the three MT stations used from the Wharepapa region added as a vertical line, and the approximate depths of the layers of these sites beneath them in a dashed horizontal line. This representation makes the argument clearer, as it can be seen how the coinciding depths of the layers from the two methods could quite correctly be claimed to be describing the same structure. The MT results were inly obtained using the results to the first minimum in the apparent resistivity curve, that is up to periods of between -1 and $0(\log \mathrm{T})$. Beyond this range, the effects of the coast seemed to be showing in the data, and no further depth information could be extracted from these periods for 1-D modelling purposes.

The seismic survey was not complete enough to determine whether a fault exists near the vicinity of the Wharepapa River, with only offset shots being recorded on one side of the river. However the purpose of this latter survey was to reinforce the results from the gravity method, as has already been discussed.

\subsection{The Final Model}

The final model has been constructed using the main results from the gravity and MT final models. The data from the Pounui vicinity has been tied in with that from around the Wharepapa and Wharekauhau region, to show the trend of the basement material in this area. The model 

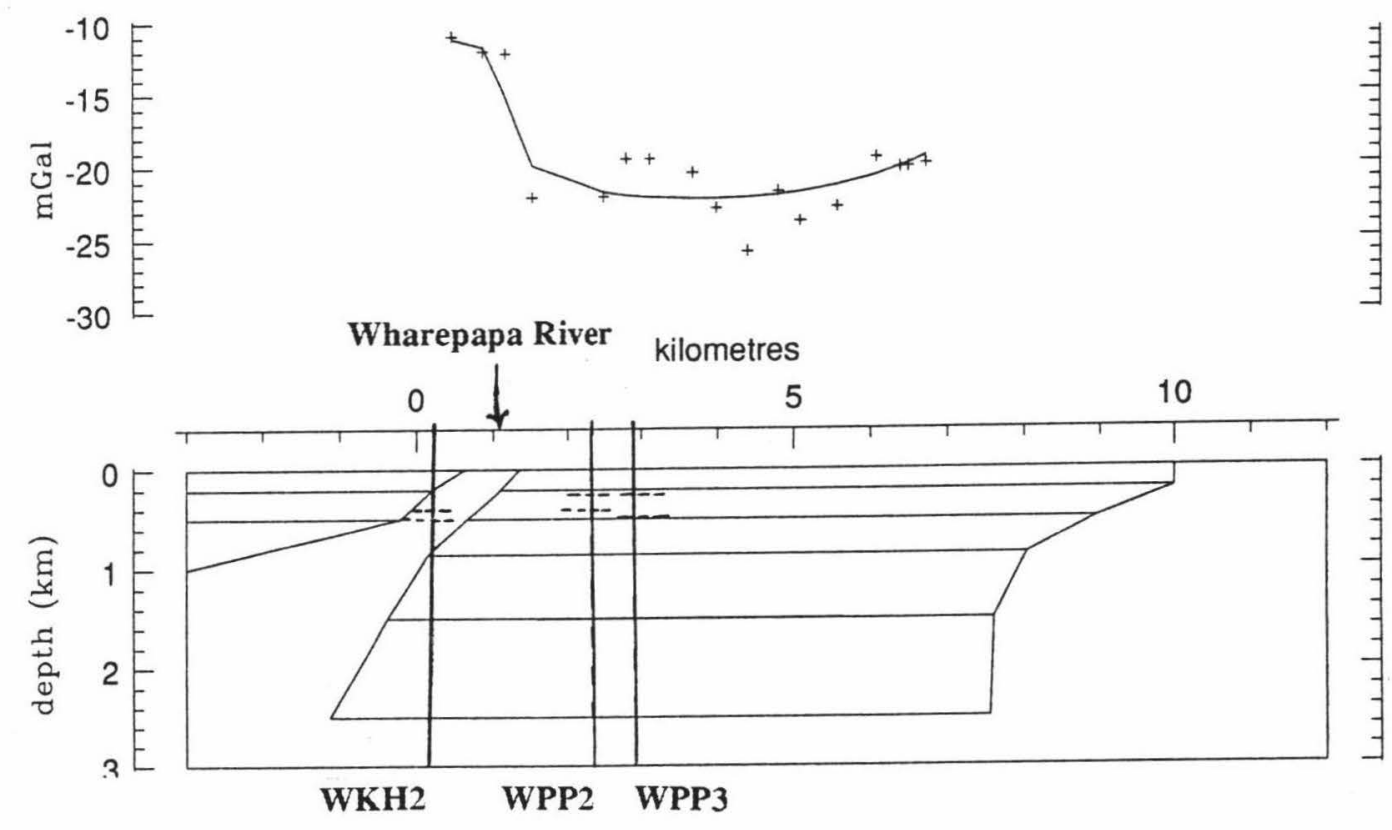

Figure 5.1 Relative positions of the MT sites on the gravity model

includes a reverse fault, whose presence provided the best fit to the gravity data. It must be kept in mind however, that models from gravity data are always open to speculation because of their non-uniqueness as a solution. However, from geological controls and data from complementary surveying methods, the final model presented can often be well constrained. For this study, there has been a tying in of results from several different methods, but use of geological control was not available to determine the exact position, thrust and dip of the fault. This is because there are 
no surface traces, which is understandable because of the fossil nature of the fault. Any surface traces have long since been buried under the marine terraces. For this reason, the true nature of the fault's orientation and dip cannot be provided.

The depth to basement has been taken from the gravity results, which have provided a 'frame' for the rest of the model, simply because the seismic and MT results did not penetrate deeply enough to conclusively detect a basement layer. The densities of the gravity model were based upon the work by Woodward (1978) and Maddocks (1970), the gravity modelling, and also constrained by the seismic data.

The final model is best represented by the gravity model in Figure 3.23 and shown below in Figure 5.2, with a few minor modifications. The MT layers coincided well with the boundaries in the gravity model, as discussed above, so do not need separate representation on the model. The model shows a sedimentary basin of thickness $2 \mathrm{~km}$, overlying a basement layer. The basin shows a small increase in depth between the Wharekauhau side and the Pounui region. A fault is shown to fracture the basin along the western edge of the study area near the Wharepapa River. To the west of this fault is a highly anomalous region, modelled from the gravity data as a separate body of higher density material. This body is the region separated from the main body by the fault. An explanation for this higher density body could be explained by the fault zone, long suggested by geologists working in the area (Grapes and Wellman, 1988). 


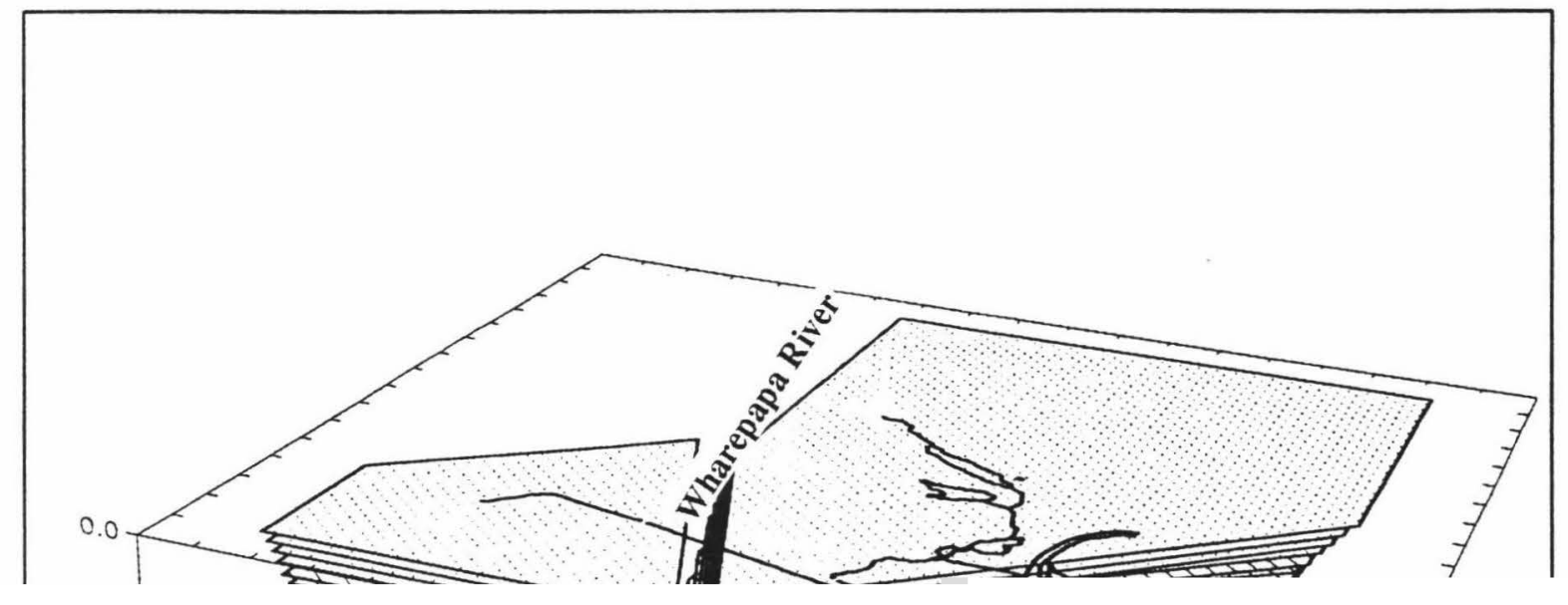




\section{Chapter 6}

\section{Conclusions}

A summary is presented in this concluding chapter and suggestions are given for future work to be carried out in the study area. 
It is better to understand a little than to misunderstand a lot /- Anatole France, "Revolt of the Angels"

\subsection{Overview and Final Conclusions}

The author was faced with varying opinions over the existence of the branch of the Wairarapa fault coinciding with the Wharepapa River, as mapped by Kingma (1967). Very little geophysical work has been carried out in in the Palliser Bay region, south of Lake Wairarapa to date, to either confirm or discount this theory. While not uniquely defining the structure of this region of the Wairarapa Basin, the study has provided sufficient evidence to confirm the the existence of a fault in the vicinity of the Wharepapa River, and an estimate of the depth to basement rock in the region.

At some stage in geological history, the part of the Wairarapa sedimentary basin under investigation must have been fractured. Modern geological theories provide evidence for this by the determination of many splinter faults in the region, not least of which is the Wairarapa fault. The 'faults' have been active through different periods of time, but the fault detected in this study is conceded to be inactive, from both geophysical and geological observations.

The gravity data has provided a defined layer coinciding with the density value of basement material. The steep anomaly to the west of the Wharepapa River was difficult to interpret. Little data was available in this area to constrain an accurate model. The final 3-D model shown in Chapter 3 fits well except for in this highly anomalous region. In this area there is much surface slumping of material and a fault zone, which is just being picked up at the edge of the study region. The gravity data shows a sharp edge to the sedimentary basin which can only be modelled by a fault. To the west of this fault, the gravity data defines sedimentary material rather than greywacke, a contrast between two different materials which would normally signify the locality of a fault. However, in this case the modelling shows a higher density sedimentary material to the left of the fault, which is detected in the gravity profiles up to $1 \mathrm{~km}$ from the Palliser Bay coastline. Beyond this, neither the cross-sectional or profile modelling could justify this second body to be used to fit the data. Geologically there has been no horizontal or vertical movement of either marine terrace, whose ages have been put at approximately 10,000 years (Grapes, 1991). This indicates the fault is at least 10,000 years old. Further confirmation of the fossil nature of the fault comes from the MT and seismic data. Results from both methods show essentially uniform layering and homogeneity in both terraces, which would be impossible if the 
fault had moved in the past 10,000 years. The fault was obviously formed sometime between the deposition of sediment in the basin and the formation of the marine terraces, which were formed by the last glacial fluvial aggradation.

The basement layer is of a comparable depth in both the the Wharepapa and Pounui regions. The electrical structure determined from the MT data quite predictably did not coincide with the depth to basement as determined by the gravitational structure. However the layers detected in the MT results, as discussed in the previous chapter, could be logically compared with the layers shown in the gravity model. The much lower depth of the third layer in the Pounui model may not be correct, because of the massiveness of the resistivity value in the second layer. With this second layer being in a more comparable range to the other three MT models, this deep layer would shallow to a layer of similar depth to the rest.

Finally, this study has illustrated the utility of geophysical investigations, in which combined interpretations of several data sets have provided both complementary and supplementary results. The gravity data has provided a template on which to base the final model. It gave an overview of the entire study area and a logical estimate of the depth to basement of the basin. The gravity method picked up the steep anomaly whose cause has been assumed to be a fault running along a greater part of the Wharepapa River and veering into the area of slumping and faulting to the west of the river. The MT work has shown the homogeneity of the marine terraces along with the seismic results with confirmation from the geology of the area, that the fault is inactive and historical. Suggestion has also been put forward that the layers determined in the MT models do indeed coincide with the gravity model, but do not reach a great enough depth to 'see' the basement layer. The seismic results were also used to help determine the material of the upper layers to constrain the density values in the gravity modelling.

\subsection{Suggestions for Further Geophysical Investigation}

Although the study area has been tectonically thrown into upheaval over time, this study has provided confirmation of Kingma's fault locality down the Wharepapa River. There is definite complexity in the region to the west of the river picked up as a very steep anomaly by the gravity. There were not enough gravity stations covering this area to be able to accurately model this region, as discussed above. After analysis of the gravity data it was obvious that there would be much interest involved in setting up further stations in this area on the western edge of and further 
west of the study area. There is little doubt that the anomalies in this western region are caused by the slumping of the land, the fragmented fault, whose trace is shown in Thrust Creek and the 'bulge' in the surface of the paddocks to the west of the Wharekauhau Stream, as can be seen in the aerial photo in Figure 1.7 The latter surface expression appears to be greywacke being extruded up to the surface, but not appearing on the actual surface. Greywacke outcrops are detected in the Wharekauhau Stream and the greywacke in the Thrust Creek region as discussed in Chapter 1 is very deformed and contorted. The tectonics in this region and the effect of gravity have all contributed in the pulverisation and distortion of the greywackes in the area. The description of the 'bulge' which is shown in the exact positioning of the steep anomaly in the Bouguer contours in Figure 3.10, as being an intrusion of greywacke is the best and most likely scenario.

An obvious and important extension of this study would be therefore to read at least another forty or fifty closely spaced gravity stations in the area mentioned above, to get a more detailed study of the anomalous region. The setting up of MT sites would not be possible, as the terrain is such that there is not a large enough flat area in this locality to make this practical. WKH1 was as far west as it would have been possible to set up an MT site in this region. The topography west of the study quickly becomes too hilly for any grand scale studies such as MT or seismic, but gravity is an easy option, and with a little walking, the stations could be easily set up. This accessibility problem may have been a previous deterrent and could explain why little work has been carried out in this region to date. However now that the ground work has been carried out by the author, a strong recommendation is made that further work is carried out to increase the size of the study area and to substantiate the anomaly just on the edge of the area, which could not be categorically explained by this study. 
- 134 - 


\section{Acknowledgements}

I would like to thank everyone who has helped me during the past two years whilst I have been working on this thesis. Firstly thank-you to my supervisor Dr Malcolm Ingham for his continual support, encouragement and invaluable assistance. Funding, without which this whole project would have been impossible, was supplied by the Geophysics Institute. Thanks go to Professor Jim Ansell for his permission to use the Institute's equipment and vehicles for transport.

All work was carried out on private farm property, so many thanks go to the following farmers and their families for permitting access onto their land, and for taking an interest in this study: Messrs Don and Nicholas Cameron, Mr Bruce Eglington and Mr Bill Shaw. Grateful thanks also go to Mr Shaw for accommodation supplied on several occasions.....and for pulling land rovers out from ditches!

Never at any stage was I short of willing helpers to assist me with fieldwork. The following people came out with me at least on one occasion, some on several: Eric Broughton, Mark Chadwick, Ray Dibble, Sharon Dobbs, Pauline Galea, Allister Gorman, Malcolm Ingham, Stefan Kleffmann and Robert Reeves; their help was invaluable.

I would like to thank everyone whom I've spoken to concerning the logistics of this study in all different areas. These include Alan Hull et al of Geological Survey, Wellington, who came up with the initial idea to investigate the fault in my study area. Dr Hugh Bibby of the DSIR for allowing me access to the Division's gravity reduction and modelling programs, and Andrew Carmen for running my data through it. Drs Ray Dibble, Tim Stern, Rodney Grapes and Professor Jim Ansell for interpretational help. I am also grateful to Dr John Amor from the University of British Columbia for giving me access to $S A K I$ and sorting out the bugs I found in the program.

On a personal level, I would like to show my appreciation to my working colleagues and friends at the Geophysic's Institute. Their help is to be noted, both on a literal level and also for 
the fun times which made the tedious or difficult aspects of my thesis easier to tackle.

Special thank-yous go to Mark Chadwick for all his help in preparing the macros involved with the typing up of this thesis and to Robert Reeves for risking life and limb holding up the landrover in gale force conditions to prevent it from rolling down a hill to certain disaster at the bottom...while I went and enlisted further help....your sense of humour made those sorts of days seem fun........afterwards! Thank you to Allister Gorman for proof-reading and interpretational help...and untangling 390 metres of seismic cable until all hours of the night, but not for assuring me that the geophone lost that day could quite possibly have been eaten by a cow in the paddock in which we were working.

During the final weeks of my work Graham McKenzie gave invaluable help in sorting out macros problems. Two very big thank-yous to Joanne Kelly for her help with drafting some of my figures, and along with Pauline Galea for their willing assistance and moral support in the final stages of my work. Thank-you also to Brett Robertson for his assistance and patience in helping me to stick in all my diagrams.

Lastly I am indebted to a group of exceptional people, without whom I would never have got to university in the first place. My family have showed me consideration, support at all levels and above all, faith in what I was doing. Without their help and support I'd have never made it through the final few months of my thesis to get it finished. The biggest thanks should therefore go to them. 


\section{References}

Bekesi, G. (1989). Geophysical Studies over the North Horowhenua Sedimentary Basin, Unpublished Masters thesis, Victoria University of Wellington

Bloom, A. R. (1951). The geology along the south-east flank of the Rimutaka Mountains, New Zealand, unpublished M.A thesis, Victoria University of Wellington

Bostick, F. X. (1977). Method of Magnetotelluric Analysis, Workshop on EM Methods

Caignard, L. (1953). Basic theory of the magnetotelluric method of geophysical prospecting, Geophys., 18 , pp.605-635.

Cape, C. D., S. H. Lamb, P. Vella, P. E. Wells and D. J. Woodward (March, 1990). Geological structure of the Wairarapa Valley, New Zealand, from seismic reflection profiling, J.R. Soc. N.Z., 20 (1) , pp.85-105.

Carter, L., K. Lewis and F. Davey (1988). Faults in Cook Strait and their bearing on the structure of central New Zealand, N.Z.J.G.G, 31 , pp.431-446.

Crawford, J. (1870). , Trans. N.Z. Inst., 2 , pp.345.

Dobrin, M. B. (1981). Introduction to Geophysical Prospecting, 3rd ed., McGraw-Hill Inc, Tokyo

Eiby, G. A (1989). Earthquakes, Heinemann Reed, Auckland

Ellis, S. M. (1987). Magnetotelluric Studies in Eastern Wairarapa, unpublished B.Sc.(Hons.) project, Victoria University of Wellington

Fischer, G. and P. Schnegg (1980). The dispersion relations of the magnetotelluric response and their incidence on the inversion problem, Geophys. J. R. astr. Soc., 62 , pp.661-673. 
Fischer, G. and B. V. Le Quang (1981). Topography and minimization of the standard deviation in 1-D magnetotelluric modelling, Geophys. J. R. astr. Soc., , pp.279-292.

Ghani, M. A (1974). Late Crustal Cenozoic Vertical Crustal Movements in the Central Part of New Zealand, PhD thesis, Victoria University of Wellington, New Zealand

Gibbs, J. G. (1974). Geology and Pedology related to Production in the southwest Wairarapa, Unpublished B.Sc.(Hons.) project, Victoria University of Wellington, New Zealand

Gorman, A. J. (1986). Using the Nimbus ES-1210 seismograph for teaching seismic reflection prospecting, Unpublished B.Sc.(Hons.) project, Victoria University of Wellington

Grapes, R. and H. Wellman (1988). The Wairarapa Fault, Geology Board of Studies Publication, Victoria University of Wellington, New Zealand (4)

Grapes, R. (1991). Aggradation surfaces and implications for displacement rates along the Wairarapa Fault, Southern North Island, New Zealand, CATENA, 18 , pp.454-469.

Gresham, J. J. (1967). Three Gravity Profiles Across the Wairarapa Fault, B.Sc.(Hons.) project, Victoria University of Wellington, New Zealand

Hales, F. W. and T. E. Edwards (1955). Some theoretical considerations on the use of multigeophones arranged linearly along the line of traverse, Geophys. Prosp., 3, pp.65-73. Hammer (1939). , Geophysics, 4, pp.180-191.

Heine, R. W. (1964). Gravity Survey in the Middle Wairarapa, N.Z.J.G.G, 7(1), pp.185-191.

Homer, L. and P. Moore (1989). Reading the Rocks - A Guide to the Geological Features of the Wairarapa Coast, New Zealand Geological Survey,

Hughes, S. L. M. (1984). The Gravity Survey of the Hawkdun Basin, Central Otago, B.Sc.(Hons.) project, Otago University, New Zealand

Iorns (24/9/32). article in, Wairarapa Daily Times

Kao, D. and D. Orr (1982). Magnetotelluric studies in the Market Weighton of Eastern England, Geophys. J. R. astr. Soc., , pp.323-337.

Katz, H. R. and R. A. Wood (1980). Submerged Margin East of the North Island, New Zealand and It's Petroleum Potential, UN ESCAP, CCOP/SOPAC technical bulletin (3) , p.221-235. 
Keller, G. V. and C. Frischknecht (1966). , in Electrical Methods of Geophysical Prospecting, London

King, L. C. (1930). Raised Beaches and other Features of the South-East Coast of the North Island of New Zealand., Trans. N.Z. Inst., 61, pp.498-523.

King, L. C. (1940). Relation between the Major Islands of New Zealand, Trans. R. Soc. N.Z, , pp.544-569.

Kingma, J. T. (1967). Geological Map of New Zealand, 1:250 000, Sheet 12 - Wellington

Kleffmann, S. (1992). A structural interpretation of Thorndon from microearthquake recordings and seismic prospecting, Unpublished Diploma project, Victoria University of Wellington

Lensen, G. J. (1958). Note on Fault Correlation Across Cook Strait, N.Z.J.G.G, 1, pp.263-268.

Leonardon, E. G. (1928). Some observations upon telluric currents and their applications to electrical prospecting, Terr. Mag. Atmos. Electr., 33 , pp.91-94.

Luetgert, J. H. (1985). Users manual for Ray84/Ray83PLT, Openfile report 88-238, , pp.US Department of the Interior Geological Survey.

Maddocks, N. A. (1970). A Gravity Survey of the West-Wairarapa Fault at Palliser Bay, B.Sc.(Hons.) project, Victoria University of Wellington, New Zealand

McKay, A. (1888). Tauherenikau and Waiohine Valleys, Reports of Geological Exploration during 1887-88, , pp.58-67.

McKay, A. (1892). On the Geology of Marlborough and South-east Nelson, NZ Geological Survey Reports on Geological Exploration, 1890-91 (21)

Mota, L. (1954). Determination of dips and depths of geological layers by the seismic refraction method, Geophys., 19 , pp.242-254.

Nettleton, L. L. (1971). Elementary gravity and magnetics for geologists and seismologists, Monograph Series (1)

Ongley, M. (1943). Surface Trace of the 1855 Earthquake, Trans. Proc. R. Soc. N. Z, 73 , pp..

Paintin, I. K. (1989). User's guide to the Gravity and Magnetic Modelling Programs on the Geophysics Division Vax System, Technical Report, 103 
Reeves, R. R. (1991). A magnetotelluric study of the Tokaanu-Waihi geothermal field, Unpublished B.Sc.(Hons.) project, Victoria University of Wellington

Roberts, E. (1855). Appendix F, in Te Ika a Maui,

Rymer, H. (2 May 1989). A contribution to precision microgravity data analysis using Lacoste and Romberg gravity meters, Geophys. J., 97(2) , pp..

Smith, P J. (1986). Hutchinson Encyclopaedia of the Earth, Century Hutchinson Ltd, London

Stern, T. A. (1979). Regional and residual gravity fields, Central North Island, New Zealand, N.Z.J.G.G, 22(4), pp.479-485.

Stevens, G. R. (1974). Rugged Landscape: The Geology of Central New Zealand, A. H and A. W. Reed, , 286pp.

Talwani, M., G. H. Sutton, and J. L. Worzel (1959). A crustal section across the Puerto Rico Trench, J. geophys. Res., 64 , pp.1545.

Talwani, M. and M. Ewing (1960). Rapid computation of gravitational attraction of threedimensional bodies of arbitrary shape, Geophys., 25 , pp.49-59.

Vennell (1891). short letter in, Rep. Austral. Ass. Adv. Sc., , pp..

Webring, M. (1985). Saki, Open file report No. 85-122

Woodward, D. J. and S. R. Hicks (1978). Gravity Models of the Wairarapa region, New Zealand, N.Z.J.G.G, 21(1) , pp.539-44.

Woodward, D. J. (1982). Reduction of Gravity Observations on the Vax 11/780 Computer, Geophysics Division Technical Note (83) 


\section{Appendix A}

\section{Field Assistants and Survey Details}

Many people helped the author through the period of field work. Their names are listed in this appendix together with the dates of each survey. 


\begin{tabular}{l|l|l}
\hline Date & \multicolumn{1}{|c|}{ Assistant(s) } & Survey Technique \\
\hline & & \\
$5 / 3 / 90$ & M. Ingham and E. Broughton & MT \\
$19 / 3 / 90$ & M. Ingham & Gravity \\
$20 / 4 / 90$ & M. Ingham & Gravity \\
$30 / 4 / 90$ & M. Ingham and E. Broughton & Gravity \\
$31 / 12 / 90$ & M. Chadwick & Gravity \\
$4 / 1 / 91$ & P. Galea & Gravity \\
$30 / 1 / 91$ & R. Reeves & Gravity \\
$31 / 1 / 91$ & R. Reeves & Gravity \\
$14 / 2 / 91$ & M. Ingham & Gravity and MT \\
$15 / 2 / 91$ & M. Ingham & Gravity and MT \\
$4 / 3 / 91$ & S. Dobbs, A. Gorman and R. Reeves & MT \\
$11 / 3 / 91$ & A. Gorman & Gravity \\
$11 / 4 / 91$ & A. Gorman & Gravity \\
$17 / 4 / 91$ & R. Dibble, M. Ingham, A. Gorman, R. & Seismic Refraction \\
& Reeves and S. Kleffmann & \\
$18 / 4 / 91$ & A. Gorman & Gravity \\
$12 / 5 / 91$ & A. Gorman & Sesimic \\
$13 / 5 / 91$ & R. Dibble, A. Gorman and Geol311 class & Seismic \\
$14 / 5 / 91$ & R. Dibble, A. Gorman and Geol311 class & Seismic
\end{tabular}

Mr E. W. Broughton - Senior Technical Officer in Geophysics Dr R. R. Dibble - Reader in Geophysics

Dr M. R. Ingham - Lecturer in Geophysics

Mr M. P. Chadwick

Miss S. A. Dobbs

Mrs. P. M. Galea - Friends and colleagues

Mr A. J. Gorman

Mr. S. Kleffmann

Mr R. R. Reeves 


$$
-144 \text { - }
$$




\section{Appendix B}

\section{Seismic Data}

The first break data from the three seismic refraction spreads set up for this survey, are displayed in this appendix. This data was read from the seismograms and used in the subsequent analysis. 


\section{PN-S3}

East end near shot (292m from shot to first geophone)

\begin{tabular}{ccc} 
Geophone & Distance from shot point & First break (ms) \\
\hline 1 & 302.0 & \\
2 & 323.0 & 23.50 \\
3 & 353.0 & 37.00 \\
4 & 383.0 & 55.50 \\
5 & 413.0 & 71.00 \\
6 & 443.0 & 93.40 \\
7 & 473.0 & - \\
8 & 503.0 & 128.50 \\
9 & 533.0 & 145.00 \\
10 & 563.0 & 162.00 \\
11 & 593.0 & 180.00 \\
12 & 623.0 & 194.50 \\
& & 205.50
\end{tabular}

West end near shot (624m from shot to first geophone)

Geophone Distance from shot point First break (ms)

$\begin{array}{rcc}1 & 293.0 & 203.00 \\ 2 & 323.0 & 195.00 \\ 3 & 353.0 & 180.00 \\ 4 & 383.0 & 166.00 \\ 5 & 413.0 & 151.50 \\ 6 & 443.0 & - \\ 7 & 473.0 & 115.50 \\ 8 & 503.0 & 103.00 \\ 9 & 533.0 & 85.00 \\ 10 & 563.0 & 66.00 \\ 11 & 593.0 & 43.00 \\ 12 & 614.0 & 17.00\end{array}$


West end far shot (shot point is the distance reference)

Geophone Distance from shot point First break (ms)

$\begin{array}{rrr}1 & 293.0 & 231.90 \\ 2 & 323.0 & 244.00 \\ 3 & 353.0 & 264.70 \\ 4 & 383.0 & 275.00 \\ 5 & 413.0 & 290.50 \\ 6 & 443.0 & 306.10 \\ 7 & 473.0 & 314.70 \\ 8 & 503.0 & 331.90 \\ 9 & 533.0 & 344.00 \\ 10 & 563.0 & 354.30 \\ 11 & 593.0 & 369.90 \\ 12 & 623.0 & 385.40\end{array}$

East end far shot (1004m from shot to geophone one)

Geophone Distance from shot point First break (ms)

$\begin{array}{rcc}1 & 293.0 & 443.60 \\ 2 & 321.0 & 430.70 \\ 3 & 350.0 & 415.70 \\ 4 & 378.0 & 410.00 \\ 5 & 407.0 & 397.90 \\ 6 & 435.0 & - \\ 7 & 464.0 & 377.40 \\ 8 & 492.0 & 365.70 \\ 9 & 521.0 & 346.40 \\ 10 & 549.0 & 344.30 \\ 11 & 578.0 & 326.40 \\ 12 & 606.0 & 318.60\end{array}$




\section{WKH-S1}

East end near shot (801m from shot to first geophone)

Geophone Distance from shot point First break (ms)

$\begin{array}{rrr}1 & 777.0 & 40.00 \\ 2 & 747.0 & 65.00 \\ 3 & 717.0 & 96.00 \\ 4 & 687.0 & 120.00 \\ 5 & 657.0 & 140.00 \\ 6 & 627.0 & 157.00 \\ 7 & 597.0 & 170.00 \\ 8 & 567.0 & 182.00 \\ 9 & 537.0 & 195.00 \\ 10 & 507.0 & 208.00 \\ 11 & 477.0 & 220.00 \\ 12 & 447.0 & 234.00\end{array}$

West end near shot (422m from shot to first geophone)

Geophone Distance from shot point First break (ms)

$\begin{array}{rrr}1 & 777.0 & 234.00 \\ 2 & 747.0 & 225.00 \\ 3 & 717.0 & 210.00 \\ 4 & 687.0 & 197.00 \\ 5 & 657.0 & 186.00 \\ 6 & 627.0 & 170.00 \\ 7 & 597.0 & 150.00 \\ 8 & 567.0 & 127.00 \\ 9 & 537.0 & 103.00 \\ 10 & 507.0 & 84.00 \\ 11 & 477.0 & 62.00 \\ 12 & 447.0 & 42.00\end{array}$


East end far shot (979m from shot to geophone one)

Geophone Distance from shot point First break (ms)

$\begin{array}{rcc}1 & 477.0 & 274.00 \\ 2 & 507.0 & 288.00 \\ 3 & 537.0 & 273.00 \\ 4 & 567.0 & 263.00 \\ 5 & 597.0 & 251.00 \\ 6 & 627.0 & 238.00 \\ 7 & 657.0 & 219.00 \\ 8 & 687.0 & 203.00 \\ 9 & 717.0 & 201.00 \\ 10 & 747.0 & 186.00 \\ 11 & 777.0 & 174.00 \\ 12 & 807.0 & -\end{array}$

West end far shot (shot point is the distance reference)

Geophone Distance from shot point First break (ms)

447.0

274.00

2

477.0

284.00

3

507.0

300.00

$4 \quad 537.0$

311.00

567.0

324.00

597.0

339.00

627.0

352.00

657.0

363.00

687.0

371.00

717.0

393.00

747.0

400.00

11

777.0

412.00 


\section{WPP-S2}

South end near shot (shot point is the distance reference)

$$
\text { Geophone Distance from shot point First break (ms) }
$$

$\begin{array}{rrc}1 & 10.0 & 26.00 \\ 2 & 30.0 & 50.00 \\ 3 & 60.0 & 80.00 \\ 4 & 90.0 & 95.00 \\ 5 & 120.0 & 112.00 \\ 6 & 150.0 & - \\ 7 & 180.0 & 152.00 \\ 8 & 210.0 & 181.00 \\ 9 & 240.0 & 192.00 \\ 10 & 270.0 & 209.00 \\ 11 & 300.0 & 224.50 \\ 12 & 330.0 & 241.00\end{array}$

North end near shot (330m from shot point to geophone one)

Geophone Distance from shot point First break (ms)

$\begin{array}{rrc}1 & 320.0 & 29.50 \\ 2 & 300.0 & 53.50 \\ 3 & 270.0 & 77.50 \\ 4 & 240.0 & 109.50 \\ 5 & 210.0 & 136.00 \\ 6 & 180.0 & - \\ 7 & 150.0 & 161.50 \\ 8 & 120.0 & 180.00 \\ 10 & 60.0 & 209.00 \\ 11 & 30.0 & 224.00 \\ 12 & 0.0 & 238.00\end{array}$


- 152 - 


\section{Appendix C}

\section{Gravity Data}

This appendix contains a listing of the locations of all gravity stations established in the study area by the author, with the inclusion of one station from the DSIR's database (Stn.123). All locations are given in grid co-ordinates from the NZMS series. Data included is the gravity values read in the field corrected for drift and converted into milligals, the height, total topographic correction, bouguer anomaly, the value of the regional at each station and the residual value, as corrected by removal of the regional. The latter being the values used for the final gravity analysis. Data in bold was not used in the final analysis for reasons described in Chapter 3. 
Appendix C - Gravity Data 


\section{GRAVITY DATA}

\begin{tabular}{|c|c|c|c|c|c|c|c|c|}
\hline Stn & Easting & Northing & Height & Gravity & Topo & Bouguer & Local Reg. & Res \\
\hline 1 & 2688099 & 5982649 & 23.7 & 53154.9 & 3.2 & 200.0 & 419.1969 & -219.1969 \\
\hline 2 & 2687724 & 5982924 & 53.0 & 53084.2 & 3.1 & 189.8 & 410.5155 & -220.7155 \\
\hline 3 & 2687299 & 5983099 & 101.3 & 52936.7 & 3.0 & 140.5 & 402.6409 & -262.1409 \\
\hline 4 & 2686925 & 5983199 & 107.2 & 52912.9 & 3.0 & 129.4 & 396.4973 & -267.0973 \\
\hline 5 & 2686724 & 5983350 & 107.6 & 52961.2 & 3.0 & 179.8 & 391.8403 & -217.5403 \\
\hline 6 & 2686349 & 5983401 & 111.7 & 52949.0 & 3.1 & 176.6 & 386.3946 & -209.7946 \\
\hline 7 & 2687899 & 5982574 & 29.0 & 53158.5 & 3.2 & 213.5 & 417.7059 & -204.2059 \\
\hline 8 & 2687699 & 5982675 & 26.1 & 53159.5 & 3.2 & 210.1 & 413.7258 & -203.6258 \\
\hline 9 & 2687499 & 5982699 & 23.5 & 53159.0 & 3.2 & 205.2 & 410.8414 & -205.6414 \\
\hline 10 & 2686974 & 5982825 & 25.2 & 53140.9 & 3.3 & 192.7 & 402.4031 & -209.7031 \\
\hline 11 & 2686474 & 5982749 & 21.9 & 53145.4 & 3.3 & 191.5 & 397.1607 & -210.6607 \\
\hline 12 & 2686775 & 5982824 & 24.8 & 53137.5 & 3.3 & 189.0 & 399.9021 & -210.9021 \\
\hline 13 & 2687250 & 5982800 & 26.0 & 53146.3 & 3.3 & 198.7 & 406.2516 & -207.5516 \\
\hline 14 & 2687449 & 5982425 & 23.2 & 53168.2 & 3.2 & 211.3 & 414.0786 & -202.7786 \\
\hline 15 & 2687649 & 5982450 & 21.9 & 53172.3 & 3.2 & 212.9 & 416.2723 & -203.3723 \\
\hline 16 & 2686274 & 5984175 & 80.6 & 52938.1 & 3.3 & 113.1 & 374.5005 & -261.4005 \\
\hline 17 & 2686649 & 5983925 & 69.0 & 53038.0 & 3.3 & 186.5 & 382.7389 & -196.2389 \\
\hline 18 & 2687049 & 5983750 & 58.5 & 53062.8 & 3.3 & 188.0 & 390.2499 & -202.2499 \\
\hline 19 & 2687324 & 5983499 & 48.8 & 53084.1 & 3.3 & 187.3 & 397.2839 & -209.9839 \\
\hline 20 & 2687624 & 5983249 & 36.7 & 53114.7 & 3.2 & 191.4 & 404.6331 & -213.2331 \\
\hline 21 & 2687849 & 5983075 & 30.6 & 53133.3 & 3.2 & 196.1 & 409.9629 & -213.8629 \\
\hline 22 & 2686649 & 5982199 & 29.0 & 53157.2 & 3.2 & 211.1 & 407.1076 & -195.8076 \\
\hline 23 & 2686399 & 5982249 & 20.7 & 53151.4 & 3.3 & 190.5 & 403.2447 & -213.4447 \\
\hline 24 & 2686949 & 5982300 & 18.4 & 53155.9 & 3.3 & 189.9 & 409.4893 & -219.5893 \\
\hline 25 & 2687249 & 5982400 & 21.8 & 53141.9 & 3.3 & 182.8 & 411.8882 & -229.0882 \\
\hline 26 & 2688100 & 5982425 & 28.7 & 53173.4 & 3.2 & 226.3 & 422.3851 & -196.0851 \\
\hline 27 & 2687949 & 5982224 & 25.6 & 53184.2 & 3.2 & 229.5 & 423.2983 & -193.7983 \\
\hline 28 & 2688250 & 5982100 & 15.2 & 53204.7 & 3.2 & 228.2 & 428.9086 & -200.7086 \\
\hline 29 & 2688349 & 5982325 & 19.3 & 53193.3 & 3.2 & 226.6 & 426.9919 & -200.3919 \\
\hline 30 & 2688574 & 5982199 & 13.4 & 53213.0 & 3.2 & 233.5 & 431.6679 & -198.1679 \\
\hline 31 & 2688399 & 5982550 & 22.7 & 53180.6 & 3.2 & 222.5 & 424.4410 & -201.9410 \\
\hline 32 & 2688225 & 5982924 & 24.8 & 53156.0 & 3.2 & 205.6 & 416.9016 & -211.3016 \\
\hline 33 & 2687450 & 5982049 & 77.7 & 53045.2 & 3.0 & 192.0 & 419.3958 & -227.3958 \\
\hline 34 & 2686975 & 5981974 & 104.3 & 52977.5 & 2.9 & 177.4 & 414.4051 & -237.0051 \\
\hline 35 & 2686299 & 5981650 & 150.0 & 52862.7 & 2.6 & 152.4 & 410.3740 & -257.9740 \\
\hline 36 & 2685549 & 5984750 & 101.1 & 52955.5 & 3.0 & 180.9 & 357.3369 & -176.4369 \\
\hline 37 & 2685774 & 5984524 & 95.1 & 52967.5 & 3.0 & 177.2 & 363.3286 & -186.1286 \\
\hline 38 & 2685974 & 5984350 & 86.9 & 52982.1 & 3.3 & 172.8 & 368.2803 & -195.4803 \\
\hline 39 & 2684075 & 5982900 & 132.2 & 52917.7 & 2.8 & 186.8 & 365.1282 & -178.3282 \\
\hline 40 & 2683925 & 5982550 & 122.0 & 52933.5 & 2.8 & 179.7 & 368.1459 & -188.4459 \\
\hline
\end{tabular}




\begin{tabular}{|c|c|c|c|c|c|c|c|c|}
\hline Stn & Easting & Northing & Height & Gravity & Topo & Bouguer & Local Reg. & Res \\
\hline 41 & 2683974 & 5982175 & 113.9 & 52954.2 & 3.0 & 180.2 & 373.9570 & -193.7570 \\
\hline 42 & 2684099 & 5982725 & 127.9 & 52928.0 & 2.8 & 186.4 & 367.8615 & -181.4615 \\
\hline 43 & 2684125 & 5982025 & 135.0 & 52916.0 & 2.9 & 180.6 & 377.9082 & -197.3082 \\
\hline 44 & 2684375 & 5981850 & 137.5 & 52913.7 & 2.8 & 180.8 & 383.4411 & -202.6411 \\
\hline 45 & 2684449 & 5981250 & 132.3 & 52921.8 & 2.7 & 173.0 & 392.6719 & -219.6719 \\
\hline 46 & 2684350 & 5980774 & 136.5 & 52917.8 & 2.6 & 173.8 & 398.0045 & -224.2045 \\
\hline 47 & 2684500 & 5980199 & 100.5 & 52998.0 & 2.7 & 176.6 & 407.7995 & -231.1995 \\
\hline 48 & 2684700 & 5979775 & 93.3 & 53030.1 & 2.5 & 190.6 & 416.1418 & -225.5418 \\
\hline 49 & 2687474 & 5981500 & 33.7 & 53189.5 & 3.1 & 244.7 & 427.4278 & -182.7278 \\
\hline 50 & 2687250 & 5981099 & 39.6 & 53200.7 & 3.0 & 264.5 & 430.1870 & -165.6870 \\
\hline 51 & 2686924 & 5980499 & 43.0 & 53212.8 & 3.0 & 278.5 & 434.3960 & -155.8960 \\
\hline 52 & 2686875 & 5980025 & 42.2 & 53225.4 & 2.8 & 284.9 & 440.3628 & -155.4628 \\
\hline 53 & 2686625 & 5979599 & 39.4 & 53236.6 & 2.8 & 287.4 & 443.0627 & -155.6627 \\
\hline 54 & 2686325 & 5979474 & 37.2 & 53252.3 & 2.8 & 297.6 & 440.9451 & -143.3451 \\
\hline 55 & 2685924 & 5979450 & 30.9 & 53243.4 & 2.8 & 276.8 & 436.1481 & -159.3481 \\
\hline 56 & 2685725 & 5979175 & 46.0 & 53242.0 & 2.7 & 302.7 & & -134.6927 \\
\hline 57 & 2685274 & 5979324 & 43.5 & 53140.6 & 2.7 & 197.6 & 429.6013 & -232.0013 \\
\hline 58 & 2684825 & 5979475 & 79.3 & 53351.9 & 2.6 & 481.7 & 64 & 59.8636 \\
\hline 59 & 2684524 & 5979600 & 70.4 & 53066.5 & 2.6 & 180.7 & 212 & -235.6212 \\
\hline 60 & 2684475 & 5979274 & 49.2 & 53124.1 & 2.7 & 192.7 & 420.1639 & -227.4639 \\
\hline 61 & 2683899 & 5979149 & 6.1 & 53202.4 & 2.9 & 187.3 & 414.6104 & -227.3104 \\
\hline 62 & 2683274 & 5978999 & 2.0 & 53207.6 & 3.0 & 183.7 & 408.8060 & -225.1060 \\
\hline 63 & 2682774 & 5982399 & 195.8 & 52864.4 & 2.5 & 258.4 & 356.0866 & -97.6866 \\
\hline 64 & 2683074 & 5981924 & 161.9 & 52900.0 & 2.6 & 220.0 & 366.3204 & -146.3204 \\
\hline 65 & 2682750 & 5980750 & 160.7 & 52960.0 & 2.4 & 267.5 & 378.4440 & -110.9440 \\
\hline 66 & 2683475 & 5980225 & 133.3 & 53041.7 & 2.6 & 287.9 & 159 & -106.7159 \\
\hline 67 & 2683149 & 5980224 & 138.6 & 53026.0 & 2.6 & 283.4 & 390.5733 & -107.1733 \\
\hline 68 & 2682750 & 5980399 & 156.0 & 52982.9 & 2.3 & 278.0 & 383.2375 & -105.2375 \\
\hline 69 & 2682274 & 5980374 & 166.5 & 52961.8 & 2.3 & 279.0 & 377.7003 & -98.7003 \\
\hline 70 & 2682300 & 5980774 & 117.1 & 52933.2 & 2.6 & 157.0 & 372.5704 & -215.5704 \\
\hline 71 & 2682449 & 5980924 & 167.5 & 52940.1 & 2.4 & 263.5 & 372.3555 & -108.8555 \\
\hline 72 & 2682849 & 5981199 & 164.0 & 52935.9 & 2.5 & 253.9 & 373.5179 & -119.6179 \\
\hline 73 & 2683149 & 5981099 & 140.9 & 52987.5 & 2.5 & 257.6 & 378.5940 & -120.9940 \\
\hline 74 & 2683149 & 5980700 & 131.7 & 53005.7 & 2.7 & 253.6 & 384.0641 & -130.4641 \\
\hline 75 & 2683800 & 5980224 & 61.6 & 53066.7 & 2.9 & 170.3 & 398.6846 & -228.3846 \\
\hline 76 & 2683524 & 5980649 & 76.6 & 53024.6 & 3.0 & 162.4 & 389.4186 & -227.0186 \\
\hline 77 & 2683799 & 5980750 & 71.6 & 53036.1 & 3.0 & 165.0 & 391.4550 & -226.4550 \\
\hline 78 & 2683499 & 5981100 & 77.4 & 53018.3 & 3.1 & 162.7 & 382.9149 & -220.2149 \\
\hline 79 & 2683750 & 5981450 & 87.2 & 52996.3 & 3.0 & 162.9 & 381.2083 & -218.3083 \\
\hline 80 & 2683425 & 5981599 & 93.7 & 52975.9 & 2.8 & 158.1 & 375.1291 & -217.0291 \\
\hline 81 & 2683549 & 5981950 & 104.7 & 52959.7 & 2.8 & 167.0 & 371.8167 & -204.8167 \\
\hline 82 & 2683324 & 5982176 & 118.4 & 52939.8 & 2.8 & 177.2 & 365.9184 & -188.7184 \\
\hline 83 & 2683100 & 5981425 & 97.2 & 52979.6 & 2.8 & 168.2 & 373.5106 & -205.3106 \\
\hline 84 & 2683225 & 5979799 & 68.7 & 53057.4 & 2.7 & 171.7 & 397.3166 & -225.6166 \\
\hline 85 & 2683524 & 5979724 & 57.9 & 53074.8 & 2.8 & 166.4 & 402.0708 & -235.6708 \\
\hline
\end{tabular}


Appendix C - Gravity Data

\begin{tabular}{|c|c|c|c|c|c|c|c|c|}
\hline Stn & Easting & Northing & Height & Gravity & Topo & Bouguer & Local Reg. & Res \\
\hline 86 & 2683774 & 5979574 & 48.6 & 53103.7 & 2.8 & 175.3 & 407.2466 & -231.9466 \\
\hline 87 & 2686700 & 5980624 & 49.2 & 53138.2 & 3.0 & 217.1 & 429.7907 & -212.6907 \\
\hline 88 & 2686525 & 5980899 & 83.9 & 53055.0 & 2.8 & 205.4 & 423.7276 & -218.3276 \\
\hline 89 & 2686199 & 5981325 & 129.9 & 52939.0 & 2.7 & 185.4 & 413.6467 & -228.2467 \\
\hline 90 & 2685900 & 5981624 & 168.7 & 52848.8 & 2.6 & 177.5 & 405.6945 & -228.1945 \\
\hline 91 & 2686700 & 5981799 & 114.5 & 52978.1 & 2.8 & 196.8 & 413.3698 & -216.5698 \\
\hline 92 & 2685524 & 5981599 & 169.1 & 52869.2 & 2.6 & 197.5 & 401.3057 & -203.8057 \\
\hline 93 & 2685049 & 5981600 & 154.3 & 52903.1 & 2.7 & 201.0 & 395.3278 & -194.3278 \\
\hline 94 & 2684999 & 5982000 & 143.7 & 52914.1 & 2.8 & 194.6 & 389.1387 & -194.5387 \\
\hline 95 & 2684599 & 5981850 & 143.6 & 52912.5 & 2.8 & 191.5 & 386.2310 & -194.7310 \\
\hline 96 & 2684750 & 5981424 & 144.0 & 52923.5 & 2.7 & 199.9 & 394.0263 & -194.1263 \\
\hline 97 & 2684549 & 5982275 & 135.2 & 52931.8 & 2.9 & 198.6 & 7015 & -181.1015 \\
\hline 98 & 2685424 & 5981224 & 180.3 & 52852.5 & 2.5 & 201.1 & 624 & -204.1624 \\
\hline 99 & 2685849 & 5981074 & 141.5 & 52943.5 & 2.6 & 211.5 & 412.7118 & -201.2118 \\
\hline 100 & 2686125 & 5980624 & 86.6 & 53083.1 & 2.8 & 236.3 & 422.4655 & -186.1655 \\
\hline 101 & 2686600 & 5980250 & 27.8 & 53227.9 & 2.9 & 261.2 & 433.7153 & -172.5153 \\
\hline 102 & 2686275 & 5979774 & 59.0 & 53166.6 & 2.7 & 257.6 & 436.1589 & -178.5589 \\
\hline 103 & 2685999 & 5978800 & 46.4 & 53213.8 & 2.6 & 271.9 & 446.0508 & -174.1508 \\
\hline 104 & 2685350 & 5978800 & 61.3 & 53173.2 & 2.5 & 261.1 & 527 & -176.6527 \\
\hline 105 & 2684449 & 597 & 11.4 & 46.6 & 2.9 & 139.2 & 953 & -283.6953 \\
\hline 106 & 2682625 & 5979549 & 94.3 & 53046.5 & 2.3 & 210.8 & 519 & -182.4519 \\
\hline 107 & 2683675 & 5979349 & 68.0 & 53111.4 & 2.7 & 220.3 & 409.0730 & -188.7730 \\
\hline 108 & 2682800 & 5979099 & 2.0 & 53191.4 & 3.0 & 169.7 & 401.5285 & -231.8285 \\
\hline 109 & 2682324 & 5979299 & 2.0 & 53181.6 & 3.1 & 164.4 & 392.9031 & -228.5031 \\
\hline 110 & 2681875 & 5979424 & 2.0 & 53172.4 & 3.2 & 159.5 & 385.6575 & -226.1575 \\
\hline 111 & 2684100 & 5978699 & 2.0 & 53232.3 & 2.9 & 203.7 & 423.2678 & -219.5678 \\
\hline 112 & 2684650 & 5978575 & 2.0 & 53238.0 & 2.9 & 207.5 & 431.9195 & -224.4195 \\
\hline 113 & 2685324 & 5978425 & 2.0 & 53251.0 & 2.6 & 218.7 & 442.5491 & -223.8491 \\
\hline 114 & 2686175 & 5978324 & 6.0 & 53177.2 & 2.6 & 151.5 & 454.8434 & -303.3434 \\
\hline 115 & 2683749 & 5978849 & 2.0 & 53222.8 & 3.0 & 196.2 & 416.8046 & -220.6046 \\
\hline 116 & 2683250 & 5979449 & 52.3 & 53089.1 & 2.8 & 167.5 & 402.3933 & -234.8933 \\
\hline 117 & 2682675 & 5979849 & 80.8 & 53017.5 & 2.4 & 158.1 & 389.7984 & -231.6984 \\
\hline 118 & 2682224 & 5979849 & 84.2 & 53001.7 & 2.5 & 151.6 & 384.2158 & -232.6158 \\
\hline 119 & 2684924 & 5978900 & 51.3 & 53125.6 & 2.6 & 194.7 & 430.9631 & -236.2631 \\
\hline 120 & 2685400 & 5979750 & 11.2 & 53198.3 & 3.0 & 196.2 & 425.3444 & -229.1444 \\
\hline 121 & 2684825 & 5980375 & 132.0 & 52920.5 & 2.6 & 164.5 & 409.4655 & -244.9655 \\
\hline 122 & 2685124 & 5980800 & 132.0 & 52920.5 & 2.6 & 167.5 & 407.3618 & -239.8618 \\
\hline 123 & 2685980 & 5979197 & 4.6 & 53245.6 & 2.9 & 226.2 & 440.3486 & -214.1486 \\
\hline
\end{tabular}


- 158 - 


\section{Appendix D}

\section{AMT Data Generated by AMTAV}

The smoothed results from AMTAV are shown in this appendix. The results from bands 1, 2 and 3 sites WKH2,WPP 2 and WPP 3 are combined, with only those used for the analysis shown. 
Key to abbreviations found in Appendices D and E

\begin{tabular}{ll} 
Symbol & Description \\
\hline R & real part of the $\mathrm{Z}_{\mathrm{NN}}$ \\
I & imaginary part of the $\mathrm{Z}_{\mathrm{NN}}$ \\
RHOE & E polarization apparent resistivity estimate \\
ELRHE & $\log$ (E polarization resistivity error value) \\
PHAE & E polarization phase estimate \\
EPHAE & $\log$ (E polarization phase error estimate) \\
RHOH & H polarization apparent resistivity estimate \\
ELRHH & $\log$ (H polarization resistivity error value) \\
PHAH & H polarization phase estimate \\
EPHAH & log (H polarization phase error estimate) \\
AZIM & azimuth of the principle impedance \\
D1,D2,D3,SKEW & dimensionality indices \\
RHO & determinant apparent resistivity \\
ELRH & log (determinant apparent resistivity error) \\
PHA & determinant phase \\
EPHA & error in the determinant phase
\end{tabular}




\section{WKH2}

\section{E and H Polarisation, Apparent Resistivities and Phases}

\begin{tabular}{lrrrrrrrr} 
Period & RHOE & ELRHE & PHAE & EPHAE & RHOH & ELRHH & PHAH & EPHAH \\
\hline 4.87000 & 44.39 & .491 & 88.1 & 77.3 & 1788.24 & .076 & 44.6 & 10.3 \\
3.65000 & 44.02 & .379 & 67.1 & 57.8 & 867.15 & .072 & 46.6 & 10.2 \\
2.73800 & 51.45 & .268 & 55.7 & 39.1 & 570.11 & .065 & 48.3 & 9.3 \\
2.05400 & 61.72 & .148 & 51.7 & 20.3 & 447.30 & .051 & 48.2 & 7.2 \\
1.54000 & 67.51 & .101 & 51.8 & 13.4 & 360.74 & .042 & 45.6 & 6.2 \\
1.15500 & 81.34 & .099 & 53.6 & 13.0 & 359.07 & .044 & 41.2 & 6.5 \\
0.86600 & 102.57 & .081 & 52.7 & 10.9 & 361.26 & .039 & 41.4 & 5.7 \\
0.64900 & 108.33 & .059 & 50.0 & 8.3 & 276.67 & .033 & 41.4 & 4.8 \\
0.48700 & 110.45 & .045 & 48.9 & 6.3 & 206.95 & .031 & 42.0 & 4.4 \\
0.36500 & 106.36 & .037 & 49.4 & 5.3 & 164.04 & .029 & 42.7 & 4.2 \\
0.27400 & 86.90 & .030 & 49.5 & 4.2 & 127.61 & .024 & 43.9 & 3.5 \\
0.20500 & 63.73 & .026 & 50.1 & 3.7 & 107.43 & .020 & 45.2 & 2.9 \\
0.15400 & 46.11 & .025 & 53.8 & 3.5 & 82.65 & .019 & 47.7 & 2.6 \\
0.11500 & 35.98 & .022 & 57.6 & 3.0 & 63.69 & .017 & 50.5 & 2.3 \\
0.08660 & 29.95 & .020 & 61.3 & 2.6 & 52.63 & .015 & 53.9 & 2.0 \\
0.06490 & 27.66 & .017 & 65.1 & 2.2 & 45.81 & .013 & 57.5 & 1.7 \\
0.04870 & 28.89 & .015 & 67.9 & 2.0 & 42.35 & .013 & 59.7 & 1.6 \\
0.03650 & 33.23 & .014 & 67.7 & 1.8 & 49.50 & .011 & 60.0 & 1.5 \\
0.02740 & 40.57 & .013 & 68.0 & 1.7 & 64.07 & .010 & 59.5 & 1.3 \\
0.02050 & 50.02 & .013 & 68.0 & 1.6 & 84.01 & .009 & 58.0 & 1.3 \\
0.01540 & 65.81 & .018 & 66.4 & 2.4 & 125.51 & .012 & 55.4 & 1.7 \\
0.01150 & 84.25 & .032 & 65.4 & 4.4 & 195.12 & .019 & 53.6 & 2.6 \\
0.00866 & 114.63 & .039 & 66.2 & 5.5 & 297.36 & .023 & 51.5 & 3.2 \\
0.00649 & 140.63 & .041 & 63.9 & 5.7 & 368.96 & .024 & 50.6 & 3.4 \\
0.00487 & 173.77 & .045 & 59.8 & 6.3 & 457.69 & .027 & 49.8 & 3.8 \\
0.00365 & 192.11 & .043 & 57.1 & 5.9 & 497.03 & .025 & 49.1 & 3.6 \\
0.00274 & 214.85 & .026 & 51.7 & 3.6 & 494.07 & .017 & 50.5 & 2.4
\end{tabular}




\section{Dimensionality Indices}

\begin{tabular}{rrrrrr} 
Period & AZIM & D1 & D2 & D3 & SKEW \\
\hline 4.87000 & -22.5 & .488 & .391 & .121 & .247 \\
3.65000 & -28.7 & .519 & .334 & .147 & .283 \\
2.73800 & -39.1 & .593 & .273 & .135 & .227 \\
2.05400 & -58.6 & .669 & .238 & .093 & .139 \\
1.54000 & -53.7 & .648 & .267 & .086 & .132 \\
1.15500 & -51.7 & .645 & .304 & .051 & .080 \\
0.86600 & -50.4 & .715 & .261 & .024 & .033 \\
0.64900 & -38.3 & .721 & .184 & .095 & .132 \\
0.48700 & -27.2 & .836 & .095 & .070 & .083 \\
0.36500 & 83.6 & .964 & .024 & .013 & .013 \\
0.27400 & 13.5 & .861 & .099 & .041 & .047 \\
0.20500 & 13.5 & .831 & .117 & .052 & .063 \\
0.15400 & 14.0 & .808 & .146 & .046 & .057 \\
0.11500 & 13.6 & .773 & .181 & .047 & .060 \\
0.08660 & 10.0 & .870 & .100 & .030 & .034 \\
0.06490 & -2.8 & .869 & .097 & .034 & .039 \\
0.04870 & -.7 & .858 & .118 & .024 & .028 \\
0.03650 & .2 & .860 & .104 & .037 & .043 \\
0.02740 & 8.9 & .845 & .106 & .049 & .058 \\
0.02050 & -18.4 & .852 & .098 & .050 & .059 \\
0.01540 & -11.1 & .811 & .155 & .034 & .042 \\
0.01150 & -9.5 & .781 & .184 & .035 & .045 \\
0.00866 & -9.7 & .736 & .201 & .063 & .086 \\
0.00649 & -8.3 & .700 & .236 & .064 & .091 \\
0.00487 & -19.7 & .690 & .206 & .104 & .151 \\
0.00365 & -6.1 & .772 & .143 & .085 & .110 \\
0.00274 & -4.6 & .780 & .161 & .059 & .076 \\
& & & & &
\end{tabular}




\section{Invariant Apparent Resistivity and Phase}

\begin{tabular}{lrrrr} 
Period & RHO & ELRH & PHA & EPHA \\
\hline 4.87000 & 320.59 & .454 & 48.2 & 71.0 \\
3.65000 & 216.28 & .355 & 46.0 & 48.2 \\
2.73800 & 183.94 & .256 & 46.0 & 30.6 \\
2.05400 & 171.52 & .151 & 46.7 & 16.4 \\
1.54000 & 157.78 & .107 & 47.3 & 12.1 \\
1.15500 & 173.03 & .105 & 47.2 & 11.8 \\
0.86600 & 193.47 & .088 & 46.9 & 10.0 \\
0.64900 & 173.08 & .069 & 45.7 & 7.3 \\
0.48700 & 151.55 & .055 & 45.4 & 5.6 \\
0.36500 & 132.50 & .048 & 46.0 & 4.9 \\
0.27400 & 105.71 & .038 & 46.6 & 4.1 \\
0.20500 & 83.15 & .033 & 47.6 & 3.6 \\
0.15400 & 62.04 & .031 & 50.7 & 3.9 \\
0.11500 & 48.10 & .027 & 54.0 & 3.8 \\
0.08660 & 39.87 & .023 & 57.6 & 3.8 \\
0.06490 & 35.70 & .020 & 61.4 & 3.7 \\
0.04870 & 35.05 & .018 & 63.9 & 3.7 \\
0.03650 & 40.68 & .016 & 63.9 & 3.3 \\
0.02740 & 51.14 & .015 & 63.8 & 3.1 \\
0.02050 & 65.03 & .015 & 63.0 & 2.9 \\
0.01540 & 91.23 & .021 & 61.0 & 3.6 \\
0.01150 & 128.78 & .036 & 59.5 & 5.6 \\
0.00866 & 186.32 & .044 & 58.7 & 6.8 \\
0.00649 & 230.85 & .046 & 57.2 & 7.0 \\
0.00487 & 285.74 & .051 & 54.8 & 7.4 \\
0.00365 & 312.48 & .049 & 53.1 & 6.8 \\
0.00274 & 327.65 & .031 & 51.4 & 3.9
\end{tabular}




\section{WPP2}

\section{E and H Polarisation, Apparent Resistivities and Phases}

\begin{tabular}{lrrrrrrrr} 
Period & RHOE & ELRHE & PHAE & EPHAE & RHOH & ELRHH & PHAH & EPHAH \\
\hline 4.87000 & 43.31 & .101 & 24.7 & 13.9 & 132.00 & .055 & 44.1 & 7.0 \\
3.65000 & 35.54 & .102 & 27.5 & 13.9 & 116.19 & .052 & 38.1 & 7.1 \\
2.73800 & 31.80 & .106 & 31.3 & 14.2 & 105.32 & .057 & 34.9 & 7.5 \\
2.05400 & 33.99 & .084 & 34.8 & 11.4 & 95.72 & .051 & 35.9 & 6.7 \\
1.54000 & 32.38 & .081 & 38.5 & 11.3 & 79.65 & .053 & 35.6 & 7.0 \\
1.15500 & 32.19 & .084 & 43.0 & 12.5 & 73.62 & .058 & 36.2 & 7.8 \\
0.86600 & 32.51 & .091 & 47.9 & 13.0 & 69.66 & .065 & 36.5 & 8.6 \\
0.48700 & 40.21 & .076 & 52.6 & 11.0 & 48.97 & .068 & 34.9 & 9.6 \\
0.36500 & 44.02 & .067 & 35.3 & 9.4 & 46.11 & .067 & 55.8 & 9.7 \\
0.27400 & 35.81 & .057 & 37.9 & 8.1 & 42.53 & .052 & 58.8 & 7.5 \\
0.20500 & 27.48 & .043 & 43.7 & 6.0 & 32.83 & .035 & 60.4 & 5.1 \\
0.15400 & 22.45 & .031 & 50.3 & 4.4 & 24.03 & .026 & 61.6 & 3.6 \\
0.11500 & 17.05 & .015 & 62.3 & 2.1 & 19.48 & .016 & 56.0 & 2.3 \\
0.08660 & 13.63 & .007 & 63.3 & 1.0 & 17.37 & .006 & 61.7 & .9 \\
0.06490 & 13.26 & .005 & 63.6 & .6 & 17.74 & .004 & 65.4 & .6 \\
0.04870 & 14.95 & .004 & 64.2 & .5 & 19.76 & .003 & 65.9 & .5 \\
0.03650 & 17.28 & .004 & 63.7 & .5 & 22.42 & .003 & 65.6 & .5 \\
0.02740 & 20.97 & .004 & 62.2 & .6 & 26.29 & .004 & 65.2 & .5 \\
0.20500 & 27.48 & .043 & 43.7 & 6.0 & 32.83 & .035 & 60.4 & 5.1 \\
0.15400 & 22.45 & .031 & 50.3 & 4.4 & 24.03 & .026 & 61.6 & 3.6 \\
0.11500 & 17.05 & .015 & 62.3 & 2.1 & 19.48 & .016 & 56.0 & 2.3 \\
0.08660 & 13.63 & .007 & 63.3 & 1.0 & 17.37 & .006 & 61.7 & .9 \\
0.06490 & 13.26 & .005 & 63.6 & .6 & 17.74 & .004 & 65.4 & .6 \\
0.04870 & 14.95 & .004 & 64.2 & .5 & 19.76 & .003 & 65.9 & .5 \\
0.03650 & 17.28 & .004 & 63.7 & .5 & 22.42 & .003 & 65.6 & .5 \\
0.02740 & 20.97 & .004 & 62.2 & .6 & 26.29 & .004 & 65.2 & .5 \\
0.02050 & 25.68 & .006 & 59.6 & .7 & 31.43 & .005 & 64.4 & .7 \\
0.01540 & 34.79 & .010 & 57.4 & 1.3 & 38.44 & .010 & 61.5 & 1.4 \\
0.01150 & 43.90 & .015 & 58.5 & 2.1 & 46.67 & .013 & 55.0 & 1.8 \\
0.00866 & 63.19 & .017 & 53.4 & 2.4 & 49.12 & .022 & 55.8 & 3.0 \\
0.00649 & 74.18 & .019 & 51.6 & 2.6 & 50.53 & .024 & 53.4 & 3.4 \\
0.00487 & 85.02 & .020 & 48.9 & 2.9 & 47.94 & .027 & 51.4 & 3.9 \\
0.00365 & 85.25 & .018 & 46.2 & 2.5 & 39.55 & .025 & 50.7 & 3.6 \\
0.00274 & 78.35 & .013 & 42.8 & 1.9 & 33.77 & .020 & 51.3 & 2.9
\end{tabular}




\section{Dimensionality Indices}

\begin{tabular}{rrrrrr} 
Period & AZIM & D1 & D2 & D3 & SKEW \\
\hline 4.87000 & -9.8 & .604 & .254 & .142 & .235 \\
3.65000 & -12.2 & .650 & .258 & .092 & .142 \\
2.73800 & -4.9 & .747 & .188 & .065 & .087 \\
2.05400 & -6.6 & .786 & .132 & .081 & .103 \\
1.54000 & -9.2 & .758 & .179 & .063 & .083 \\
1.15500 & -14.8 & .742 & .182 & .076 & .102 \\
0.86600 & -60.6 & .752 & .186 & .062 & .082 \\
0.48700 & .1 & .676 & .125 & .200 & .296 \\
0.36500 & -59.5 & .710 & .161 & .130 & .183 \\
0.27400 & -48.0 & .729 & .190 & .081 & .111 \\
0.20500 & -52.9 & .778 & .168 & .054 & .069 \\
0.15400 & 42.7 & .833 & .115 & .052 & .062 \\
0.11500 & -7.7 & .899 & .071 & .029 & .033 \\
0.08660 & -13.9 & .905 & .069 & .026 & .029 \\
0.06490 & -13.6 & .897 & .073 & .030 & .034 \\
0.04870 & -13.9 & .913 & .065 & .022 & .024 \\
0.03650 & -23.6 & .917 & .060 & .023 & .025 \\
0.02740 & -25.0 & .910 & .058 & .032 & .035 \\
0.02050 & -22.0 & .912 & .053 & .036 & .039 \\
0.01540 & -32.6 & .900 & .068 & .032 & .035 \\
0.01150 & -36.3 & .875 & .083 & .042 & .049 \\
0.00866 & 80.4 & .910 & .060 & .030 & .033 \\
0.00649 & -75.4 & .823 & .115 & .062 & .075 \\
0.00487 & -78.6 & .808 & .151 & .041 & .051 \\
0.00365 & 60.5 & .851 & .114 & .034 & .040 \\
0.00274 & 60.2 & .784 & .177 & .039 & .049
\end{tabular}




\section{Invariant Apparent Resistivity and Phase}

\begin{tabular}{llllr} 
Period & RHO & ELR & PHA & EPH \\
\hline 4.87000 & 77.24 & .107 & 35.1 & 8.1 \\
3.65000 & 66.80 & .105 & 33.4 & 7.7 \\
2.73800 & 60.63 & .108 & 33.5 & 8.2 \\
2.05400 & 58.53 & .091 & 35.6 & 7.2 \\
1.54000 & 51.51 & .092 & 37.3 & 7.7 \\
1.15500 & 49.99 & .102 & 39.6 & 9.0 \\
0.86600 & 49.84 & .113 & 41.5 & 10.2 \\
0.48700 & 46.44 & .109 & 42.6 & 10.2 \\
0.36500 & 47.43 & .101 & 44.3 & 9.8 \\
0.27400 & 40.43 & .081 & 47.4 & 8.4 \\
0.20500 & 30.28 & .056 & 51.9 & 6.5 \\
0.15400 & 23.36 & .040 & 55.8 & 5.1 \\
0.11500 & 18.28 & .022 & 59.2 & 3.1 \\
0.08660 & 15.38 & .010 & 62.5 & 1.7 \\
0.06490 & 15.35 & .006 & 64.6 & 1.2 \\
0.04870 & 17.21 & .005 & 65.1 & 1.1 \\
0.03650 & 19.72 & .005 & 64.7 & 1.0 \\
0.02740 & 23.52 & .006 & 63.7 & 1.0 \\
0.02050 & 28.45 & .007 & 62.1 & 1.3 \\
0.01540 & 36.62 & .013 & 59.5 & 2.0 \\
0.01150 & 45.42 & .019 & 56.8 & 2.7 \\
0.00866 & 55.87 & .027 & 54.7 & 3.6 \\
0.00649 & 61.38 & .030 & 52.6 & 3.9 \\
0.00487 & 64.04 & .034 & 50.2 & 4.2 \\
0.00365 & 58.31 & .030 & 48.6 & 3.6 \\
0.00274 & 51.58 & .024 & 47.3 & 2.7 \\
& & & &
\end{tabular}




\section{WPP3}

\section{E and H Polarisation, Apparent Resistivities and Phases}

\section{Period RHOE ELRHE PHAE EPHAE RHOH ELRHH PHAH EPHAH}

$\begin{array}{rrrrrrrrr}4.87000 & 20.41 & .227 & 23.6 & 33.3 & 1090.34 & .029 & 37.5 & 4.0 \\ 3.65000 & 16.74 & .184 & 24.7 & 26.4 & 611.13 & .029 & 41.2 & 4.1 \\ 2.73800 & 14.67 & .154 & 28.4 & 21.6 & 407.45 & .029 & 42.5 & 4.0 \\ 2.05400 & 14.56 & .129 & 33.1 & 17.8 & 290.76 & .029 & 43.5 & 3.9 \\ 1.54000 & 15.06 & .123 & 38.7 & 16.4 & 264.60 & .027 & 40.7 & 3.8 \\ 0.15500 & 16.52 & .100 & 44.3 & 14.3 & 219.93 & .025 & 39.9 & 3.5 \\ 0.86600 & 18.73 & .076 & 48.7 & 10.9 & 154.23 & .024 & 40.4 & 3.4 \\ 0.64900 & 20.85 & .053 & 50.3 & 7.6 & 107.41 & .022 & 42.7 & 3.1 \\ 0.48700 & 22.33 & .039 & 50.4 & 5.6 & 83.09 & .019 & 44.7 & 2.8 \\ 0.36500 & 24.38 & .039 & 49.6 & 5.6 & 75.01 & .022 & 46.1 & 3.1 \\ 0.27400 & 25.00 & .034 & 51.1 & 4.9 & 63.26 & .021 & 46.7 & 3.0 \\ 0.20500 & 25.67 & .028 & 53.6 & 4.0 & 50.20 & .018 & 48.3 & 2.6 \\ 0.15400 & 26.84 & .024 & 56.1 & 3.4 & 39.79 & .017 & 50.8 & 2.4 \\ 0.11500 & 27.12 & .020 & 59.1 & 2.9 & 31.34 & .015 & 53.5 & 2.2 \\ 0.08660 & 27.13 & .010 & 63.0 & 1.4 & 23.17 & .010 & 56.6 & 1.4 \\ 0.06490 & 29.44 & .006 & 63.9 & .8 & 20.56 & .007 & 60.2 & 1.0 \\ 0.04870 & 32.42 & .005 & 64.0 & .7 & 21.68 & .006 & 62.4 & .9 \\ 0.03650 & 36.24 & .004 & 63.8 & .6 & 24.46 & .005 & 63.3 & .7 \\ 0.02740 & 42.91 & .004 & 63.4 & .6 & 30.10 & .005 & 63.9 & .7 \\ 0.02050 & 52.14 & .005 & 62.7 & .6 & 37.74 & .005 & 63.9 & .8 \\ 0.01540 & 58.00 & .006 & 61.7 & .8 & 41.31 & .007 & 62.8 & .9 \\ 0.01150 & 63.77 & .008 & 59.9 & 1.1 & 43.92 & .010 & 61.4 & 1.3 \\ 0.00866 & 75.69 & .010 & 58.3 & 1.4 & 47.61 & .013 & 58.2 & 1.8 \\ 0.00649 & 89.39 & .012 & 57.3 & 1.6 & 50.60 & .016 & 53.6 . & 2.2 \\ 0.00487 & 110.36 & .013 & 54.7 & 1.9 & 54.49 & .019 & 48.6 & 2.6 \\ 0.00365 & 143.08 & .014 & 52.5 & 1.9 & 64.62 & .020 & 44.1 & 2.9 \\ 0.00274 & 199.54 & .013 & 51.2 & 1.8 & 81.37 & .020 & 39.0 & 2.9\end{array}$


Dimensionality Indices

\begin{tabular}{lrrrrr} 
Period & AZIM & D1 & D2 & D3 & SKEW \\
\hline & & & & & \\
4.87000 & -60.1 & .525 & .405 & .070 & .133 \\
3.65000 & -52.3 & .563 & .363 & .074 & .131 \\
2.73800 & -51.8 & .542 & .358 & .100 & .185 \\
2.05400 & -51.9 & .545 & .390 & .065 & .119 \\
1.54000 & -50.5 & .559 & .387 & .054 & .096 \\
1.15500 & -55.5 & .605 & .333 & .062 & .103 \\
0.86600 & -54.2 & .627 & .293 & .080 & .128 \\
0.64900 & -57.4 & .635 & .243 & .123 & .193 \\
0.48700 & -66.6 & .715 & .200 & .085 & .118 \\
0.36500 & -59.0 & .759 & .198 & .043 & .056 \\
0.27400 & -54.5 & .821 & .162 & .017 & .020 \\
0.20500 & -49.8 & .726 & .188 & .086 & .119 \\
0.15400 & -42.2 & .782 & .144 & .074 & .095 \\
0.11500 & 80.3 & .852 & .084 & .064 & .075 \\
0.08660 & -88.8 & .892 & .086 & .022 & .025 \\
0.06490 & 77.3 & .877 & .099 & .023 & .027 \\
0.04870 & 65.3 & .868 & .099 & .033 & .038 \\
0.03650 & 66.8 & .865 & .087 & .048 & .055 \\
0.02740 & 69.0 & .866 & .080 & .054 & .062 \\
0.02050 & 60.0 & .882 & .063 & .055 & .062 \\
0.01540 & 36.3 & .894 & .058 & .048 & .054 \\
0.01150 & 29.7 & .884 & .070 & .046 & .052 \\
0.00866 & 80.2 & .842 & .101 & .056 & .067 \\
0.00649 & 68.8 & .842 & .114 & .044 & .052 \\
0.00487 & 45.5 & .809 & .158 & .033 & .040 \\
0.00365 & 37.1 & .780 & .186 & .035 & .045 \\
0.00274 & 35.4 & .761 & .194 & .045 & .059
\end{tabular}




\section{Invariant Apparent Resistivity and Phase}

\begin{tabular}{rrrrr} 
Period & \multicolumn{1}{c}{ RHO } & ELR & PHA & EPH \\
\hline 4.87000 & 162.21 & .209 & 30.8 & 13.4 \\
3.65000 & 109.15 & .172 & 33.4 & 11.8 \\
2.73800 & 82.50 & .145 & 35.9 & 10.9 \\
2.05400 & 68.51 & .122 & 38.8 & 10.1 \\
1.54000 & 65.96 & .116 & 40.4 & 9.9 \\
1.15500 & 62.12 & .099 & 43.1 & 9.1 \\
0.86600 & 54.97 & .077 & 45.5 & 7.8 \\
0.64900 & 48.08 & .056 & 47.3 & 6.1 \\
0.48700 & 43.57 & .044 & 48.3 & 5.0 \\
0.36500 & 43.52 & .044 & 48.4 & 5.1 \\
0.27400 & 40.30 & .039 & 48.9 & 4.6 \\
0.20500 & 36.12 & .033 & 50.8 & 3.9 \\
0.15400 & 32.82 & .029 & 53.3 & 3.7 \\
0.11500 & 29.28 & .025 & 56.2 & 3.3 \\
0.08660 & 25.03 & .014 & 59.7 & 2.2 \\
0.06490 & 24.59 & .009 & 62.1 & 1.7 \\
0.04870 & 26.59 & .008 & 63.3 & 1.5 \\
0.03650 & 29.93 & .006 & 63.6 & 1.3 \\
0.02740 & 36.20 & .006 & 63.7 & 1.2 \\
0.02050 & 44.75 & .007 & 63.3 & 1.4 \\
0.01540 & 49.42 & .009 & 62.3 & 1.7 \\
0.01150 & 53.32 & .012 & 60.7 & 2.1 \\
0.00866 & 60.39 & .016 & 58.3 & 2.5 \\
0.00649 & 67.47 & .019 & 55.5 & 2.7 \\
0.00487 & 77.62 & .023 & 51.7 & 2.9 \\
0.00365 & 96.08 & .024 & 48.4 & 2.8 \\
0.00274 & 127.30 & .024 & 45.2 & 2.4
\end{tabular}




\section{PN2}

\section{E and H Polarisation, Apparent Resistivities and Phases}

\begin{tabular}{rrrrrrrrr}
\multicolumn{1}{c}{ Period } & RHOE & ELRHE & PHAE & EPHAE & RHOH & ELRHH & PHAH & EPHAH \\
\hline 15.40000 & 38.252 & .021 & 13.6 & 2.6 & 7.515 & .045 & -14.1 & 45.7 \\
11.55000 & 27.670 & .020 & 12.2 & 2.6 & 4.377 & .050 & -9.1 & 46.7 \\
8.65900 & 18.990 & .020 & 10.2 & 2.8 & 2.888 & .052 & -19.3 & 47.2 \\
6.49400 & 10.551 & .021 & 10.7 & 3.3 & 1.876 & .144 & -15.5 & 47.0 \\
4.86900 & 8.371 & .118 & 17.4 & 6.8 & 2.826 & .234 & -4.1 & 41.8 \\
3.65200 & 7.260 & .214 & 23.9 & 10.2 & 4.696 & .325 & 4.3 & 36.5 \\
0.08660 & 213.226 & .344 & 41.4 & 18.8 & 925.026 & .322 & 43.4 & 15.0 \\
0.06490 & 230.722 & .344 & 41.4 & 18.7 & 1071.972 & .322 & 43.4 & 15.2 \\
0.01540 & 139.119 & .229 & 58.3 & 8.3 & 436.785 & .222 & 28.2 & 10.8 \\
0.01160 & 112.587 & .140 & 59.4 & 7.7 & 270.782 & .129 & 22.2 & 8.0 \\
0.00866 & 89.247 & .046 & 59.9 & 7.0 & 163.801 & .035 & 15.3 & 4.8 \\
0.00649 & 62.073 & .043 & 58.5 & 6.3 & 85.287 & .038 & 12.4 & 5.3 \\
0.00487 & 40.325 & .038 & 53.7 & 5.3 & 38.406 & .039 & 10.4 & 5.8 \\
0.00365 & 22.192 & .035 & 48.0 & 4.9 & 18.265 & .039 & 12.0 & 5.7 \\
0.00274 & 12.505 & .031 & 41.9 & 4.4 & 7.409 & .042 & 11.2 & 6.0
\end{tabular}

\section{Dimensionality Indices}

\begin{tabular}{rrrrrr} 
Period & AZIM & D1 & D2 & D3 & SKEW \\
\hline 15.39900 & 30.4 & .624 & .288 & .088 & .141 \\
11.54800 & 27.6 & .612 & .320 & .068 & .111 \\
8.65900 & 31.7 & .674 & .268 & .058 & .087 \\
6.49400 & 41.3 & .561 & .336 & .103 & .184 \\
4.86900 & 41.8 & .490 & .365 & .145 & .297 \\
3.65200 & 35.5 & .511 & .398 & .091 & .179 \\
0.08660 & 2.8 & .707 & .246 & .047 & .066 \\
0.06490 & -3.2 & .683 & .213 & .105 & .153 \\
0.01540 & -47.4 & .629 & .257 & .114 & .180 \\
0.01155 & -48.2 & .560 & .292 & .148 & .265 \\
0.00866 & -49.8 & .594 & .268 & .138 & .233 \\
0.00649 & -45.6 & .634 & .246 & .121 & .190 \\
0.00487 & -45.1 & .597 & .259 & .144 & .242 \\
0.00365 & 43.6 & .551 & .252 & .198 & .359 \\
0.00274 & 43.9 & .572 & .237 & .191 & .334
\end{tabular}




\section{Invariant Apparent Resistivity and Phase}

\begin{tabular}{rrrrr}
\multicolumn{1}{c}{ Period } & \multicolumn{1}{c}{ RHO } & ELRH & PHA & EPHA \\
\hline 15.40000 & 16.709 & .052 & 29.7 & 40.3 \\
11.55000 & 11.341 & .054 & 37.4 & 40.2 \\
8.65900 & 7.642 & .055 & 50.7 & 40.2 \\
6.49400 & 3.684 & .071 & 48.7 & 40.3 \\
4.86900 & 3.608 & .161 & 57.4 & 40.2 \\
3.65200 & 3.675 & .251 & 64.7 & 40.2 \\
0.08660 & 493.593 & .348 & 40.5 & 15.5 \\
0.06490 & 529.358 & .368 & 38.4 & 14.5 \\
0.01540 & 223.434 & .284 & 37.4 & 6.7 \\
0.01160 & 156.352 & .179 & 37.9 & 6.4 \\
0.00866 & 103.685 & .074 & 38.0 & 6.0 \\
0.00649 & 60.012 & .079 & 37.9 & 6.3 \\
0.00487 & 32.474 & .077 & 36.9 & 5.9 \\
0.00365 & 14.865 & .073 & 35.7 & 5.5 \\
0.00274 & 6.345 & .077 & 34.6 & 5.7
\end{tabular}




\section{Appendix E}

\section{Data from best fitting Monte-Carlo models}

This final appendix contains the calculated apparent resistivity and phase data for the best fitting Monte-Carlo models at each of the four sites, WKH2, WPP2, WPP3 and PN2. 


\section{WKH2}

Apparent resistivity and Phase for best fitting Monte-Carlo model

\begin{tabular}{lrr} 
Period & Apparent Resistivity & Phase \\
\hline & & \\
4.87 & 110.6686 & 40.0 \\
3.65 & 107.0514 & 39.5 \\
2.738 & 103.0884 & 38.9 \\
2.054 & 98.7875 & 38.4 \\
1.540 & 94.1718 & 37.9 \\
1.155 & 89.2825 & 37.4 \\
0.866 & 84.1826 & 37.1 \\
0.649 & 78.9587 & 36.9 \\
0.487 & 73.7229 & 37.0 \\
0.365 & 68.6128 & 37.3 \\
0.274 & 63.7912 & 38.0 \\
0.205 & 59.4452 & 39.2 \\
0.154 & 55.7864 & 41.0 \\
0.115 & 53.0534 & 43.3 \\
0.0866 & 51.5184 & 46.2 \\
0.0649 & 51.4985 & 49.7 \\
0.0487 & 53.3715 & 53.4 \\
0.0365 & 57.5961 & 57.2 \\
0.0274 & 64.7294 & 60.7 \\
0.0205 & 75.4292 & 63.5 \\
0.0154 & 90.4106 & 65.5 \\
0.0155 & 110.2987 & 66.3 \\
0.00866 & 135.2780 & 66.0 \\
0.00649 & 164.4433 & 64.3 \\
0.00487 & 194.9510 & 61.5 \\
0.00365 & 221.6639 & 57.7 \\
0.00274 & 238.5948 & 53.5 \\
0.00205 & 242.3859 & 49.4 \\
0.00154 & 234.9669 & 46.3 \\
0.00116 & 222.2207 & 44.5
\end{tabular}




\section{WPP2}

Apparent resistivity and Phase for best fitting Monte-Carlo model

\begin{tabular}{lcc} 
Period & Apparent Resistivity & Phase \\
\hline 6.49 & 35.9379 & 39.5 \\
4.87 & 34.6288 & 38.9 \\
3.65 & 33.2062 & 38.3 \\
2.738 & 31.6769 & 37.8 \\
2.054 & 30.0535 & 37.3 \\
1.54 & 28.3555 & 36.9 \\
1.155 & 26.6099 & 36.6 \\
0.866 & 24.8514 & 36.5 \\
0.649 & 23.1229 & 36.6 \\
0.487 & 21.4742 & 37.1 \\
0.365 & 19.9620 & 37.9 \\
0.274 & 18.6488 & 39.3 \\
0.205 & 17.6028 & 41.1 \\
0.154 & 16.8987 & 43.5 \\
0.115 & 16.6184 & 46.2 \\
0.0866 & 16.8528 & 49.3 \\
0.0649 & 17.7008 & 52.3 \\
0.0487 & 19.2645 & 55.0 \\
0.0365 & 21.6302 & 57.1 \\
0.0274 & 24.8272 & 58.2 \\
0.0205 & 28.7512 & 58.1 \\
0.0154 & 33.0631 & 56.9 \\
0.0155 & 37.1286 & 54.5 \\
0.00866 & 40.1375 & 51.4 \\
0.00649 & 41.4693 & 48.0 \\
0.00487 & 41.0673 & 45.0 \\
0.00365 & 39.4373 & 42.6 \\
0.00274 & 37.2861 & 41.0 \\
0.00205 & 35.1860 & 40.1 \\
0.00154 & 33.4541 & 39.7 \\
0.00116 & 32.1405 & 39.4
\end{tabular}




\section{WPP3}

Apparent resistivity and Phase for best fitting Monte-Carlo model

\begin{tabular}{lrc} 
Period & Apparent Resistivity & Phase \\
\hline & & \\
6.49 & 61.7122 & 38.3 \\
4.87 & 58.9876 & 37.6 \\
3.65 & 56.0559 & 36.9 \\
2.738 & 52.9385 & 36.2 \\
2.054 & 49.6685 & 35.6 \\
1.54 & 46.2913 & 35.1 \\
1.155 & 42.8651 & 34.7 \\
0.866 & 39.4597 & 34.6 \\
0.649 & 36.1546 & 34.7 \\
0.487 & 33.0372 & 35.2 \\
0.365 & 30.2000 & 36.2 \\
0.274 & 27.7393 & 37.7 \\
0.205 & 25.7553 & 39.9 \\
0.154 & 24.3538 & 42.7 \\
0.115 & 23.6509 & 46.0 \\
0.0866 & 23.7791 & 49.8 \\
0.0649 & 24.8947 & 53.8 \\
0.0487 & 27.1840 & 57.5 \\
0.0365 & 30.8620 & 60.8 \\
0.0274 & 36.1567 & 63.3 \\
0.0205 & 43.2610 & 64.8 \\
0.0154 & 52.2372 & 65.3 \\
0.0115 & 62.8720 & 64.6 \\
0.00866 & 74.5386 & 63.0 \\
0.00649 & 86.1931 & 60.6 \\
0.00487 & 96.5845 & 57.7 \\
0.00365 & 104.5333 & 54.5 \\
0.00274 & 109.1085 & 51.3 \\
0.00205 & 109.8926 & 48.4 \\
0.00154 & 107.4131 & 46.1 \\
0.00116 & 103.1673 & 44.7
\end{tabular}




\section{PN2}

Apparent resistivity and Phase for best fitting Monte-Carlo model

\begin{tabular}{lrr} 
Period & Apparent Resistivity & Phase \\
\hline & & \\
15.40 & 31.7786 & 11.4 \\
11.55 & 24.8033 & 13.2 \\
8.66 & 19.5354 & 15.7 \\
6.49 & 15.6392 & 19.0 \\
4.87 & 12.8583 & 23.1 \\
3.65 & 11.0019 & 28.1 \\
2.738 & 9.9330 & 33.6 \\
2.054 & 9.5490 & 39.3 \\
1.54 & 9.7655 & 44.3 \\
1.155 & 10.4761 & 48.2 \\
0.866 & 11.5195 & 50.6 \\
0.649 & 12.6673 & 51.8 \\
0.487 & 13.6858 & 52.1 \\
0.365 & 14.4710 & 52.1 \\
0.274 & 15.1120 & 52.4 \\
0.205 & 15.7964 & 52.9 \\
0.154 & 16.6579 & 53.6 \\
0.115 & 17.7244 & 54.3 \\
0.0866 & 18.9888 & 54.8 \\
0.0649 & 20.4635 & 55.2 \\
0.0487 & 22.1733 & 55.4 \\
0.0365 & 24.1284 & 55.4 \\
0.0274 & 26.3146 & 55.1 \\
0.0205 & 28.6765 & 54.3 \\
0.0154 & 31.0936 & 53.1 \\
0.0115 & 33.3602 & 51.4 \\
0.00866 & 35.1839 & 49.3 \\
0.00649 & 36.2272 & 46.9 \\
0.00487 & 36.2115 & 44.3 \\
0.00365 & 35.0515 & 41.9 \\
0.00274 & 32.9463 & 40.0 \\
0.00205 & 30.3387 & 38.9 \\
0.00154 & 27.7677 & 38.9 \\
0.00116 & 25.7059 & 39.9
\end{tabular}


The End 